\title{
Geodetic, hydrologic and seismological signals associated with precipitation and infiltration in the central Southern Alps, New Zealand
}

\author{
by
}

Nicolas Kiyoshi Oestreicher

A thesis submitted to Victoria University of Wellington for the degree of Master of Science in Geology

School of Geography, Environment and Earth Sciences Victoria University of Wellington

2018 


\section{Abstract}

The Southern Alps of New Zealand is an actively deforming mountain range, along which collision between the Pacific and Australian plates is manifest as elevated topography, orographic weather, active contemporary deformation, and earthquakes. This thesis examines interactions between surface processes of meteorological and hydrological origin, the ground surface deformation, and processes within the seismogenic zone at depth. The two main objectives of the thesis are a better understanding of the reversible repetitive ground surface deformation in the central Southern Alps and the analysis of the evolution of the rate of microseismicity in the area to explore relationships between seismicity rates and the hydrologic cycle.

Surface deformation in the central Southern Alps is characterised by a network of 19 continuous GPS stations located between the West Coast (west) and the Mackenzie Basin (east), and between Hokitika (north) to Haast (south). These show repetitive and reversible movements of up to $\sim 55 \mathrm{~mm}$ on annual scales, on top of long-term plate motion, during a 17 year-long period. Stations in the high central Southern Alps exhibit the greatest annual variations, whereas others are more sensitive to changes following significant rain events. Data from 22 climate stations (including three measuring the snowpack), lake water levels and borehole pressure measurements, and numerical models of solid Earth tides and groundwater levels in bedrock fractures, are compared against geodetic data to examine whether these environmental factors can explain observed patterns in annual ground deformation. Reversible ground deformation in the central Southern Alps appears strongly correlated with shallow groundwater levels. Observed seasonal fluctuation and deformation after storm events can be explained by simple mathematical models of groundwater levels. As a corollary, local hydrological effects can be accounted for and ameliorated during preprocessing to reduce noise in geodetic data sets being analysed for tectonic purposes. 
Two catalogues of earthquakes (containing 38909 and 89474 events) in the area spanning the period 2008-2017 were built using a matched-filtered detection technique. The smaller catalogue is based on 211 template events, each of known focal mechanism, while the latter is based on 902 templates, not all of which have focal mechanisms, providing greater temporal resolution. Microseismicity data were examined in both time and frequency domains to explore relationships between seismicity rates and the hydrologic cycle. Microseismicity shows a pronounced seasonality in the central Southern Alps, with significantly more events detected during winter than during summer. These changes cannot be easily accounted for by either acquisition or analysis parameters. Two models of hydrologically-induced seasonal seismicity variations have been considered - surface water loading and deep groundwater circulation of meteoric fluids — but neither model fully explains the observations, and further work is required to explain them fully. An observed diurnal variation in earthquake detection rate is believed to originate mostly from instrumental effects, which should be accounted for in future seismological studies of earthquake occurrence in the central Southern Alps.

Relationships and correlations observed between hydrological, geodetic, and seismological data from the central Southern Alps provide clear indications that surface processes exert at least some degree of influence on upper-crustal seismicity adjacent to the Alpine Fault. 


\section{Acknowledgements}

First of all, I am very grateful to my supervisors, John Townend and Simon Cox. They have been very helpful and supportive throughout this year, despite mountains of more important tasks, especially in the months following the M7.8 Kaikoura earthquake on 14 November 2016. Thank you, Simon, for inviting me home and bringing me to the mountains - one of my very best experiences in New Zealand. I am grateful to Huw Horgan and Sam McColl for their in-depth readings and reviews.

I am also grateful to Paul Denys of the University of Otago whose expert analysis of GPS data prompted this study in the first place. Paul provided all of the geodetic data used in this thesis, including the results obtained with two different preprocessing routines, as well as books and knowledge on how data was prepared. Thanks to Rupert Sutherland, who helped with interpretation of DFDP-1B piezometric data. I am grateful to Carolin Boese whose painstaking analysis of seismic data provided the templates used in this thesis; to Calum Chamberlain and Chet Hopp for their impressive work with EQcorrscan, and their help in applying it to new data; and to Richard Arnold and John Haywood of the School of Mathematics and Statistics, who helped me a lot with statistics and time series analysis.

I pay special thanks to Jürgen Hansmann and Simon Löw for sharing their model (REROD) and their passion, and David Hood for thought-provoking discussions and ideas concerning the link between tidal influences and seismicity, and his help with modelling solid Earth tides. To Aleksandr Beliaev for his help with Linux, Belinda Smith Lyttle for her help with ArcGIS and her kindness when I had problems with maps. To Felipe G. Nievinski for his support when evaluating the importance of multipath in the time series in this thesis, Huw Horgan and Brian Anderson for the talks on permafrost and support. I thank Guy Simpson for his help in organising my Master's study and for ongoing support this year, and Holly Godfrey for her insightful comments and suggestions. 
I would like to thank the institutions that were involved in this project and particularly EQC (the Earthquake Commission Programme in Seismology and Fault Mechanics at Victoria University of Wellington) who met the costs of the field work I was fortunate enough to take part in, notably the servicing of the SAMBA array in March, with helicopter flights in a paradisiacal environment. GNS Science, the National Institute for Water and Atmospheric Research (NIWA), the national Geological hazards monitoring Network (GeoNet), Genesis Energy and Meridian Energy all provided data for this thesis.

I give special thanks to Sam, Rachel, Seb, Andy, Hamish and my other office mates for the laughs and diurnal tea and coffee trips. I thank all my flatmates, with a special thought for Chris, who cooks delicious meals and was very supportive during my final weeks. I thank my friends who supported me throughout my thesis, from Switzerland and New Zealand amongst other countries, and who visited me here. Very special thanks to Nicolas (the other one) who keeps being my pillar of strength, no matter how far away from each other we are, Lukas for all the wonderful shared activities, Flavio, Tobias, Violette, Mattijs, Sara, and all the others. I cannot name them all — this thesis is already long enough.

I address my particular gratitude to my family for their support and the fantastic travel together in January. Finally, I dedicate this thesis to my Oma, who always had a piece of good advice and would have been very proud to welcome me back home, but sadly left for her own journey in March. 


\section{Contents}

Abstract iv

Acknowledgements $\quad$ v

Contents vii

List of Figures $\quad$ xiv

List of Tables $\quad$ XV

1 Introduction $\quad 1$

1.1 Background and motivation ................ . . 1

1.2 Geodetic observations in the central South Island . . . . . . . . . . 6

1.3 Climate in New Zealand . . . . . . . . . . . . . . . . . . 7

1.4 Seismicity in the central South Island . . . . . . . . . . . . . . 7

1.5 Objectives . . . . . . . . . . . . . . . . . 9

1.6 Thesis structure . . . . . . . . . . . . . . . . . . . . . 10

2 Data and Methodology 11

2.1 Data Acquisition . . . . . . . . . . . . . . . . . . . 11

2.2 Notes on statistical and time series analysis . . . . . . . . . . . . 12

2.3 Geodetic analysis . . . . . . . . . . . . . . . . . . 15

2.3.1 The Southern Alps Geodetic Experiment New Zealand . . . 15

2.3.2 GPS data preprocessing . . . . . . . . . . . . . . . . 17

2.3.3 cGPS positioning and accuracy . . . . . . . . . . 25

2.4 Meteorological and hydrological data . . . . . . . . . . . . . 31

2.4.1 Rainfall data . . . . . . . . . . . . . . . . . . . 32

2.4 .2 Snowfall data . . . . . . . . . . . . . . . 35

2.4.3 Air pressure and temperature data . . . . . . . . . . 38

2.4 .4 Lake level data . . . . . . . . . . . . . . . . . . . . 40

2.4.5 Groundwater data . . . . . . . . . . . . . . . 41 
2.5 Microseismicity . . . . . . . . . . . . . . . . 48

2.5.1 Catalogue expansion using matched-filtering . . . . . . . 50

2.5.2 Noise-induced apparent seasonality . . . . . . . . . . . . 53

2.5.3 Two mechanisms that could change the stress state at depth 54

2.5.4 Seismicity induced by periodic loading and unloading . . . . 55

2.5.5 Seismicity induced by periodic poroelastic stressing . . . . . 55

3 Results $\quad 59$

3.1 Geodetic observations . . . . . . . . . . . . . . . . . . . . . 59

3.1 .1 cGPS: reference stations . . . . . . . . . . . . . . 60

3.1.2 Comparison with modelled Earth tides . . . . . . . . . . 61

3.1.3 Comparison with atmospheric pressure . . . . . . . . . . 63

3.1.4 Comparison with surface air temperature . . . . . . . . . . 64

3.1 .5 Comparison with rainfall . . . . . . . . . . . . . . . 66

3.1.6 Comparison with snow depth _. . . . . . . . . . . 69

3.1.7 Comparison with lake levels . . . . . . . . . . . . . . 71

3.1.8 Comparison with modelled groundwater levels . . . . . . . 75

3.1.9 Local bedrock properties around stations . . . . . . . . 75

3.2 Microseismicity observations . . . . . . . . . . . . . . . . 79

3.2 .1 Results of EQcorrscan detection . . . . . . . . . . . . . . 79

3.2 .2 Frequency analysis of seismicity . . . . . . . . . . . 81

3.2 .3 Diurnal variations in detection rate . . . . . . . . . . . 82

3.2 .4 Annual variations in seismicity . . . . . . . . . . . . . . 84

3.2.5 Comparisons with hydrological observations . . . . . . . 85

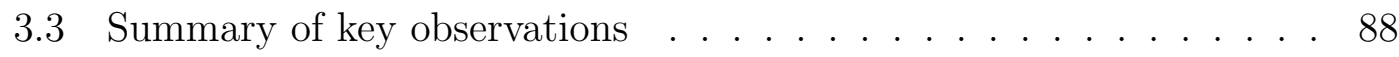

4 Discussion $\quad 91$

4.1 Transient and seasonal cGPS position cycles . . . . . . . . . . 91

4.1 .1 Instrumental noise . . . . . . . . . . . . . . . . . . 91

4.1 .2 Tides . . . . . . . . . . . . . . . . . . . . . . . . 93

4.1.3 Ice and snow wedging bedrock fractures _ . . . . . . . . 93

4.1.4 Thermoelasticity of the near-surface . . . . . . . . . . . 94

4.1.5 Seasonal surface loading . . . . . . . . . . . . . . 95

4.1.6 Groundwater level-induced surface deformation . . . . . . 97

4.1.7 Possible evolution in a warming climate . . . . . . . . . . 97

4.2 Hydrogeological controls on microseismicity rates . . . . . . . . . 99

4.2.1 Evidence for triggering by regional earthquakes . . . . . . . 99

4.2.2 Loading-unloading seasonal stress variations . . . . . . . . . 99 
4.2.3 Coupled drained and undrained seasonal stress variations . . 100

\section{Conclusions}

5.1 Reversible ground surface deformation . . . . . . . . . . . . 106

5.2 Seasonality in microseismicity rate . . . . . . . . . . . . . . . 107

5.3 Future work . . . . . . . . . . . . . . . . . . . . . . . 108

$\begin{array}{lr}\text { Bibliography } & 109\end{array}$

$\begin{array}{lr}\text { Appendix } & 125\end{array}$

$\begin{array}{ll}\text { A Supplementary meteorological data } & 125\end{array}$

A.1 Seasonality in rainfall . . . . . . . . . . . . . . . . . . . . 125

A.2 Snowfall . . . . . . . . . . . . . . . . . . . . 131

A.3 Seasonality in lake levels . . . . . . . . . . . . . . . . . . 132

A.4 Atmospheric pressure and near-surface air temperature . . . . . . . 133

B Supplementary geodetic data and maps 135

B.1 Burnett Rock (BNET) . . . . . . . . . . . . . . . . . 136

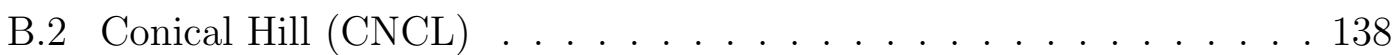

B.3 Gunn Ridge (GUNR) . . . . . . . . . . . . . . . . . . . . . . 140

B.4 Haast $(\mathrm{HAAS})$. . . . . . . . . . . . . . . . . . . . . . . . . 142

B.5 Hokitika $(\mathrm{HOKI})$. . . . . . . . . . . . . . . . . . . 144

B.6 Hoophorn Spur $(\mathrm{HORN}) \ldots \ldots$. . . . . . . . . . . . . . 146

B.7 Karangarua (KARA) . . . . . . . . . . . . . . . . . . . . . . . . . . 148

B.8 Leo Creek (LEOC) . . . . . . . . . . . . . . . . . . . . . . 150

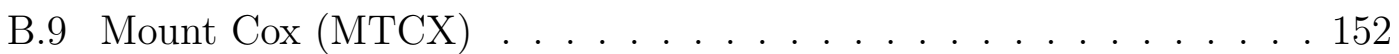

B.10 Mount John (MTJO) . . . . . . . . . . . . . . . . . 154

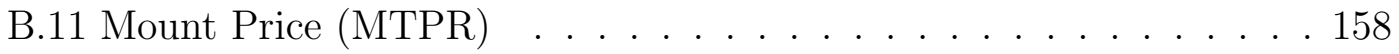

B.12 Annette Plateau (NETT) . . . . . . . . . . . . . . 160

B.13 Pilkington Glacier (PILK) . . . . . . . . . . . . . . . . . 162

B.14 Quarry (QUAR) . . . . . . . . . . . . . . . . 164

B.15 Waka Mara (WAKA) . . . . . . . . . . . . . . . 166

$\begin{array}{ll}\text { C Supplementary microseismicity analysis } & 169\end{array}$ 


\section{List of Figures}

1.1 Schematic cartoon of the central Southern Alps hydrologic cycle . . 2

1.2 Location Map . . . . . . . . . . . . . . . . . . . . 4

1.3 General map of the area . . . . . . . . . . . . . . 5

2.1 Example of comparison cloud plot . . . . . . . . . . . . 15

2.2 cGPS at Annette Plateau (NETT) . . . . . . . . . . . . 16

2.3 Preprocessed ground displacement at Annette Plateau (NETT) . . 20

2.4 Horizontal displacement at Annette Plateau (NETT) cGPS station 20

2.5 Time series of ground position at Annette Plateau (NETT) . . . . . 21

2.6 3D model of motion at Annette Plateau (NETT) . . . . . . . . . . 21

$2.72 \mathrm{D}$ annual movement at Annette Plateau (NETT) . . . . . . . . . . 23

2.8 Autocorrelation plot for Annette Plateau and missing data. . . . . . 24

2.9 Annual rainfall at monitoring sites . . . . . . . . . . . . . 32

2.10 Time series of rainfall at Franz Josef . . . . . . . . . . . . . . . . 34

2.11 Monthly rainfall at Franz Josef between 1982 and 2017. . . . . . . . 34

2.12 Frequency analysis of rain at Franz Josef . . . . . . . . . . . . . . 35

2.13 Photo of Mueller Hut station . . . . . . . . . . . . . . . . . . 36

2.14 Snow at Mueller Hut per ordinal day. . . . . . . . . . . . . . . . . 37

2.15 Completed data set for snow at Mueller Hut. . . . . . . . . . . . . . 38

2.16 Comparison of snow by station. . . . . . . . . . . . . . . . . 39

2.17 Lake Pukaki and Lake Tekapo levels . . . . . . . . . . . . . . . . . . 40

2.18 Pressure data from piezometers 1 and 2 in DFDP-1B . . . . . . . . 42

2.19 Parameter calibration for reservoir depletion . . . . . . . . . . 46

2.20 Parameter calibration for snow melt . . . . . . . . . . . . . . . . . . 46

2.21 Map with all templates and their focal mechanism . . . . . . . . . . 49

2.22 Time series of used templates . . . . . . . . . . . . . . . 50

2.23 Ternary diagram of focal mechanisms . . . . . . . . . . . . . 51

2.24 Example of a template for the cross-correlation analysis . . . . . . . 52

2.25 Example of detection threshold time series $2 \ldots \ldots$. . . . . . . 54 
3.1 Amplitude of movement versus altitude of GPS stations . . . . . . . 60

3.2 Time series of ground position for Haast . . . . . . . . . . . . . . . 61

3.3 cGPS and theoretical Earth Tides at Annette Plateau (NETT) . . . 62

3.4 Atmospheric pressure and ground motion at Haast (HAAS) . . . . . 64

3.5 Air temperature at Mueller Hut and ground motion at Annette Plateau (NETT). . . . . . . . . . . . . . . . . 65

3.6 Daily rainfall at Mueller Hut and Mount Cook village. . . . . . . . 66

3.7 Comparison between cGPS at Annette Plateau (NETT) and Hoophorn

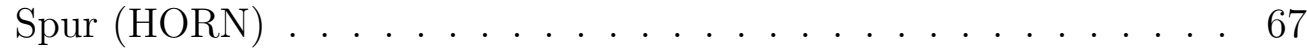

3.8 Haast (HAAS) cGPS versus rainfall at Haast . . . . . . . . . . . . . 68

3.9 Orientation of displacement after heavy rain at Haast (HAAS) . . . 69

3.10 Annette Plateau (NETT) cGPS versus snow depth at Mueller Hut, on an ordinal year . . . . . . . . . . . . . . . . . . 70

3.11 Snow depth and ground motion at Annette Plateau (NETT) . . . . 71

3.12 Comparison between Burnett Rock (BNET) and Lake Pukaki . . . 72

3.13 Mt John (MTJO) station, close to Mount John Observatory. . . . . 74

3.14 Modelled displacement due to groundwater at Haast (HAAS) . . . . 76

3.15 Modelled deformation at Annette Plateau (NETT): REROD . . . . 76

3.16 Pilkington Glacier and cGPS at Pilkington Glacier (PILK) . . . . . 78

3.17 Time series of seismicity, catalogue 1 . . . . . . . . . . . . . . 80

3.18 Normalised cumulative number of detections . . . . . . . . . . . . 80

3.19 Relative differential cumulative number of detections . . . . . . . . 81

3.20 Periodogram of number of events per hour. . . . . . . . . . . . . . . 82

3.21 Comparison between number of detections and gaps . . . . . . . . . 83

3.22 Number of gaps per minute versus voltage for all stations . . . . . . 84

3.23 Median number of detections per month of the year . . . . . . . . 85

3.24 Ordinal comparison between seismicity and snow depth . . . . . . . 86

3.25 Comparison between seismicity and snow depth . . . . . . . . . 87

3.26 Comparison between seismicity and Lake Tekapo water level . . . . 87

3.27 Comparison between seismicity and Lake Tekapo water level . . . . 88

4.1 Fractures under Annette Plateau (NETT) cGPS station . . . . . . . 94

4.2 Schematic loading profile . . . . . . . . . . . . . . . . . 100

4.3 Theoretical poroelastic pressure evolution (linear input) . . . . . . . 102

4.4 Theoretical poroelastic pressure evolution (sinusoidal input) . . . . 103

A.1 Monthly rainfall at Fox Glacier between 1967 and 1994. . . . . . . . 126

A.2 Monthly rainfall at Haast between 1982 and 2017. . . . . . . . . . . 126

A.3 Monthly rainfall at Hokitika between 1963 and 2017 . . . . . . . . 127 
A.4 Monthly rainfall at Kowhitirangi between 1965 and 2017. . . . . . . 127

A.5 Monthly rainfall at Ivory Glacier between 2009 and 2017. . . . . . . 128

A.6 Monthly rainfall at Lake Pukaki Guide Hill between 2000 and 2017. 128

A.7 Monthly rainfall at Tekapo between 2000 and 2016. . . . . . . . . . 129

A.8 Monthly rainfall at Mount Cook village between 1928 and 2017. . . 129

A.9 Monthly rainfall at Mueller Hut between 2010 and 2017. . . . . . . 130

A.10 Time series of rain at Mueller Hut for the period 2010 - 2017 . . . . 130

A.11 Accumulation of snow at Rose Ridge. . . . . . . . . . . . . . . . . . 131

A.12 Accumulation of snow at Mount Cook Ews. . . . . . . . . . . . . . 132

A.13 Lake levels per day of the year . . . . . . . . . . . . . . . . . 133

A.14 Pressure time series . . . . . . . . . . . . . . . . . . . . . . . 134

A.15 Temperature time series . . . . . . . . . . . . . . . . 134

B.1 Time series of ground position at Burnett Rock (BNET) . . . . . 136

B.2 Detailed geologic map around Burnett Rock (BNET) . . . . . . . . 137

B.3 Conical Hill (CNCL) cGPS versus rainfall at Franz Josef EWS . . . 138

B.4 Detailed geologic map around Conical Hill (CNCL) . . . . . . . . . 139

B.5 Time series of ground position at Gunn Ridge (GUNR) . . . . . . . 140

B.6 Detailed geologic map around Gunn Ridge (GUNR) . . . . . . . . . 141

B.7 cGPS at Haast (HAAS) versus Mean Air Temperature at Haast. . . 142

B.8 Detailed geologic map around Haast (HAAS) . . . . . . . . . . . . 143

B.9 cGPS at Hokitika (HOKI) versus Mean Air Temperature at Franz Josef. . . . . . . . . . . . . . . . . . . . . . . . . . . . . 144

B.10 Detailed geologic map around Hokitika (HOKI) . . . . . . . . . . 145

B.11 Time series of ground position at Hoophorn Spur (HORN) . . . . . 146

B.12 Detailed geologic map around Hoophorn Spur (HORN) . . . . . . . 147

B.13 Modelled displacement due to groundwater at Karangarua (KARA) 148

B.14 Detailed geologic map around Karangarua (KARA) . . . . . . . . . 149

B.15 Time series of ground position at Leo Creek (LEOC) . . . . . . . . 150

B.16 Detailed geologic map around Leo Creek (LEOC) . . . . . . . . . . 151

B.17 Comparison between Burnett Rock (BNET) and Lake Pukaki lake

level. . . . . . . . . . . . . . . . . . . . . 152

B.18 Detailed geologic map around Mt Cox (MTCX) . . . . . . . . . . 153

B.19 cGPS at Mount John versus Mean Air Temperature at Lake Tekapo. 154

B.20 Comparison between Mt John (MTJO) and Lake Tekapo lake level. 155

B.21 Detailed geologic map around Mt John (MTJO) . . . . . . . . . . 156

B.22 Time series of ground position at Mt Price (MTPR) . . . . . . . . . 158

B.23 Detailed geologic map around Mt Price (MTPR) . . . . . . . . . . 159 
B.24 cGPS at Annette Plateau (NETT) versus Rainfall at Mueller Hut . 160

B.25 Detailed geologic map around Annette Plateau (NETT) . . . . . . . 161

B.26 Snow depth at Rose Ridge and ground motion at Pilkington Glacier

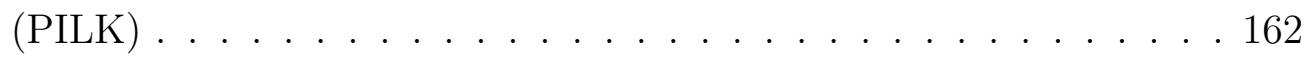

B.27 Detailed geologic map around Pilkington Glacier (PILK) . . . . . . 163

B.28 Time series of ground position at Quarry (QUAR) . . . . . . . . . . 164

B.29 Detailed geologic map around Quarry (QUAR) . . . . . . . . . . . 165

B.30 Time series of ground position at Waka Mara (WAKA) . . . . . . . 166

B.31 Detailed geologic map around Waka Mara (WAKA) . . . . . . . . . 167

C.1 Time series of seismicity, catalogue $2 \ldots \ldots 96$

C.2 Periodogram of number of events per hour, catalogue 2 . . . . . . . 170

C.3 Comparison between number of detection and gaps, catalogue 2 . . 171

C.4 Number of detections per day during a year, catalogue 2 . . . . . . 171

C.5 Ordinal comparison between seismicity and snow depth, catalogue 2172

C.6 Comparison between seismicity and snow depth, catalogue 2 . . . . 172

C.7 Comparison between rate of seismicity and Lake Pukaki water level 173

C.8 Cloud comparison plot of seismicity versus Lake Pukaki . . . . . . . 173 


\section{List of Tables}

2.1 Colour code for Figures . . . . . . . . . . . . . . . . . . . 13

2.2 Locations of GPS stations _ . . . . . . . . . . . . . 17

2.3 cGPS data processing strategies and models used . . . . . . . 19

2.4 Missing data at each cGPS station. . . . . . . . . . . . . 22

2.5 Percentage of missing data at each rainfall station. . . . . . . . . 33

2.6 Percentage of missing data at each pressure station. . . . . . . . 38

2.7 Percentage of missing data at each air temperature station. . . . . . 39

2.8 Percentage of missing data for the lakes. . . . . . . . . . . . . 41

2.9 Example of REROD parameters . . . . . . . . . . . . . 47

3.1 Cross-correlation: Haast (HAAS) $\ldots \ldots \ldots$. . . . . . . 63

3.2 Cross-correlation: Annette Plateau (NETT) … . . . . . 65

3.3 Offsets due to earthquakes at Mount John (MTJO) . . . . . . . 73

B.1 Cross-correlation: Burnett Rock (BNET) ․ . . . . . . . 136

B.2 Cross-correlation: Conical Hill (CNCL) . . . . . . . . . . . 138

B.3 Cross-correlation: Gunn Ridge (GUNR) … . . . . . . 140

B.4 Cross-correlation: Haast (HAAS) … . . . . . . . . . 142

B.5 Cross-correlation: Hokitika (HOKI) . . . . . . . . . . . . 144

B.6 Cross-correlation: Hoophorn Spur (HORN) . . . . . . . . . . . 146

B.7 Cross-correlation: Karangarua (KARA) . . . . . . . . . . . 148

B.8 Cross-correlation: Leo Creek (LEOC) … . . . . . . . . 150

B.9 Cross-correlation: Mt Cox (MTCX) . . . . . . . . . . . . 152

B.10 Cross-correlation: Mt John (MTJO) . . . . . . . . . . . . 154

B.11 Cross-correlation: Mt Price (MTPR) . . . . . . . . . . . 158

B.12 Cross-correlation: Annette Plateau (NETT) … . . . . . . 160

B.13 Cross-correlation: Pilkington Glacier (PILK) … . . . . . . 162

B.14 Cross-correlation: Quarry (QUAR) . . . . . . . . . . . . . 164

B.15 Cross-correlation: Waka Mara (WAKA) . . . . . . . . . . 166 


\section{Chapter 1}

\section{Introduction}

\subsection{Background and motivation}

The central Southern Alps of New Zealand is one of the most tectonically active regions in the world, situated in a transpressive setting between the Australian and Pacific plates. The relative plate velocity during the late Quaternary is approximately $37 \pm 2 \mathrm{~mm} / \mathrm{a}$, with much of this motion being accommodated by the Alpine Fault (Norris and Cooper, 2001).

The Alpine Fault is a dextral strike-slip fault with a subordinate vertical component of slip (Norris and Cooper, 2001). Paleoseismic data suggests the fault is late in the interseismic phase of its typical earthquake cycle. The recurrence time has been calculated at $329 \pm 68$ a by Berryman et al. (2012) and at $291 \pm 23 \mathrm{a}$ by Cochran et al. (2017), with the last major earthquake occurring in AD 1717 (Sutherland et al., 2007). In the last decade, the Alpine Fault has been interpreted to be locked to a depth of $6 \mathrm{~km}$ to $12 \mathrm{~km}$ (e.g. Sutherland et al., 2007), resulting in the progressive accumulation of elastic strain in the region. The contemporary build-up of strain is likely to be relieved in the next large Alpine Fault rupture (Beavan et al., 2007, Sutherland et al., 2007).

The convergence has thickened the crust and raised a mountain chain to more than $3 \mathrm{~km}$ elevation for the highest summits. This places an obstacle in the way of the prevailing westerly winds, modifying the atmospheric circulation (Cox and Sutherland, 2007). Heavy rainfall of approximately $10 \mathrm{~m} / \mathrm{a}$ occurs on the western side of the Alps, whereas a more arid climate exists on the eastern side $(\sim 1 \mathrm{~m} / \mathrm{a}$ rainfall, see Figure 1.2) (Tait and Fitzharris, 1998), and snow represents a significant 


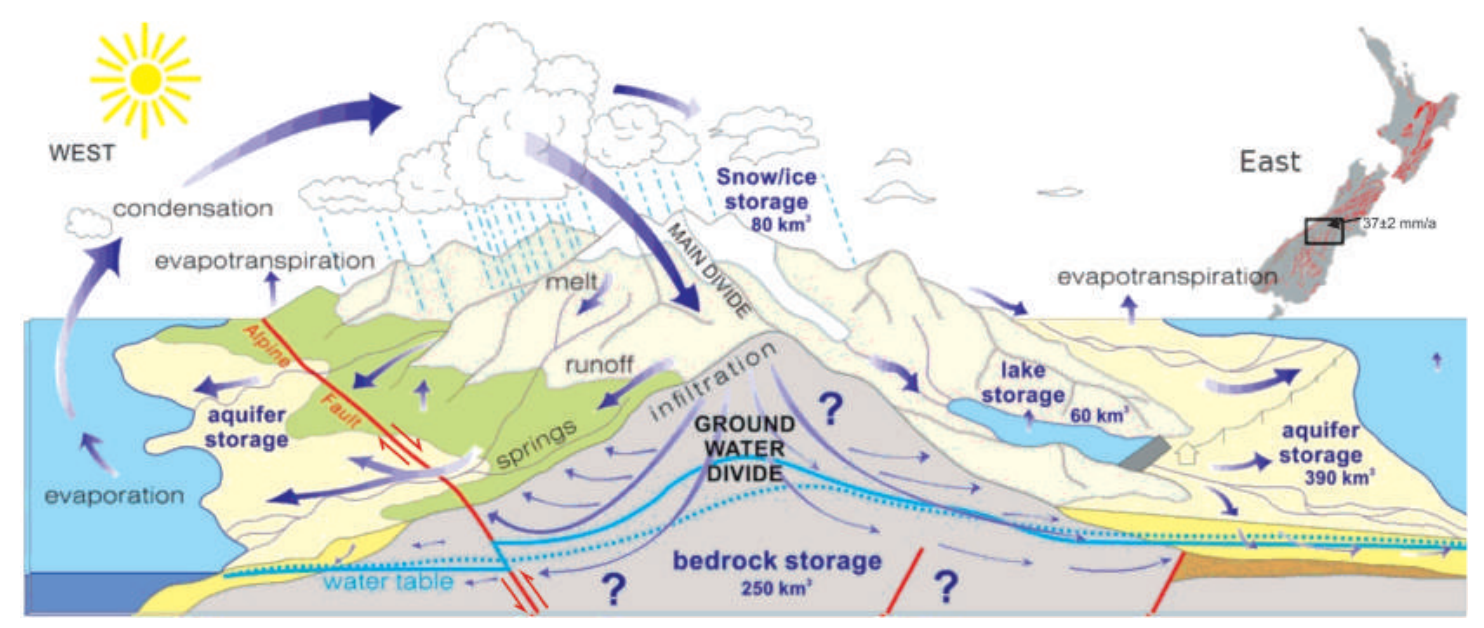

Figure 1.1: Schematic cartoon of the central Southern Alps hydrologic cycle, modified after Simon Cox.

proportion of the precipitation in the mountains (Kerr et al., 2013), approaching $100 \%$ on the highest peaks.

The hydrologic cycle in the central Southern Alps is schematically represented in Figure 1.1. When it rains, or when the snow melts in the mountains, a portion of the water evaporates and re-enters the atmosphere, a portion infiltrates and enters the groundwater system, and a portion stays on the surface and directly feeds rivers and lakes (runoff). Recent studies suggest that there is a significant infiltration of meteoric water into the mountains, which penetrates deep into the upper crust (Menzies et al., 2014, Cox et al., 2015, Sims et al., 2015, Menzies et al., 2016, Sutherland et al., 2017). However, little is known about the volume of groundwater stored or its temporal fluctuations.

Near the Main Divide (the line separating the surface water catchments of the Tasman Sea in the west and the Pacific Ocean in the east, Figure 1.1), meteoric water penetrates into bedrock through dense fracture networks (Cox and Findlay, 1995). These fractures were created during the rapid uplift, with the highest rates of uplift being below the highest mountains in New Zealand (Beavan et al., 2010a).

Bedrock in the central Southern Alps is composed of two major tectonic units. The western side of the Alpine Fault (the fault's footwall, sitting on the Australian Plate) is characterised by Paleozoic metasedimentary and granitic basement rocks, together known as the Western Province (Landis and Coombs, 1967). The Torlesse terrane forms the hanging wall of the Alpine Fault, on the Pacific Plate side (Mackinnon, 1983). The Torlesse terrane is primarily composed of mudstone, sandstone and conglomerates, with intense metamorphism near the Alpine Fault, and a progressive lowering of the metamorphic grade towards the southeast (Cox 
and Barrell, 2007), expressing the differential burial depth and exhumation rates of rocks in the hanging wall of the Alpine Fault (Norris and Cooper, 2001).

Consequently, the Southern Alps landscape is dominated by schist and greywacke rocks. However, the landforms are overprinted by Pleistocene glaciations that carved glacial valleys, depositing till and other sediments in lower areas throughout the region (Cox and Barrell, 2007). A general geologic map for the central part of the study area (Figure 1.3) and detailed geologic maps at each GPS station used in this thesis (Appendix B) illustrate the different lithologies described above.

In the central Southern Alps, ongoing active tectonic processes at depth (Little et al., 2005) are overlaid by rough climatic conditions at the surface (Salinger, 1980), from the sparsely inhabited West Coast to remote areas surrounding New Zealand's highest peak, Aoraki / Mt Cook. The region is, therefore, well suited to study interactions between surface processes of meteorological and hydrological origins and processes at depths corresponding to the seismogenic zone, which is one of our main sources of motivation for this study.

Another motive for this study is the compelling investigation of possible environmental causes for an unexplained observation of cyclic ground surface deformation. This observation (Beavan et al., 2004, Denys et al., 2005) was made using a continuous regional GPS network, which has been in place since the start of the century. Moreover, the seasonal surface motion could be a manifestation of the entrance of meteoric water in the ground (Hansmann et al., 2012b), the start of a long journey through the Earth's upper crust.

Finally, this study aims at bringing new insights in the hydrogeology of the region and better understanding the related surface deformation for filtering of the geodetic data. It also aims at analysing the shallow microseismicity and looking at possible links with the hydrologic cycle. 


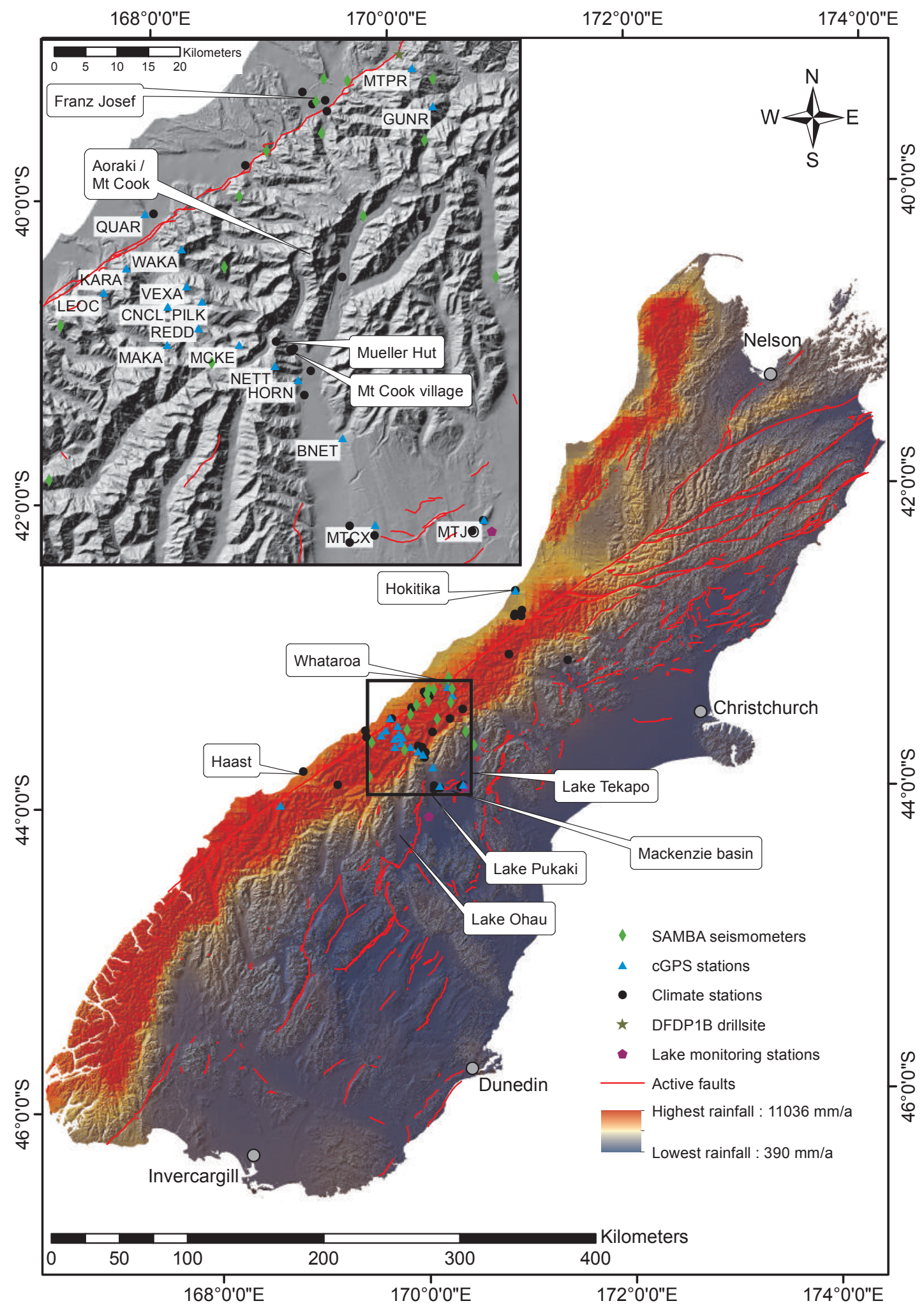

Figure 1.2: Location map showing all stations used in this study. The inset map enlarges the main area of interest in the central Southern Alps (black square). Mapped active faults are represented as red lines (GNS Science, 2014). Interpolated total annual rainfall is from the raster version available from NIWA (Tait et al., 2012), made with the Virtual Climate Station Network, and covering the period 1972-2013. 


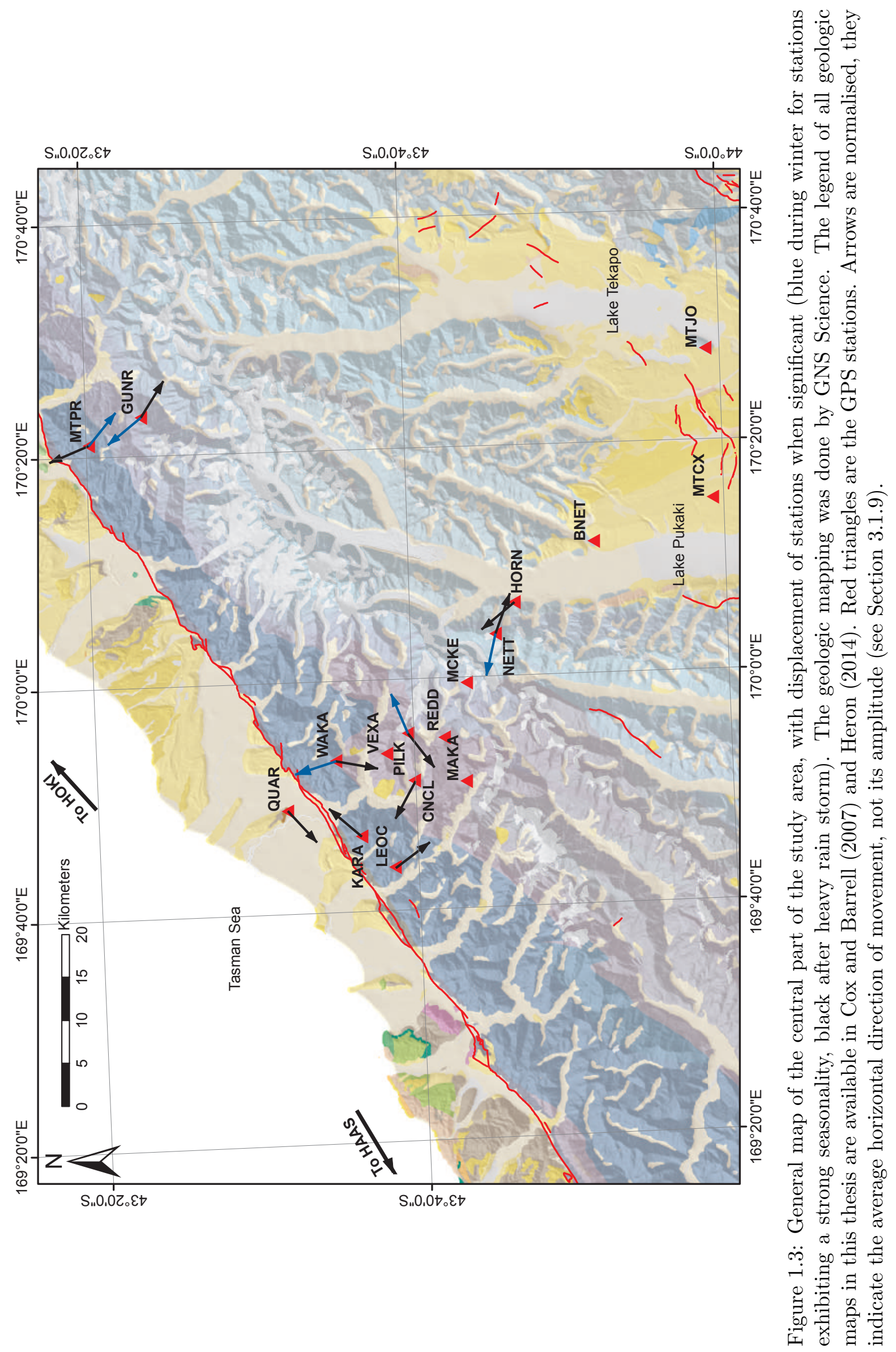




\subsection{Geodetic observations in the central South Island}

Most geodetic studies in the central Southern Alps have focused on large-scale plate motion and long term strain rates, in an attempt to characterise the rapid shortening, high uplift and associated high erosion rates (Beavan et al., 2004, 2007, 2010a, Denys et al., 2005, Denys and Pearson, 2016).

A network of continuous (cGPS) and semi-continuous (semi-cGPS) GPS stations was built in the region in early 2000. The Southern Alps Geodetic Experiment New Zealand (SAGENZ) was improved through the years from 4 cGPS and 6 semicGPS sites to 13 cGPS and 6 semi-cGPS sites nowadays (see Figure 1.2). Soon after its construction, the network allowed a study of the vertical rates of movement along a transect through the central Southern Alps (Beavan et al., 2004). A later study based on more data (Beavan et al., 2010a) refined the results and found that the highest rates of vertical motion are situated on both sides of the Main Divide, east of the Alpine Fault, approximately in the region between Pilkington Glacier (PILK) and Hoophorn Spur (HORN) (see Figures 1.1 and 1.2). The highest values in this zone are $\sim 5 \mathrm{~mm} / \mathrm{a}$, with the exception of Annette Plateau (NETT) cGPS station, having vertical speed significantly lower ( $\sim 3 \mathrm{~mm} / \mathrm{a})$ (Beavan et al., 2010a). Because Annette Plateau (NETT) exhibits a strong seasonality in its position, the authors concluded that it could be influenced by a thermoelastic effect of the near-surface around the site (Beavan et al., 2004).

A study of the horizontal and vertical rates of displacement showed that Annette Plateau (NETT) is not the only station to show seasonal variations in its position, although it has the highest amplitude of seasonal movement (Denys et al., 2005). The authors concluded that possible explanations for the seasonality observed in cGPS time series throughout the region is: a loading of the snow and ice in winter, swelling of the surface rocks due to filling of the bedrock fractures with water in spring, and thermoelasticity of the shallow subsurface (Denys et al., 2005). They also separated the SAGENZ network into triangular subnetworks to permit more detailed calculation of strain rates in the region, removing a sinusoidal curve representing the seasonal variations in cGPS positions for the stations concerned. 


\subsection{Climate in New Zealand}

New Zealand's climate is influenced by the strong Antarctic circumpolar currents and their associated wind drifts flowing from west to east (Knauss and Garfield, 2016). The South Island receives depressions coming year-round from the west (Salinger, 1980). The airflow rises as it encounters the obstructing Southern Alps. Doing so, it cools, and the saturation limit decreases, condensation occurs, and it rains on the westerly, windward side of the Southern Alps. The West Coast of the South Island is one of the wettest places on Earth with a record of nearly $16 \mathrm{~m}$ of rain in a single year (1998) for a rain gauge in the Cropp River catchment (see Figure 1.2).

On the leeward side of the Main Divide, the drier air mass goes down, warms and becomes water unsaturated. Consequently, the central South Island plains, east of the central Southern Alps is one of the driest places in New Zealand. The average annual rainfall is estimated at $<1 \mathrm{~m} / \mathrm{a}$ in the eastern part of the South Island and $>7 \mathrm{~m} / \mathrm{a}$ in the western part (Tait and Fitzharris, 1998, Tait and Turner, 2005, Tait et al., 2006, Woods et al., 2006) with averages over $11 \mathrm{~m} / \mathrm{a}$ in the Southern Alps (Wratt et al., 1996).

\subsection{Seismicity in the central South Island}

The central Southern Alps is a region of intense deformation, with a high plate velocity between the Australian and Pacific plates and correspondingly high rates of deformation (Beavan et al., 2004), mostly accommodated in the long term by slip on the Alpine Fault (Sutherland et al., 2000). This major structure, oriented SW-NE, runs along the West Coast of the central South Island (see Figure 1.2). Rapid exhumation of rocks in the hanging wall of the fault is compensated by rapid weathering and erosion. The fastest uplift rate is located around the Main Divide (Beavan et al., 2010a), above the locked portion of the Alpine Fault, and around $20 \mathrm{~km}$ southeast of its surface trace. We investigate data from the Southern Alps Microseismic Borehole Array (SAMBA, see Figure 1.2) to detect and analyse the rate of microseismicity in this region.

Recent studies have investigated crustal structure in terms of microseismicity occurring in the region, which is characterised by areas of shallow microseismic swarm activity, with two particularly active zones. One is located northeast of our focus area (Bourguignon et al., 2015), and one is in our zone of interest and uses 
the SAMBA array of seismometers amongst others (Feenstra et al., 2016). The observed shallow microseismicity in the latter is concentrated in an area of high resistivity (Boese et al., 2012), high P-wave velocity (Feenstra et al., 2016) under the region of the highest peaks in the Southern Alps, close to the Main Divide and around Aoraki / Mt Cook. This zone also corresponds to a shallower $(\sim 8 \mathrm{~km})$ base of the seismogenic crust than further east or west (Feenstra et al., 2016).

The central Southern Alps is also characterised by low-frequency earthquakes (LFEs) at depth of approximately $20 \mathrm{~km}$ to $30 \mathrm{~km}$, with swarms of events interspersed by calm periods (Chamberlain et al., 2014). Some swarms are provoked by distant regional earthquakes, while some others cannot be related to any major events or started before the main shock, like in the case of the 2009 M7.8 Dusky Sound Earthquake (Chamberlain et al., 2014).

Boese et al. (2012) analysed in detail the first 14 months recorded by the SAMBA array (November 2008 - December 2009) and built a catalogue of $\sim 1800$ earthquakes, including 211 with calculated focal mechanism solutions. The depth of these quakes is typically less than $15 \mathrm{~km}$ (Boese et al., 2012).

The background shallow seismicity for the extended period from November 2008 to April 2010 was analysed by Boese et al. (2014). Different triggering processes were assessed to explain the observed sequences of events, with fluid diffusion as the preferred hypothesis, despite potential clock-advance of critically stressed faults (Boese et al., 2014). The clock-advance theory implies that significant regional events trigger the ruptures of critically stressed faults in the region (teletriggering) causing them to rupture earlier than they would have otherwise, temporarily increasing the rate of seismicity. Quieter periods with fewer events than the usual background rate should follow these triggering events. To test these hypotheses, a longer monitoring period is needed (Boese et al., 2014).

At the last servicing, in March 2017 the SAMBA deployment was still continuously recording data. The prolonged period covered by this thesis (November 2008March 2017) enables more swarms to be analysed and the hypotheses above to be addressed. We will however not focus on the teletriggering of microseismicity, the main shock-aftershock sequences, and the clock-advance theories. Instead, we address the hypothesis that surface hydrologic processes influence the seismogenic crust and the rate of microseismicity under the central Southern Alps.

A change in the surface hydrology can induce a change of stress in the seismogenic crust and, therefore, can modulate the rate of seismicity. Improved techniques of field investigation since this thought was first expressed (Drake, 1912) allowed for 
substantial progress in the last decades (Costain et al., 1987, Costain and Bollinger, 2010).

The idea that pore-fluid pressure changes in the crust can trigger earthquakes is nowadays commonly accepted, particularly when induced by injection of fluids at depth or removal of fluids from deep reservoirs (Zoback, 2007). When fluid migrates in the crust, it preferentially follows cracks in the case of a fractured reservoir, or it can diffuse through pores of the rock. Diffusion depends on the permeability and porosity. Fluid diffusion changes the pore-pressure which is linked to the effective stress (Hillis, 2000). The latter is usually defined as the stress minus the pore-pressure (Zoback, 2007). In the case of pore-pressure changes related to meteorological conditions, more studies have been performed in intraplate (e.g. Hainzl et al., 2014) than in interplate (e.g. Amos et al., 2014) settings.

\subsection{Objectives}

This research has two objectives:

1. As discussed above, a number of recent studies note a high seasonal component of motion in GPS time series from the central Southern Alps (Denys et al., 2005, Beavan et al., 2004, 2010a). The first objective of this study is to examine and test the hypothesis that, in the context of extreme precipitation, changes in groundwater level, which fluctuates seasonally during the year in response to changes in rainfall and snowfall, may explain this movement. We test the hypothesis by comparison of time series and modelling of groundwater reservoirs.

2. The second objective of this study is to analyse the evolution of the seismicity rates in the region. In particular, we investigate whether external forces associated with annual climatic variations can produce a poroelastic response that may influence geologic processes in the shallow, seismogenic crust. 


\subsection{Thesis structure}

In this study, chapters are partitioned into sections that separate the geodetic and seismic parts of the research, while respecting a classic thesis structure: Chapter 2 presents the methods applied and the data acquisition for the geodetic, climatic and seismic data; Chapter 3 includes the results and some comparisons between data sets; Chapter 4 gathers some of our ideas and hypotheses; the conclusions are in Chapter 5. In Appendix A, we present meteorological data sets that we used to construct some of our ideas but were not included in the main text. Appendix B shows detailed maps for all cGPS stations employed in this study, with the directions of significant movements, and tables of cross-correlation coefficient between the cGPS position and environmental data.

The work presented in this thesis was done by Nicolas Kiyoshi Oestreicher unless otherwise acknowledged. For consistency throughout the thesis, in anticipation of preparing the results for publication, and due to the importance of other people, primarily my supervisors, John Townend and Simon Cox, the first-person plural ("we") is used rather than the first-person singular ("I"). 


\section{Chapter 2}

\section{Data and Methodology}

The main tools used in this study are statistical time series analysis in both the time and frequency domains, and comparison and cross-correlation of data sets. This requires efficient management, storage and processing of large quantities of data, taken from the various sources listed hereafter.

\subsection{Data Acquisition}

Our analysis involves many types of data from many different sources. Figure 1.2 shows a location map of all stations used in this study, distinguished by data type.

We obtained pre-processed cGPS data from Paul Denys (University of Otago), along with information about the corrections that were done to the raw data. Data from climate stations (rainfall, atmospheric pressure, temperature, snowfall) were prepared by NIWA (National Institute of Water and Atmospheric Research, https://www.niwa.co.nz/, last accessed August 2017) and downloaded through the CliFlo platform (https://cliflo.niwa.co.nz/, last accessed August 2017). NIWA also provided non-publically available snow gauge data from Mueller Hut for the period of 17.09.2013-02.12.2016 (see Figure 1.2). Meridian Energy (https://www.meridianenergy.co.nz/, last accessed August 2017) provided Lake Pukaki water level measurements (for the period of 01.01.200031.12.2015), and lake level and rainfall data for Lake Tekapo were provided by Genesis Energy (https://www.genesisenergy.co.nz (for the period of 01.01.200002.11.2016), last accessed August 2017). Genesis Energy also provided access to Rose Ridge SIN (Snow and Ice Monitoring Network) station data for the period of 18.03.2015-08.06.2017. Borehole pressure measurements for the period 03.02.2011- 
23.11.2016 recorded by the four piezometers in the DFDP-1B were provided by Rupert Sutherland (VUW) and the geological maps were constructed from data obtained from GNS Science (https://www.gns.cri.nz/, last accessed August 2017) and Simon Cox (pers. comm., 2017).

We use seismic data from 13 sensors from the SAMBA (Southern Alps Microearthquake Borehole Array) deployment along with four sensors from the GeoNet (https://www.geonet.org.nz/, last accessed August 2017) network for the period of 06.11.2008-27.03.2017. Continuous waveform data from the GeoNet stations were partly downloaded from their FDSN (International Federation of Digital Seismograph Networks) platform (http://service.geonet.org.nz/, last accessed August 2017) and partly retrieved from the VUW archives. Seismic data for the SAMBA array were all taken from the VUW archives.

\subsection{Notes on statistical and time series analysis}

We use a consistent colour code throughout the thesis, unless specified in the figure caption (see Table 2.1).

Throughout this thesis, box-and-whisker plots are used to illustrate the distribution of various parameters through time. In each plot the box defines the first and third data quartiles, the whiskers represent values between the 5th and 95th percentiles, outliers are plotted as individual circles, and a red line marks the median value (e.g. Figure 2.9).

We apply low-pass filters to several time series data sets to remove high-frequency noise. The filter is implemented in Python using the scipy signal processing toolbox (Jones et al., 2001). The daily sampling rates of these data sets of interest corresponds to a Nyquist frequency of $\sim 5.787 \times 10^{-6} \mathrm{~Hz}$. An example of filtering, where we use a low-pass frequency limit of $\sim 3.858 \times 10^{-7} \mathrm{~Hz}$ and a third-order digital Butterworth filter is on Figure 2.5.

When comparing two time series, we make extensive use of cross-correlation, as in Appendix B. The temporal cross-correlation coefficient (values between -1 and $+1)$ quantifies the extent to which two time series are linearly correlated. 
Table 2.1: Colour code for the Figures in the rest of the thesis

\begin{tabular}{ll}
\hline Variable & Colour \\
\hline cGPS & Black \\
Lake level & Deep sky blue \\
Atmospheric pressure & Green \\
Rainfall & Blue \\
Seismicity rate & Grey \\
Snowfall & Dodger blue \\
Temperature & Red \\
Tides & Purple \\
\hline
\end{tabular}

-1 means a perfect negative correlation, +1 is a perfect positive correlation, and 0 means no correlation. The cross-correlation coefficient ccorr is defined as:

$$
\operatorname{ccorr}_{\mathrm{k}}(X, Y)=\frac{\operatorname{cov}_{\mathrm{k}}(X, Y)}{\sigma_{X} \sigma_{Y}}=\frac{\frac{1}{N-k+1} \sum_{i=k}^{N-k}\left(X_{i}-\bar{X}\right)\left(Y_{i+k}-\bar{Y}\right)}{\frac{1}{N} \sqrt{\sum_{i=1}^{N}\left(X_{i}-\bar{X}\right)^{2} \sum_{i=1}^{N}\left(Y_{i}-\bar{Y}\right)^{2}}}
$$

where $X, Y$ are the two variables that we want to test, $k$ is the lag time considered, $\operatorname{ccorr}_{\mathrm{k}}(X, Y)$ is the cross-correlation coefficient between $X$ and $Y$ with a lag time of $k$ samples, $N$ is the number of samples, $\operatorname{ccov}_{\mathrm{k}}(X, Y)$ is the cross-covariance of $\mathrm{X}$ and $\mathrm{Y}$ with a lag of $k, \sigma_{i}$ is the standard deviation of the variable i, $\bar{X}, \bar{Y}$ are the mean of respectively $X$ and $Y$, defined as: $\bar{X}=\frac{1}{N} \sum_{i=1}^{N} X_{i}$. We obtain a list of cross-correlation coefficient for each of the lags. We also consider negative lags. Here, a negative lag is more indicative that no significant positive lag is detected, as we do not expect, for example, to detect cGPS movement preceding an environmental variable. We select the maximum cross-correlation between lags of \pm 30 days, without weighting of the coefficients.

We produce autocorrelation functions using the statsmodels module in Python (Seabold and Perktold, 2010) to examine periodicities in individual data sets (e.g. Figure 2.8). The time series is cross-correlated with a lagged copy of itself, for each time increment between zero and the maximum value chosen. The autocorrelation of a time series with a time lag of zero always results in a coefficient of 1 . 
Time increments are in days in this thesis, as this is the chosen sampling rate. On our plots, the light blue zone is the $99 \%$ confidence interval for a standard deviation following Bartlett's formula (Snedecor and Cochran, 1989). All autocorrelation coefficient values outside of this zone are considered significant. Autocorrelation plots are interpreted in parallel with the partial autocorrelation plot (not illustrated), which enables the determination of the autocorrelation at each time lag $t$ that is not explained by the autocorrelation at time lag $t-1$.

Limitations of the cross-correlation coefficient are:

- The cross-correlation coefficient can be close to zero for two nonlinearly correlated variables.

- A cross-correlation coefficient significantly different from zero means that the two variables are linearly correlated, but they are not necessarily linearly dependent (i.e. a high cross-correlation coefficient does not imply causality between variables).

- Variation of cross-correlation coefficient with lag time and data cloud plot sometimes provide more information and insight into the interpretation of the cross-correlation function than a cross-correlation coefficient alone.

To minimise these limitations, we visually inspect superposed time series, comparison cloud plots (e.g. Figure 2.1) and evolution of cross-correlation coefficients-lags plots. However, we often only display the maximum values of cross-correlation coefficients with their associated lags (a cross-correlation coefficient of 0.98 with a lag of 3 units of time, or days, would be denoted as 0.98 (3)) and sometimes superposed time series (e.g. Figure 3.3).

Throughout the thesis, we often use the terms GPS, cGPS and semi-cGPS stations (or sites). The distinction between these terms is that cGPS describes only continuous GPS stations, semi-cGPS is for semi-continuous GPS stations, and GPS contains both cGPS and semi-cGPS stations, and thus all stations used in this study. Semi-cGPS stations record continuously, but only during part of the year. We also include stations with more than $25 \%$ of missing data in semi-cGPS in this study. We acknowledge that the term GNSS more accurately captures the range of signals recorded by these units but adhere to the term GPS due to its common usage and applicability in our case (only GPS signals were processed to form our solutions). 


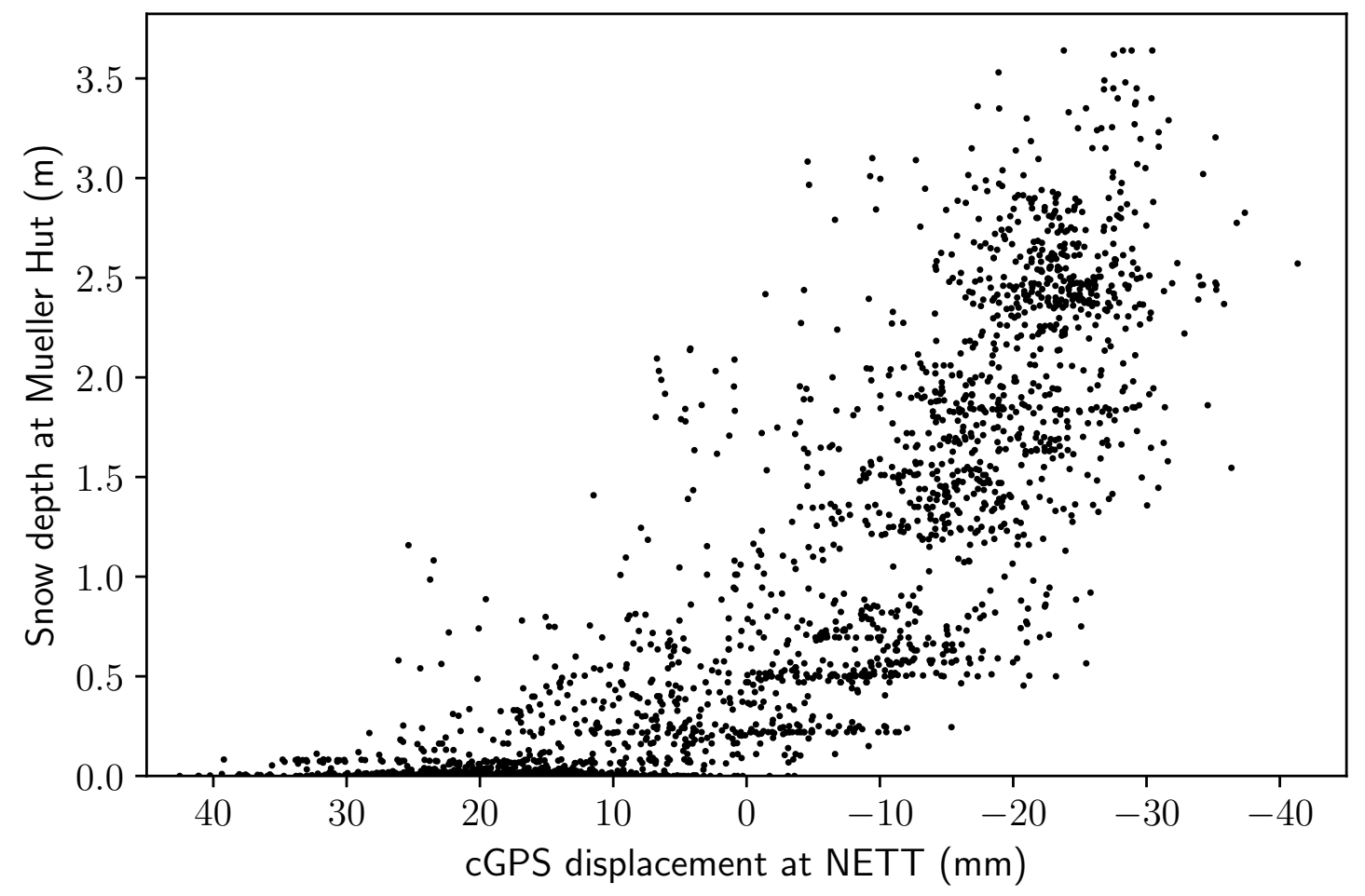

Figure 2.1: Example of comparison cloud plot: cGPS displacement at Nett versus snow depth at Mueller Hut. The displacement of cGPS is along the direction described in Section 2.3.2.

\subsection{Geodetic analysis}

In this Section, we first introduce the GPS stations we use throughout the thesis. We then describe the preprocessing methods that were applied to GPS data. We finally give a non-exhaustive list of physical parameters influencing the GPS, and that could potentially explain the observed variations in GPS position time series in the central Southern Alps.

\subsubsection{The Southern Alps Geodetic Experiment New Zealand (SAGENZ)}

In 2000, the Southern Alps Geodetic Experiment New Zealand (SAGENZ) constructed 12 solar-powered GPS sites (see Table 2.2). The project was a collaboration between the University of Otago, GNS Science, the Massachusetts Institute of Technology (MIT) and the University of Colorado at Boulder (Denys et al., 2005). Since then, the network has been improved and modified and is still in operation with 19 sites (see Figure 1.2). GPS signals are initially recorded and stored in the receiver. Every hour, the pseudorange data is transmitted via radio signal to a 


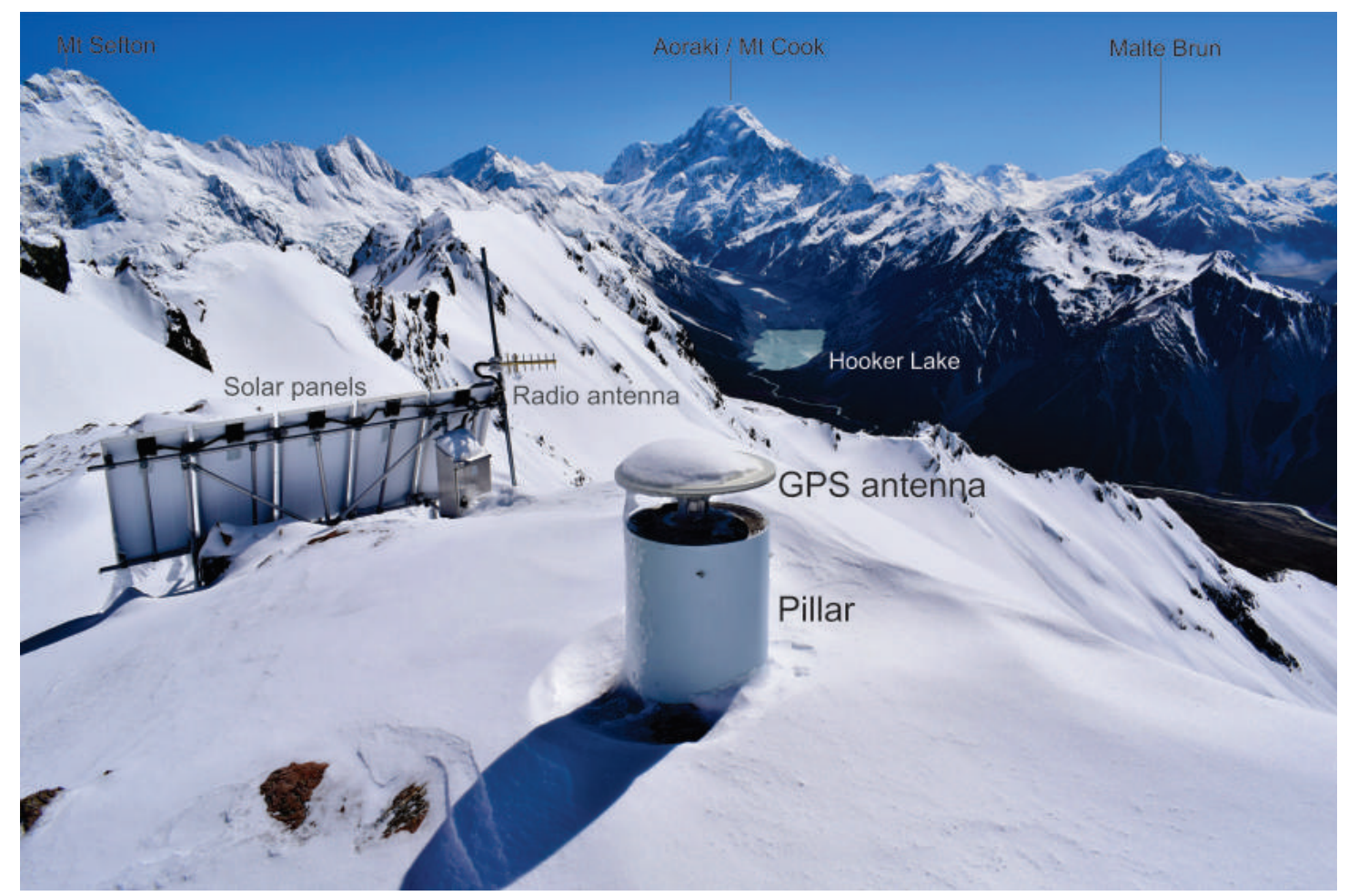

Figure 2.2: cGPS at Annette Plateau (NETT). The cGPS antenna and concrete pillar are in the first plan. Solar panels, batteries and the radio antenna are in the background. The Sealy range, Mount Sefton, Aoraki/Mt Cook, Hooker glacier and lake are in the far distance (View to the NNE). The picture was taken on 30 October 2016.

computer and then to GNS Science. Each site comprises a battery powered with solar panels, a sensor, mounted on a pillar made of concrete and stainless steel to ensure a solid fixation to the bedrock (see Figure 2.2), and a radio transmitter. Some periods of missing data are due to defective equipment, primarily because of power failures. These typically occur during winter, when snow can accumulate on the solar panels, or vegetation and nearby summits obscure the sun.

Six of the SAGENZ GPS stations in the Southern Alps used in this study are semicontinuous (semi-cGPS), meaning they record continuously, but only during part of the year (see Table 2.4). The antenna is often transferred between two semicGPS stations to keep the cost of the programme low while recording at more stations. Some semi-cGPS were upgraded to cGPS over time (e.g. Waka Mara (WAKA)). The stations are spread from the West Coast, close to the Tasman Sea to the central part of the South Island. Most of the stations are situated in mid-altitude, on ridges or small peaks. Three stations (MCKE, Annette Plateau (NETT), Pilkington Glacier (PILK)) are at high-altitude, over $1700 \mathrm{~m}$, close to the Main Divide. Two (Hokitika (HOKI), Quarry (QUAR)) are close to the sea level in the westerly part of the study area. Figure 1.2 shows a map of all stations 
Table 2.2: Locations of GPS stations.

\begin{tabular}{lllll}
\hline Station & Name & Latitude $(\mathrm{S})$ & Longitude $(\mathrm{E})$ & Altitude $(\mathrm{m})$ \\
\hline BNET & Burnett Rock & 43.514495 & 170.112451 & 758 \\
CNCL & Conical Hill & 43.395847 & 169.512108 & 1222 \\
GUNR & Gunn Ridge & 43.233148 & 170.232132 & 1564 \\
HAAS & Haast & 44.042353 & 168.470799 & 1054 \\
HOKI & Hokitika & 42.424646 & 170.590354 & 54 \\
HORN & Hoophorn Spur & 43.463838 & 170.061984 & 960 \\
KARA & Karangarua & 43.363020 & 169.463059 & 1403 \\
LEOC & Leo Creek* & 43.383475 & 169.441238 & 1309 \\
MAKA & Makarora* & 43.431486 & 169.510908 & 1653 \\
MCKE & MCKE* & 43.433569 & 169.590422 & 1902 \\
MTCX & Mount Cox* & 43.590601 & 170.154516 & 828 \\
MTJO & Mount John Obs. & 43.590854 & 170.275380 & 1044 \\
MTPR & Mount Price & 43.201107 & 170.210191 & 1549 \\
NETT & Annette Plateau & 43.452206 & 170.034039 & 2252 \\
PILK & Pilkington Glacier & 43.393813 & 169.551755 & 1753 \\
QUAR & Quarry & 43.315405 & 169.485695 & 58 \\
REDD & Red Deer Col* & 43.420743 & 169.551582 & 1562 \\
VEXA & Vexation* & 43.381575 & 169.533557 & 1495 \\
WAKA & Waka Mara & 43.350254 & 169.530712 & 1416 \\
\hline
\end{tabular}

* Semi-continuous GPS station

used in this study. A list of the stations with their primary characteristics can be found in Table 2.2 and detailed maps are in Appendix B for all stations but Makaroa (MAKA), MCKE, Red Deer Col (REDD) and Vexation (VEXA), which have too much missing data $(>30 \%)$ for statistical analysis.

\subsubsection{GPS data preprocessing}

Each GPS station records its pseudorange data every 30-seconds. The Bernese software package v5.2 (Dach et al., 2015) uses precise satellite orbit, satellite clock estimation and satellite antenna phase centre model (Schmid et al., 2007) from the Antenna Exchange Format (ANTEX, I08.ATX ) to build a daily solution. This solution is obtained via the ITRF2014 (International Terrestrial Reference Frame 2014) reference frame and a three parameters Helmert transformation (Dach et al., 2015). Corrections for the atmospheric delay effect and the non-tidal and tidal 
oceanic loading are then applied (see below). Finally, a regional filtering is carried out using stations with a sufficiently linear behaviour (hence, considered as less affected by other sources of noise) during the period 2000-2009 (Wdowinski et al., 1997) (see Table 2.3). This regional filtering reduces the common mode error (part of the noise that is common to all stations in a region).

The atmospheric delay is calculated and corrected separately for the ionosphere and the troposphere. The ionosphere (above $\sim 80 \mathrm{~km}$ altitude) is characterised by rich layers of electrons and ions, mostly produced by photochemical reactions with the sun. Ionosphere activity depends upon the solar and geomagnetic activities. A first-order ionospheric delay is removed with a linear combination often called ionosphere-free linear combination:

$$
L_{3}=\frac{f_{1}^{2} L_{1}-f_{2}^{2} L_{2}}{f_{1}^{2}-f_{2}^{2}}
$$

where $f_{1,2}$ are the carrier frequencies and $L_{1,2}$ are the phase observables in meters. Hernndez-Pajares et al. (2007) show that this first-order approximation is sufficient and second-order ionospheric delay has a sub-millimetric amplitude (and is therefore negligible for the scale of our study). The modelling of tropospheric effects is done from the Global Mapping Function (Boehm et al., 2006). A $7^{\circ}$ elevation cut-off angle is used, a compromise to minimise the constraint effects and the multipath errors.

Non-tidal atmospheric displacements are modelled following Ray and Ponte (2003). The FES2004 tidal atlas (Lyard et al., 2006) is used to correct the effects of ocean loading. Ambiguity resolution is made in agreement with Dach et al. (2015) (see Table 2.3).

Outliers are removed with the Median Absolute Deviation (MAD) robust estimator at the fourth level with $\sigma=1.4826 \times M A D$. Figure 2.3 shows the obtained data set in the three spatial directions for the Annette Plateau (NETT) station. Figure 2.4 is the horizontal displacement recorded in this data set. A clear annual cyclicity is readily observable in these two figures. Denys et al. (2005) suggested that the cyclic displacements at these sites could be induced by snow loading, rock porosity, thermoelastic strain or local effects such as topographic conditions and orientation (Denys et al., 2005). Offsets caused by major earthquakes in the region and postseismic decays that follow are removed with the methods described in Denys et al. (2016) and Denys and Pearson (2016). The corrections described in Section 2.3.2 were calculated at the University of Otago by Denys $(2001,2016)$. 
Table 2.3: cGPS data processing strategies and models used, from P. Denys (University of Otago, School of Surveying)

\begin{tabular}{|c|c|c|}
\hline Model & Note & Process \\
\hline Frame & & ITRF2014 \\
\hline Observables & & Double Differenced Phase \\
\hline Sessions & & $\begin{array}{l}24 \mathrm{~h} \text {, Epoch Interval: } 180 \mathrm{~s} \text { interval } \\
\text { (Data Cleaning: } 30 \mathrm{~s} \text { ) }\end{array}$ \\
\hline Elevation Cut-off & & $7^{\circ}$ \\
\hline Antenna PCV & & Absolute, I08.ATX \\
\hline Ocean Loading Model & a & FES2004 \\
\hline Ionospheric Refraction & & $\begin{array}{l}\text { Ionosphere-Free Linear Combination } \\
\text { (first Order effect only) Zenith Delay: } \\
\text { Hourly, Troposphere Gradient: Daily }\end{array}$ \\
\hline Tropospheric Refraction & & $\begin{array}{l}\text { Mapping Functions: Global Pressure } \\
\text { Temperature Model (GMF) }\end{array}$ \\
\hline Ambiguities & & $\begin{array}{l}\text { Fixed: strategy includes phase-based } \\
\text { widelane, QIF, direct L1/L2 depend- } \\
\text { ing upon baseline length }\end{array}$ \\
\hline Global Ionosphere Model & & CODE \\
\hline Daily Solutions & $\mathrm{b}$ & Helmert: 3 parameters \\
\hline
\end{tabular}

a. Calculated by Onsala Space Observatory

b. Daily solutions transformed into a set of regional (Australia and Pacific) IGS stations. 

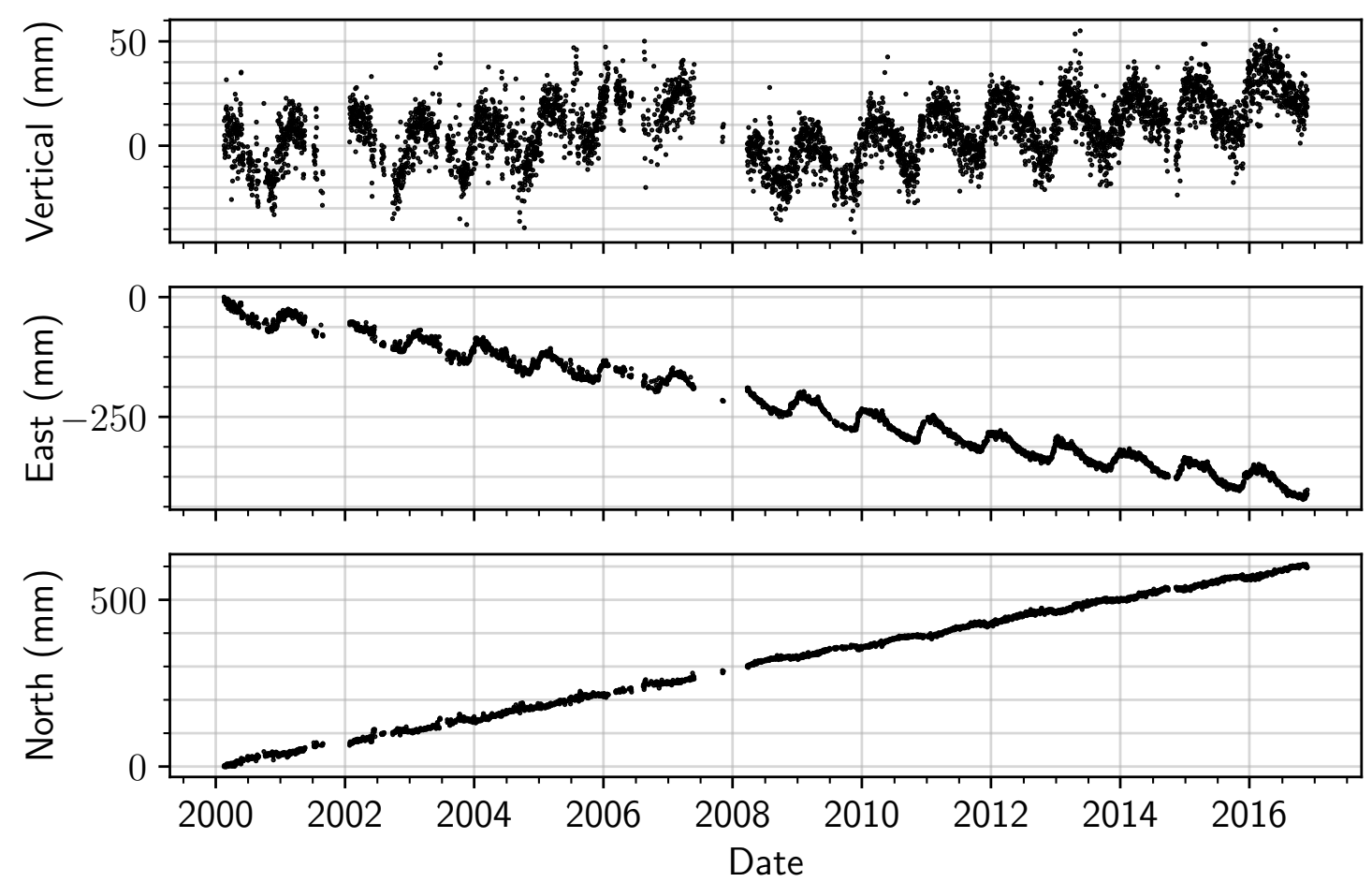

Figure 2.3: Preprocessed data set for ground displacement at Annette Plateau (NETT), relative to ITRF2014 reference frame, since 18 February 2000. The contemporary tectonic plate motion is clearly visible, as well as a centimetre-scale annual cyclicity. Note that the amplitude scale varies between components.

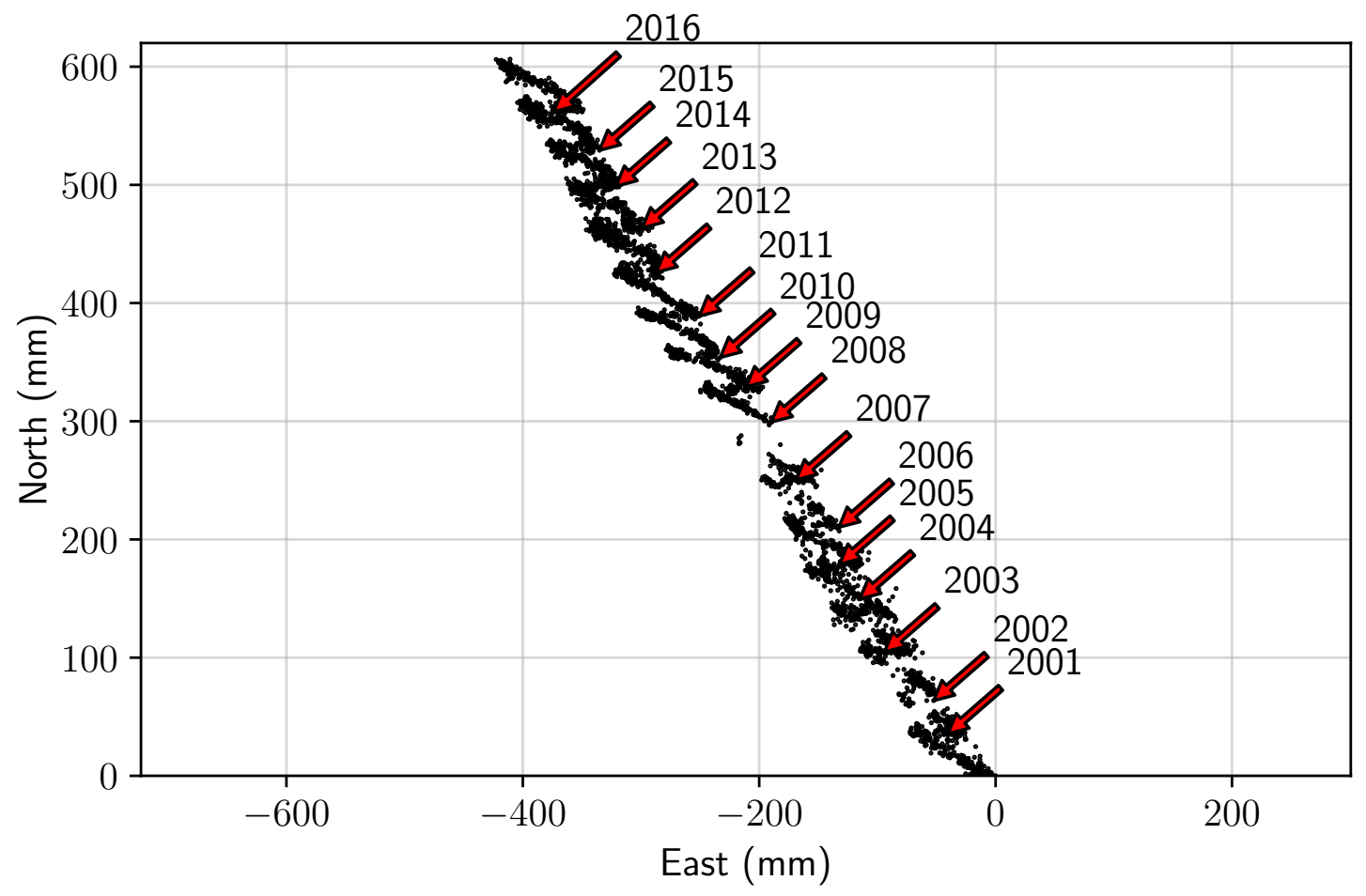

Figure 2.4: Horizontal displacement at Annette Plateau (NETT) cGPS station, relative to ITRF2008 reference frame, showing the contemporary long-term trend and the annual cycles. 

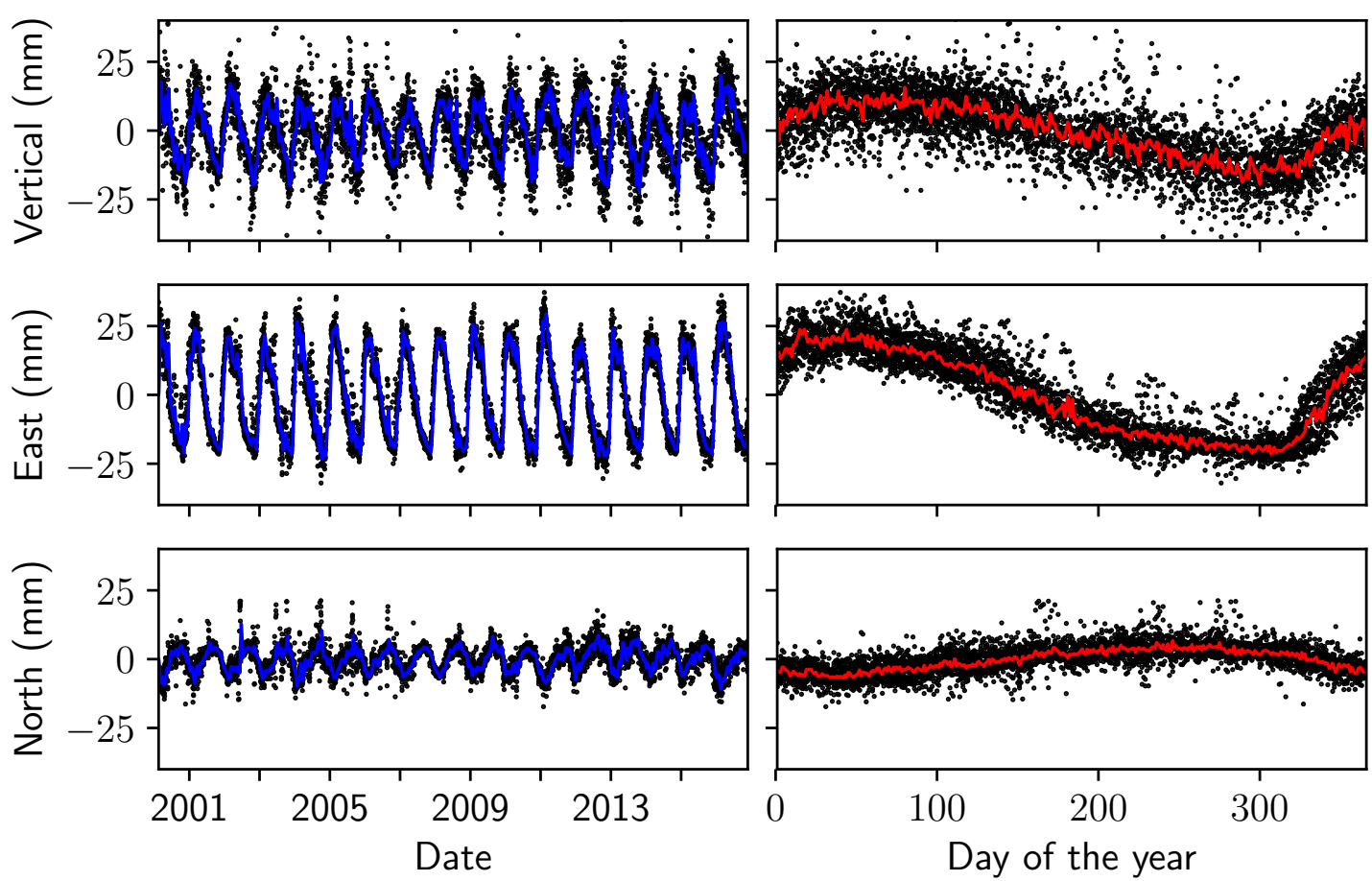

Figure 2.5: Time series of ground position at Annette Plateau (NETT), in the three spatial directions with a low-pass filtering of the data in blue (left), relative to ITRF2014 reference frame. Same data represented on an ordinal year, with the daily median in red (right).

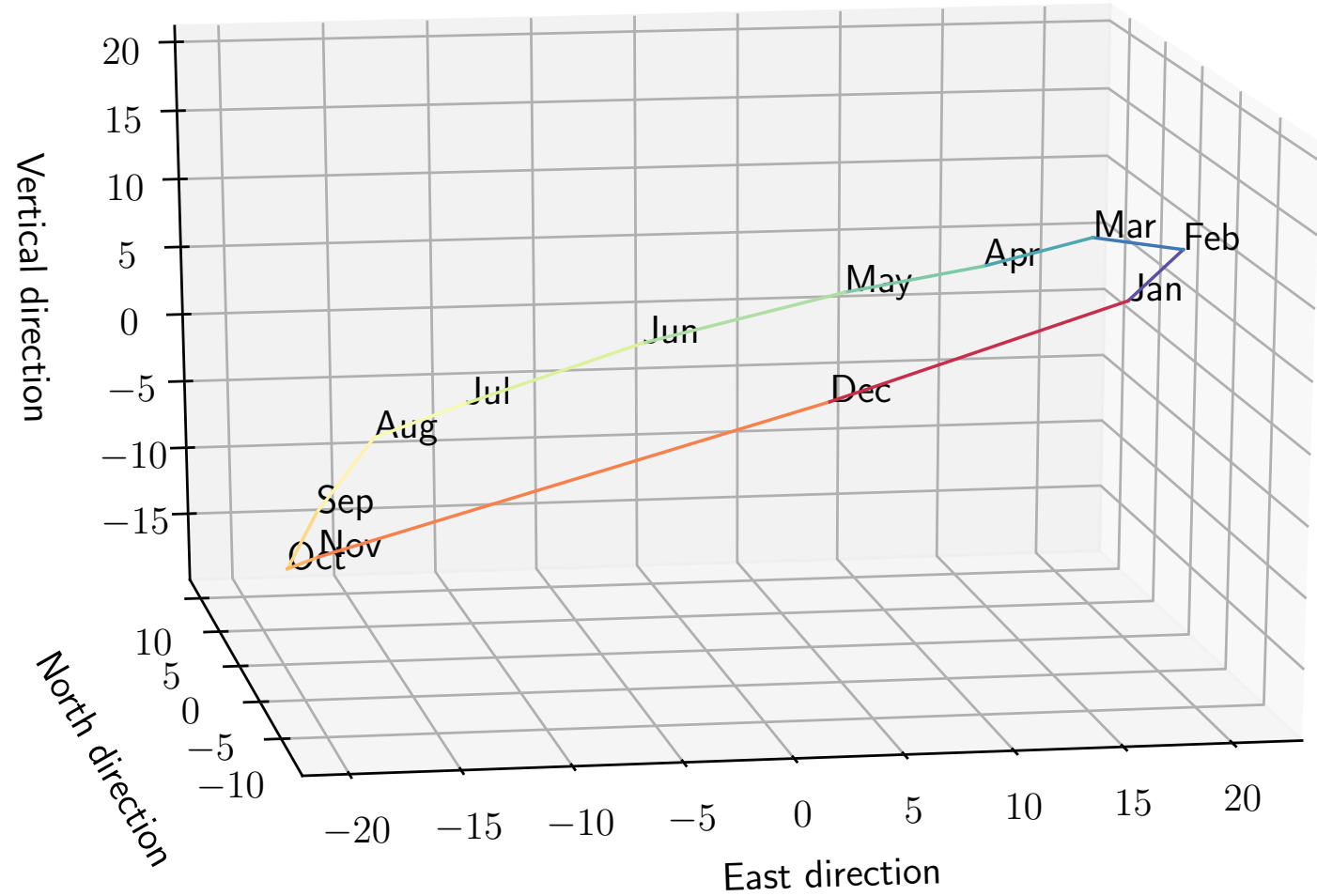

Figure 2.6: 3D model of motion at Annette Plateau (NETT), based on the monthly median of daily GPS solutions. 
Table 2.4: Missing data at each cGPS station.

\begin{tabular}{lll}
\hline Station & Name & Missing Data (\%) \\
\hline BNET & Burnett Rock & 5.7 \\
CNCL & Conical Hill & 4.8 \\
GUNR & Gunn Ridge & 3.3 \\
HAAS & Haast & 1.2 \\
HOKI & Hokitika & 4.3 \\
HORN & Hoophorn Spur & 19.5 \\
KARA & Karangarua & 4.7 \\
LEOC & Leo Creek* ${ }^{*}$ & 26.9 \\
MAKA & Makarora* & 78.7 \\
MCKE & MCKE* & 70.3 \\
MTCX & Mount Cox* & 32.4 \\
MTJO & Mount John Observatory & 1.3 \\
MTPR & Mount Price & 12.9 \\
NETT & Annette Plateau & 22.0 \\
PILK & Pilkington Glacier & 21.1 \\
QUAR & Quarry & 6.3 \\
REDD & Red Deer Col* & 72.8 \\
VEXA & Vexation* & 54.5 \\
WAKA & Waka Mara & 11.3 \\
\hline
\end{tabular}

* Semi-continuous GPS station

For the purposes of this study, we remove the long-term trend reflecting the contemporary tectonic plate motion, after the preprocessing described above was complete. Some data are missing (see Table 2.4), which is problematic for a statistical analysis of the time series. We filled the missing values by infilling data gaps using the median per ordinal day from periods of data continuity. The median per day of the year (Figure 2.5) is used to fill the rest of the data set. Daily median per month of the year was also used to build three-dimensional models of the movement at each station (e.g. Figure 2.6). 


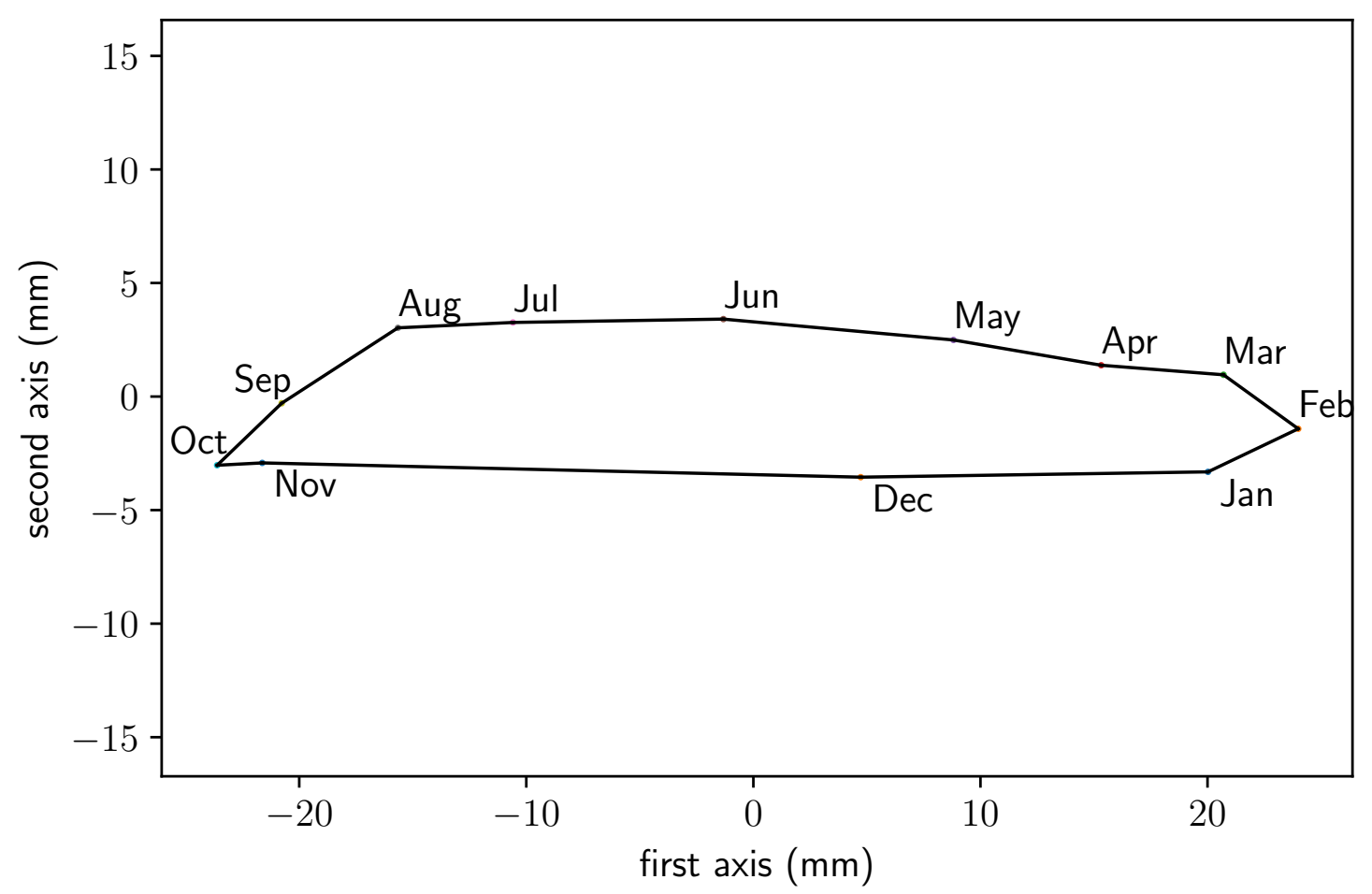

Figure 2.7: Average annual 2D movement at Annette Plateau (NETT), along the two first eigenvectors (sorted by eigenvalues).

\section{Regression and rotation of displacement data}

Certain stations show a well-marked annual cycle. For these, we constrain the movement to one dimension for analysis. Here, we detail the procedure for station Annette Plateau (NETT). The direction of displacement for the other stations concerned can be found on the maps in Appendix B.

The spatial direction of the maximum displacement is the abscissa of the graph, which is coplanar with the least squares regression plane in Figure 2.7. We calculate the eigenvectors to obtain the transformation matrix from the first coordinate system to the rotated one. By inverting this matrix, we can compute the new position of every point in the new 2D coordinate system (Figure 2.7). In constraining the movement along the principal axis, we can better correlate the GPS motion with other data sets, for example, climatic data. The displacement model is often approximately contained in a plane. In contrast, we lose some information by reducing the movement to one dimension. The hysteresis that can be seen in 2D (e.g. Figure 2.7) will not be subject of investigation in this thesis and could become the object of a more detailed analysis. Figure 2.8 shows the final filled data set for Annette Plateau (NETT) and the autocorrelation plot. 

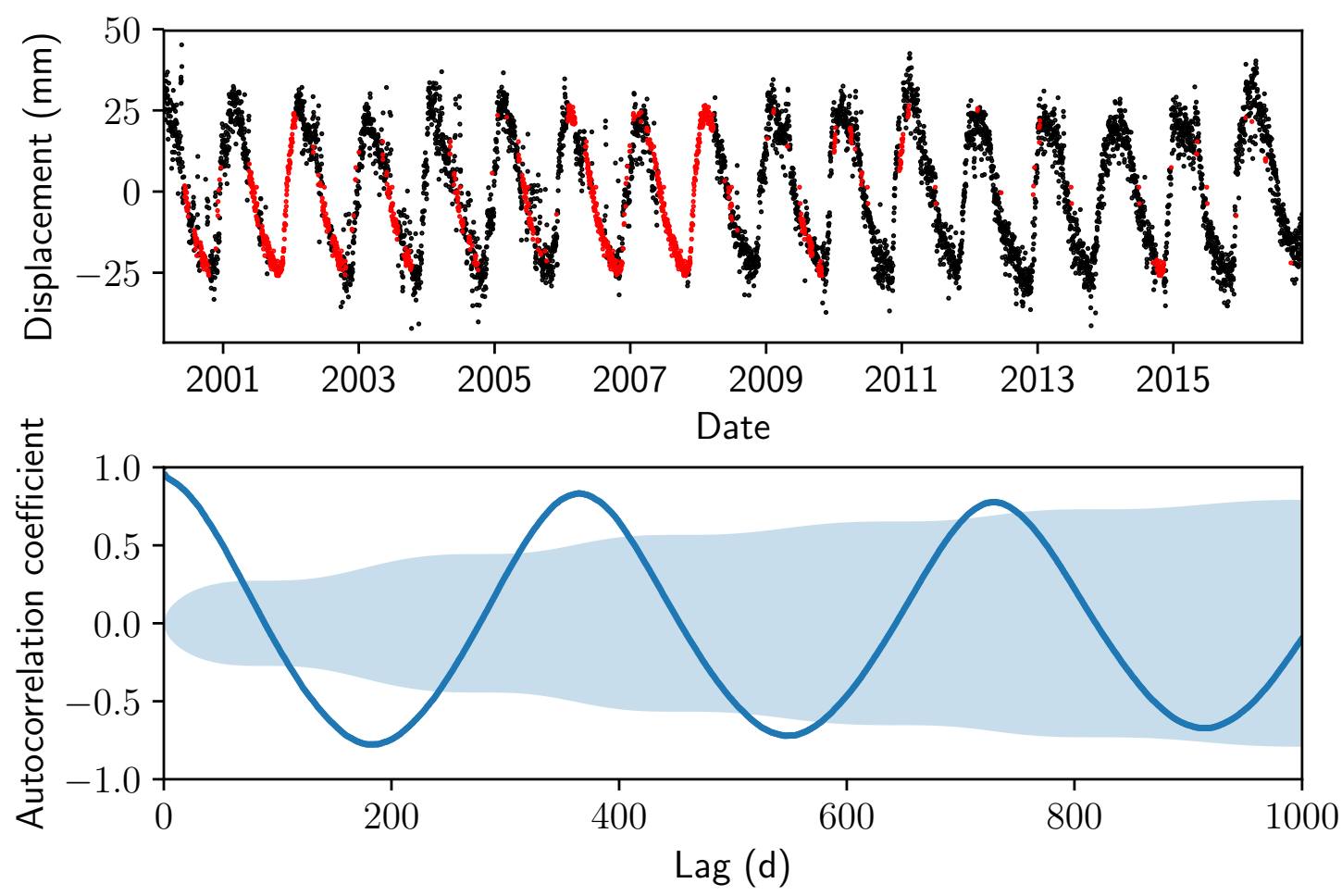

Figure 2.8: data set filled using a median year and constrained on one dimension. Measured displacement are in black, artificial data are in red. $20 \%$ of data are artificial (top); autocorrelation plot, lags are in days (bottom). The blue domain represents the limit of the $95 \%$ confidence interval with a standard deviation calculated from Bartlett's formula. 


\subsection{3 cGPS positioning and accuracy}

Here, we evaluate the importance of a range of physical parameters on GPS positioning and accuracy. The material in this Section, together with the comparison between time series in Section 3.1 will provide the basis for assessing which of these environmental and instrumental factors could explain the observed variations in GPS time series in our study area, in Section 4.1.

\section{Instrument noise and monument movement}

The seasonal variations seen with cGPS devices are small, generally of only a few millimetres (Dong et al., 2002, Beavan et al., 2004), which is close to the amplitude of the level of instrumental noise. To be able to work at this scale, we, therefore, need to minimise instrumental variations as much as possible. The quality of the construction material and method of station placement are critical. Antennae in the Southern Alps are mounted on concrete pillars (see Figure 2.2), attached to the bedrock and reinforced with stainless steel bars. The monument construction method is a critical part of the installation because the monument could be a primary source of noise in the time series.

Monument noise is thought to explain a seasonal movement at a cGPS site in Austria (Kenyeres and Bruyninx, 2009), which is similar in amplitude and time to the seasonality observed in Annette Plateau (NETT) or Pilkington Glacier (PILK) for example. However, the noise properties of continuous GPS devices built on concrete pillars in New Zealand were compared to the ones from U.S. deep drilledbraced monuments, considered as some of the most three-dimensionally stable monuments (Beavan, 2005). Monument noise is no worse in the New Zealand cGPS network, despite cheaper equipment, and should not exceed one millimetre per year in all the stations used in this study (Beavan, 2005). Monument noise cannot, therefore, explain the observed large amplitudes of motion in the central Southern Alps.

When an antenna is changed, there is an unavoidable offset, related to the construction of the antenna itself. Indeed, each model has its own antenna phase centre (APC), not always corresponding to the actual geometric centre of the antenna (El-Hattab, 2013). Therefore, even a careful geometric centering of the antenna would lead to an offset if the APC of the former and new antennae are not at the same spot. The APC is affected by the altitude of the station, and the environment around the antenna, therefore it needs to be estimated for every 
station. The offset is removed directly from the cGPS time series, knowing the date of an antenna change (Beavan et al., 2007).

For stations located at high-altitude in an alpine environment, snow and ice can build-up on the antenna and add to the level of noise, up to a magnitude of error around $10^{-1} \mathrm{~m}$. This phenomenon is driven by precipitation, direction and force of the wind, and sun exposure. An example can be seen in Figure 2.2, where snow has accumulated on the antenna.

Some other sources of noise are errors in the satellite orbital models and satellite clock, atmospheric delays due to mismodeling of ionospheric or tropospheric conditions (temperature, humidity, pressure) and multipath. Errors in the satellite orbital models and satellite clock will not be studied in this thesis, they are unavoidable at our level and have a regional impact that cannot explain differences between two close cGPS stations using the same satellites (Lou et al., 2014). Atmospheric delays are produced by miscalculations in the ionospheric conditions, and in the tropospheric conditions (e.g. pressure, temperature, water content). Each passage of an anticyclone or trough of low pressure modifies the pressure, temperature and humidity $(\mathrm{P}-\mathrm{T}-\mathrm{H})$ conditions in the troposphere and, hence, the delay of the signal from the satellite to the station.

Multipath effects are caused by reflections of the signal from the satellite on objects around the antenna, causing the station to lose accuracy and appear to shift slightly in position. Mapping the objects responsible for the multipath effects around a station can be done using the signal to noise ratio (Bilich and Larson, 2007). Suitable candidates are reflective surfaces like buildings, mountains or trees, for example. cGPS devices can be sensitive enough to detect small variations in their environment, like vegetation growth (Small et al., 2010). Multipath effects can be used to detect the changes in humidity in the surrounding soil (Chew et al., 2014) or the depth of snow around the station (Nievinski and Larson, 2014) for example.

If a station is completely buried under the snow, incoherence in the position and loss of accuracy are observed (Ray et al., 2008). Snow may also cause power outages at solar-powered stations, by covering the panels. Most of the high-altitude stations used in this study are situated on ridges and in windy places, which enable them to remain snow free and record all year round (see Appendix B). 


\section{Freezing and thawing of near-surface}

cGPS stations move with the bedrock to which they are attached. If the bedrock is fractured, freezing of water in the fractures can lead to their expansion and movements of bedrock blocks. This freezing and thawing effect happens only where the ground temperature is in the range of freezing and thawing of water. In the mountains, there are zones of permafrost, seasonal frost, and sporadic frost. The spatial distribution of these zones depends on many factors, but principally altitude and slope aspect. Permafrost is the zone defined by a period of at least two years with no ground thawing (Gruber and Haeberli, 2009). In the Southern Alps of New Zealand, permafrost begins at an altitude of around $2300 \mathrm{~m}$ (Allen et al., 2009).

None of the cGPS stations in the SAGENZ network is situated in the permafrost zone. Installing stations at high altitude is challenging with regard to accessibility, security when servicing, stability of the equipment and requires material of higher quality. A few of the Southern Alps GPS stations are situated in the zone of seasonal frost, and most of them are in the zone of sporadic frost, below $\sim 1400 \mathrm{~m}$.

At a local scale around the antenna, the Southern Alps bedrock is highly fractured. In the zone of seasonal frost, ice and snow build in the fractures during winter and melt during summer. Water freezing in the fractures is associated with a volume expansion of $9 \%$ (Lundberg et al., 2016), which can potentially expand fractures and induce movement of blocks of rock away from each other. Snow coverage insulates the ground from the fluctuating air temperature (Lundberg et al., 2016) and prevents melting of the ice in the fractures. Therefore, in the seasonal frost zone, we can expect water to freeze in the fractures of the surface rocks in early winter and, for the most part, to remain frozen until the spring or summer.

\section{Thermoelasticity of the shallow subsurface}

Another movement of the near-surface that could contribute to the displacement of the cGPS stations is thermoelasticity of the shallow subsurface. Rocks expand with an increase in temperature, with the isobaric thermal expansion coefficient being typically in the order of $10^{-5} 1 /{ }^{\circ} \mathrm{C}$ at the atmospheric pressure and temperature (Robertson, 1988).

This effect was observed in California (Prawirodirdjo et al., 2006). However, Yan et al. (2009) have calculated the contributions of both the thermal expansion of the monument and the bedrock together to vertical measurements of GPS around 
the world. They found that the annual displacement induced by thermoelasticity of monuments and bedrock should be less than half a millimetre for New Zealand. Their global model predicts a maximum displacement of $1.3 \mathrm{~mm}$ between summer and winter in some regions in the Northern Hemisphere where the continental climate leads to strong seasonal differences of temperature.

\section{Major regional earthquakes}

Every time a regional earthquake strikes the South Island with a high enough magnitude, there is a potential that some cGPS stations will experience a coseismic offset. Following this initial movement, the station often moves slowly until reaching a new equilibrium. This post-seismic decay (described, quantified and modelled by Denys et al. (2016)), is understood as a combination of after-slip and viscoelastic relaxation.

\section{Landslides}

If we build a station on a landslide, the cGPS displacement can be used to monitor the slip, providing a relatively cheap method to understand material movement with reliable results. The Southern Alps are known for its large number of landslides, due to the topography and a high erosion rate. Despite site examinations and care when choosing the sites for the SAGENZ network, one of the stations (Gunn Ridge (GUNR), Figure B.6) has since proven to be located on unstable land (Denys and D'Anastasio, 2016). A characteristic of landslide motion is that it tends to be unidirectional and driven by gravity. A point at the surface of the land affected by the landslide will typically move in a down-slope direction. Upward movements (against the gravity), such as the ones observed at some sites in the SAGENZ network, are rarely observed (Massey et al., 2013, Leung and Ng, 2016, Rouyet et al., 2016) and cannot be caused by the landslide itself.

\section{Tides}

The sun and the moon both exert a gravitational attraction on Earth that may affect GPS measurements on a scale that is significant to our study. Movements of the ground of a few centimetres are expected due to solid Earth tides, and gravitational effects do not necessarily induce the same displacement on satellites orbits. 
In New Zealand, oceanic tides were shown to have a significant influence on coastal regions (Goring and Walters, 2002) and they have the potential to induce a regional loading from the ocean and a displacement of cGPS position. The effect should dissipate with distance from the coast. Solid Earth tides and atmospheric tides should have a bigger influence on the northern part of the country (Goring and Walters, 2002) and have a regional impact. Modelled tidal effects on GPS stations is removed from the raw GPS data before using it.

\section{Surface loading}

cGPS position could be influenced by local to regional surface loading of various origins (e.g. water in a reservoir, snow, soil moisture, atmospheric loading).

There have been multiple studies of flexure and ground displacement induced by surface water loading, including: Southern Norway (Fjeldskaar, 1990); Lake Laja in Chile, Bevis et al. (2004); the Amazon basin in Brazil (Bevis, 2005); the Great Salt Lake, Utah, USA (Elsegui et al., 2003); and in South-Eastern Asia, where studies have shown a crustal deformation induced by the surface water load of the monsoon. In Bangladesh, two-thirds of the country can be flooded in extreme events (Steckler et al., 2010), and along the Himalayas, the loading of the GangesBrahmaputra plain affects the whole region (Chanard et al., 2014). These studies provide good examples of cGPS response to surface water loading and a good source for comparison with the cGPS data in the current study.

Similarly, the mass of accumulated snow exerts a pressure on the ground, which can induce an elastic movement of the rocks. Examples have been documented from Japan (Murakami and Miyazaki, 2001), USA (Ouellette et al., 2013), and Iceland (Grapenthin et al., 2006).

Earth displacement due to increased soil moisture during winter, snow cover and atmospheric loading was also analysed at a global scale by Blewitt et al. (2001). They concluded that annual exchange of water and air masses between hemispheres results in a displacement of up to $3 \mathrm{~mm}$ vertically in some regions and around $1.5 \mathrm{~mm}$ horizontally. These effects are taken into account in the preprocessing of the cGPS data. 


\section{Groundwater}

A change in the groundwater level provokes a change in poroelastic pressure and the filling of fractures with water in bedrock. This, in turn, controls opening and closure of fractures and expansion and contraction of pores and therefore, a volumetric deformation of the rock mass. A study of infiltration rates in the fractured schist above the Tatare tunnel, in the West Coast district (Sims et al., 2015), revealed that between $0.3 \%$ and $20 \%$ of the rainfall infiltrates the bedrock and actively modifies the depth of the groundwater table.

Numerous studies have shown a link between the groundwater level, poroelastic pressure, and displacement of the surface, focussing on anthropogenic changes in the water table elevation (often due to over-exploitation of an aquifer and reservoir depletion (Motagh et al., 2007, Amos et al., 2014, Chen et al., 2017), and tunnelling and groundwater drawdown (Lombardi, 1988, 2004, Strozzi et al., 2011, Preisig et al., 2012)), ground response to an aquifer recharge (King et al., 2007, Boutt, 2010), and mixed anthropogenic and natural groundwater level changes (Watson et al., 2002, Ji and Herring, 2012, Hu et al., 2016).

Finally, studies have addressed the case of surface displacement induced by nonanthropogenic groundwater changes in slopes and mountainous areas. These circumstances apply to our study, as most of the Southern Alps cGPS stations are situated in remote mountainous regions where there is little human activity (see Figure 1.2). In alpine valleys in the central Alps, Switzerland, Hansmann et al. (2012b) linked groundwater table elevation changes to surface displacement through filling/drying of bedrock fractures with meteoric water before the tunnelling of the Gothard Base Tunnel. They installed six high-precision relative GPS networks in a topographically similar environment to our study area and recorded a natural cyclic movement in the years preceding the tunnel excavation, with a similar amplitude and a similar response time to the ones we have in some of our stations (Löw et al., 2007). Due to the quick response to heavy rainfall and snow melting, Hansmann et al. (2012b) explain the displacement of the bedrock by changes in groundwater elevation in the fractures of the surrounding mountain slopes. The filling of fractures with water increases their pore-fluid pressure and reduces the effective stress (defined as the stress minus the pore-pressure (Zoback, 2007)). Assuming a linearity between stress and strain, the reduction of normal effective stress on a fracture results in a deformation of the rock-mass surrounding the fracture. This strain can be measured by cGPS, with enough fractures and added volume of water. 
Bedrock in the Southern Alps is highly fractured, due to the intensive ongoing tectonic processes (Cox and Findlay, 1995). In such conditions, it is commonly accepted that a majority of meteoric water flows through fractures in the rock mass (Masset and Löw, 2010). The opening of fractures due to their filling with water occurs mainly in the shallow saturated zone of the fractured bedrock, therefore, depends on the depth of the shallow groundwater table. Fracture opening/closing by this method is expected to occur between the saturated and vadose zones mostly. Below this depth, it is often assumed that hydraulic conductivity and permeability progressively decrease, due to the increase in stress with depth (Achtziger-Zupančič et al., 2017). However, Upton and Sutherland (2014) challenge this assumption for the Fiordland region (southern Southern Alps), based on data from the Manapouri tunnel. Furthermore, Masset and Löw (2010) and Achtziger-Zupančič et al. (2017) show that permeability does not always decrease with increasing depth, and, in particular conditions of highly fractured bedrock, appears to primarily depend on the proximity to rock discontinuities and mean fracture spacing interval.

Similarly to Upton and Sutherland (2014) in the Fiordland region, Menzies et al. (2014, 2016), Cox et al. (2015), and Sutherland et al. (2017) demonstrate that deep meteoric water circulates under the central Southern Alps, with pore-pressure sometimes significantly higher than hydrostatic pressure. For example, Sutherland et al. (2017) recorded a pore fluid pressure gradient $9 \pm 1 \%$ higher than hydrostatic pressure in the DFDP-2B borehole. They reveal a gravity-driven underground fluid flux in the rock mass, in good agreement with supposed gravity-driven fluctuations of the groundwater table (Welch and Allen, 2012, Evans et al., 2015). Following Masset and Löw (2010), Hansmann et al. (2012b), and Achtziger-Zupančič et al. (2017), we estimate that the effect of the groundwater-induced surface deformation in our study area acts mostly from the surface to an approximate depth of $400 \mathrm{~m}$, with strong lateral variabilities, due to topography and heterogeneity of faults and fractures spacing in the bedrock.

\subsection{Meteorological and hydrological data}

In this section, we present the meteorological and hydrological data that we use in this thesis. These are rainfall, snowfall, atmospheric pressure, near-surface air temperature, lake levels, barometric pressure in the Deep Fault Drilling Project 1B (DFDP-1B) borehole, as a proxy for the groundwater level under the mountains, 


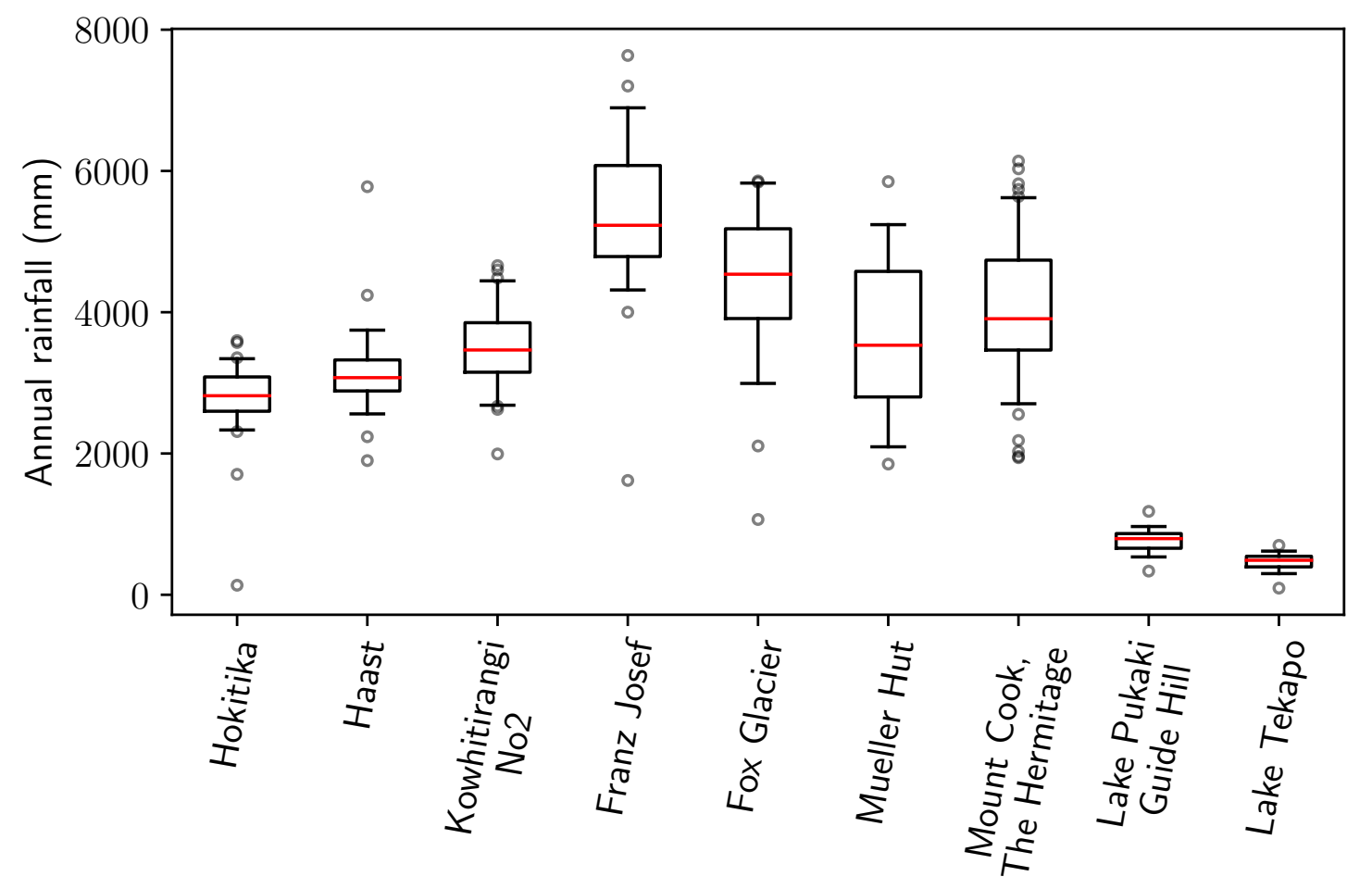

Figure 2.9: Annual rainfall at some of the monitoring sites in the central South Island. Rain gauges are sorted by distance from the South Island's west coast, from left to right. The period of recording for each site is in Table 2.5.

and two mathematical models for groundwater table fluctuations estimation. The processing of data and percentage of completion of each data set is shown.

\subsubsection{Rainfall data}

We use daily total rainfall from 16 rain gauges distributed between the West Coast of the South Island, close to the Tasman Sea, to the eastern side of the Main Divide, and the Mackenzie Basin (see Figure 1.2). We selected these stations based on their locations, time of service and completion of data sets. The period of record and missing data at each site are in Table 2.5. There are large differences in total annual rainfall received from one station to another, depending on which side of and at what distance from the Main Divide they are. Figure 2.9 shows the annual rainfall received for each site. Note that the easterly part of the study area is more arid than the west and that the wettest stations are close to the Main Divide, on its western side (see section 1.3).

Prior to performing statistical analysis on the meteorological time series, we fill the gaps in the data sets. We define two types of gaps. The first occurs when there is more than a day between two measurements. In this case, we fill the gaps 
Table 2.5: Percentage of missing data, start and end date of the data set at each rainfall station.

\begin{tabular}{llll}
\hline Station & Missing Data (\%) & Start & End \\
\hline Fox Glacier & 3.8 & $1967-01-03$ & $1994-02-27$ \\
Franz Josef & 5.3 & $1982-01-04$ & $2016-06-29$ \\
Franz Josef + THC + EWS & 20.7 & $1926-11-03$ & $2017-07-31$ \\
Haast & 7.3 & $1982-01-03$ & $2017-07-31$ \\
Hokitika & 0.0 & $1963-12-03$ & $2017-07-31$ \\
Hokitika Aero & 0.0 & $1963-12-03$ & $2016-09-16$ \\
Ivory Glacier & 24.3 & $2009-02-06$ & $2017-07-31$ \\
Kowhitirangi No2 & 0.1 & $1965-02-03$ & $2017-07-01$ \\
Lake Pukaki Aerodrome & 0.2 & $2008-12-16$ & $2017-07-31$ \\
Lake Pukaki Guide Hill & 0.9 & $2000-01-02$ & $2017-06-01$ \\
Lake Tekapo & 0.0 & $2000-11-04$ & $2016-11-02$ \\
Mahitahi & 8.9 & $2000-01-02$ & $2004-03-01$ \\
Mount Cook & 2.4 & $1928-06-03$ & $2017-07-31$ \\
Mueller Hut & 0.8 & $2010-04-16$ & $2017-07-31$ \\
\hline
\end{tabular}

by dividing the amount of rain received during that time by the number of days concerned. For the second type of gaps, when no measurement is available at all, we arbitrarily assign a value of $0 \mathrm{~mm}$ of rain. A completion of each data set used can be found in Table 2.5.

Figures 2.10 and 2.11 show an extract of the time series of rain and the monthly amount of rain for Franz Josef (see Figure 1.2). Rainfall occurs all year-round, with a lack of any marked seasonality. Analysis of time series in the frequency domain in Figure 2.12 shows the seasonality (one-year cycle) (on the left side) and shorter cyclicities. This highlights that the influence of anticyclones and troughs of low-pressure cycles on rain is high in this region (Wratt et al., 1996, Salinger and Mullan, 1999, Godoi et al., 2016). 


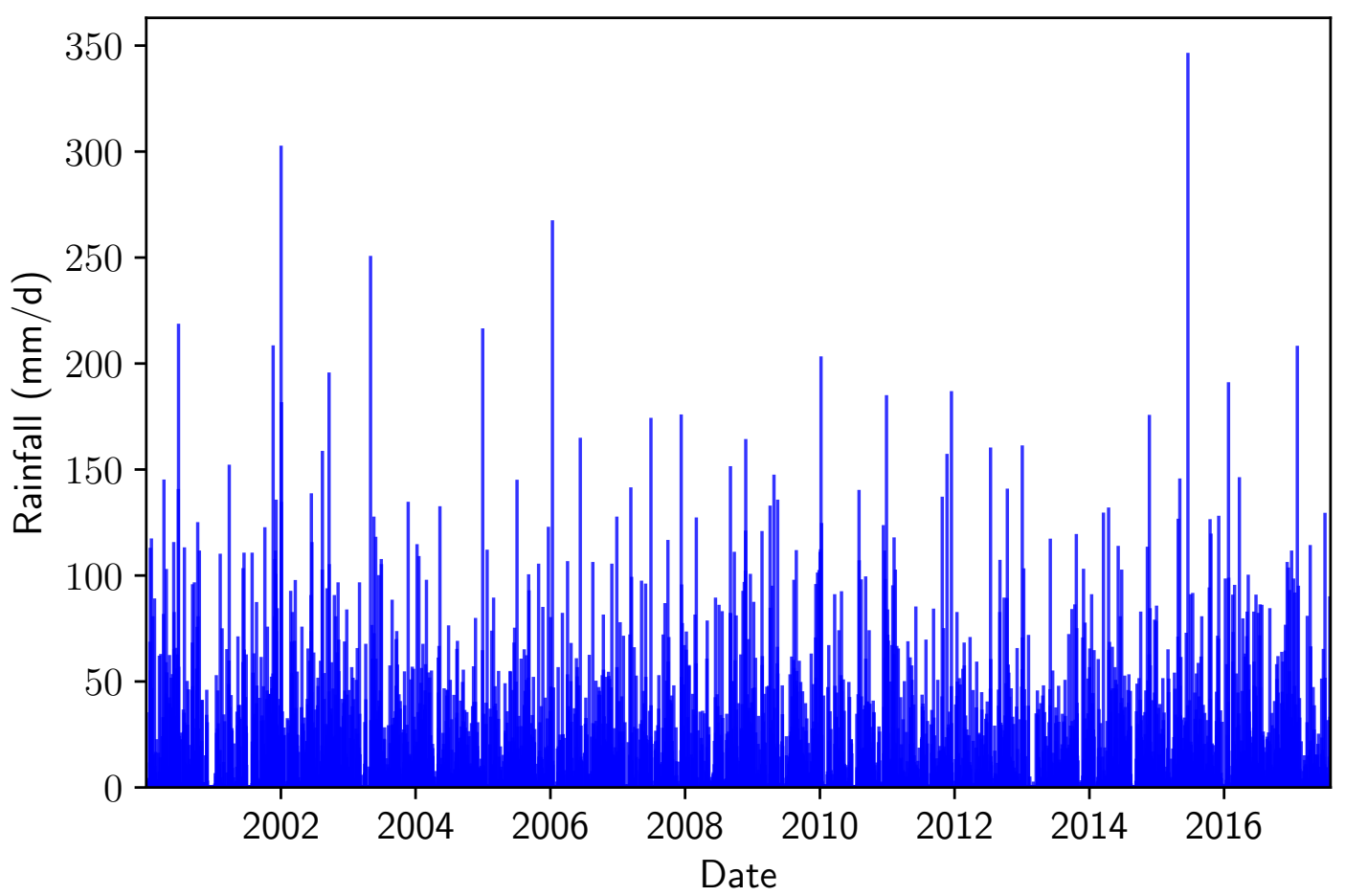

Figure 2.10: Extract of time series of rainfall at Franz Josef (2000-2017).

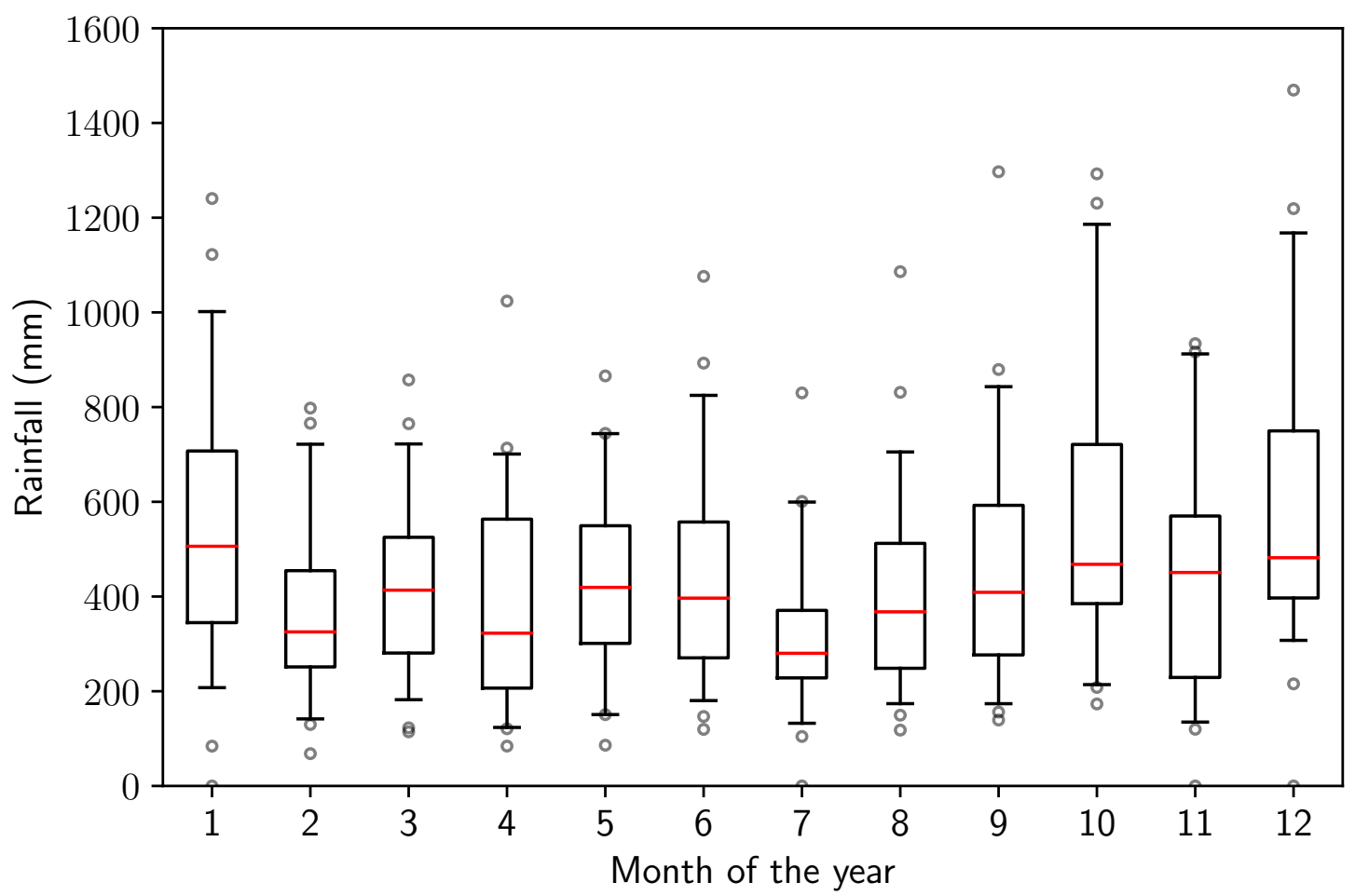

Figure 2.11: Monthly rainfall at Franz Josef between 1982 and 2017. 


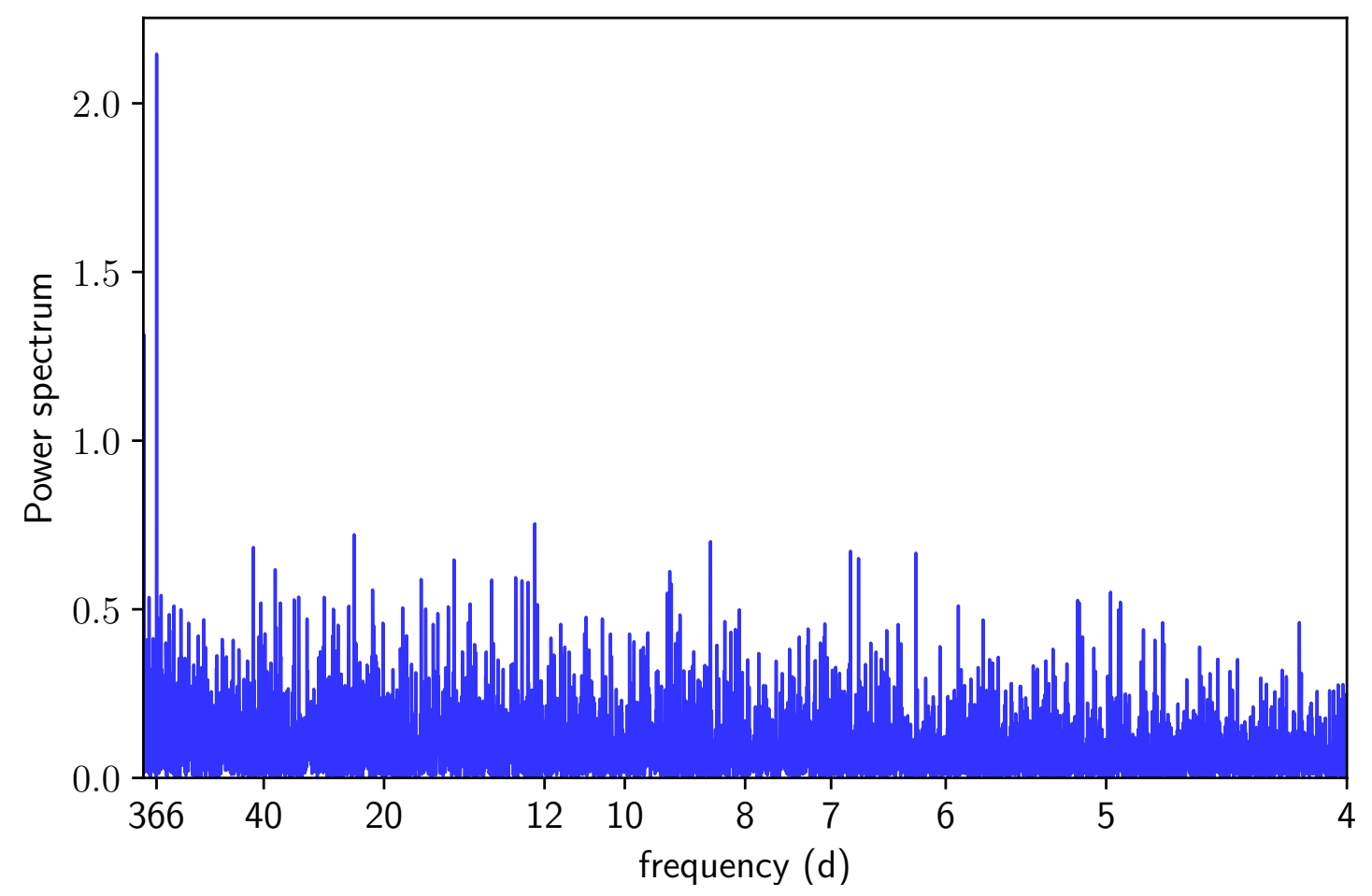

Figure 2.12: Frequency analysis of rain at Franz Josef for the period 1953 - 2017.

\subsubsection{Snowfall data}

Snow constitutes a significant proportion of the precipitation in the Southern Alps (Kerr et al., 2013, Webster et al., 2015). We use snow depth data from three continuous snow gauges to evaluate the quantity of snow in the study area through the year.

The National Institute of Water and Atmospheric Research (NIWA) installed a network of SIN (Snow and Ice Monitoring Network) snow gauges in the Southern Alps, to record the amount of snow in the mountains. One of them was built close to Mueller Hut in 2010. The installation, visible in Figure 2.13, consists of an ultrasonic emitter and receptor installed on a mast above the ground. By sending a pulse to the ground, the sensor measures the distance to the snow and deduces snow height from the known distance to the ground. The station also estimates snow density and Snow Water Equivalent (SWE). A pillow measuring three meters in diameter is hidden under the snow and records the pressure on it. From this, the weight of the snow mass above the pillow is calculated and, using the mass and height of snow, estimates are derived for the SWE.

We use raw data from Mueller Hut snow gauge for the period 2013-2016. All negative height values were removed as bad measurements; the different data sets 


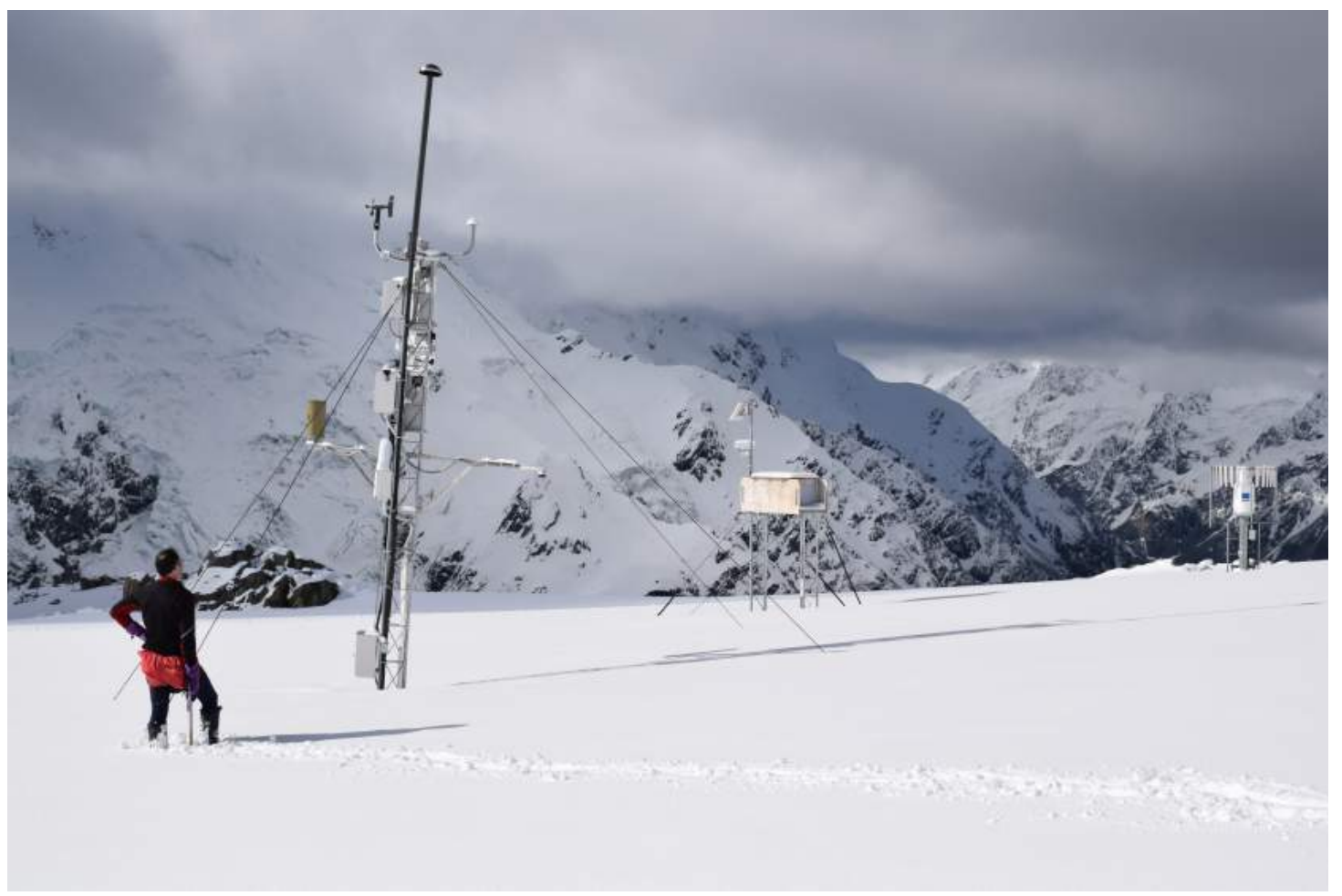

Figure 2.13: Mueller Hut station, with Simon Cox for scale. The rain gauge is on the right, the snow gauge on the left. The box between them is the battery, fuel cell, fuel container and controller. Hooker Valley and the lower part of Mount Cook is in the background (View to the NNE). The picture was taken on 29 October 2016. 


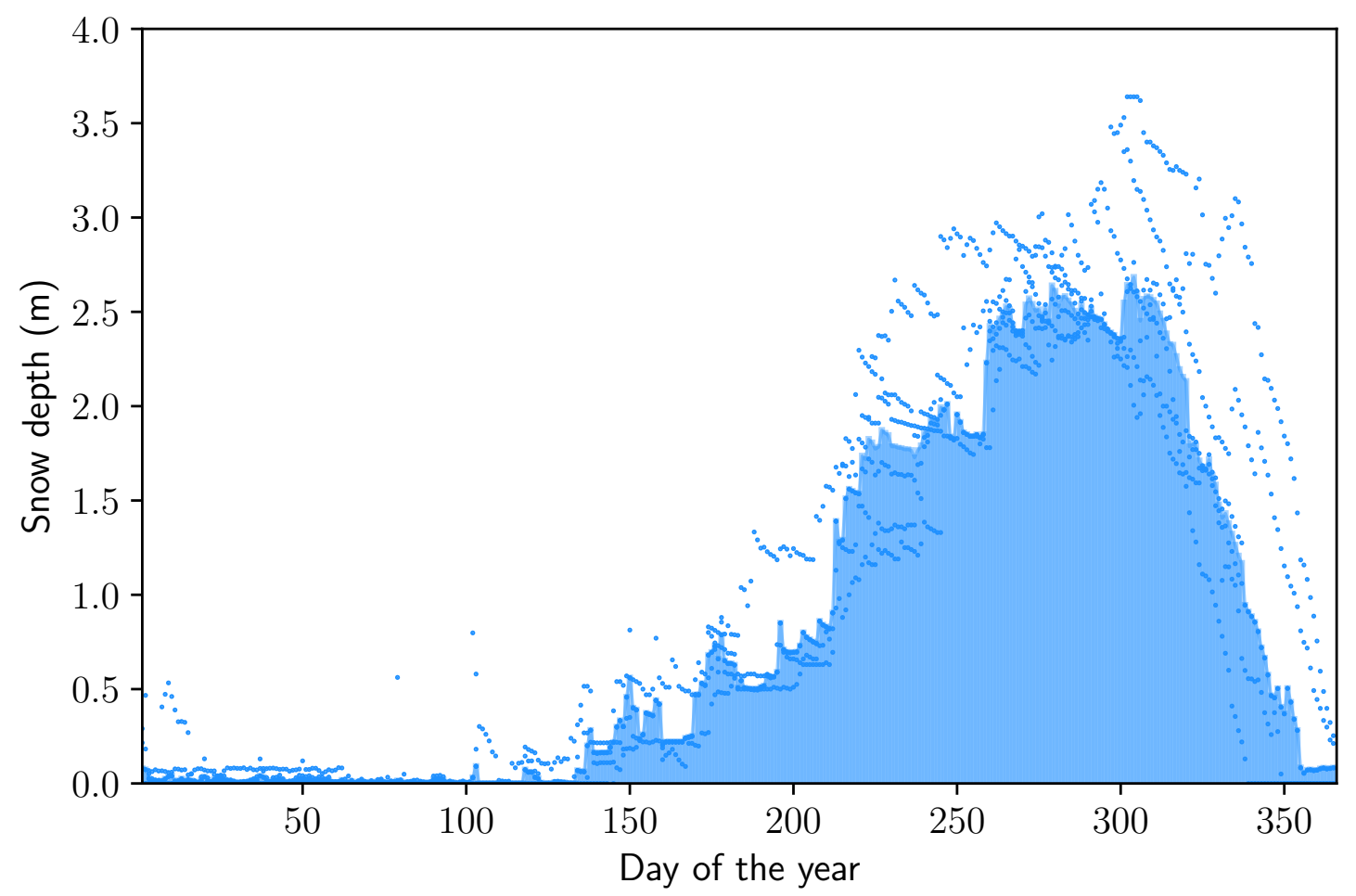

Figure 2.14: Snow at Mueller Hut per ordinal day. All gaps in the data set were filled using the median per ordinal day (blue polygon).

were concatenated with the data from NIWA CliFlo database, covering the period 2010-2013. Like GPS and rainfall data, gaps in snow measurements need editing prior to statistical analyses. Filling gaps with zeros is not a sensible option as it introduces artificial spikes in the data set, neither was a linear interpolation. We, therefore, took the median per ordinal day (see Figure 2.14), using the median of all snow height values at that calendar day from other years with data to fill a gap, day by day (see Figure 2.15). An advantage of this method is that it effectively takes into account the summer period with no snow and reproduces the asymmetric pattern of the cycle well (see Figure 2.14). A disadvantage of this method is that for extreme years with significant gaps, like 2012, the snow height is less likely to follow the median year, and a sharp shift is introduced between the filled data and measured data. $31 \%$ of the data set was artificially filled with this method (see red points in Figure 2.15).

Figure 2.16 compares the depth of snow in winter at some of the snow gauges we used. Mueller Hut is the closest station to most of the cGPS stations at high altitude, but its record is shorter than the one from Rose Ridge. We often use these two stations, and not the Mount Cook Electronic Weather Station (EWS), which is situated at Mount Cook village on the valley floor at low altitude, where 


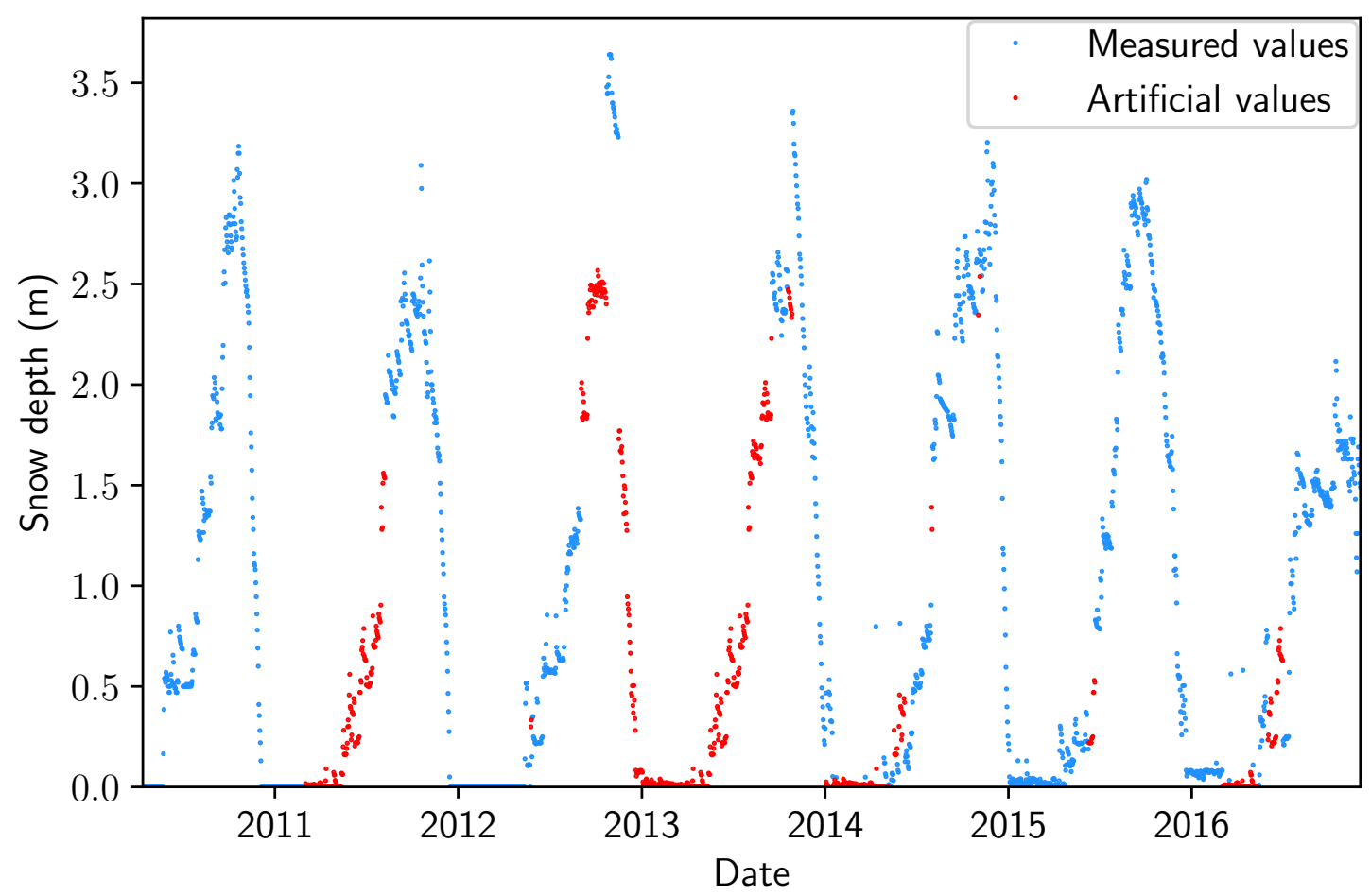

Figure 2.15: Completed data set for snow at Mueller Hut (altitude: $1800 \mathrm{~m}$ ). Measured values are in blue and artificial values are in red. The percentage of missing values is $31 \%$.

Table 2.6: Percentage of missing data, start and end date of the data set at each atmospheric pressure station.

\begin{tabular}{llll}
\hline Station & Missing data $(\%)$ & Start & End \\
\hline Haast & 0.5 & $2000-01-01$ & $2013-01-01$ \\
Mount Cook & 1.2 & $2006-04-04$ & $2017-07-31$ \\
Franz Josef & 0.1 & $2003-05-31$ & $2017-07-31$ \\
\hline
\end{tabular}

the snow does usually not last the whole winter and melts quicker than above $\sim 1800 \mathrm{~m}$.

\subsubsection{Air pressure and temperature data}

Atmospheric pressure and near-surface air temperature measurements were downloaded from the CliFlo database for the following climate stations (already used for the rainfall data): Haast Automatic Weather Station (AWS), Franz Josef EWS and Mount Cook EWS for the air pressure, Franz Josef EWS, Mueller Hut, Mount Cook EWS and Lake Tekapo stations for the air temperature. For information on data completeness and recording periods available at each station, see Table 2.6 


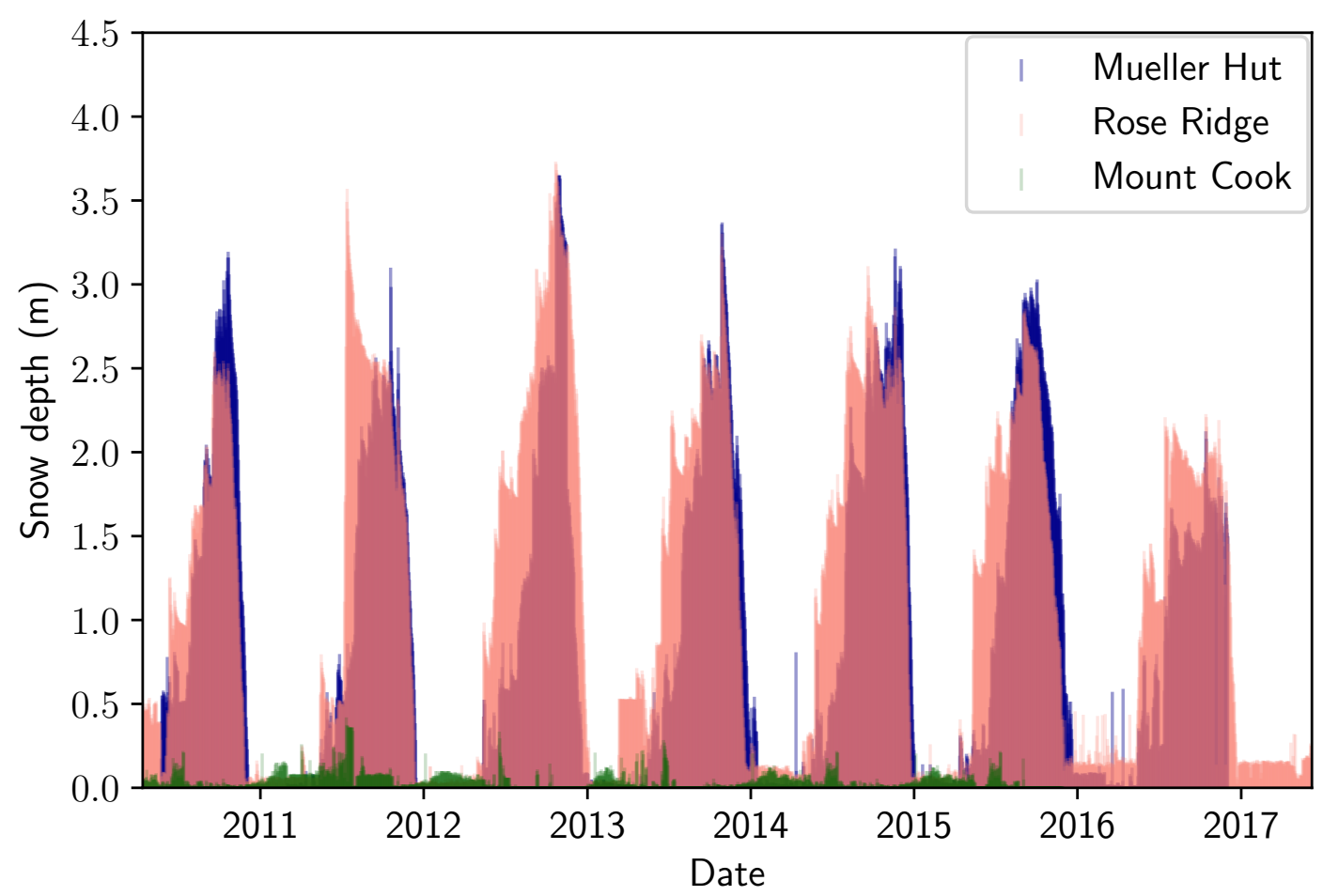

Figure 2.16: Comparison between snow data sets at Mueller Hut, Rose Ridge and Mount Cook EWS. The snow depth at the two first stations is comparable; Mount Cook EWS receives less snow due to its lower altitude. We have no data since the 27.11.2015 for Mount Cook EWS, since the 02.12.2016 for Mueller Hut and since the 08.06.2017 for Rose Ridge.

Table 2.7: Percentage of missing data, start and end date of the data set at each air temperature station.

\begin{tabular}{llll}
\hline Station & Missing data $(\%)$ & Start & End \\
\hline Mueller Hut & 31.7 & $2010-04-16$ & $2017-07-31$ \\
Mount Cook & 5.1 & $2000-03-31$ & $2017-07-31$ \\
Franz Josef & 0.1 & $2003-06-02$ & $2017-07-31$ \\
Lake Tekapo & 5.8 & $2003-06-20$ & $2017-07-31$ \\
\hline
\end{tabular}




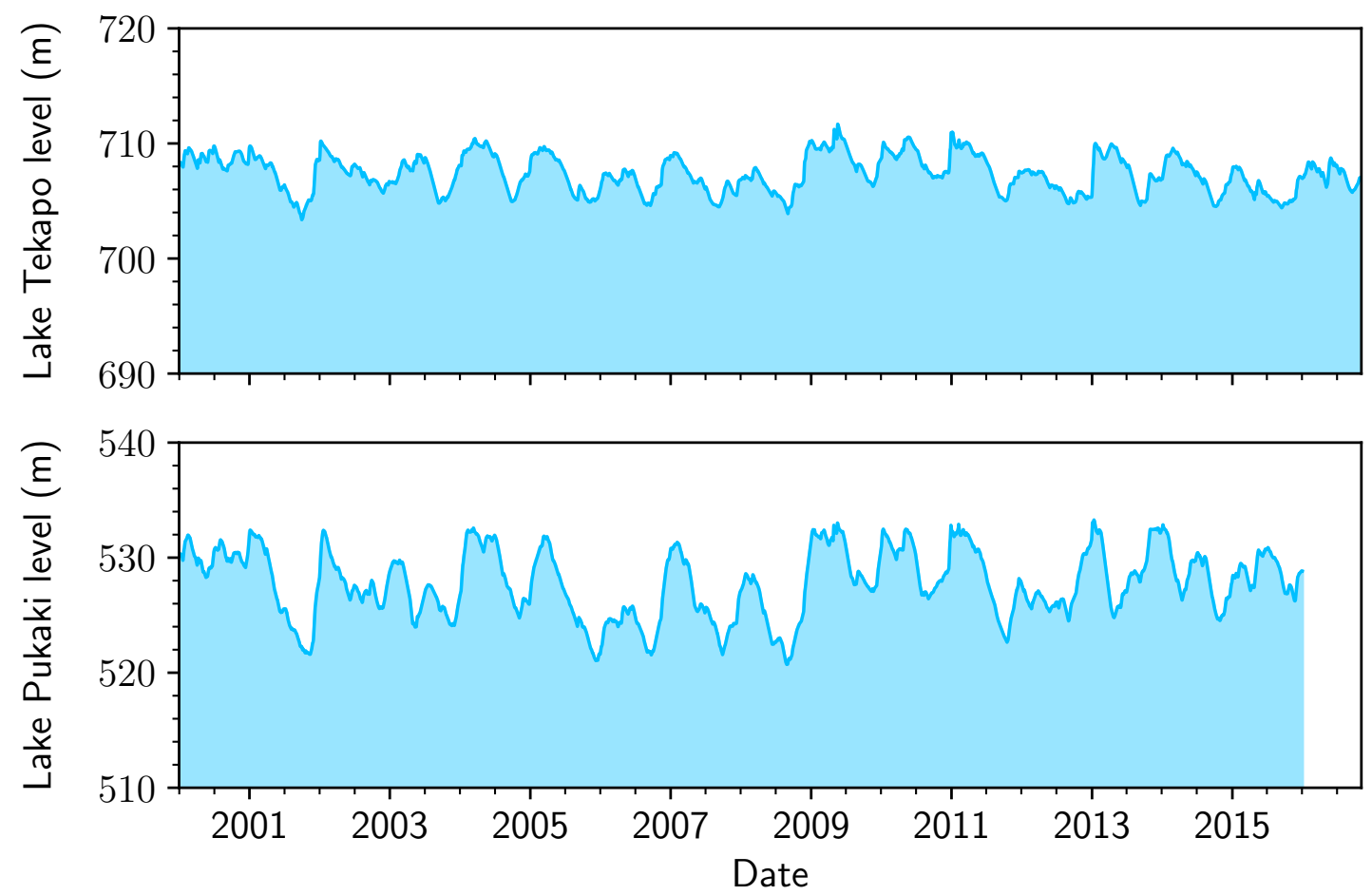

Figure 2.17: Lake Pukaki and Lake Tekapo levels above mean sea level.

for atmospheric pressure and Table 2.7 for air temperature. We use the same processing method as followed for snowfall data (see section 2.4.2).

\subsubsection{Lake level data}

The three biggest lakes in the region are all dammed for hydroelectric purposes. Lakes Ohau (see Figure 1.2) and Pukaki are controlled by Meridian Energy and Lake Tekapo by Genesis Energy, with levels only fluctuating within a defined range. The altitude of the surface of Lake Ohau with respect to mean sea level varies between $519.45 \mathrm{~m}$ and $520.40 \mathrm{~m}$. For Lake Tekapo, levels vary from $701.8 \mathrm{~m}$ (rarely under $704.1 \mathrm{~m}$ ) to $710.9 \mathrm{~m}$. Lake Pukaki level is consented to vary from $518 \mathrm{~m}$ to $532.5 \mathrm{~m}$ (Knight, 2009). Anthropogenic control of lake levels alters the natural fluctuations of level. An analysis of historical lakes levels (Knight, 2009) show that the construction of the dam decreased the amplitude of annual variations at Lake Ohau, but increased them at Lake Tekapo and Lake Pukaki. Lake Pukaki had a significant change in its level in 1976 - 1979, with a rise of $37 \mathrm{~m}$ as the reservoir was artificially raised. Our focus is on Lake Pukaki and Lake Tekapo, because fluctuations are of smaller amplitude at Lake Ohau and because there is a lack of nearby GPS data. The time series of levels of lakes Pukaki and Tekapo are shown in Figure 2.17. 
Table 2.8: Percentage of missing data, start and end date of the data set at each lake.

\begin{tabular}{llll}
\hline Name & Missing data $(\%)$ & Start Date & End Date \\
\hline Lake Pukaki & - & $2000-01-01$ & $2015-12-31$ \\
Lake Tekapo & 0.05 & $2000-01-01$ & $2016-11-02$ \\
\hline
\end{tabular}

We fill the data set with a linear interpolation around the gaps, which are rare. Table 2.8 lists the main characteristics of the two data sets.

\subsubsection{Groundwater data}

Direct measurements of groundwater levels in the Southern Alps are rare. Therefore bedrock hydrology in the area is poorly understood. We rely instead on various proxies to extrapolate the groundwater levels. For example, the level of rivers could allow us to estimate the flux of water coming out of the mountains, which is dependent on the surface runoff in their catchment areas and on groundwater flux upstream. Similarly, the lake levels provide information on the long-term fluctuations of water in catchment areas, overprinted with an anthropogenic component as the lakes are controlled for hydroelectricity generation.

On the West Coast, the Deep Fault Drilling Project (DFDP) installed four piezometers in the DFDP1B borehole at Gaunt Creek in the Waitangitaona River, near Whataroa (see Figure 1.2). They monitor the pore-pressure in different compartments of fractured bedrock at various depths. P3 and P4 are the two shallowest piezometers, at $92.4 \mathrm{~m}$ and $72.4 \mathrm{~m}$ from the surface, respectively. Their pressure is influenced by fluctuations in the shallow water table and the level of the adjacent Waitangitaona River. P2 is situated in a layer of cataclasite, just above the fault gouge, at $114.9 \mathrm{~m}$ depth below the surface. Finally, P1 is located in the footwall at $136.0 \mathrm{~m}$ depth below the surface. See Sutherland et al. (2013) for a detailed borehole log. Figure 2.18 shows the data retrieved from the archives for piezometers 1 and 2. Note that there are not enough data to extrapolate any potential seasonality. Pressure in the hanging wall, close to the Alpine Fault is significantly higher than the pressure in the footwall, below the Alpine Fault (Sutherland et al., 2012), and the long-term trend indicates a slow equilibration of the pressure on both sides of the fault, possibly as a result of the drilling. Due to these limitations, we elect to not use the pressure record in the DFDP-1B borehole as a proxy for groundwater levels in the area. 


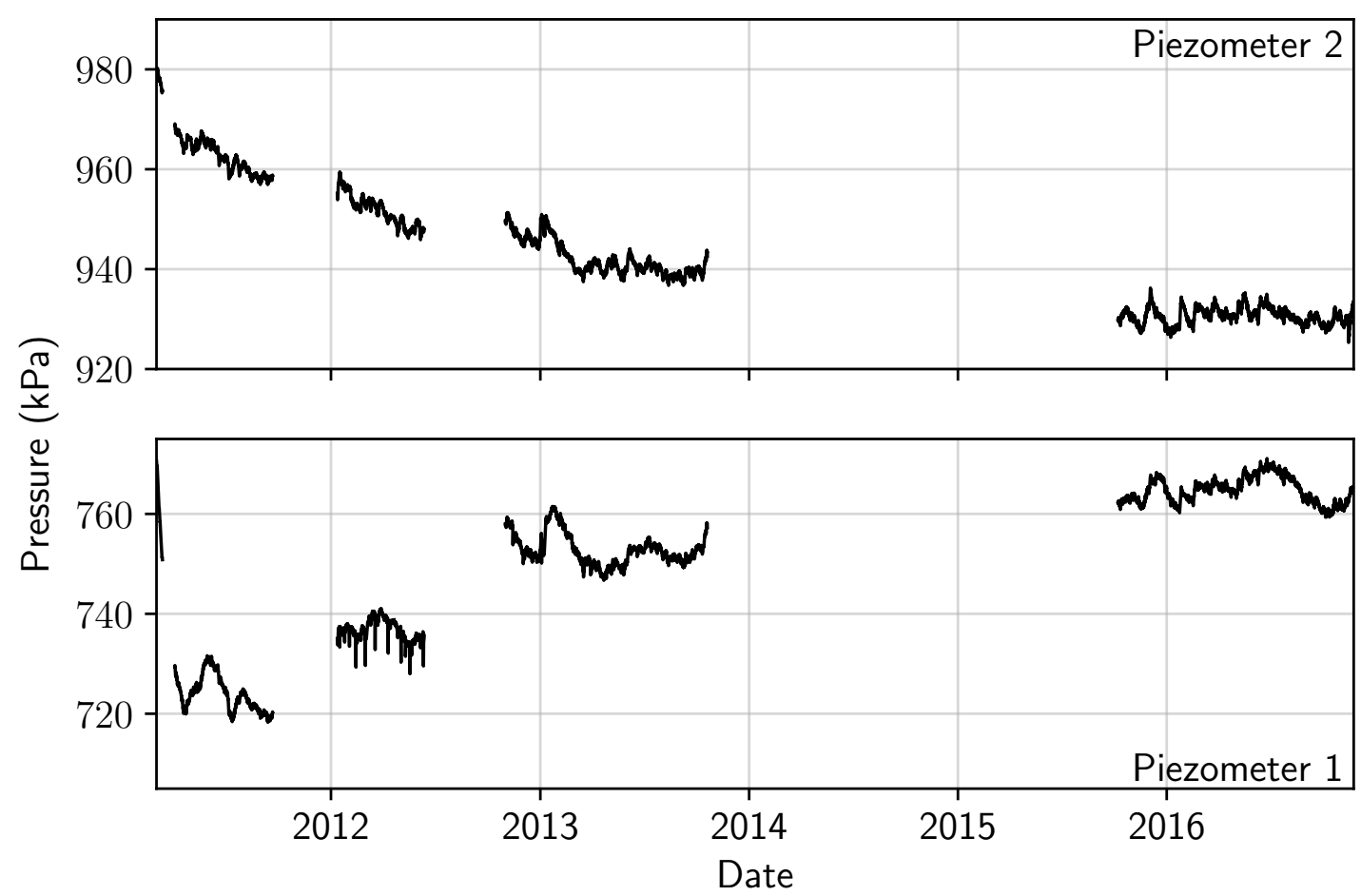

Figure 2.18: Pressure record in DFDP-1B for piezometers 1 and 2, situated on each side of the Alpine Fault at Gaunt Creek.

Satellites can also track groundwater level changes, for example by recording changes in the gravity field between each passage over a zone. This was one objective of the Gravity Recovery and Climate Experiment mission (GRACE), used elsewhere, for example by Steckler et al. (2010), Fu et al. (2012), Pan et al. (2016) to link seasonal variations of hydrologic mass loads with surface deformation. However, Zemansky et al. (2013) demonstrate that the resolution of this method is too broad to be applied in New Zealand. They also show that Thermal Infrared Imagery (TIR) is not suitable, for the same reason. Another available technique to track surface deformation is the satellite Interferometric Synthetic Aperture Radar (InSAR), already successfully used in New Zealand for millimetric to metric scale vertical displacements (Beavan et al., 2010b, Hamling et al., 2017). While there is real potential to use InSAR to measure specific changes in earth position at millimetre scale, the methods are beyond the scope of this project.

Finally, mathematical modelling of the shallow groundwater level is done through climatic data (rainfall, snowfall, pressure, temperature, soil moisture, evapotranspiration) if available and with knowledge of local hydrogeology. As previously stated, our current knowledge of the groundwater is poor, and we build two simple 
mathematical models without assumptions on local to regional groundwater flow, a linear rainfall-runoff model and a coupled rainfall-snow depth model.

\section{Linear groundwater reservoir model}

To examine the relationship between the ground displacement and the groundwater table fluctuations, we first construct a one-dimensional linear model of a groundwater reservoir and the corresponding surface deformation. We consider the situation in which the depletion of the reservoir depends upon the amount of water in it: in other words,

$$
Q(t)=k_{1} \times W(t)
$$

where $Q(t)$ is the runoff at a time $t, W(t)$ is the groundwater level, and $k_{1}$ is a constant. We assume that the change in groundwater level is caused only by either rainfall or reservoir depletion, therefore

$$
\frac{d W(t)}{d t}=p(t)-Q(t)
$$

where $d W(t) / d t$ is the change of water level during a time interval $d t$ and $p(t)$ is the recharge of the reservoir due to rainfall. We introduce a second parameter, $k_{2}$, known as the infiltration correction, which we treat as constant for the sake of simplicity. In this case

$$
p(t)=k_{2} \times r(t)
$$

where $r(t)$ is the measured rainfall at the weather station of interest. We do not make any correction for altitude or location, in the absence of appropriate information as to how rainfall varies with these parameters.

Combining the three previous equations results in a mathematical representation of a linear groundwater reservoir:

$$
\frac{d W(t)}{d t}=k_{2} \times r(t)-k_{1} \times W(t)
$$

or equivalently

$$
\frac{d W(t)}{d t}+k_{1} \times W(t)=k_{2} \times r(t)
$$


Multiplying both sides of this equation by $e^{k_{t} t}$ and integrating between times $i$ and $i+1$ for $i \in[0,1,2, \ldots]$ with the initial condition $W(0)=W_{0}$ yields the following:

$$
\begin{aligned}
\int_{t_{i}}^{t_{i+1}} e^{k_{1} \tau} W^{\prime}(\tau)+k_{1} e^{k_{1} \tau} W(\tau) d \tau & =\int_{t_{i}}^{t_{i+1}} k_{2} e^{k_{1} \tau} r(\tau) d \tau \\
\longrightarrow\left[e^{k_{1} \tau} W(\tau)\right]_{t_{i}}^{t_{i+1}} & =k_{2} \int_{t_{i}}^{t_{i+1}} e^{k_{1} \tau} r(\tau) d \tau
\end{aligned}
$$

Here, we presume the epoch-to-epoch changes in rainfall to be small enough that we can treat $r(t)$ as a constant, in which case

$$
e^{k_{1} t_{i+1}} W\left(t_{i+1}\right)-e^{k_{1} t_{i}} W\left(t_{i}\right)=k_{2} r\left(t_{i+1}\right) \int_{t_{i}}^{t_{i+1}} e^{k_{1} \tau} d \tau
$$

or equivalently

$$
W\left(t_{i+1}\right)=e^{-k_{1}\left(t_{i+1}-t_{i}\right)} W\left(t_{i}\right)+\frac{k_{2} r\left(t_{i+1}\right)}{e^{-k_{1} t_{i+1}}}\left[\frac{1}{k_{1}} e^{k_{1} \tau}\right]_{t_{i}}^{t_{i+1}}
$$

Thus, we have the overall solution

$$
\begin{gathered}
W(0)=W_{0} \\
W\left(t_{i+1}\right)=e^{-k_{1}\left(t_{i+1}-t_{i}\right)} W\left(t_{i}\right)+\left(1-e^{-k_{1}\left(t_{i+1}-t_{i}\right)}\right) \frac{k_{2}}{k_{1}} r\left(t_{i+1}\right) \forall i=0,1,2, \ldots
\end{gathered}
$$

This model represents only recharge by rain and a classic logarithmic reservoir depletion during dry periods. Evaporation, snow, vegetation or preferential groundwater flow are not considered in this linearised model.

We optimise our model using rainfall observations to determine the best-fitting values of the constants $k_{1}$ and $k_{2}$, which together describe the reservoir in this idealised situation.

\section{Coupled rainfall-snow depth groundwater reservoir model}

A good way to test whether the groundwater-induced surface deformation theory is valid is to stop the influx of water (i.e. stop the rain) and observe whether the ground deforms following the reservoir depletion curve. Such situations naturally occur at high altitude stations, where snow accumulates during winter. When snow insulates the ground, there is less infiltration, and reservoir depletion is observable. To expand the analysis described in the previous section, we apply a 
more realistic model that incorporates information regarding snow depth, called REROD (REversible ROck-slope Deformation), and developed by Hansmann et al. (2012b) in Fortran90.

As part of this study, we implement REROD in Python, adapting it to the Southern Alps. The model takes into account the effects of snow cover (i.e. no or reduced infiltration), the increased amount of water when the snow melts or when it rains on a thin snow layer (summer to early winter or spring, taken separately), and the limiting situation when the reservoir reaches saturation. See Hansmann et al. (2012a) for a more detailed background on this mathematical model and its parameters.

We follow the method of Hansmann et al. (2012b) to fix some of the variables. For the reservoir depletion, we select a year with low precipitation during the snow period and fit a function of the form:

$$
f(t)=a\left(1-e^{-\frac{1}{\tau}}\right)+b
$$

We do this with a least-squares method (see Figure 2.19). This gives us the parameters $a$, the amplitude of the observed maximum change in groundwater level, $b$, the minimum value of depletion, and $\tau$, a time constant, which can be understood as $\frac{1}{k_{1}}$ from our first model (Equation 2.3). We also calibrate the snow melting, using the period of 2010-2013 as a calibration period and 2013-2016 as a validation period. Figure 2.20 shows the rate of surface deformation compared to the rate of snow melting during the melt period. The dashed line is a linear best-fit formula that has been constrained to cross the origin (i.e. no ground deformation due to snow when there is no change of snow height). The slope of this line gives us a factor for the transformation of snow melt into ground deformation. We also choose approximate values for the depth of snow above which we consider that there is no infiltration, the fraction of rain that infiltrates through snow in early winter and during the spring snow melting, the maximum recharge water volume, the minimum state of the reservoir observed in late winter, the minimum rainfall considered as inducing a displacement and the factor of transformation of recharge by the rainfall into displacement (see Table 2.9).

An important caveat is that these two models are only mathematical and do not give an absolute value of the depth to the groundwater table or volume of transferred water. A more realistic model for groundwater in the Southern Alps could incorporate the topography in $2 \mathrm{D}$ or $3 \mathrm{D}$, and field measurements. 


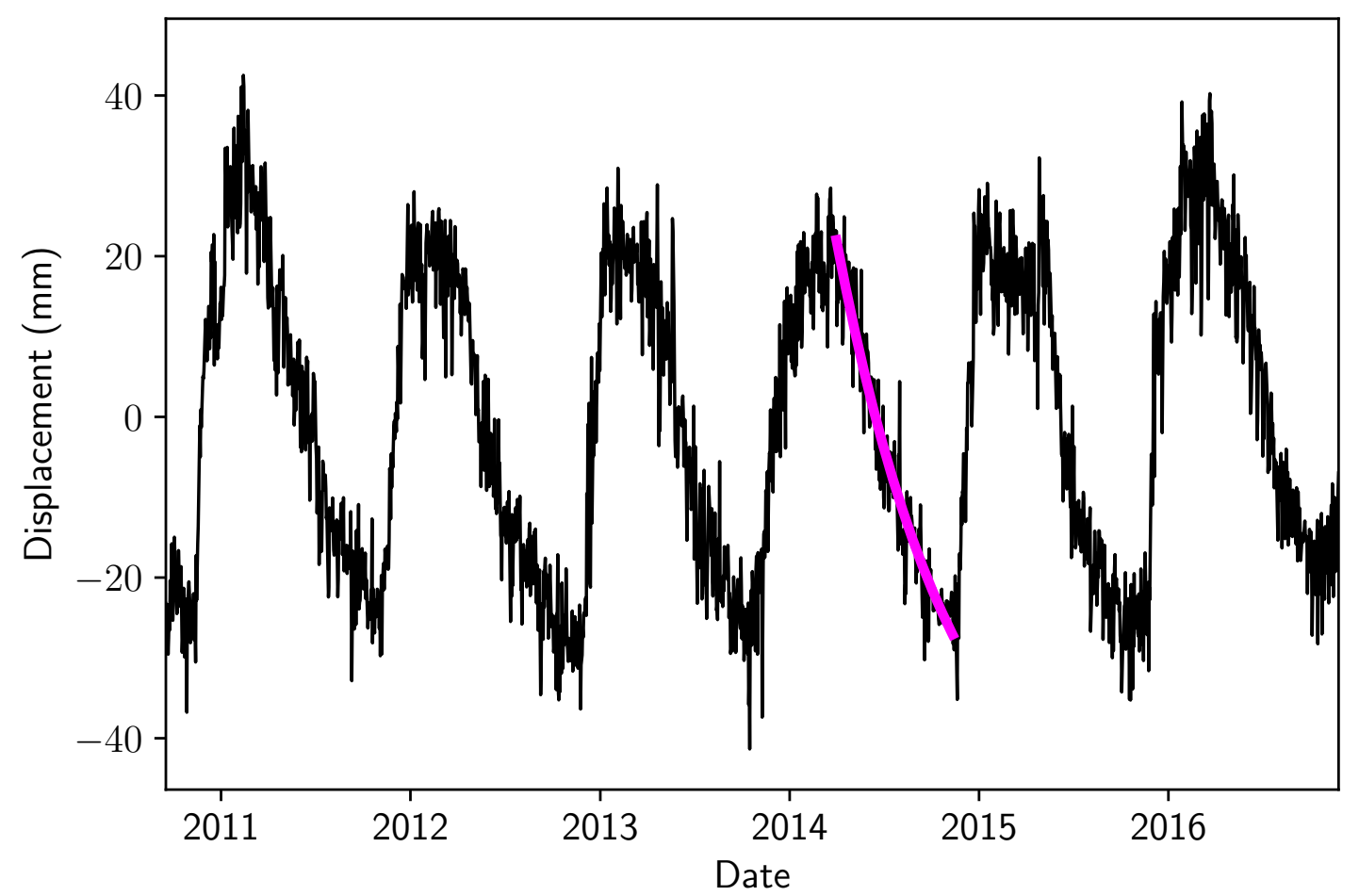

Figure 2.19: Parameter calibration for reservoir depletion. Black is the GPS measurement along the main direction of displacement; magenta is the mathematical exponential depletion model.

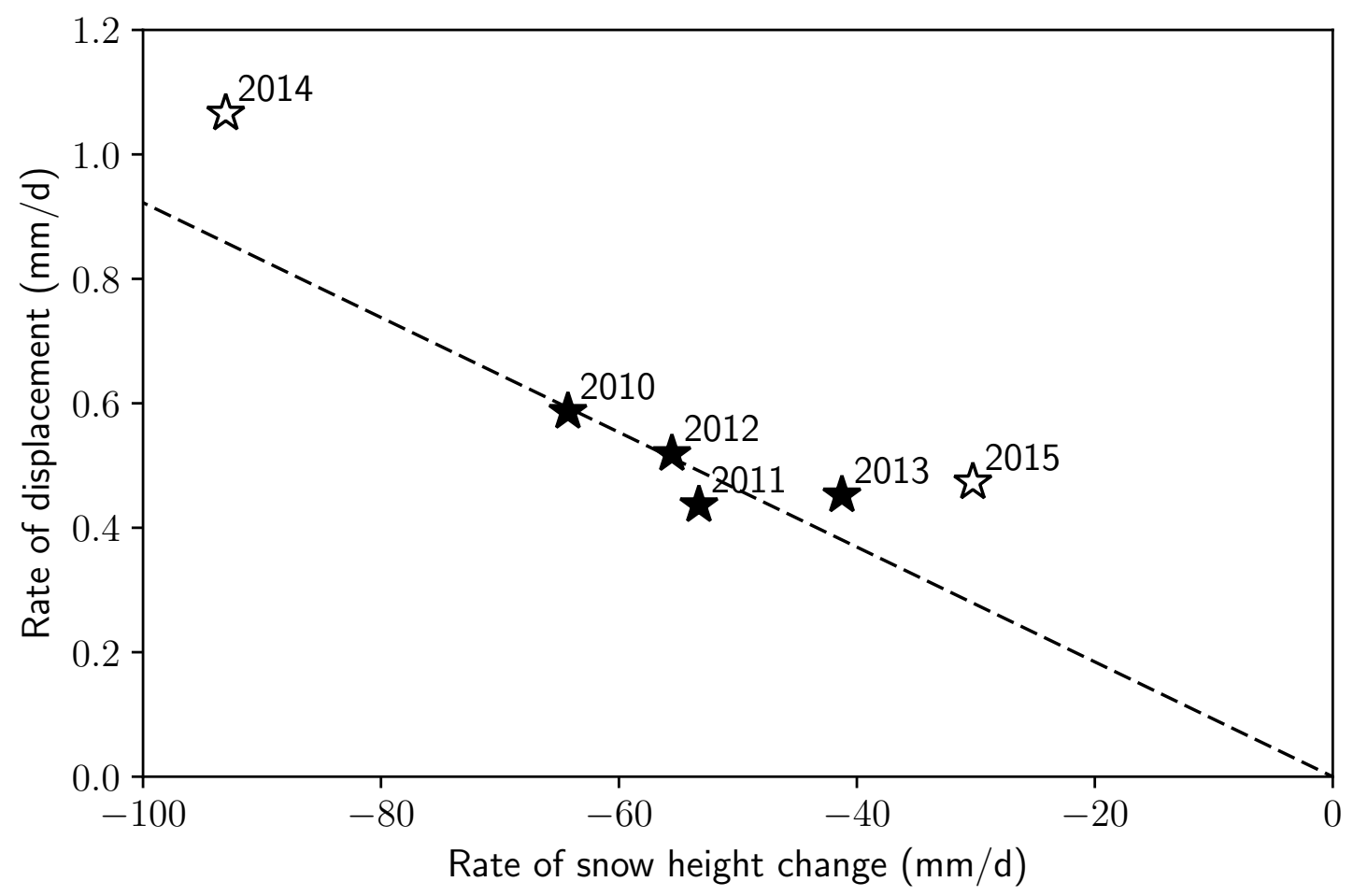

Figure 2.20: Parameter calibration for snow melt. Filled stars are in the calibration period; unfilled stars are in the validation period. The dashed line is the best fit for the calibration period, constrained to cross the origin. 
Table 2.9: Example of parameters estimation for Annette Plateau, using the new version of REROD developed in this thesis.

\begin{tabular}{lll}
\hline Variable & Unit & Estimated value for Annette Plateau \\
\hline $\mathrm{a}$ & $\mathrm{mm}$ & 53 \\
$\mathrm{~b}$ & $\mathrm{~mm}$ & -20 \\
$\tau$ & $\mathrm{d}$ & 99 \\
rain limit & $\mathrm{mm}$ & 10 \\
snow limit & $\mathrm{m}$ & 0.05 \\
snow melting limit & $\mathrm{m}$ & 0.05 \\
recharge limit & $\mathrm{mm}$ & 20 \\
rain on snow & & 0.2 \\
rain during snowmelt & & 0.9 \\
rain factor 1 & 0.15 \\
rain factor 2 & & 0.06 \\
snow melting factor & & 0.9 \\
snow infiltration limit & & 0.1 \\
snow melt with rain & & 0.1 \\
\hline
\end{tabular}




\subsection{Microseismicity}

To study the seismicity rates under the highest mountains in the Southern Alps, we need to be able to detect very small earthquakes. We do this by cross-correlating continuous seismic time series with known earthquake waveforms (referred to as templates) to find new events, using a match-filtering detection method developed by Chamberlain et al. (2014) (see Section 2.5.1) and two previously developed catalogues of earthquakes (Boese et al., 2012) for the period November 2008December 2009. One of the two catalogues contains focal mechanism solutions for all its 211 earthquakes (see Figure 2.21). Using this catalogue allows us to study the different types of mechanisms individually, and see if different types of earthquakes have different rates over time. This information is important, because we could expect different tectonic stress regimes to have different responses to hydrogeological processes depending on which principal stress is vertical. The second catalogue contains a larger number of events, and we use 902 templates to have a more complete overview of the microseismicity in the region. None of the catalogues of detections contains information on the focal mechanism, location or magnitude of the detected events. This information requires more computing and calculations that were not done, due to time constraints.

In this Section, we first describe the matched-filtering technique that we use to build the two catalogues of microseismicity, we then give an overview of potential sources of noise-induced seasonality in seismicity rates, and we explain further our hypotheses to link the surface hydrologic cycles to changes in the seismicity rates in the central Southern Alps. 


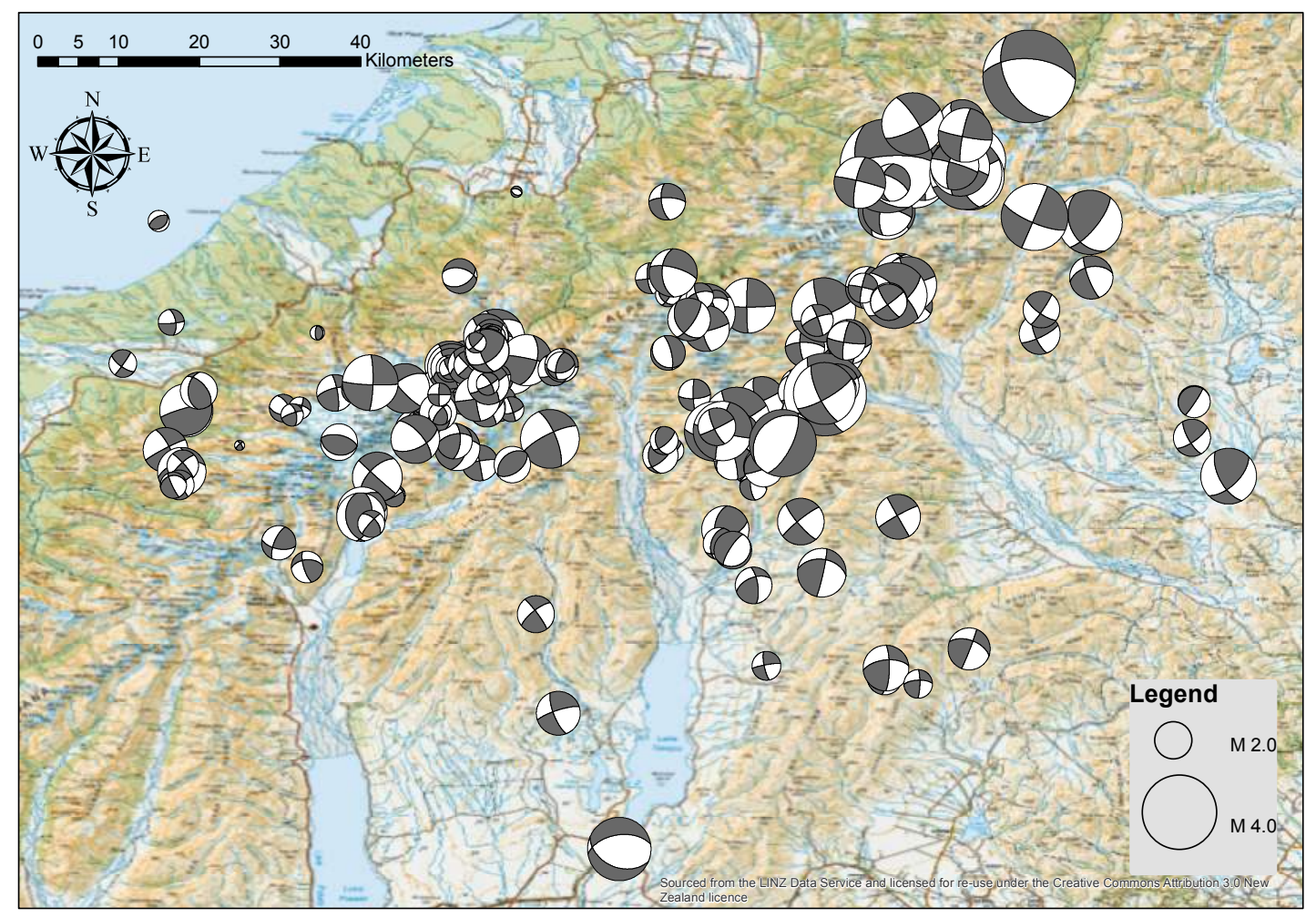

Figure 2.21: Map with all templates and their focal mechanism, with compression in black and extension in white. Template events happened between November 2008 and December 2009. Radius of circles is based on the local magnitude $\mathrm{M}_{\mathrm{L}}$ calculated by Boese et al. (2012). 


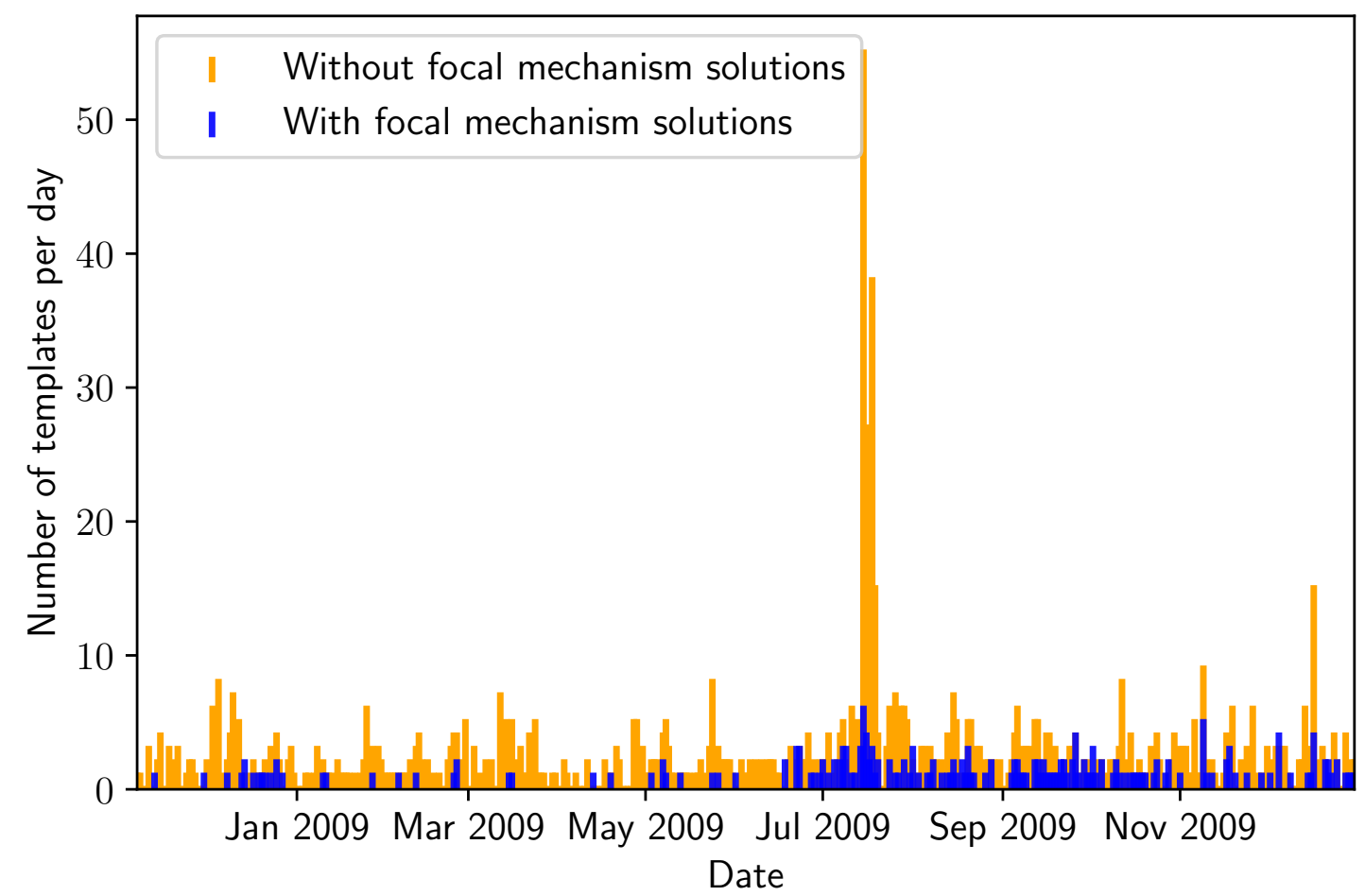

Figure 2.22: Time series of templates used for our two catalogues of detected events. The blue templates are events with focal mechanism solutions calculated by Boese et al. (2012), templates in orange are events without focal mechanism solutions.

\subsubsection{Catalogue expansion using matched-filtering}

The first step for expanding a catalogue of events with a matched-filtered detection method (Warren-Smith et al., 2017) is to select earthquakes with known seismic signatures, that we would like to cross-correlate with the seismic time series. For our catalogue with focal mechanism solutions, we select the earthquakes from the focal mechanism catalogue from Boese et al. (2012), sorting events by type, using a short program from Álvarez-Gómez (2014) who applied the method of Kaverina et al. (1996), (Figure 2.23). For our catalogue without templates focal mechanism solutions, templates are built by selecting earthquakes from the full catalogue in Boese et al. (2012) for whom picks were available in the VUW archives (picks are times of the first arrival of a seismic wave, in each channel, at each station in the network).

To develop template events for cross-correlation, the waveforms are first filtered with a third-order band-pass filter of $2-9 \mathrm{~Hz}$ and resampled at a rate of $20 \mathrm{~Hz}$. The continuous data records from the SAMBA and GeoNet stations were then cut to $3 \mathrm{~s}$ long time series containing the earthquake signature, with a pre-arrival time 


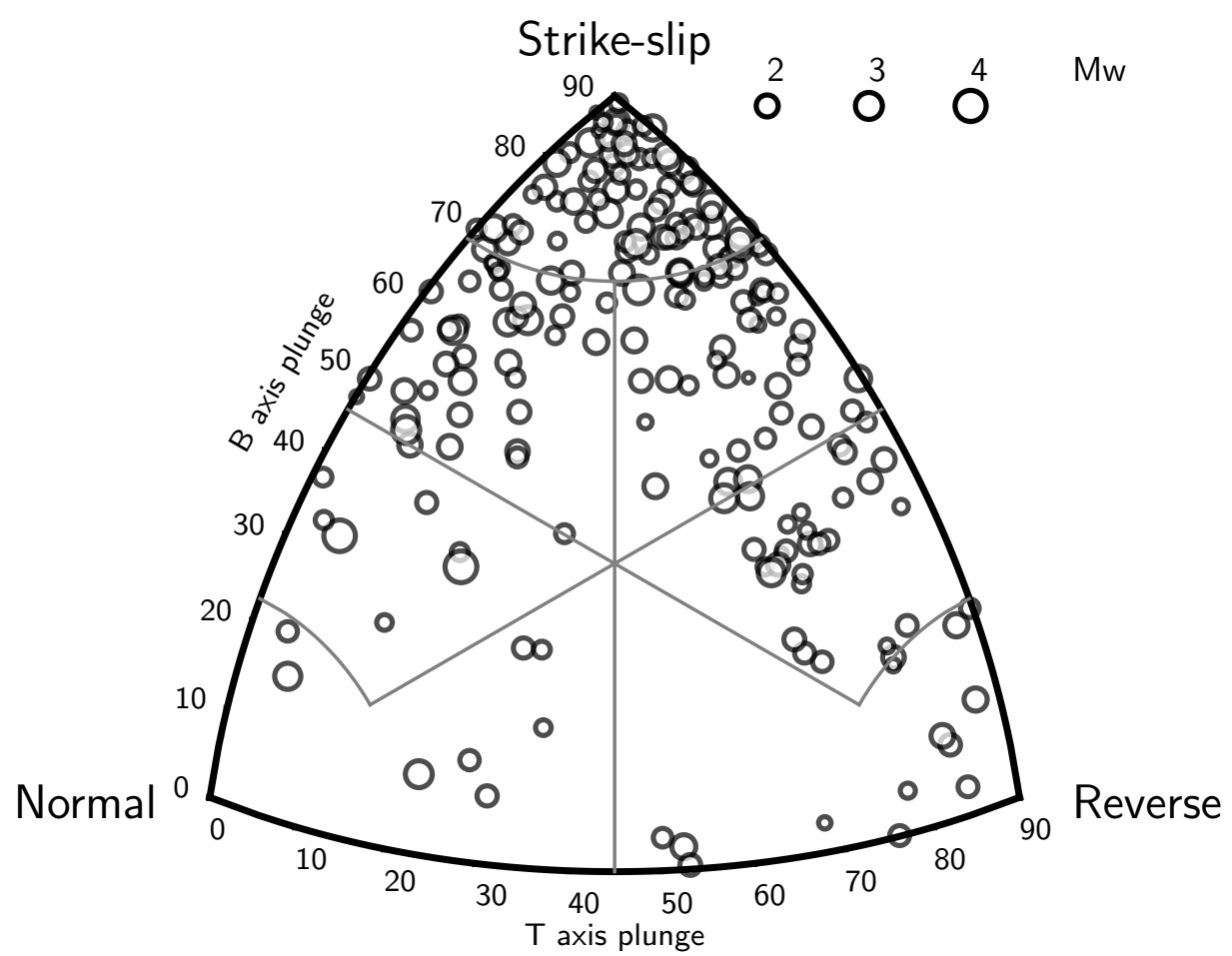

Figure 2.23: Ternary diagram of focal mechanisms for 211 earthquakes templates. Strikeslip events are at the top of the ternary diagram, normal in the bottom left, reverse in the bottom right.

of $0.15 \mathrm{~s}$ (see Figure 2.24). The result is a list of $3 \mathrm{~s}$ long waveforms, one for each channel at each station, that form a template.

Next, we preprocess the continuous stream with the same parameters as for the creation of the templates (2-9 Hz bandpass filter, down-sampling to $20 \mathrm{~Hz}$ ). We pad data gaps with zero functions, which do not significantly alter the crosscorrelation function where gaps are small. If gaps represent more than $20 \%$ of the daily data stream, we remove the channel to avoid false detections from the anomalous population of zeros. We check if anomalous amplitude spikes are present for each channel, for each day. If any are found, the concerned channel is turned-off for the day.

Then, match-filter detection begins, cross-correlating all templates with the continuous stream, at each station and for each channel. This intensive process results in a list of detections above a threshold value of the cross-correlation coefficient, which we set at eight times the Median Absolute Deviation (MAD). MAD is defined as the median of the absolute value of the cross-correlation sum for a given template. Every time a detection is registered, no other detection will be taken into account during two seconds around this detection to avoid multiple detections of one event. 


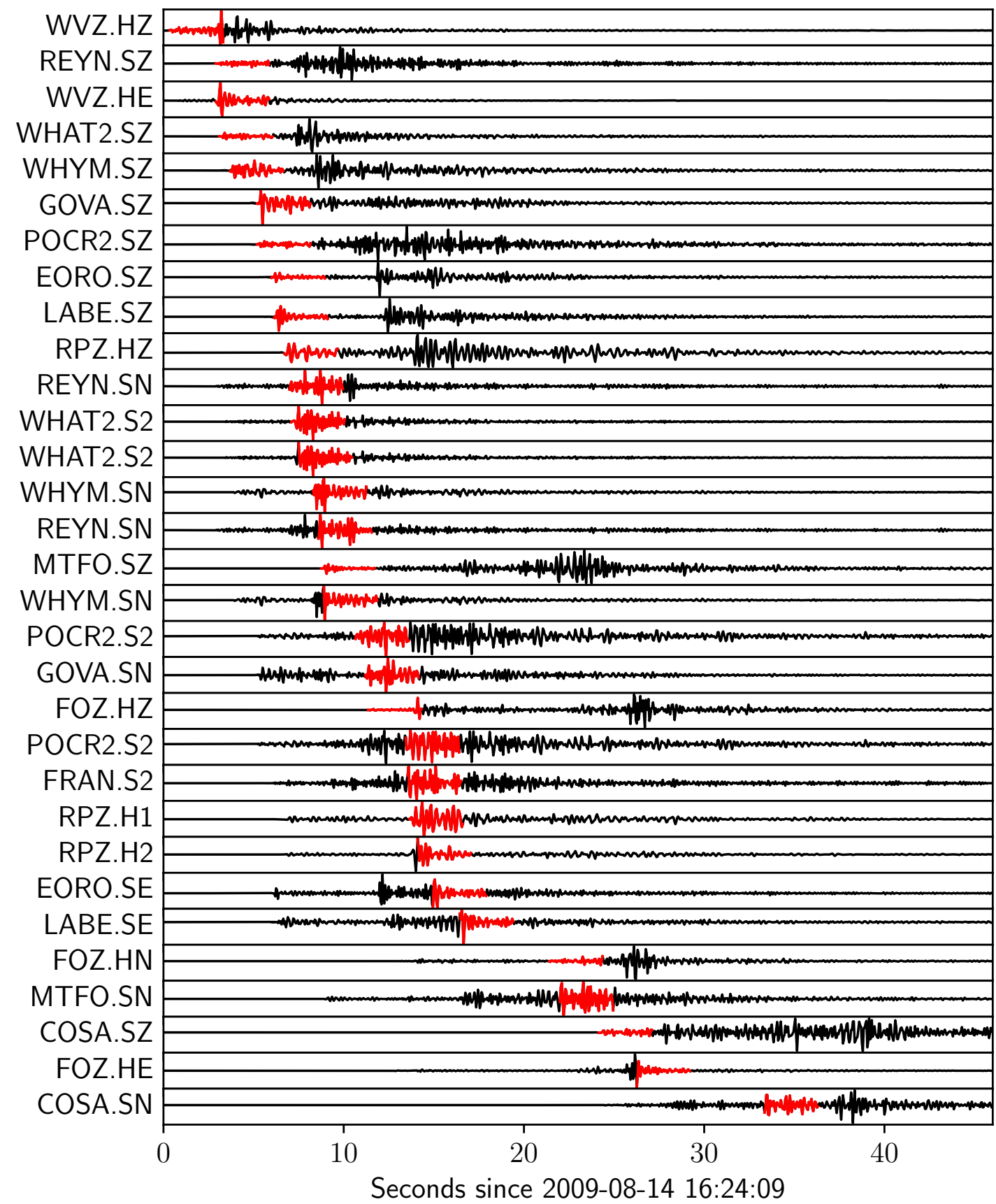

Figure 2.24: Template (in red) for the highest magnitude earthquake of the catalogue, $\mathrm{M}_{\mathrm{L}}$ 4.2. The event occurred on 14 August 2009, at 16:24:5.75 UTC at an estimated depth of $8.19 \mathrm{~km}$. The continuous stream was filtered with a third-order bandpass filter between $2 \mathrm{~Hz}$ and $9 \mathrm{~Hz}$, the same parameters are used for all templates and all channels of the continuous stream in this analysis. 
Detections that occur on less than five stations are eliminated, independently of the number of channels detecting the template at each station. By doing this, the number of false detections is minimised. We also process a basic declustering in time, considering all detections closer than 5 seconds as originating from a single event, even if they come from different templates.

For the remaining detections, now referred to as events, we analyse the frequency and rate of earthquakes, by focal mechanism type for the catalogue with templates focal mechanism solutions. Results of this work can be found in the section 3.2.

\subsubsection{Noise-induced apparent seasonality}

There are potential variations in the number of detections due to seasonality in levels of noise. In addition to recording earthquakes, seismometers can be sensitive to seismic movements from many sources around the station, such as landslides (Suriñach et al., 2005), avalanches (van Herwijnen and Schweizer, 2011), anthropogenic noise (Eibl et al., 2015) and more consistently, phenomena like bedload transport in nearby rivers (Hsu et al., 2011) and glacier-ice movement (Roux et al., 2010). Of the sources of noise listed above, many exhibit a seasonal behaviour which can affect detection of earthquakes.

We expect more rockfalls to occur in summer than in winter for example because the ground is directly exposed to the sun rays up to the zone of permafrost. Without the snow, there is no insulating layer, and the ground is exposed to higher air temperature. As the albedo is lower for dark rocks and soils than for light snow, the ground also heats when exposed to direct sun rays, resulting in melting and rockfalls.

Similarly, during early to mid-summer, the volume of the rivers increases due to snow melt. As the rivers are carrying more water, their energy and sedimentload potential grow, resulting in higher amounts of suspended load and bedload. Noise induced by the latter can be heard during flood events and are recorded by seismometers (Hsu et al., 2011). Because a larger part of the rainfall is stored as snow in the mountains during winter, bedload transport events tend to be fewer then.

While snow avalanches occur more during winter, falling seracs happen more during summer, as well as rock falls. The seasonal contribution to the noise level of these three processes is therefore considered minor. 


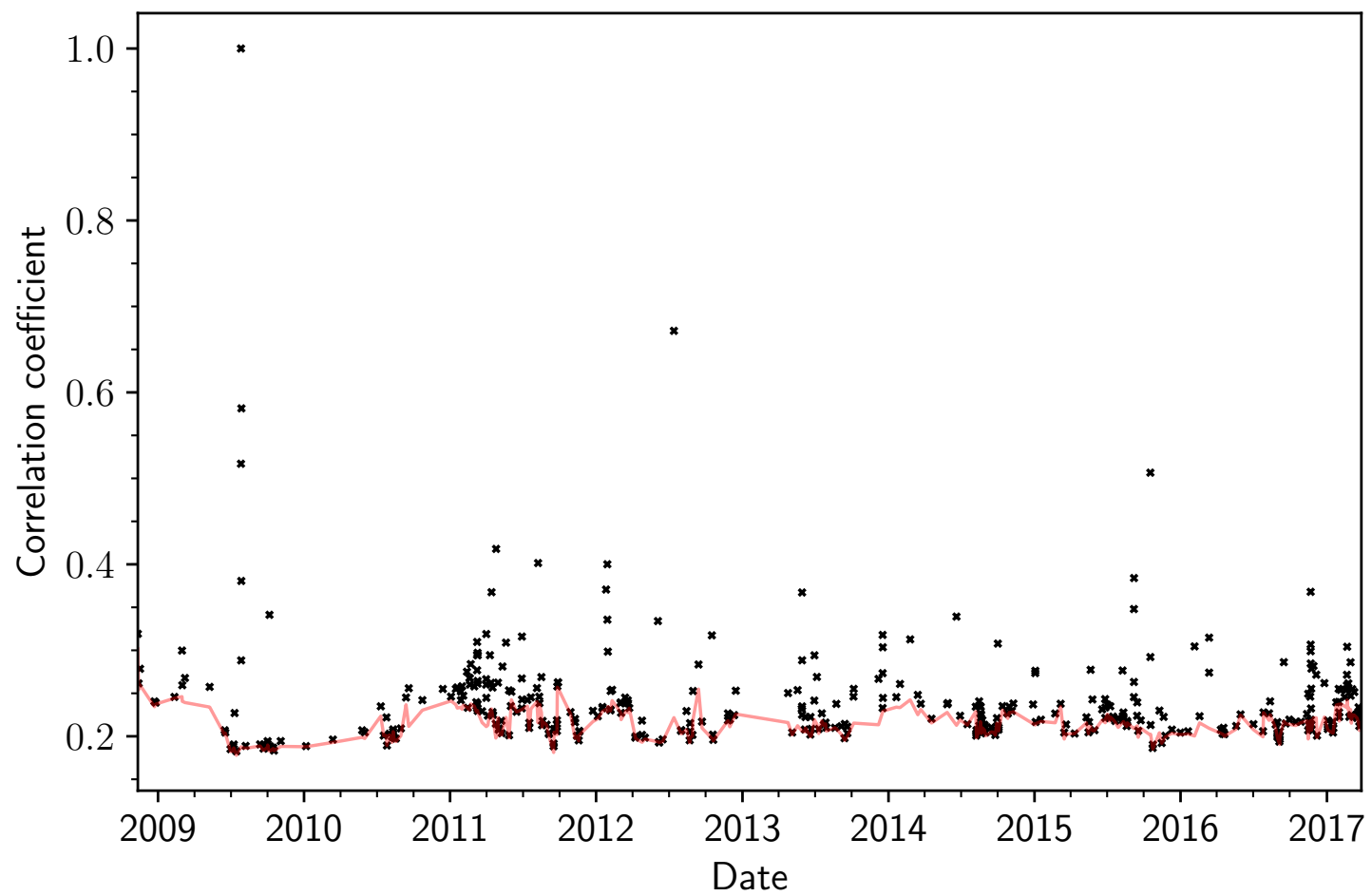

Figure 2.25: Analysis of detection threshold. The template event was on 27 July 2009 at 08:07:19 (point with coefficient 1). The magnitude was $\mathrm{M}_{\mathrm{L}} 1.97$ and the depth was $2.2 \mathrm{~km}$. black dots are the 413 detections, the red line is the threshold of detection.

To test if noise level fluctuations cause seasonality in the results of the matchfiltered detection method, we check the time series of individual templates and the evolution over time of their cross-correlation threshold (see Figure 2.25). We find a reasonably constant cross-correlation threshold value, suggesting the level of noise does not vary significantly enough to affect the number of earthquakes detected on a seasonal timescale.

\subsubsection{Two mechanisms that could change the stress state at depth}

We envisage two separate mechanisms that could change the stress state at depth (Simpson et al., 1988):

1. elastic surface loading induced stress modulation

2. groundwater table change induced poroelastic stress modulation.

The key difference between these two processes is that the former produces an immediate response to the load and modifies the elastic stress, whereas the latter 
depends upon the rock permeability and the diffusion time of the water infiltrating from the surface, and modifies the effective stress at depth.

\subsubsection{Seismicity induced by periodic loading and unloading elastic stresses}

Mass-loading-unloading processes at the surface provoke elastic responses of the crust (e.g. isostasy due to ice sheets (Schofield, 1964)). If the load is heavy enough, it can have a regional influence (see Section 2.3.3), due to a change in the elastic stress-strain in the crust.

In Japan, an increase in seismicity in winter is thought to be triggered by the snow load (Heki, 2001, 2003). Unloading-induced seismicity has been identified in California, where Amos et al. (2014) link the unloading due to groundwater depletion with microseismicity at the San Andreas Fault. In Nepal, the observed increase in seismicity during winter is thought to be caused by an increased Coulomb failure condition due to surface water unloading in the neighbouring Ganges plain (Bollinger et al., 2007). The hypothesis of seasonal changes in Coulomb failure conditions was further explored using cGPS, satellite altimetry measurements as well as gravity to show the changes in geodetic strain (Bettinelli et al., 2008). The surface water load provoked by the monsoon induces extension during summer and compression during winter (Bettinelli et al., 2008). The seasonal water loading model in the region affects the density and elastic structure of the crust (Chanard et al., 2014). Recently, Kundu et al. (2017) confirmed that unloading of the Ganges-Brahmaputra plain during winter is likely to be the primary process modulating seismicity rates. They however also showed that fluid migration, with a time-lag of 5-6 months between the infiltration of water and the diffusion to the seismogenic zone, is possible.

\subsubsection{Seismicity induced by periodic drained and undrained poroelastic stresses}

Pore-pressure is modified by migration of fluids, along cracks and fractures in the bedrock. We evaluate the possibility that water coming from the surface snow and glacier ice melt in spring and summer could generate a fluid migration to the seismogenic depth, acting like a seasonal poroelastic pressure wave. When reaching the zone of earthquake swarm nucleation, at an average depth of $4 \mathrm{~km}$ to $8 \mathrm{~km}$, 
the small increase in poroelastic pressure can be expected to cause the minimum horizontal stress to decrease, therefore increasing the effective stress, and inducing seismicity.

Hydroelectricity represents $60.4 \%$ of electricity generation in New Zealand in 2016 (Ministry of Business, Innovation and Employment, 2017), and a large number of lakes and river flows are now artificially controlled for this purpose. Lake Pukaki was dammed from 1976 to 1979, raising water levels by $37 \mathrm{~m}$ (Reyners, 1988). An increase in seismicity was observed close to the lake $(0 \mathrm{~km}$ to $15 \mathrm{~km})$, which was associated with a decrease in the rate of background seismicity $(15 \mathrm{~km}$ to $50 \mathrm{~km}$ ). After lake level reached its current range of elevation, the seismicity returned to its previous rate. During the $37 \mathrm{~m}$ lake level rise, the groundwater level rose $20 \mathrm{~m}$, with a time lag of 11 months, before stabilising again (Reyners, 1988). Reyners (1988) interpreted the spatial and temporal variations of seismicity as fluid-migration from Lake Pukaki, which is perched in the glacial till, to the groundwater table, $70 \mathrm{~m}$ below. 
We construct a mathematical model to evaluate the coupled drained and undrained poroelastic pressure response at depth corresponding to the seismogenic crust, following a pulse of fluid from the surface. Knowing the average hydraulic diffusivity $\omega$ and the average distance from the surface to the seismogenic zone $d$, we can calculate the evolution of theoretical pore-pressure with time $P(t)$, following a modified version of the method proposed by Durá-Gómez and Talwani (2010), Mulargia and Bizzarri (2014), and varying due to the fluid migration:

$$
\begin{aligned}
P(t) & =(1-\gamma) P_{0} \operatorname{erf}\left(\frac{d}{2 \sqrt{\omega t}}\right)+\gamma P_{0} \operatorname{erfc}\left(\frac{d}{2 \sqrt{\omega t}}\right) \\
\gamma & =\frac{B}{3} \frac{1+\nu}{1-\nu}
\end{aligned}
$$

Here, $P_{0}$ is the initial input fluid pressure, $\nu$ is the undrained Poisson's modulus, and $B$ is the Skempton coefficient of the bedrock (Detournay and Cheng, 1993). $\operatorname{erf}(x)$ is the error function and $\operatorname{erfc}(x)$ is the complementary error function, defined as:

$$
\begin{aligned}
\operatorname{erf}(x) & \equiv \frac{2}{\sqrt{\pi}} \int_{0}^{x} e^{-t^{2}} d t \\
\operatorname{erfc}(x) & \equiv 1-\operatorname{erf}(x) \\
& =\frac{2}{\sqrt{\pi}} \int_{x}^{\infty} e^{-t^{2}} d t
\end{aligned}
$$

Using this mathematical model, we can vary the input parameters, and compare it to the observed time series of seismicity rate, to assess the hypothesis that surface water flux induces a response of the effective stress at depth, and modifies the rate of microseismicity in the central Southern Alps. 


\section{Chapter 3}

\section{Results}

This chapter is partitioned into three sections. In Section 3.1, we compare geodetic data at GPS sites considered in this study with hydrologic and atmospheric data sets, to determine the parameters that are more likely (or less likely) to have a causal relationship with the observed GPS position shifts. In Section 3.2, we present our catalogue of matched-filtered earthquakes in the central Southern Alps and compare this catalogue with geophysical and hydrologic data sets. Finally, Section 3.3 summarises the key observations forming the basis of detailed discussion in Chapter 4.

\subsection{Geodetic observations}

Some of the GPS stations in the central Southern Alps show significant seasonal signals (e.g. Figure 1.3 and 2.8). Denys et al. (2005) previously suggested that displacements at these sites were induced by snow loading, rock porosity, thermoelastic strain or local effects such as topographic conditions and orientation. We compare meteorological data with GPS movements with the intention to assess the questions: Which meteorological or hydrological variables change simultaneously with the measured geodetic ground deformation, and which of them are more likely to cause it? 


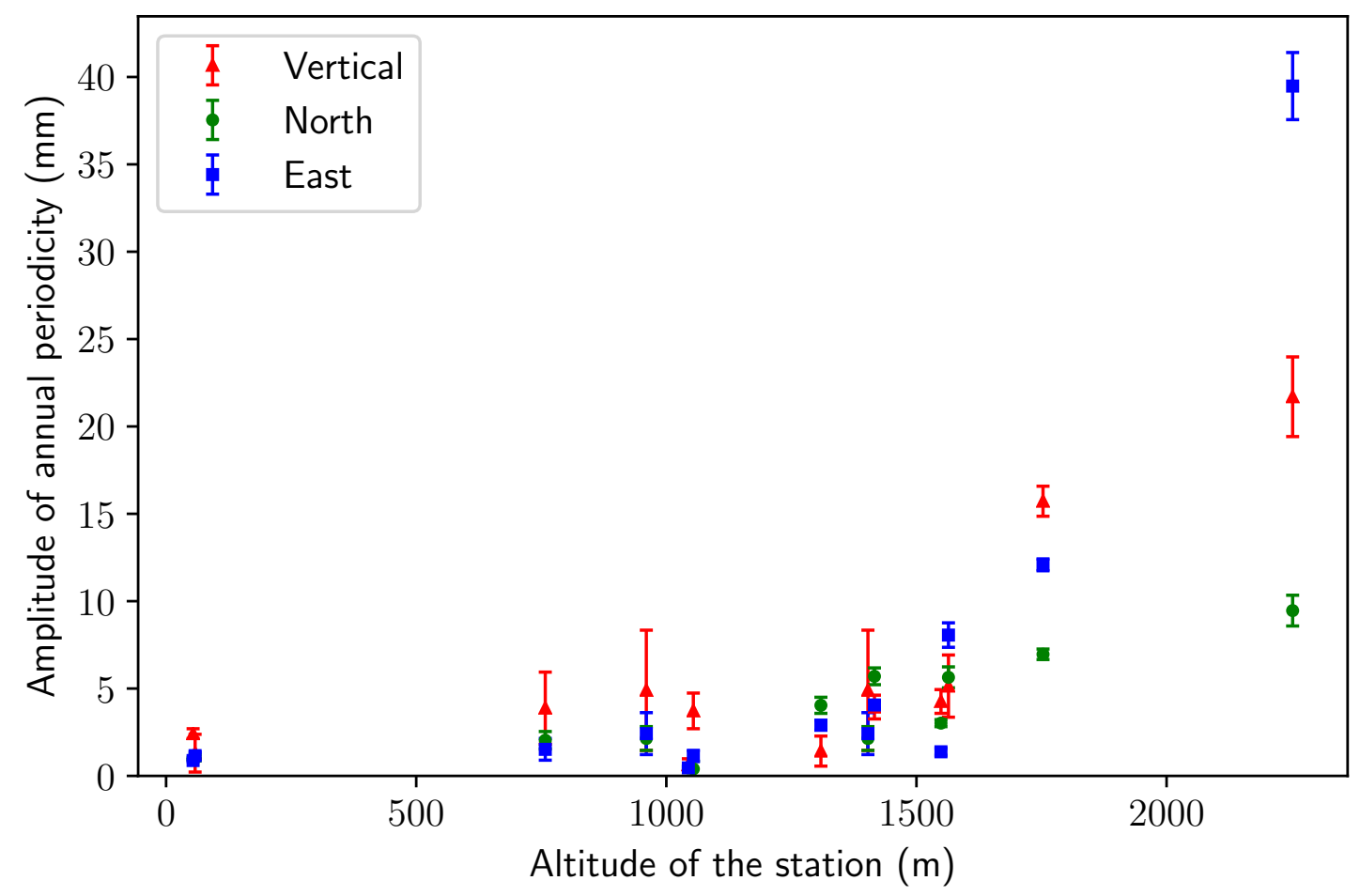

Figure 3.1: Peak-to-peak annual amplitude of displacement versus altitude at each cGPS station, in the three spatial directions. Data for the amplitude of the annual movement and standard deviation was calculated during pre-processing by Paul Denys (University of Otago).

\subsection{1 cGPS: reference stations}

Analysis of the cGPS time series enlightens the fact that there are mainly two primary types of reversible movements. One of them is cyclic and seasonal, while the other occurs on short-term periods and does not seem to exhibit any significant periodicity (e.g. Figure 3.2). The latter is found at the cGPS stations on the West Coast and in the central Southern Alps, but seems to be absent or have amplitude too tiny to emerge from the levels of noise at sites situated in the eastern part of the study area.

The peak-to-peak amplitude of seasonal displacement at each cGPS station in relation to its altitude (Figure 3.1) shows that sites at highest elevation have greatest seasonal variations, and the uncertainty represented by the standard deviation is greatest in the vertical direction, as is usually the case (Beavan et al., 2004). This suggests that the seasonal type of cGPS position fluctuations could be controlled by an environmental factor, which is modulated by the altitude of the GPS station. 

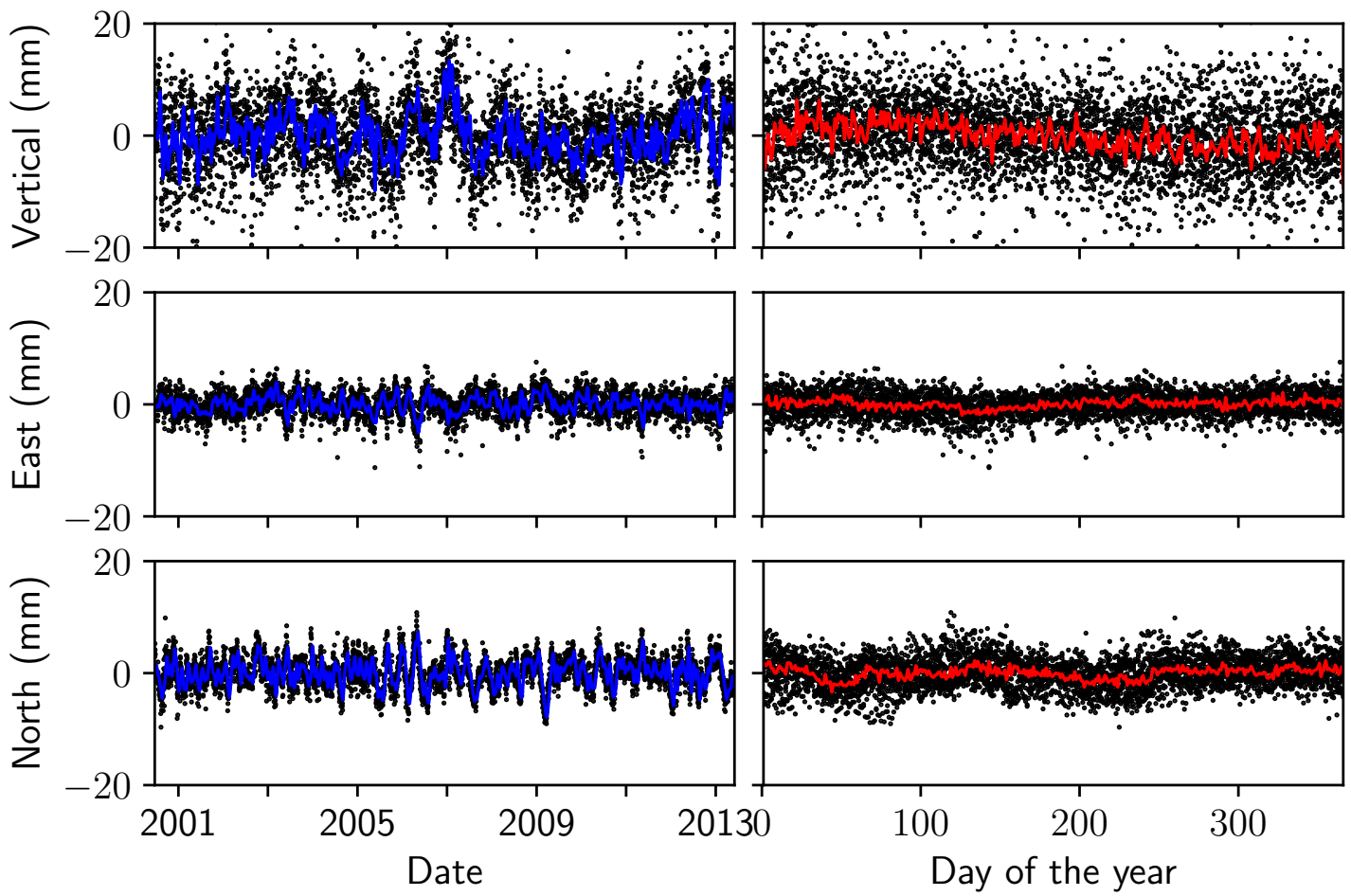

Figure 3.2: Time series of ground position for Haast, in the three spatial directions with a low-pass filtering of the data in blue (left). Same data represented on an ordinal year, with the daily median in red (right).

Therefore, we focus on two reference stations when comparing cGPS time series with other data sets, one for each of the two types of motion described above. All time series comparisons were, studied at each cGPS sites, and some additional examples are given in Appendix B. For stations showing a strong seasonality and with movement reduced in one dimension, we select Annette Plateau (NETT) as reference, because this station shows the largest amplitude of seasonal changes ( $>40 \mathrm{~mm}$, see Figure 2.8). For stations in the west and central parts of the study area, we select Haast (HAAS) as reference (see Figure 3.2), because this station exemplifies the short-term reversible movement $( \pm 20 \mathrm{~mm})$, without significant influence of the seasonal reversible movement $(<4 \mathrm{~mm})$.

\subsubsection{Comparison of cGPS time series with modelled Earth tides}

The gravitational attraction between the Earth and the Sun and Moon is studied for stations in the central Southern Alps. We model the theoretical movement of the station Annette Plateau (NETT) due to solid Earth tides in three dimensions (see Figure 3.3). David Hood (University of Otago) helped to construct the model, 

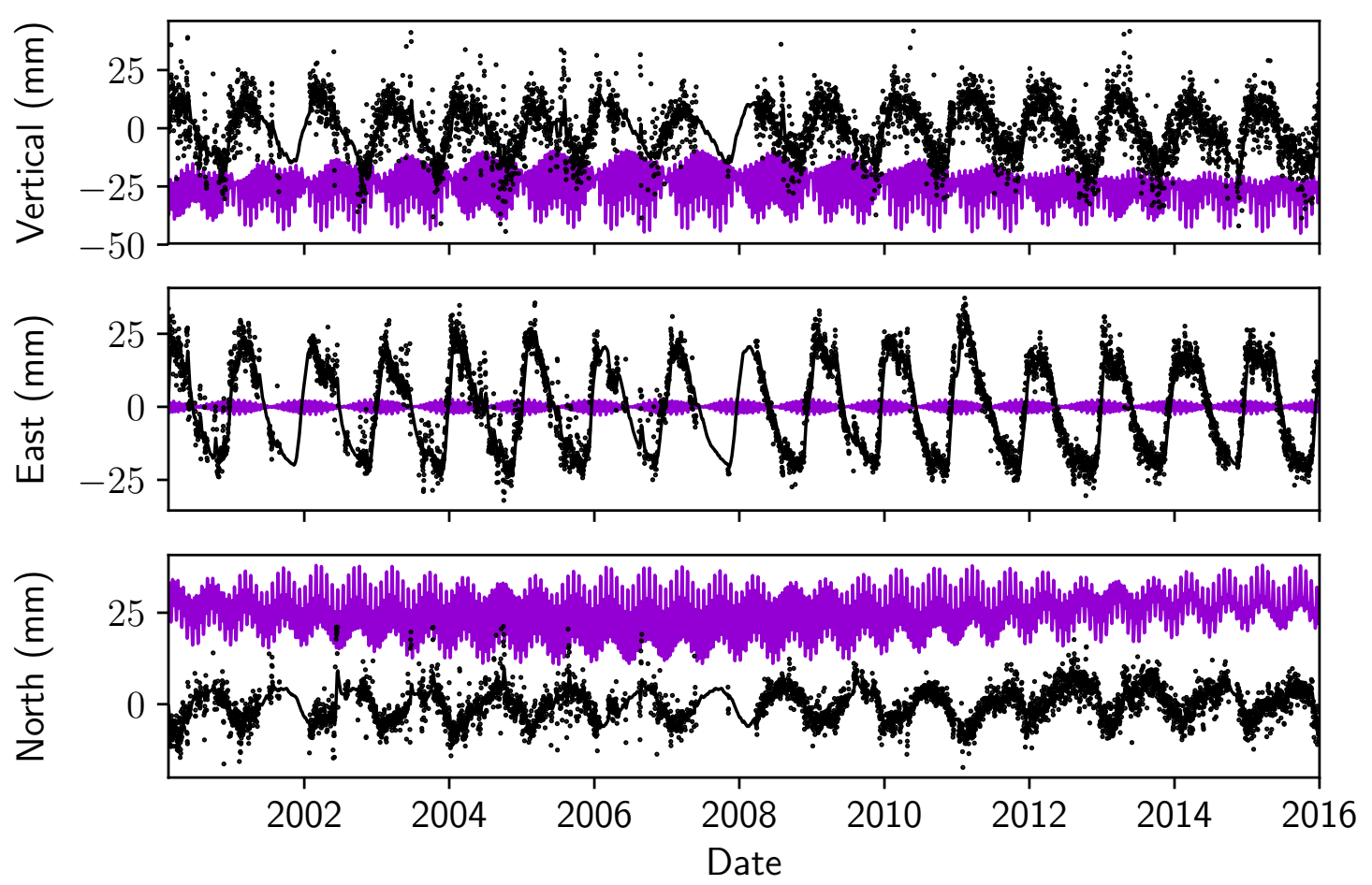

Figure 3.3: Time series of GPS (black) and theoretical Earth Tides (purple, without the semi-diurnal tides) at Annette Plateau (NETT) cGPS station. Note that each spatial component has a different scale. The cross-correlation coefficients and associated best time lags are $0.26(1)(\mathrm{U}), 0.12(27)(\mathrm{E})$ and $-0.09(27)(\mathrm{N})$.

based on the R code from Gama and Milbert (2015), itself modified from Mathews et al. (1997). The amplitude of the movement is similar to the one we study for the annual cycles (see Section 2.3.2), but semi-diurnal earth tides induce movements an order of magnitude larger, and the direction of the movement is not coherent with the one recorded by Annette Plateau (NETT) cGPS station. The highest amplitude movement cycles are for the semi-diurnal solar and lunar components, which we do not study because our minimum temporal resolution taken for the GPS signal is one day. The next highest amplitudes are for solar and lunar diurnal components, with their periods of respectively $24 h$ and $23.93 h$. Longer period signals are dominated by the lunar month and semi-annual and annual solar cycles.

As the effect of Earth tides on GPS is already removed during pre-processing of the GPS data (see Section 2.3.2), we expect to see no clear correlation between GPS and modelled Earth tides. Figure 3.3 displays these tides superimposed on the GPS signal for the same station.

Calculations indicate the east component of the solid Earth tides is the smallest, yet the east component in cGPS data is the one showing the biggest amplitude of annual movement at Annette Plateau (NETT). Additionally, the influence of semi- 
Table 3.1: Cross-correlation coefficients at Haast (HAAS)

\begin{tabular}{llll}
\hline & North & East & Up \\
\hline Rainfall (Haast) & $0.19(0)$ & $-0.13(0)$ & $-0.11(0)$ \\
Snowfall (Mueller Hut) & $0.04(1)$ & $0.05(0)$ & $-0.21(2)$ \\
Temperature (Franz Josef) & $0.02(13)$ & $0.14(4)$ & $0.24(3)$ \\
Pressure (Haast) & $-0.08(26)$ & $0.09(1)$ & $0.34(1)$ \\
Lake Level (Lake Pukaki) & $0.19(29)$ & $-0.12(19)$ & $0.08(0)$ \\
\hline
\end{tabular}

annual Earth tides cannot be seen in the cGPS record, and the cross-correlation coefficients are smaller than 0.3 in all three spatial directions. This suggests that the seasonal signal is unlikely to be caused by solid Earth tides. Similarly, if oceanic tides cause GPS movements, the sea should have greater influence on stations close to the coast and these should display a larger amplitude signal. Instead, we find stations close to the sea show little annual signal (e.g. station Hokitika (HOKI), see Appendix B), whereas it is those in the high mountains that show greater cyclicity (e.g. station Annette Plateau (NETT), see Figure 2.8). Atmospheric tides are a phenomenon with a regional to global scale, but would not cause the observed variation between stations that are located relatively close to each other (e.g. Annette Plateau (NETT) and Hoophorn Spur (HORN)).

Solid Earth tides, atmospheric tides and oceanic tides do not match the patterns in our cGPS data and are therefore considered unlikely to explain the variations seen in the cGPS position data sets.

\subsubsection{Comparison of cGPS time series with atmospheric pressure}

We compare records of atmospheric pressure as a proxy for the passage of anticyclones/troughs of low pressure and associated variations in water vapour, with the north, east and vertical position at Haast (HAAS) (see Figure 3.4). Atmospheric pressure is weakly correlated with Haast (HAAS) cGPS records for both horizontal components, and only the vertical component has a cross-correlation coefficient higher than 0.3 (exact values of cross-correlation coefficients are in Table 3.1). The largest displacement at Haast (HAAS) is horizontal and not vertical (e.g. Figure 3.4), suggesting the corrections for atmospheric delays are effective and atmospheric delays cannot explain the cGPS site displacement. 


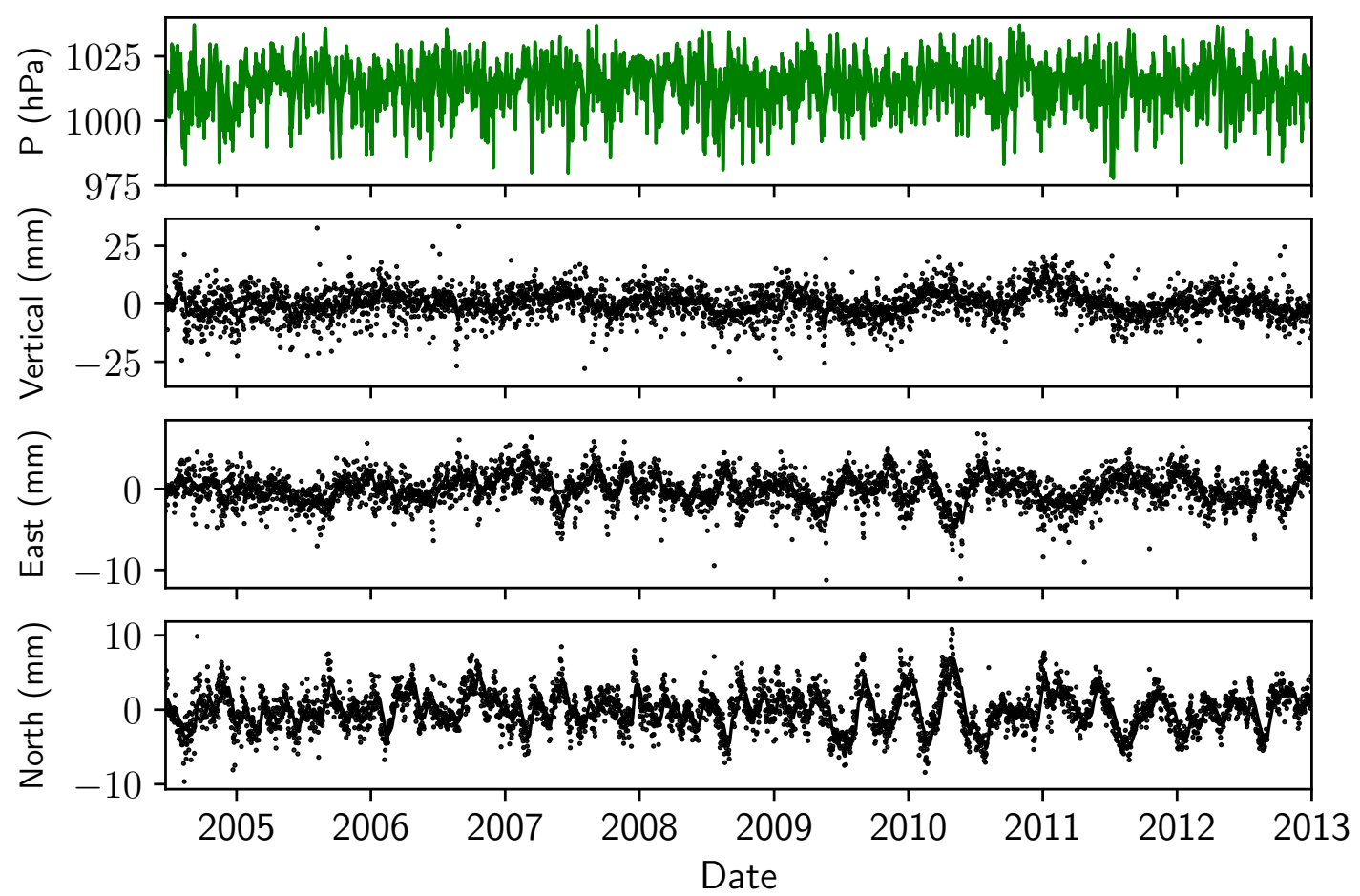

Figure 3.4: Atmospheric pressure (green) compared to the ground motion at Haast (HAAS) (black). The cross-correlation coefficients and associated best time lag in days are respectively $0.34(1)(\mathrm{U}), 0.09(1)(\mathrm{E})$ and $-0.08(0)(\mathrm{N})$.

\subsubsection{Comparison of cGPS time series with surface air temperature}

The cGPS and the daily mean temperature of the air are well correlated at sites with a seasonal movement (e.g. Figure 3.5, cross-correlation coefficients can be found in Table 3.2). However, the cGPS frequently exhibits an asymmetry that is not present in the temperature data set. Higher cross-correlation coefficients are also expected for sites with a significant seasonality, as the air temperature record is dominated by a strong seasonality too, with highest temperatures recorded during summer and vice-versa during winter. In Hokitika, on the West Coast and even more in Mount John (see Appendix B), in the east part of the study area, temperature varies significantly throughout the year, yet local cGPS stations Hokitika (HOKI) and MTJO have small seasonal cyclicity. Despite the good correlation coefficients at some stations, the near-surface air temperature is unlikely to explain the cGPS movements. 


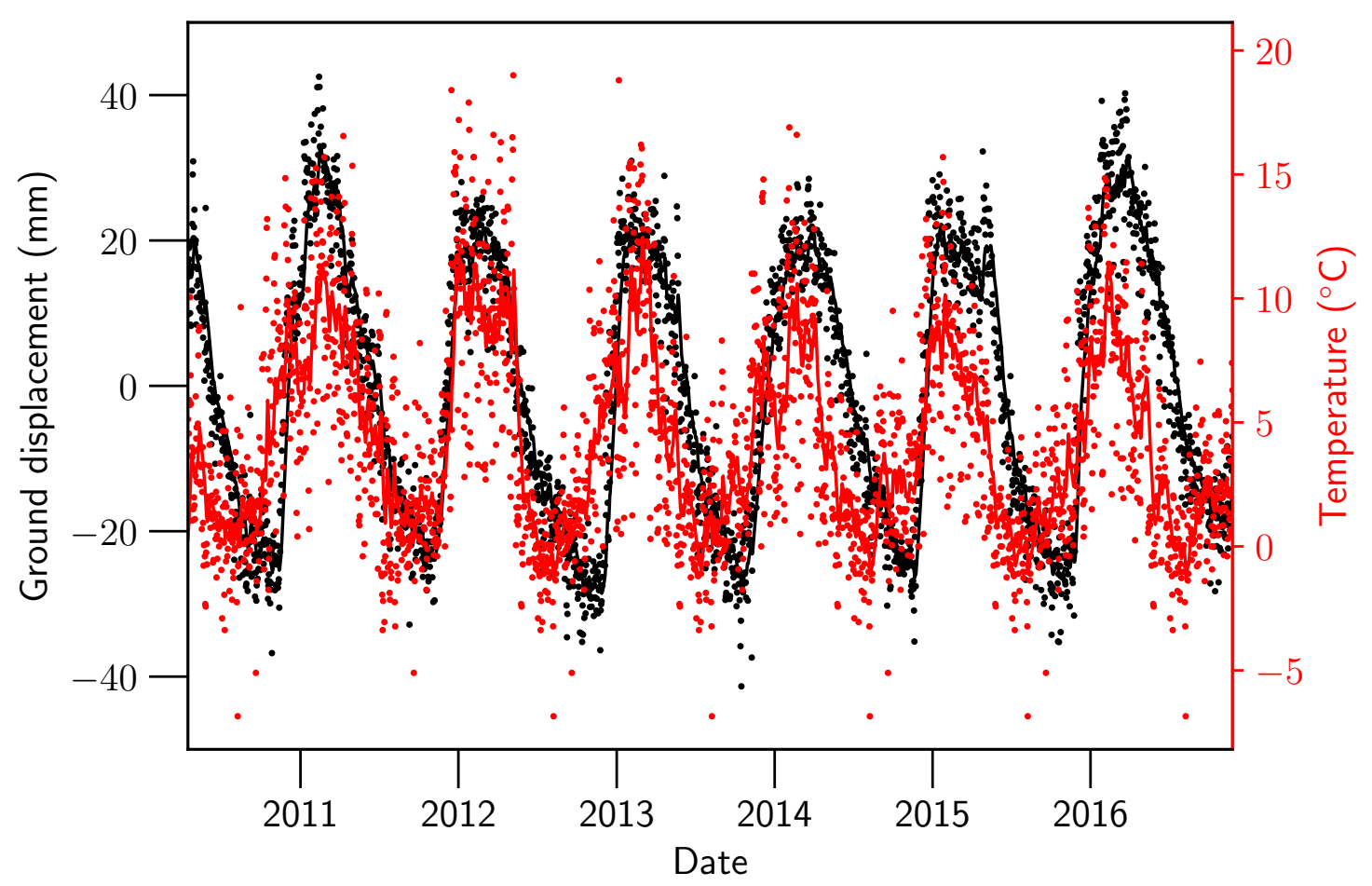

Figure 3.5: Air temperature at Mueller Hut (red) and ground motion at Annette Plateau (NETT)(black), along the single direction defined in Section 2.3.2.

Table 3.2: Cross-correlation coefficients at Annette Plateau (NETT)

\begin{tabular}{lllll}
\hline & North & East & Up & PC 1 \\
\hline Rainfall (Mueller Hut) & $-0.14(0)$ & $0.16(0)$ & $-0.07(2)$ & $0.12(0)$ \\
Snowfall (Mueller Hut) & $0.59(29)$ & $-0.84(10)$ & $-0.72(3)$ & $-0.86(8)$ \\
Temperature (Mueller Hut) & $-0.52(2)$ & $0.55(0)$ & $0.44(2)$ & $0.55(3)$ \\
Pressure (Mount Cook) & $-0.09(27)$ & $0.12(27)$ & $0.26(1)$ & $0.13(2)$ \\
Lake Level (Lake Pukaki) & $-0.42(10)$ & $0.51(4)$ & $0.31(0)$ & $0.48(0)$ \\
\hline
\end{tabular}




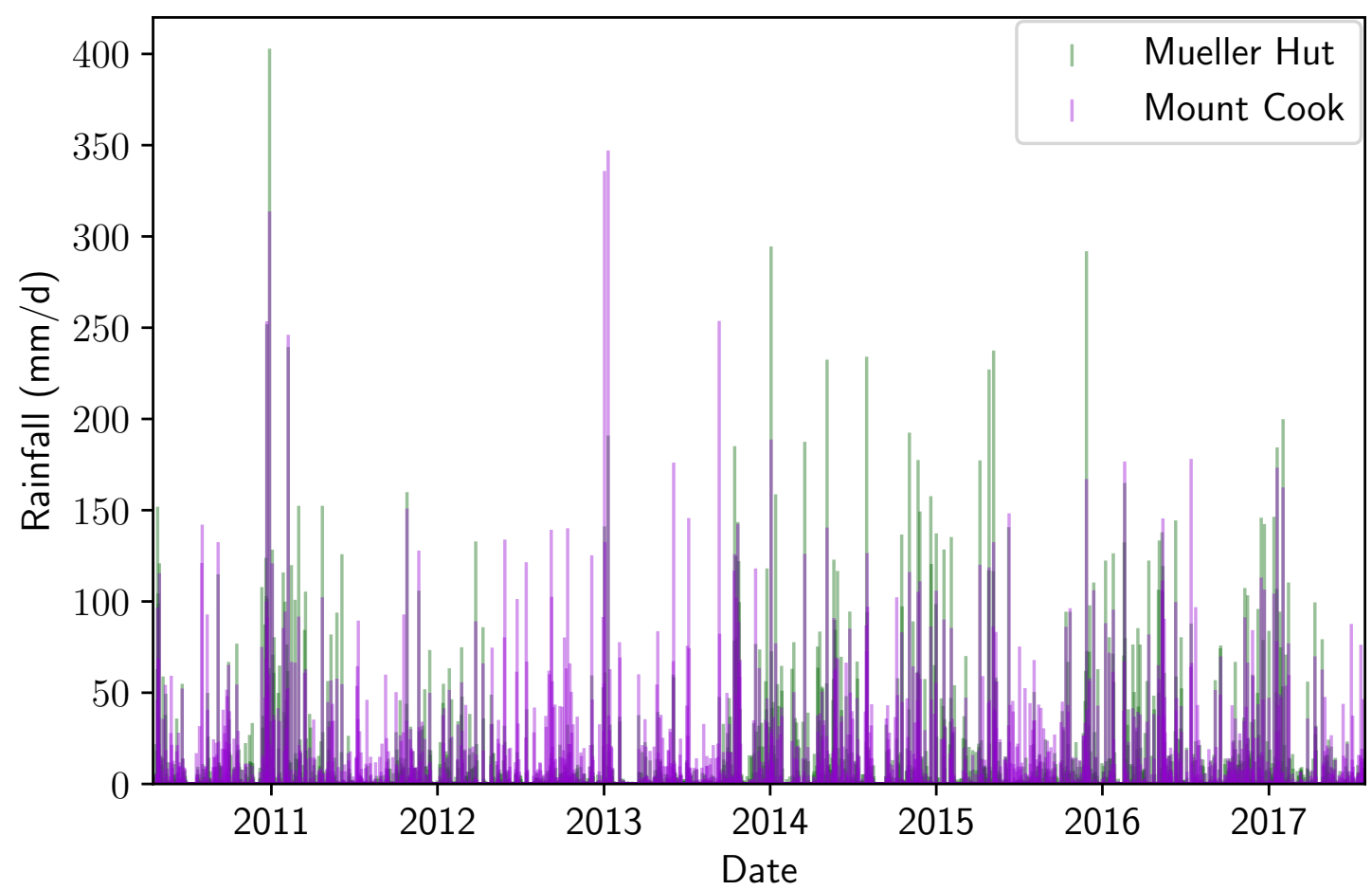

Figure 3.6: Comparison between daily rainfall at Mueller Hut (green) and Mount Cook village (purple), separated by $\sim 3200 \mathrm{~m}$ and $1050 \mathrm{~m}$ of altitude. The cross-correlation coefficient is 0.77 , with a best time-lag of $0 \mathrm{~d}$.

\subsubsection{Comparison of cGPS time series with rainfall}

One of the issues we encounter is that climate and GPS stations do not share sites. This is a problem when comparing rainfall data to GPS data as rainfall intensity is notorious for showing strong spatial variations as frontal weather systems pass across the Southern Alps (Sturman and Wanner, 2001). Daily rainfall totals, however, are smoothed and more susceptible to represent a wider area around the rain gauge. We use only daily rainfall totals in this study, for comparison with daily median cGPS motion. A comparison of daily rainfall at Mueller Hut and Mt Cook village is provided in Figure 3.6. The Mueller Hut and Mt Cook rain gauges are useful for representing climatic conditions at Annette Plateau (NETT) and Hoophorn Spur (HORN) respectively. A comparison of daily cGPS position between these two sites is provided in Figure 3.7. The cross-correlation coefficients are much higher 0.77 for the two rainfall data sets than for cGPS position time series $<0.36$ at Annette Plateau (NETT) and Hoophorn Spur (HORN). The amplitude of motion is also twice higher at Annette Plateau (NETT), indicating that despite strong similarities in the weather pattern, amount of rain and atmospheric pressure changes, the two cGPS stations experience differences in seasonal movements. 

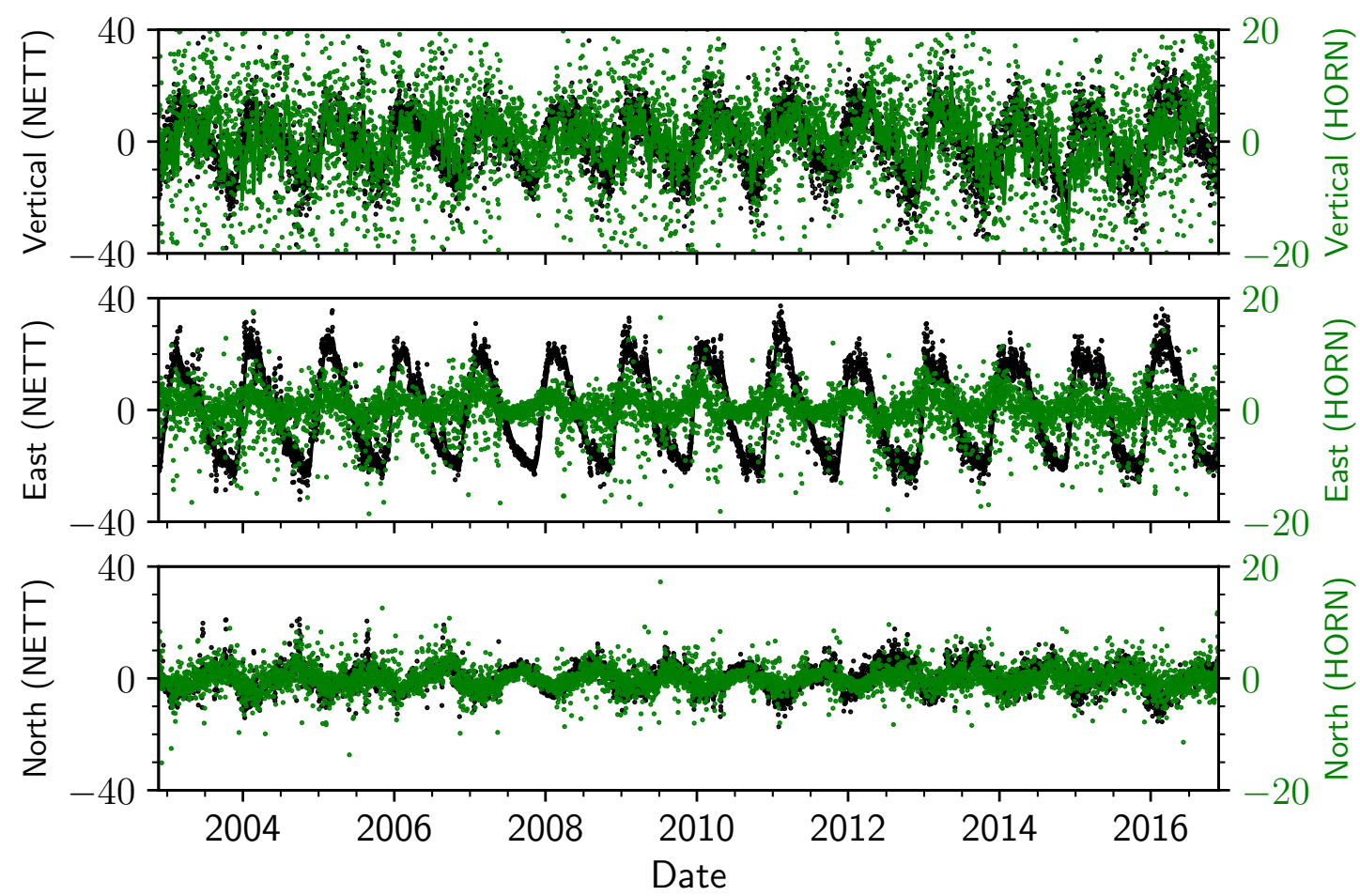

Figure 3.7: Comparison between cGPS at Annette Plateau (NETT) and Hoophorn Spur (HORN), separated by $\sim 4500 \mathrm{~m}$ and $\sim 1290 \mathrm{~m}$ of altitude. Note that the data have been scaled by maximum range to highlight potential correlations, such that the scale is not the same for the two stations. The cross-correlation coefficients and associated time-lags are $0.28(0)(\mathrm{U}), 0.23(25)(\mathrm{E})$ and $0.36(0)(\mathrm{N})$. 

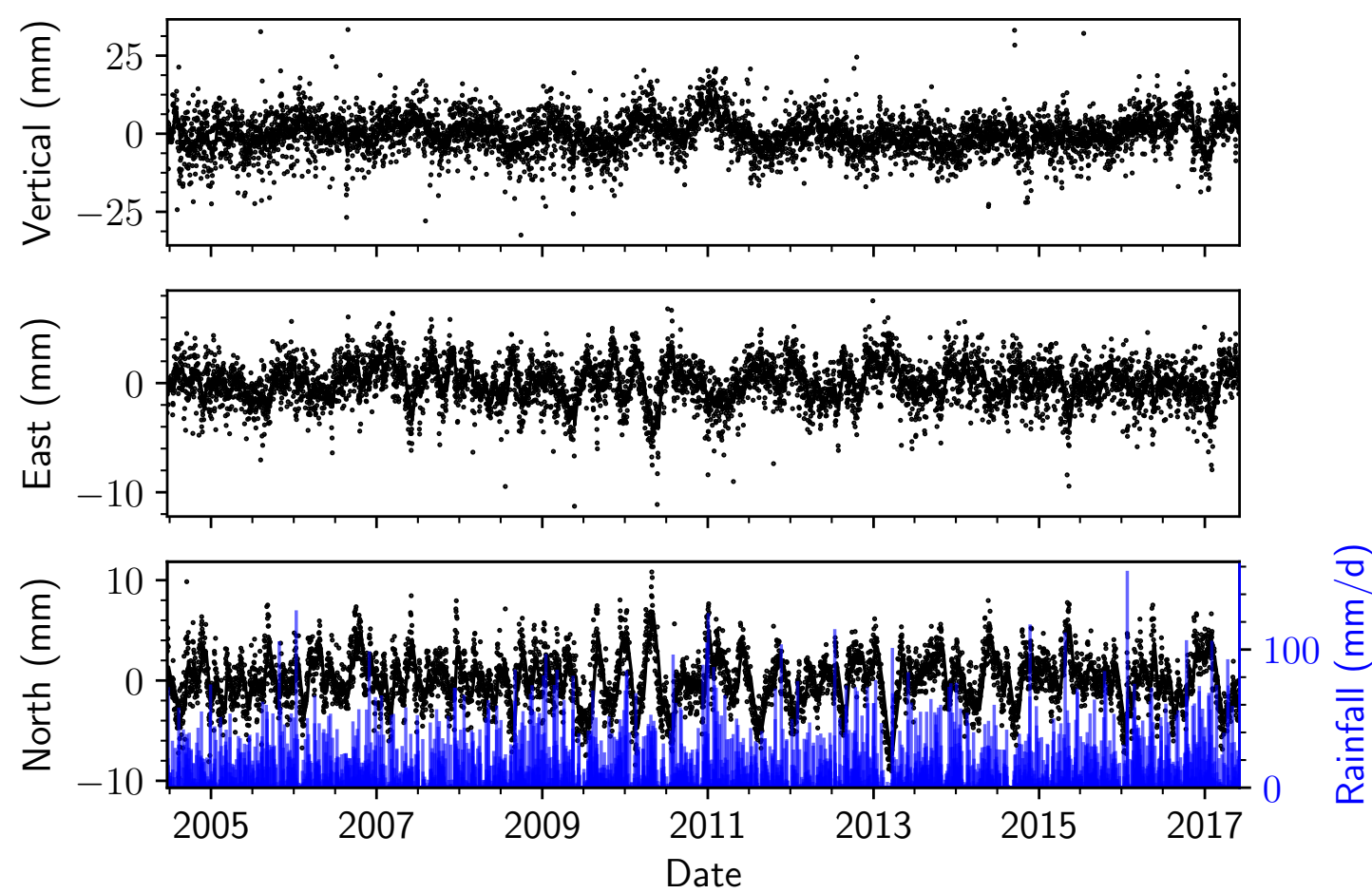

Figure 3.8: Comparison between cGPS at Haast (HAAS) and rainfall at Haast. The cross-correlation coefficients are $-0.11(\mathrm{U}),-0.13(\mathrm{E}), 0.19(\mathrm{~N})$.

Through a cursory investigation, we observe that certain stations show clear movements following rain storms. One of the best examples of this occurring is at Haast (HAAS). Figure 3.8 shows the comparison between Haast (HAAS) and the daily total amount of rain in Haast. Here we see significant $(>3 \mathrm{~mm})$ shifts in position following large rainfall events (e.g. early 2016).

To explore this further, we characterise events where there is more than $50 \mathrm{~mm}$ total rain in one day, following a dry period of three weeks with less than $80 \mathrm{~mm}$ total rain. Figure 3.9 indicates the direction of horizontal movement of Haast (HAAS) cGPS station after such heavy rain, ignoring displacements with amplitude under $3 \mathrm{~mm}$. The shifts tend to be toward the northwest, generally in the direction of the slope, and at a high angle to foliation in the schist (see Figure B.8).

The same orientation (normal to the slope) is found at most of the sites with a short-term reversible movement. For sites with a large seasonality, it seems that the ground reacts after heavy rain events only during summer and not in winter, supporting the idea that the rainfall could be related to the short-term reversible displacement, but be inhibited by another effect in winter. We note that the stations concerned by the seasonality are at altitudes where precipitation comes as snow instead of rain during winter. We also observe that stations with less rain (southeast of our study area, in the Mackenzie Basin) do not exhibit any 


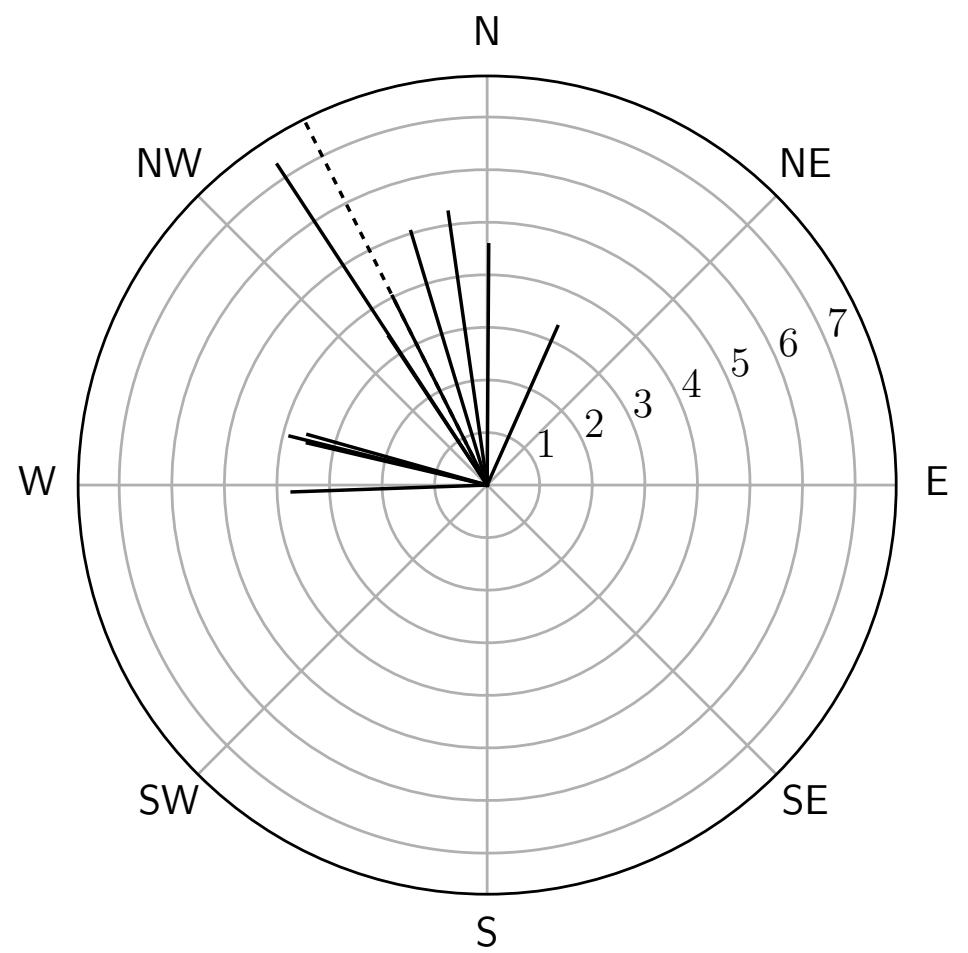

Figure 3.9: Orientation of displacement after heavy rain at Haast (HAAS). An event is defined as a day with more than $50 \mathrm{~mm}$ of rain, following a 3-weeks period with less than $80 \mathrm{~mm}$ in total. The distance from the origin represents the displacement after the rain event in millimetres. Displacement under $3 \mathrm{~mm}$ are not shown. The dashed line is the median horizontal orientation of displacement.

significant motion after rainfall, but that a good spatial correlation exists between total annual rainfall at the station and amplitude of ground motion (Figure 1.2 and 1.3).

\subsubsection{Comparison of cGPS time series with snow depth}

All stations in the central Southern Alps experience some snow during winter. However, for stations in the zone of seasonal frost, the snow tends to accumulate through winter, conversely to stations in the zone of sporadic frost. In the case of the highest altitude station in the SAGENZ network, Annette Plateau (NETT), the seasonality in cGPS position is also found in the record of snow depth at Mueller Hut climate station, and the asymmetry of both signals are concurrent. The ground however often starts to move in the winter direction (ENE and down, see Figure 2.6) before the first snow is recorded at Mueller Hut (see Figure 3.10). There are great similarities between the median snow depth per day of the year at Mueller Hut and the median displacement per day of the year at Annette Plateau (NETT) (see Table 3.2), but subtle differences can be explained by the 


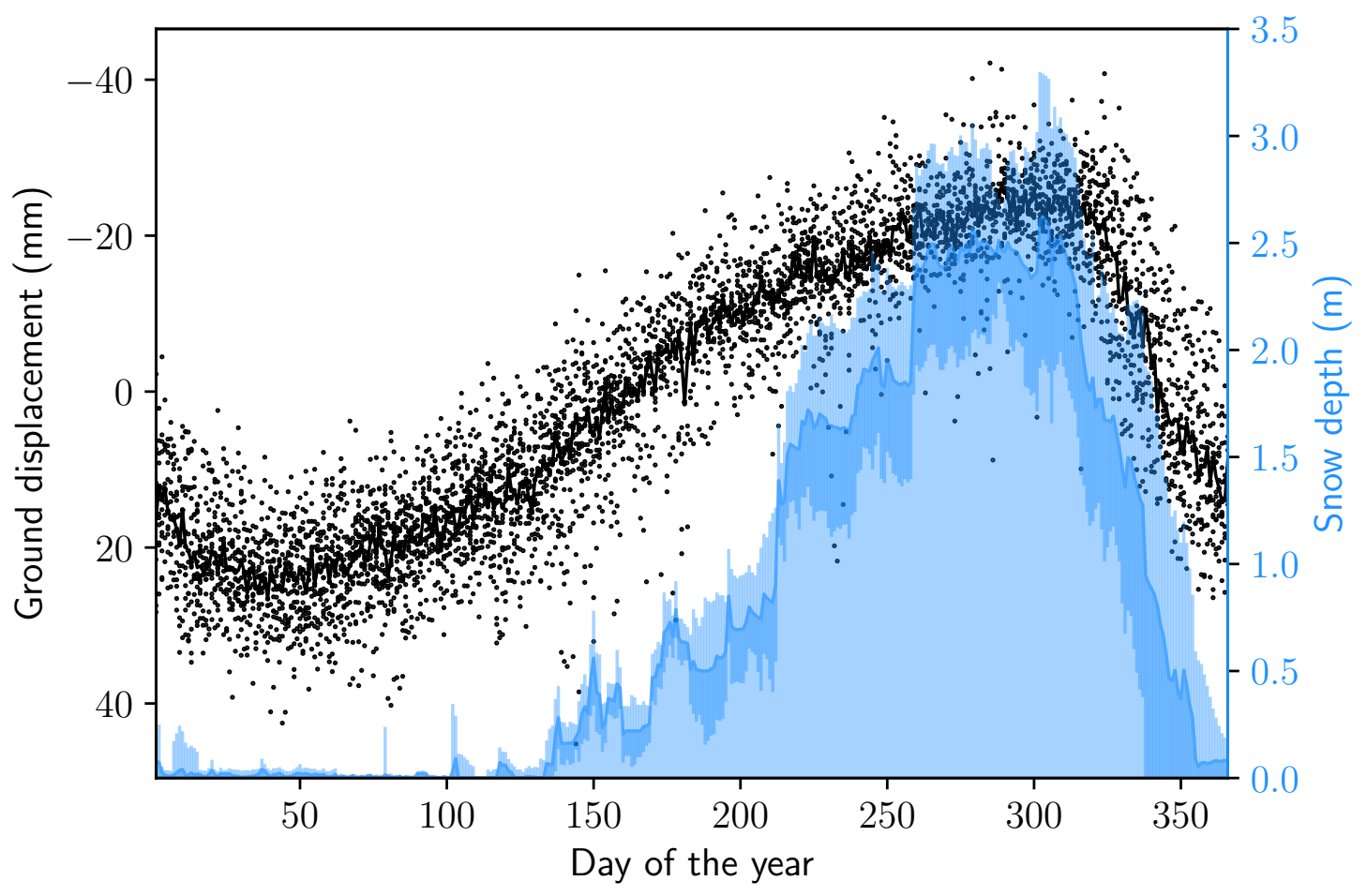

Figure 3.10: cGPS at Annette Plateau (NETT), along the single direction defined in Section 2.3.2, versus snow depth at Mueller Hut, on an ordinal year. Snow is in blue with the standard deviation per day, cGPS data points are in black, and the black line is a low-pass filtering. For better readability, the displacement axis is inverted.

distance between the climate station and the cGPS. The snow gauge at Mueller Hut is $1800 \mathrm{~m}$ above sea level, whereas Annette Plateau (NETT) is $450 \mathrm{~m}$ higher, where we expect more snow, that comes earlier and melts later in the season. When the snow melts, the response of the ground is rapid $\left((0.5 \pm 0.1) \frac{\mathrm{mm}}{\mathrm{d}}\right.$ for the period of 2010-2015, see Figure 2.20). There are more fluctuations during summer than during winter (Figures 3.11) and a logarithmic-like depression during winter (Figure 3.10), as the snow accumulates again.

The spatial and interannual variability of snow depth is high in New Zealand alpine catchments (Kerr et al., 2013). While it is possible to correlate the median displacement per day of the year at Annette Plateau (Annette Plateau (NETT)) and the median snow depth per day of the year at Mueller Hut with some degree of confidence, there is greater uncertainty for Pilkington Glacier (PILK). Pilkington Glacier (PILK) is situated on the other side of the Main Divide and at some distance from Mueller Hut and Rose Ridge (the closest snow gauges).

The time series comparison shows that the seasonality at Annette Plateau (NETT) cGPS position is also found in the record of snow depth (see Figure 3.11), and the asymmetry of both signals is concurrent. The seasonality at Annette Plateau 


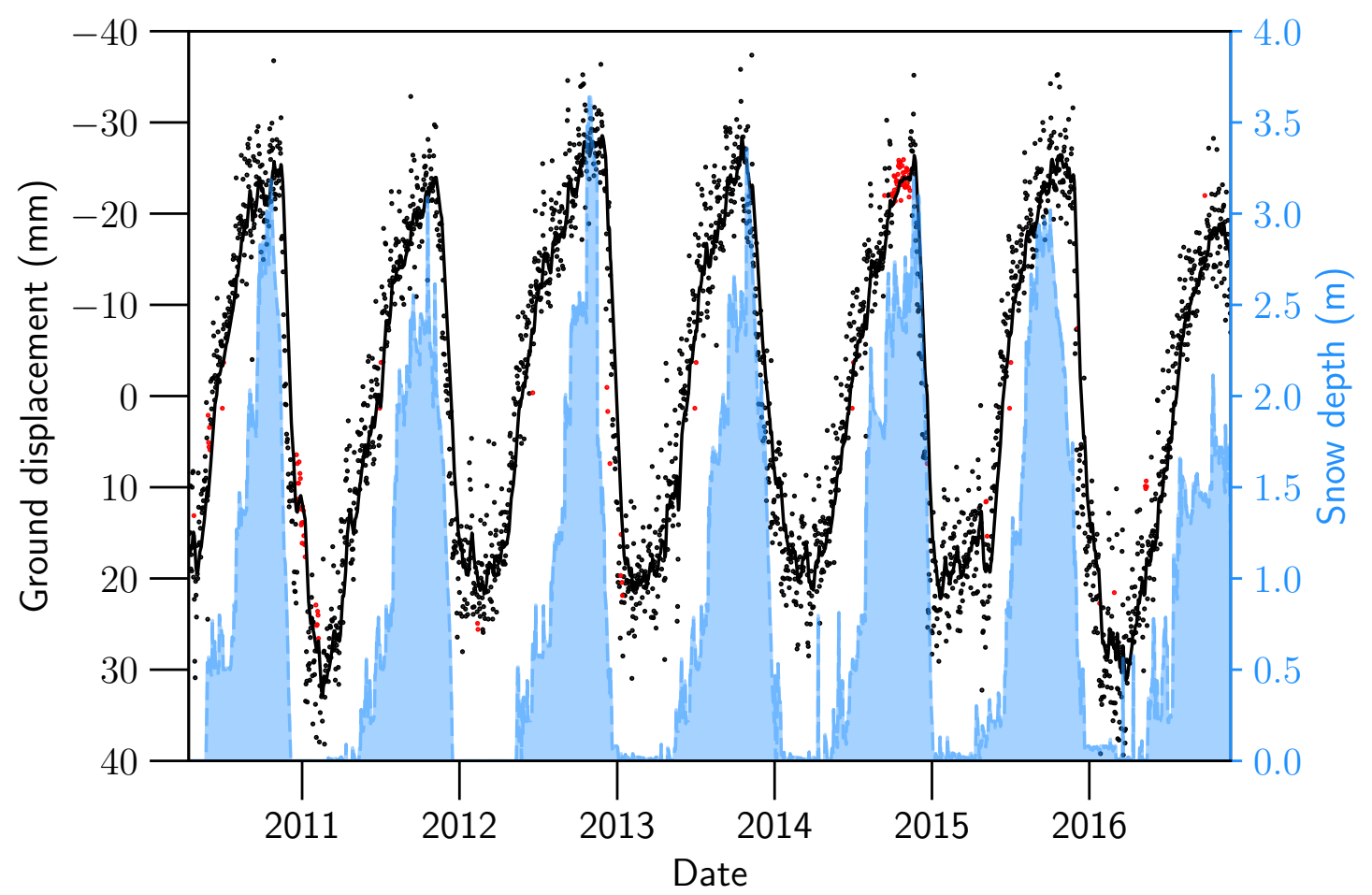

Figure 3.11: Snow depth at Mueller Hut (blue) and ground motion at Annette Plateau (NETT) (measurements in black, artificial values in red), along the single direction defined in Section 2.3.2. For better readability, the displacement axis is inverted.

(NETT) cGPS displacement exhibits, however, a higher inter-annual regularity than the snow depth at Mueller Hut. An example of it is the first half of winter 2016, with significantly less snow than the median year, but a cGPS displacement close to the median of other years. More examples are in Figure B.26, for displacement at Pilkington Glacier (PILK) cGPS versus snow depth at Rose Ridge SIN (Snow and Ice Monitoring Network) station. The horizontal direction of displacement at cGPS sites with significant seasonality is coherent with zones of snow accumulation (see Figure 1.3), and topographic highs around the sites.

\subsubsection{Comparison of cGPS time series with lake levels}

The closest GPS stations to Lake Pukaki are Mt Cox (MTCX) and Burnett Rock (BNET) (see Figure 1.3). The latter is situated $\sim 4500 \mathrm{~m}$ north of Lake Pukaki, at an altitude of $748 \mathrm{~m}, 220 \mathrm{~m}$ to $240 \mathrm{~m}$ higher than the lake surface. The seasonal movement at Burnett Rock (BNET) cGPS has an amplitude of less than a millimetre (see Figure 3.12). Only the north component is weakly negatively correlated with the level of the lake (cross-correlation coefficient of -0.32 (0)). Burnett Rock (BNET) had an offset of around $\sim 7 \mathrm{~mm}$ to the west, $\sim 0 \mathrm{~mm}$ to the north 

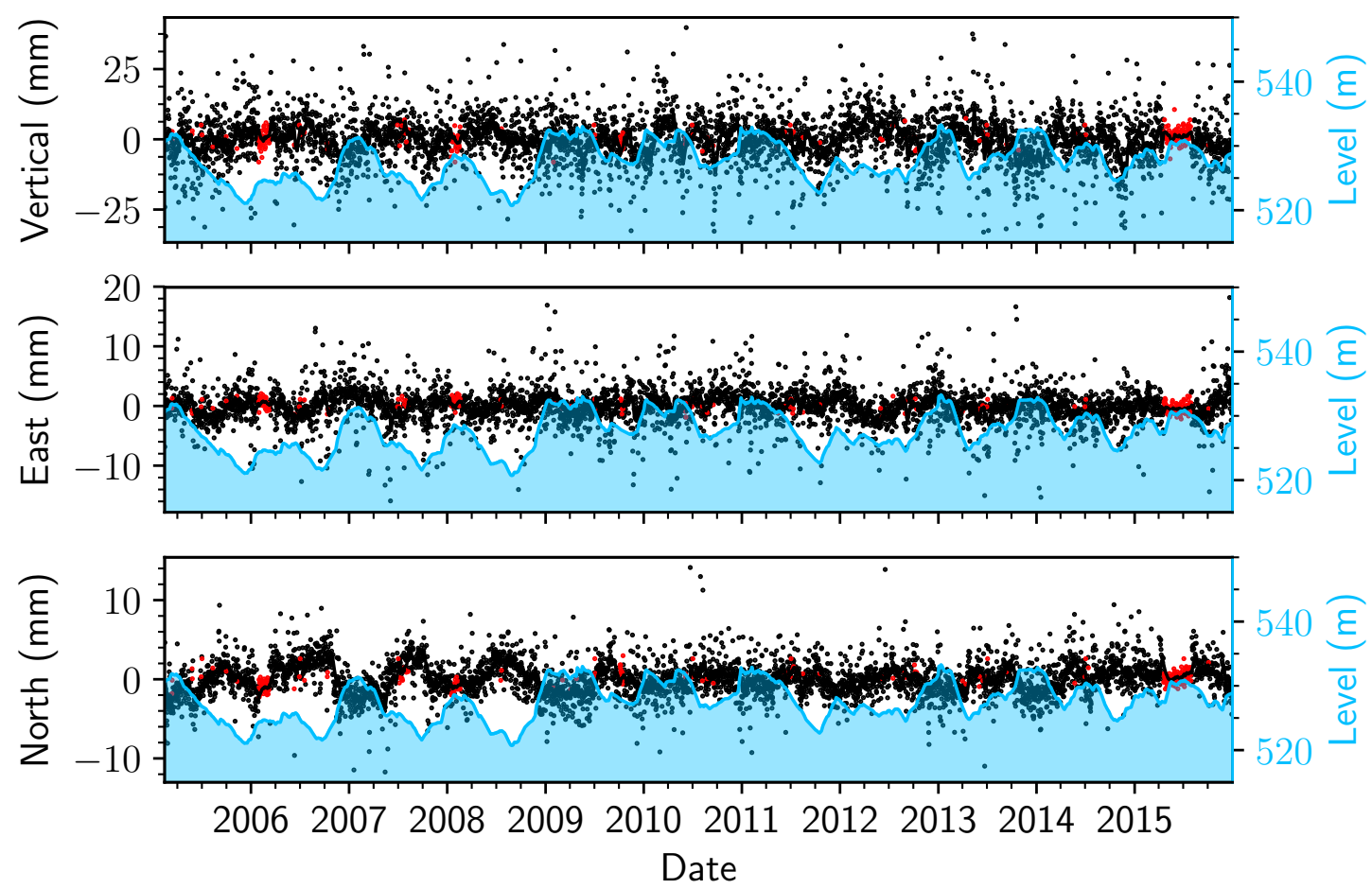

Figure 3.12: Comparison between Burnett Rock (BNET) position measured (black), artificially filled (red) and Lake Pukaki lake level (blue). Note that the scale is different for each cGPS component. The cross-correlation coefficients are -0.11 (29) (U), 0.06 (0) $(\mathrm{E}),-0.32(0)(\mathrm{N})$.

and vertically during the $\mathrm{M}_{\mathrm{W}} 7.82009$ Dusky Sound earthquake (where $\mathrm{M}_{\mathrm{W}}$ is the moment magnitude). This offset and the following post-seismic decay are removed with the method described in Section 2.3.2.

Mt Cox (MTCX) is situated $\sim 5400 \mathrm{~m}$ from the east of Lake Pukaki at an altitude of $828 \mathrm{~m}$. Like at Burnett Rock (BNET), the ground does not have a significant seasonal movement $(<1 \mathrm{~mm})$ and the correlation between cGPS data and lake level are weak (see Table B.9).

Water levels at Lake Pukaki rose $11 \mathrm{~m}$ when the snow melted in late 2008. This event also caused Lake Tekapo levels to increase by $6 \mathrm{~m}$. The beginning of 2008 was relatively dry, particularly May and June, resulting in low-levels of both lakes before winter. Cox and Allen (2009) noted that the summer of 2008 was one of the warmest since the beginning of the 21 st century and the lakes were close to their minimum when the snow started melting. We can calculate the load that the added volume of water represents at the time. The equation of water balance for 
Table 3.3: Offsets caused by distal earthquakes at Mount John (MTJO)

\begin{tabular}{llcccc}
\hline $\mathbf{M}_{\mathbf{W}}$ & Name & Date & East $(\mathbf{m m})$ & North $(\mathbf{m m})$ & Vertical $(\mathbf{m m})$ \\
\hline 8.1 & Macquarie Is. & 23.12 .2004 & -2 & 5 & 0 \\
7.8 & Dusky Sound & 15.07 .2009 & -8 & -3 & -8 \\
7.1 & Darfield & 04.09 .2010 & -3 & -2 & -3
\end{tabular}

a lake (Bengtsson, 2012) is:

$$
\begin{aligned}
\frac{d V}{d t} & =A(h) \times \frac{d h}{d t} \\
& =Q_{\text {in }}-Q_{\text {out }}(h)+Q_{G W, \text { in }}-Q_{G W, \text { out }}+(P-E) \times A(h)
\end{aligned}
$$

where $\frac{d V}{d t}$ is the lake volume change during the time interval $d t ; A(h)$ is the surface of the lake, which depends on the lake level; $\frac{d h}{d t}$ is the level change of the surface during the time interval $d t ; Q_{i n}$ is the surface lake inflow, from rivers and runoff; $Q_{\text {out }}(h)$ is the surface lake outflow, controlled at the dam (including spills); $Q_{G W, \text { in }}$ is the groundwater inflow to the lake; $Q_{G W, \text { out }}$ is the groundwater discharge to the aquifer; $P$ is the precipitation directly on the lake; $E$ is the evaporation of water from it.

The average surface of Lake Pukaki, $A(\bar{h})$, is $179 \mathrm{~km}^{2}$. Therefore, a rise of $11 \mathrm{~m}$ between September 2008 and January 2009, $\frac{d h}{d t}$, represents an excess volume of inflow close to $1.97 \times 10^{12} \mathrm{~L}$, accumulated in 4 months, $\frac{d V}{d t}$. The total lake storage is $2.34 \times 10^{12} \mathrm{~L}$, and the average daily inflow in the lake varies through the year, between less than $1 \times 10^{2} \mathrm{~L} / \mathrm{d}$ to more than $6 \times 10^{6} \mathrm{~L} / \mathrm{d}$ (Caruso et al., 2017a).

cGPS station Mt John (MTJO) (Mount John) is situated on the southwest side of Lake Tekapo (Figure 3.13), at an altitude of $1044 \mathrm{~m}, 320 \mathrm{~m}$ higher than the Lake and $\sim 800 \mathrm{~m}$ to the west. Here again, the correlation between the lake level and the ground position is weak (Figure B.20). The north component has a crosscorrelation coefficient of -0.14 at zero time-lag and a greatest cross-correlation coefficient of -0.21 with a lag of $29 \mathrm{~d}$. Three earthquakes generated significant shifts in the position of Mt John (MTJO) (Table 3.3).

In late 2008 , the $6 \mathrm{~m}$ rise of the surface $\left(98 \mathrm{~km}^{2}\right)$ of the lake corresponds to $5.9 \times 10^{11} \mathrm{~L}$ of added water, while the total lake storage was estimated to be $7.05 \times 10^{11} \mathrm{~L}$ (Caruso et al., 2017a). 


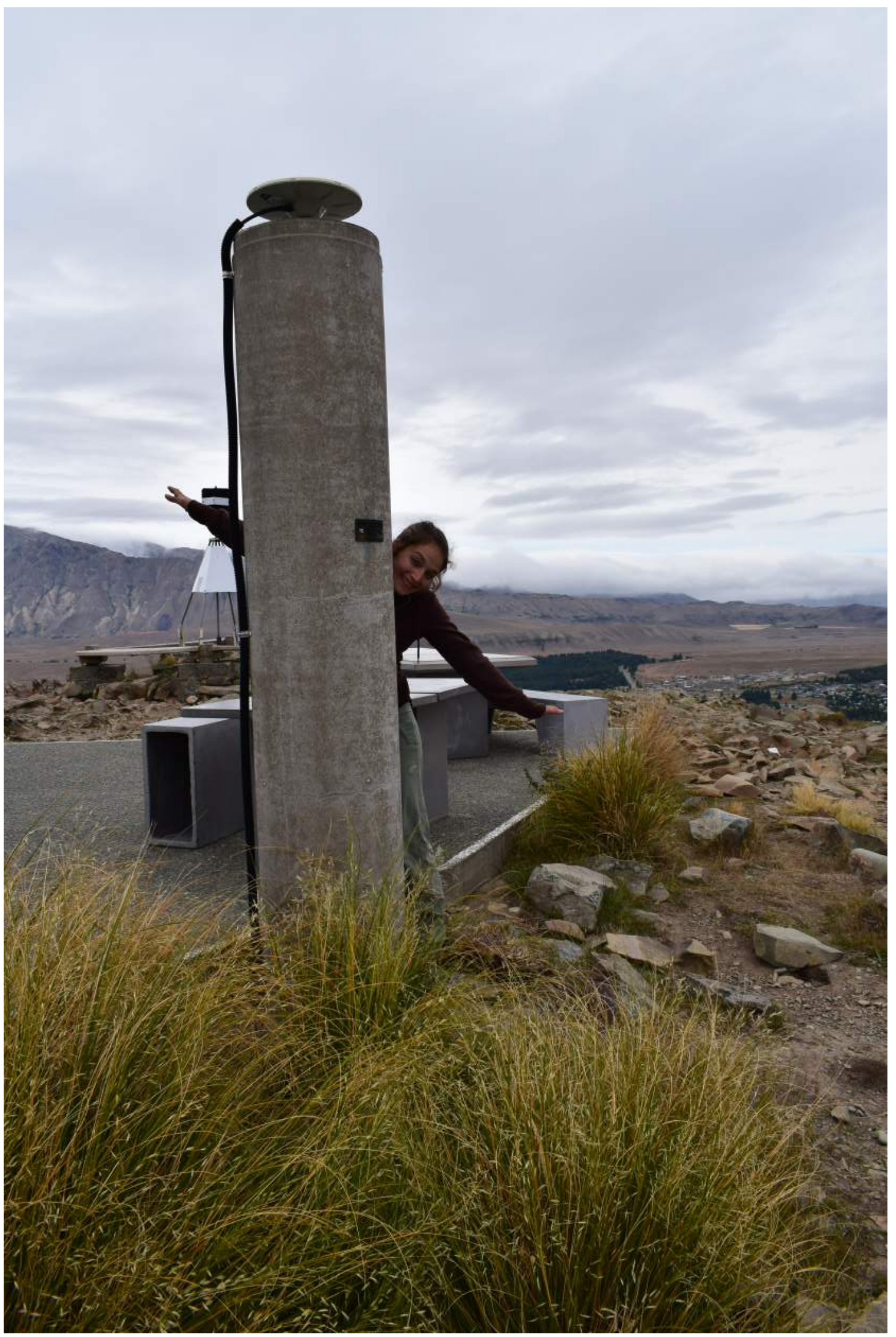

Figure 3.13: Mt John (MTJO) station, close to the Observatory of Mount John with V. Mesnil for scale. The altitude is $1044 \mathrm{~m}$. Tekapo is in the background, the lake is on the left, down the hill (View to the SE). Picture taken on 2 January 2017. 
Rapid lake water volume increases of between $10^{11} \mathrm{~L}$ to $10^{12} \mathrm{~L}$ do not show clear, measurable position offsets at GPS sites within $5 \mathrm{~km}$ of the lakes. Furthermore, there are no clear seasonal variations in position relating to lake level fluctuations. Instead, the most significant offsets are those caused by distal earthquakes.

\subsubsection{Comparison of cGPS time series with modelled ground- water levels}

To examine if groundwater infiltration and loading could be responsible for observed changes in cGPS position in the mountains, we model a unidimensional displacement using equations set out in Section 2.4.5 (Figure 3.14). The modelled ground displacement including only the recharge via rainfall and a progressive, logarithmic reservoir depletion during dry periods is well correlated with the GPS displacement. We observe that the model reproduces the movement for stations in mid-altitude, situated close to a slope (e.g. Haast (HAAS)). However, the model breaks down for high-altitude stations, where the strong annual motion is not reliably reproduced, and for stations in the eastern part of the study area, where annual rainfall is low (see Figure 1.2).

For the highest altitude stations in the network, we compare cGPS position with the modelled displacement due to the fluctuations of the groundwater table, adding the effect of infiltration inhibition by the snow layer in winter, with the REROD model (e.g. Figure 3.15). REROD better reproduces the seasonal cGPS motion at Annette Plateau (NETT) and Pilkington Glacier (PILK). The fit is however not perfect, and a parameter optimisation of the model could improve the results, for example using the PEST software (Model-Independent Parameter Estimation and Uncertainty Analysis), as proposed by Hansmann (2017).

\subsubsection{Local bedrock properties around stations}

We previously found that relatively short inter-stations distances, such as the 4000 m separating Annette Plateau (NETT) and Hoophorn Spur (HORN), were sufficient to induce differences in direction and amplitude of movements (see Section 3.1.5, map in Figure 1.3). Therefore, we study the properties of the bedrock at a local scale around each station. Some detailed geologic maps are in Appendix B. Here, we try to relate the observed GPS position displacements with the local geology and local properties of the bedrock. 

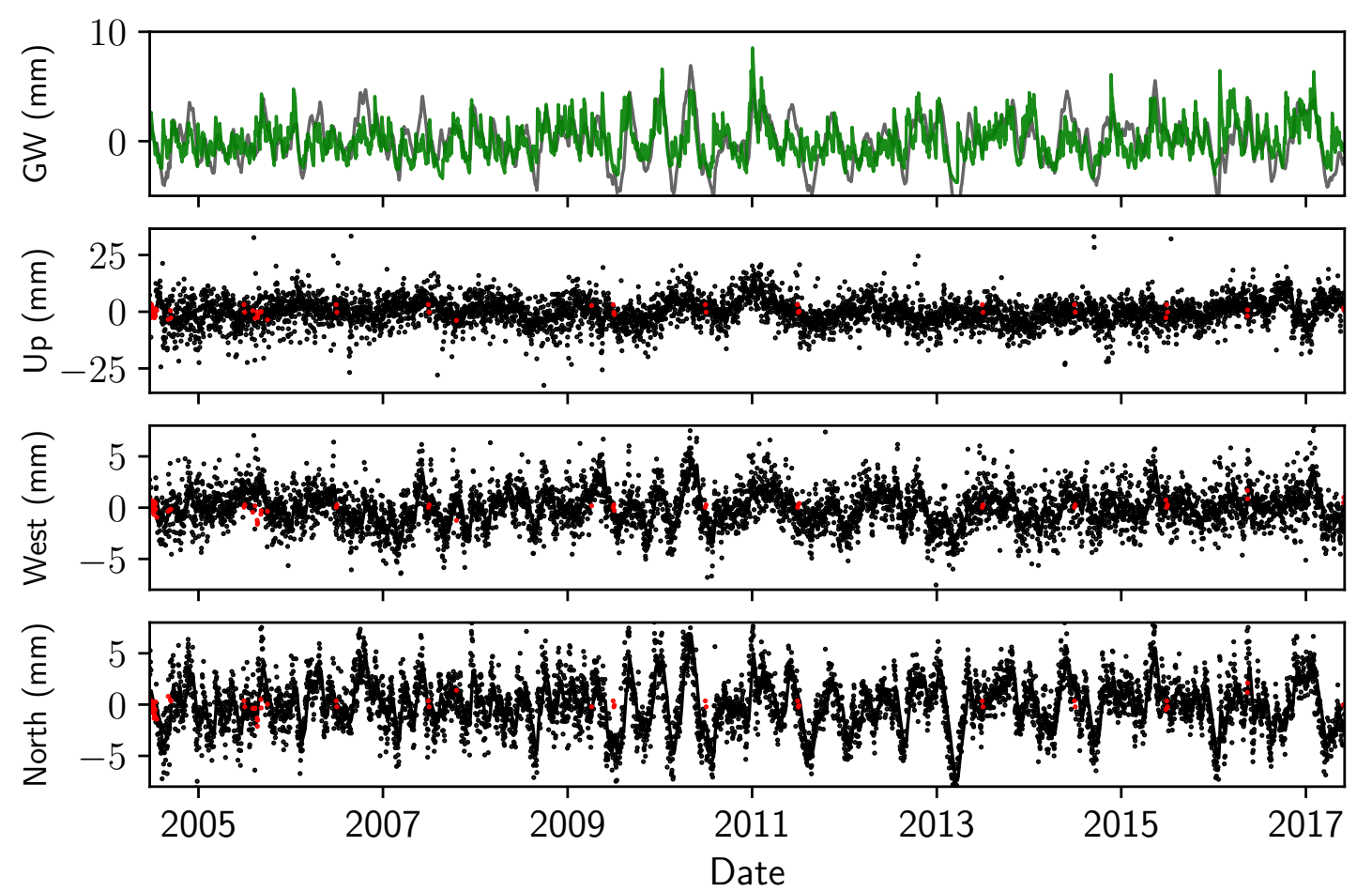

Figure 3.14: Modelled unidimensional displacement due to groundwater level only (green), with north component of cGPS for comparison (grey). cGPS position at Haast (HAAS) (Measured in black, artificial in red). Note that the scale is different for the vertical component.

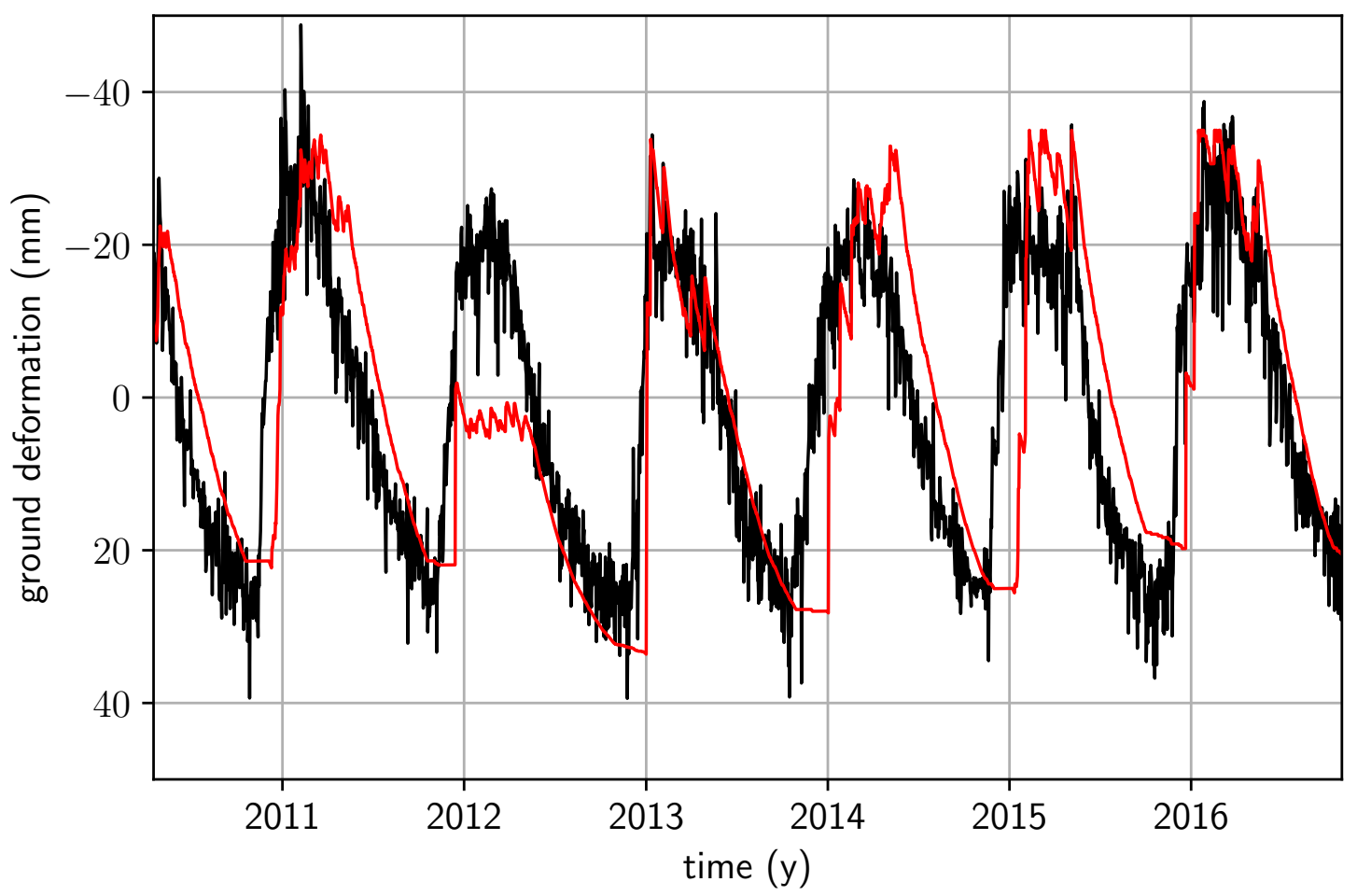

Figure 3.15: cGPS displacement at Annette Plateau (NETT) (black), along the single direction defined in Section 2.3.2, versus modelled deformation using REROD, with manual calibration (red). 
Regarding the seasonal motion observed at high-altitude stations (e.g. Annette Plateau (NETT) and Pilkington Glacier (PILK)), we compute the direction of displacement, following the method described in Section 2.3.2. These are given in blue on the maps (Figure 1.3, Appendix B). We observe that the horizontal orientation of displacement in winter for stations with a significant seasonal cycle is coherent with the geographical zones of snow accumulation around the stations. Annette Plateau (NETT) is situated metres away from Annette Plateau Glacier (see Figure B.25), where accumulation occurs in winter. Pilkington Glacier (PILK) is located southwest of Pilkington glacier (see Figure 3.16). Gunn Ridge (GUNR) and Mt Price (MTPR) show displacement directed in the direction of local topographic highs, where we also expect an accumulation of snow (see Appendix B). Annette Plateau (NETT) and Pilkington Glacier (PILK) exhibit downward vertical direction during winter (see Figure 2.6), seasonal vertical displacements at Gunn Ridge (GUNR) and Mt Price (MTPR) are not significant. At a regional scale, the horizontal direction of displacement in early winter for these four stations is also coherent with the location of topographic highs (surroundings mountains), and with the orientation of local sets of fractures, if any. However, we note that we did not have the chance to visit each of these stations and that we rely on the geologic maps to make this last assumption.

In other words, the seasonal motion could be influenced by local snow accumulation zones, and by regional contraction of the mountain masses during winter (and related expansion during summer). A process involving opening of fractures during summer and closure during winter could also be envisaged.

Concerning the short-term reversible motion observed at stations between the West Coast and east of the Main Divide, we find in Section 3.1.5 that movements are well-correlated with heavy rainfall. We observe that:

- stations affected by this type of motion are situated in various geologic and tectonic units (Figure 1.3). The motion at GPS stations in the central Southern Alps does not seem to originate from a particular geologic setting.

- stations with the highest amplitude of movement are all situated on ridges or summits, close to a slope (Appendix B).

- the direction of horizontal displacement is coherent with the orientation of the slope, and the vertical direction is most often oriented upwards during and shortly after rainstorm events. 


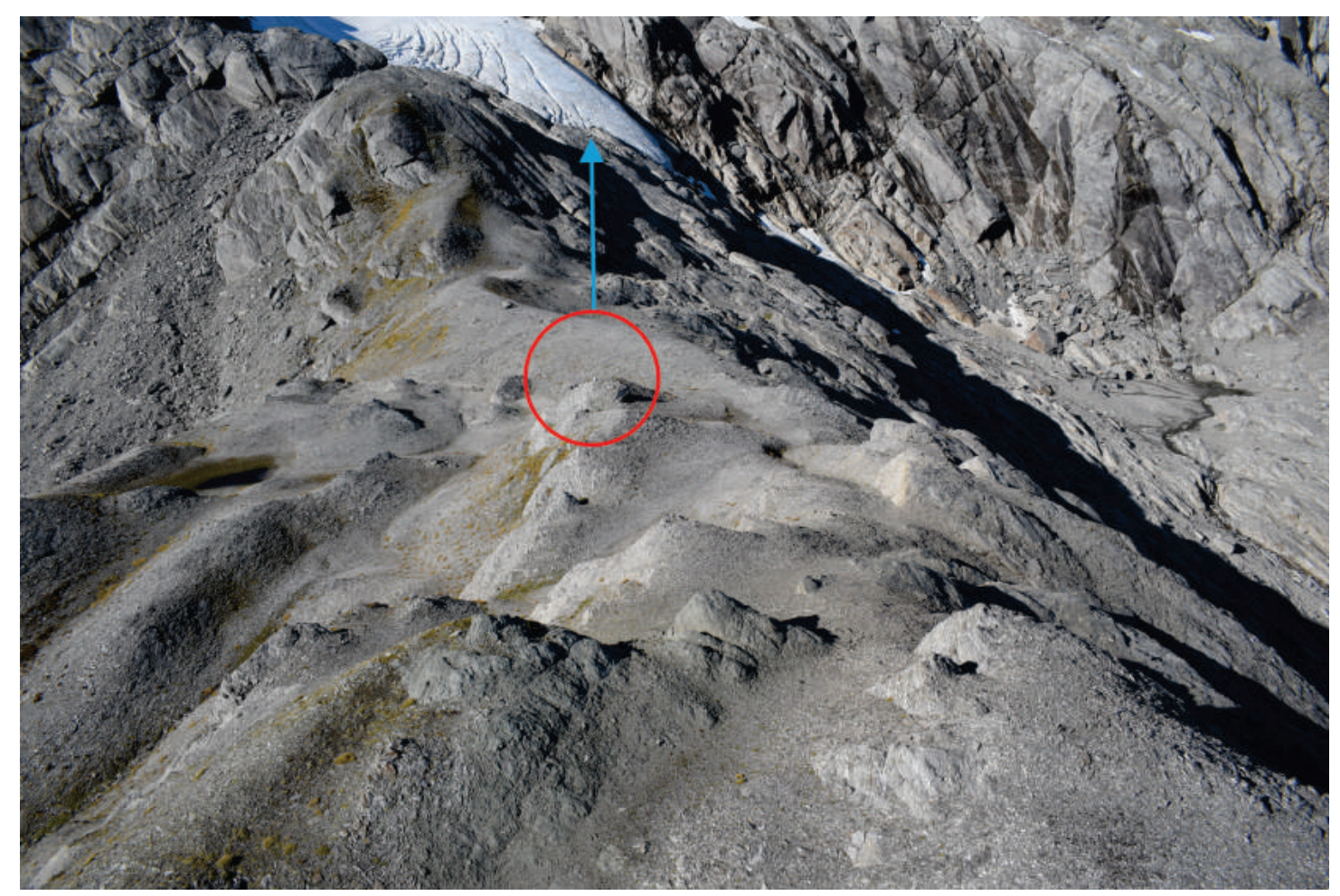

Figure 3.16: Photo of Pilkington Glacier (PILK) cGPS station. The antenna is in the red circle, next to the solar panels. Pilkington Glacier is in the background (blue arrow), at $\sim 400 \mathrm{~m}$ from Pilkington Glacier (PILK). View to the NE, picture taken on $30 \mathrm{March}$ 2017. 
- displacements at Annette Plateau (NETT), Pilkington Glacier (PILK), Gunn Ridge (GUNR) and Mt Price (MTPR) are not well constrained if we consider all rainstorm events. Conversely, if we consider only summer rainstorms (when there is no significant snow layer), the orientation of motion is coherent with the seasonal motion and is in the opposite direction (Figure 1.3).

\subsection{Microseismicity observations}

In this section, we first present our two microseismicity catalogues and compare them with a range of environmental variables, and some factors inherent to the method and data acquisition.

\subsubsection{Results of EQcorrscan detection}

Our first catalogue comprises 38909 detections, from 211 templates (see Figure 2.21), each with corresponding focal mechanism analysis (Boese et al., 2012). Our second catalogue resulted in 89474 detections, based on 902 templates, without focal mechanisms (see Figure C.1). Here, we give results of the analysis of the catalogue with focal mechanism. The results for the second catalogue are in Appendix C.

From the visual inspection of time series in Figure 3.17, it looks like the number of detections is related to the number of available stations. We, therefore, try to normalise the number of detections per day by the number of stations available on this day (see Figure 3.17). We note that there is not a significant change after normalisation. Normalisation is based on the assumption that there is a positive linear correlation between the number of available stations and number of resulting detections. This is not guaranteed and may be wrong (Chamberlain, 2017). Therefore, we choose to use the catalogue of events without normalisation for the rest of the analysis. The time series are dominated by swarms of events interspersed by periods of background seismicity for both catalogues (Figures 3.17 and Appendix C).

We also analyse the cumulative number of events, grouped by focal mechanism type (Figure 3.18). The seismicity in the region is dominated by strike-slip events, as is the catalogue of templates (Figure 2.23). If we normalise each different groups of events to their maximum value and remove a linear fit, we can better compare the timing of variations (Figure 3.19). The reverse and strike-slip events 


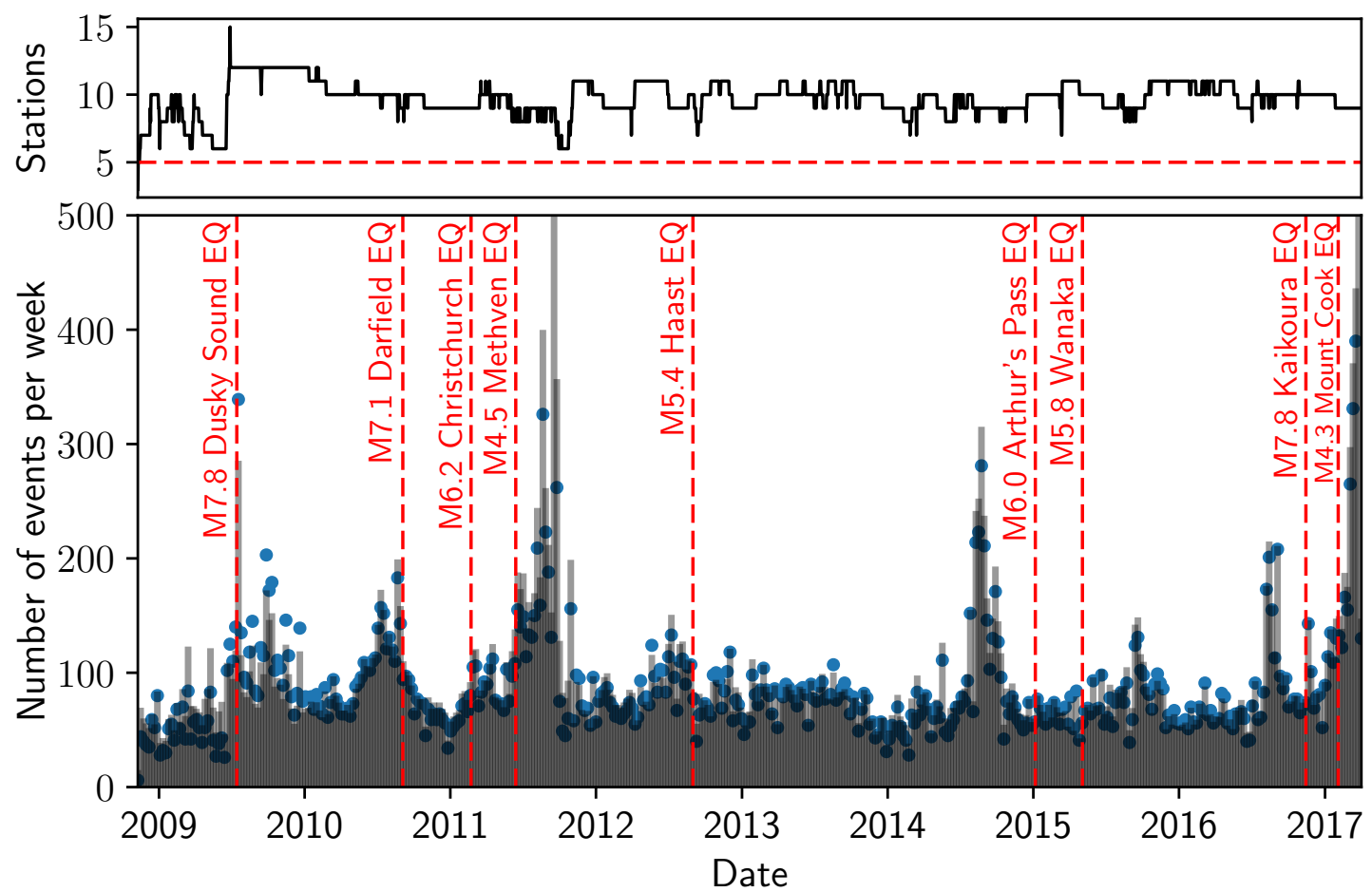

Figure 3.17: Top: Number of available stations for EQcorrscan. Five stations (red line) is the threshold under which a detection is eliminated. Bottom: raw number of detections per week (blue points), normalised number of detections per week (grey bars) and major earthquakes on the South Island.

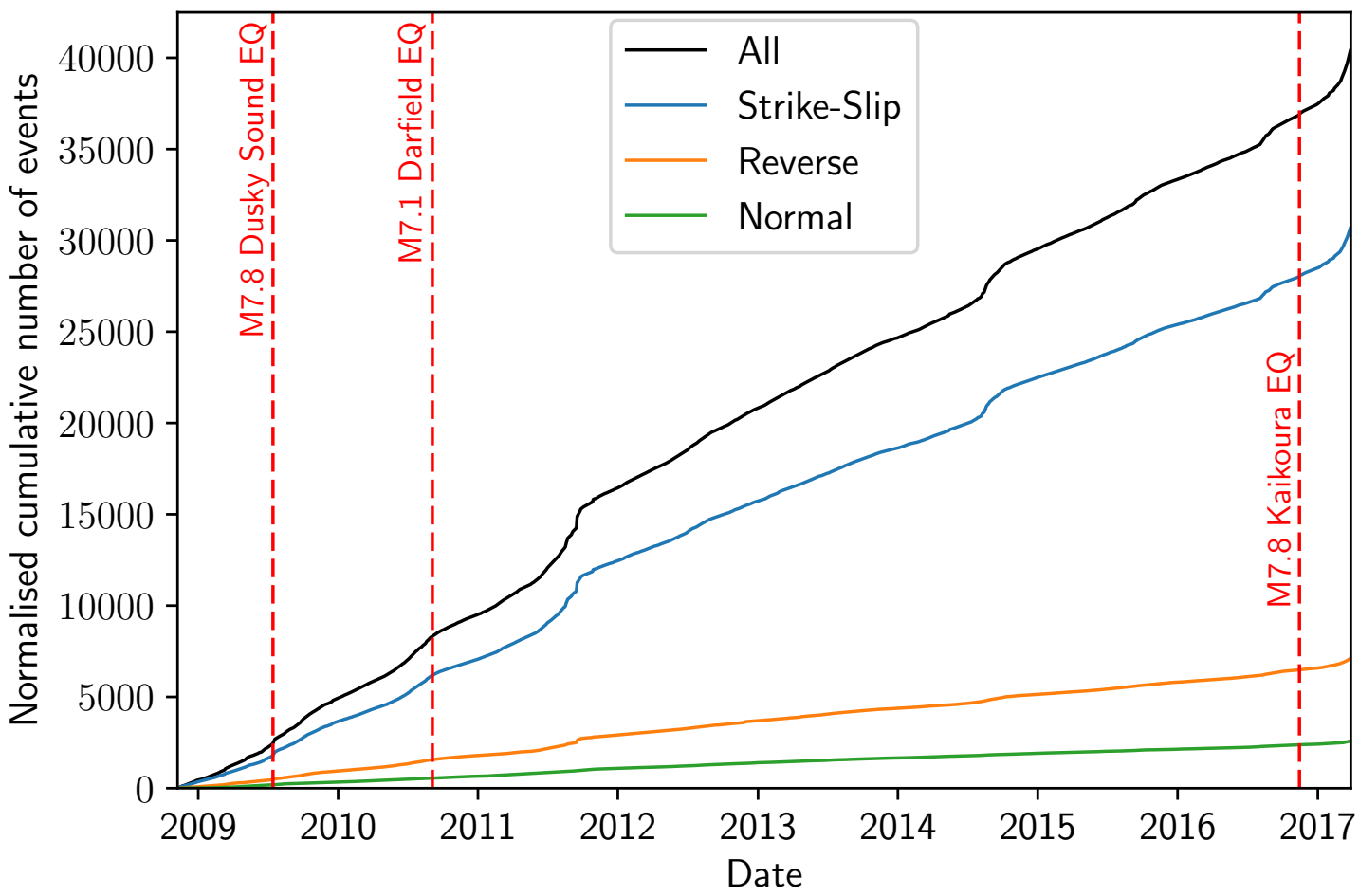

Figure 3.18: Normalised cumulative number of detections since 9 November 2008, grouped by focal mechanism. 


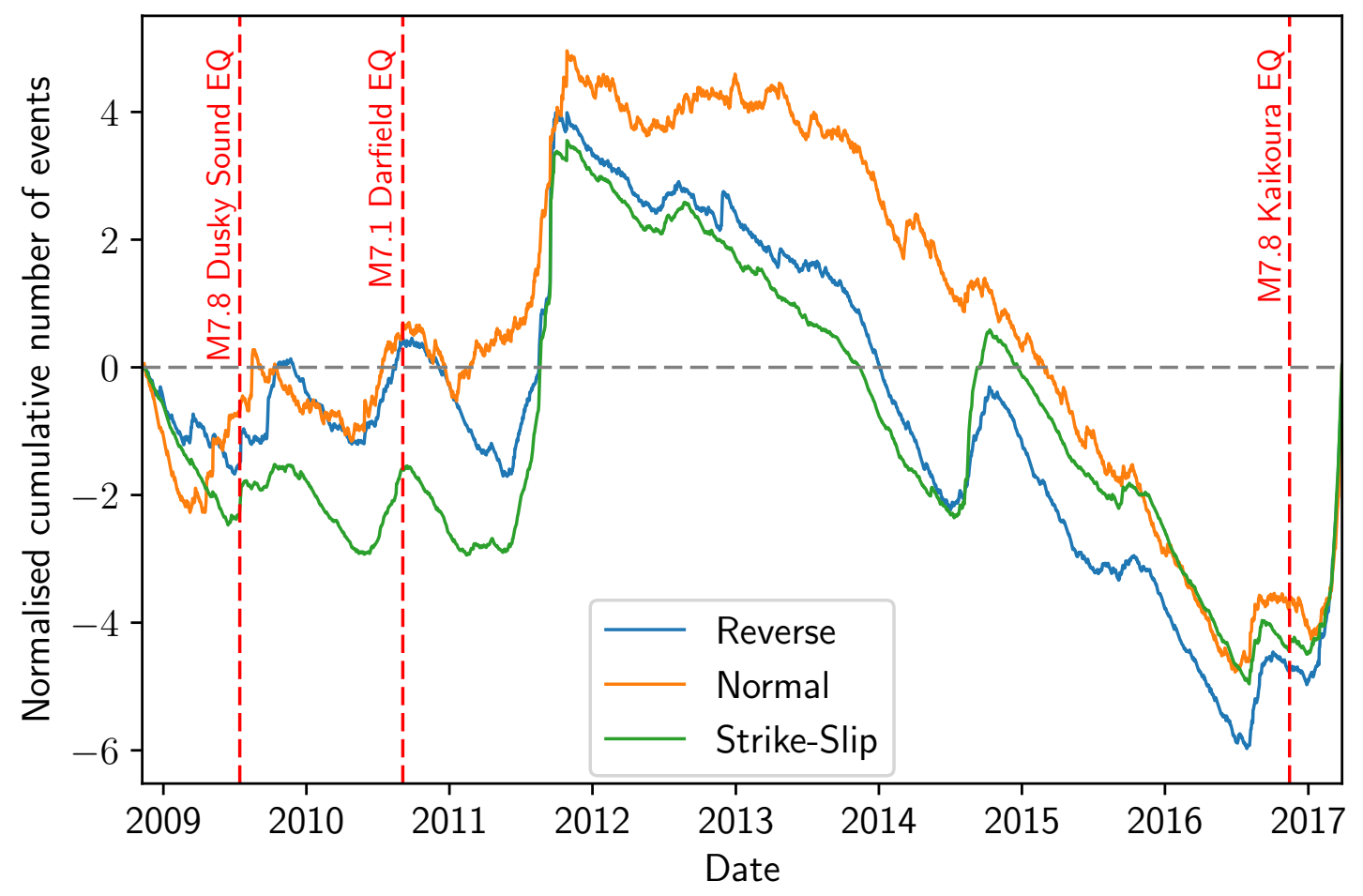

Figure 3.19: Relative differential cumulative number of detections since 9 November 2008, grouped by focal mechanism, for three categories (three sub-triangles in Figure 2.23).

often exhibit similar trends, while the normal detections sometimes have differences. For instance, in 2009, an increase in the rate of normal earthquakes can be observed before the M7.8 Dusky Sound earthquake, while reverse and strike-slip events only increase directly after the triggering event. In early 2014, the rate of normal earthquakes quickly increases, without changes in the two other types of mechanisms. In August 2014, the swarm of events was dominated by reverse and strike-slip earthquakes, with a much smaller increase in the rate of normal earthquakes. Most of the time, however, we do not observe big differences between types of focal mechanisms.

\subsubsection{Frequency analysis of seismicity}

We calculate the number of events per hour on the entire data set that we infill with zeros (for hours without events). This data set is then used for a frequency domain analysis (see Figure 3.20). While the small peaks detected interestingly correspond to periodicities of tidal influences for the most part $(0.5 \mathrm{~d}, 1 \mathrm{~d}, 14 \mathrm{~d}$, $28 \mathrm{~d}, 180 \mathrm{~d}$ and $366 \mathrm{~d}$, (Agnew, 2007)), we focus here on the two main periodicities of one day and one year (Figure 3.20). 


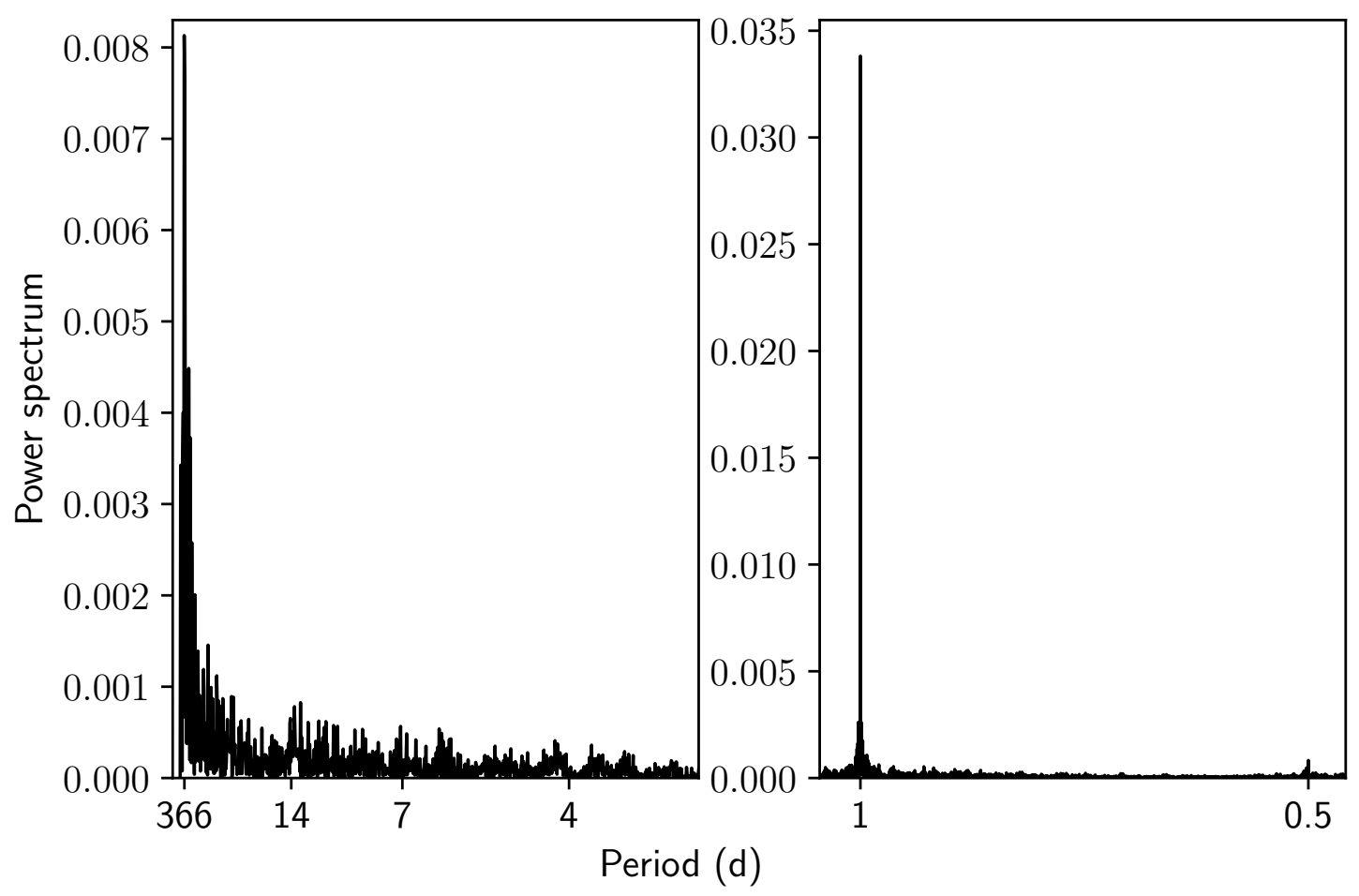

Figure 3.20: Periodogram of number of events per hour. Note that the scale is not the same for the low and high frequencies. The two major periodicities are centred around one year and one day. More subtle peaks are centred around $0.5 \mathrm{~d}, 6 \mathrm{~d}, 7 \mathrm{~d}$ and $14 \mathrm{~d}$ amongst others, on this figure.

\subsubsection{Diurnal variations in detection rate}

To investigate daily cyclicity, we group event occurrence by minute. There are many more detections during the day than during the night (Figure 3.21). Furthermore, the detection threshold does not fluctuate through the day. Therefore, it does not cause the fluctuating number of detections. Despite a possible difference in noise level between the day and the night (e.g. due to anthropogenic activities or local weather conditions), we showed here that EQcorrscan's match-filtering method is robust enough to overcome the fluctuations in noise level if any.

Another explanation for the daily variation of detection occurrence is the station limitations themselves. During station maintenance in March 2017, we discovered power supply issues at some stations. Instruments in the SAMBA array are powered by solar panels charging a $12 \mathrm{~V}$ battery. Weak batteries disrupt continuous data recordings. When the battery is too low, even though the seismometer detects motion, the signal may not be transferred to the memory card, causing data loss. As the only source of power is the Sun, we expect there to be more power outages during the night, and therefore, fewer detections. The same is expected to be the case for winter months, in comparison with summer. 


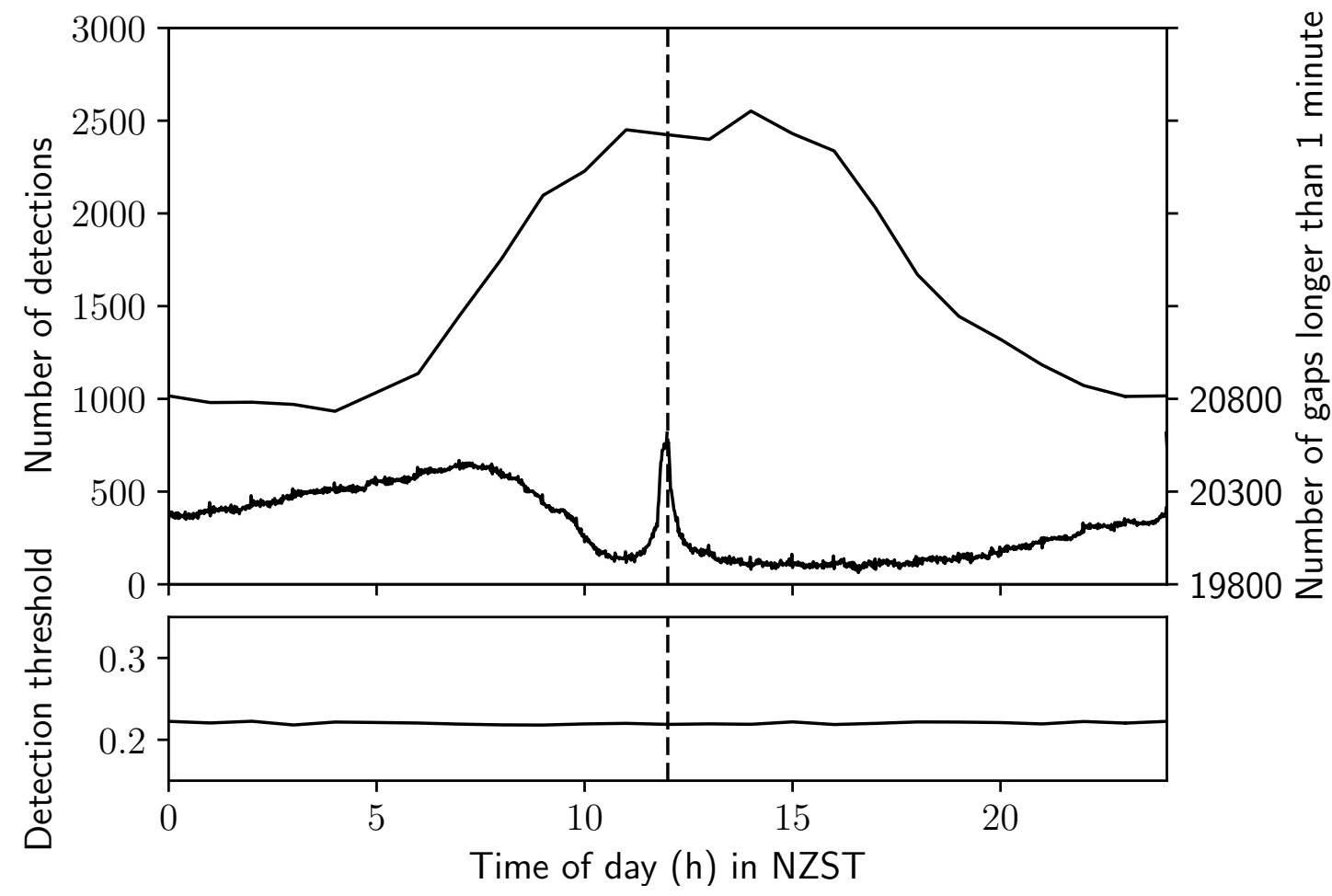

Figure 3.21: Top: Median of the number of detections per minute of the day and total number of gaps longer than a minute grouped per minute of the day. Bottom: Related median of threshold of detection per minute. Vertical dashed line is at $12 \mathrm{pm}$, the usual beginning (end) of the continuous seismic streams.

To check this hypothesis, we run two different tests. First, we analyse gaps in the continuous stream for certain stations. We find a total of 209689 gaps that last longer than one minute.

The second test we run is to check the health file (which contains logs information on the disk usage or battery voltage every 30 minutes). If the voltage is too low to record waveforms at night data could be less often stored on the memory card during the night-time. We found that the voltage is lower during the night than during the day, at each station. There are fewer extrema during the night, possibly because the batteries were too weak to save the health file itself. An anomaly around the end/start of each continuous stream (Figure 3.22), with some missing bits of data around 00:00 UTC could exhibit an issue during data preprocessing. We also see that, as expected, the number of gaps gradually increases during the night and starts to decrease around 8 am (NZST), when the sun rises, and the battery starts to charge again. We determine that the number of gaps is partially dependent on the voltage of the battery and that it has an influence on the number of detections. However, we see that the number of detections starts to rise from around $6 \mathrm{am}$, while the number of gaps is still increasing. Therefore, we conclude 


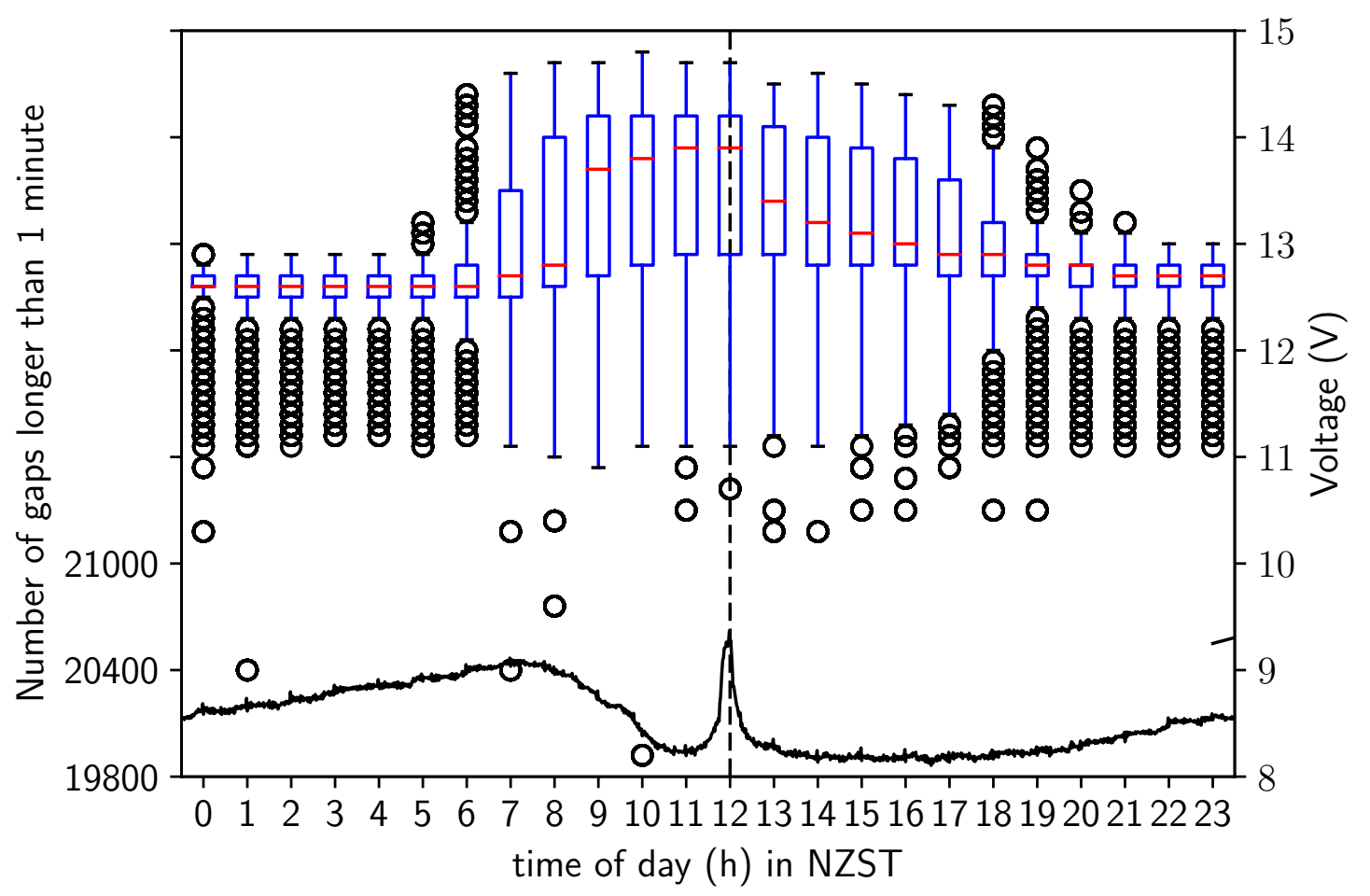

Figure 3.22: Total number of gaps per minute versus voltage for all stations, per hour.

that gaps in the continuous streams are not the only reason for a higher rate of seismicity during the day.

\subsubsection{Annual variations in seismicity}

Knowing that we have more gaps when there is less sun, we expect there to be more detections during summer than during winter, because there are fewer daylight hours, the sun's elevation angle is lower, and snow cover can prevent the solar panels from charging the battery. However, the data in Figure 3.23 demonstrates that there are more detections during winter. Furthermore, the median threshold cross-correlation coefficient per month is relatively constant. The level of noise could potentially influence the threshold, and we run another check to confirm that differences in levels of noise do not result in differences in the number of detections.

We take the highest median of threshold per month and discard all detections with a detection value lower than this threshold. The result still shows more events in winter despite an artificially higher threshold.

Finally, we verify that template noise does not influence detection by checking the time series of detections and detections values for all templates individually. As 

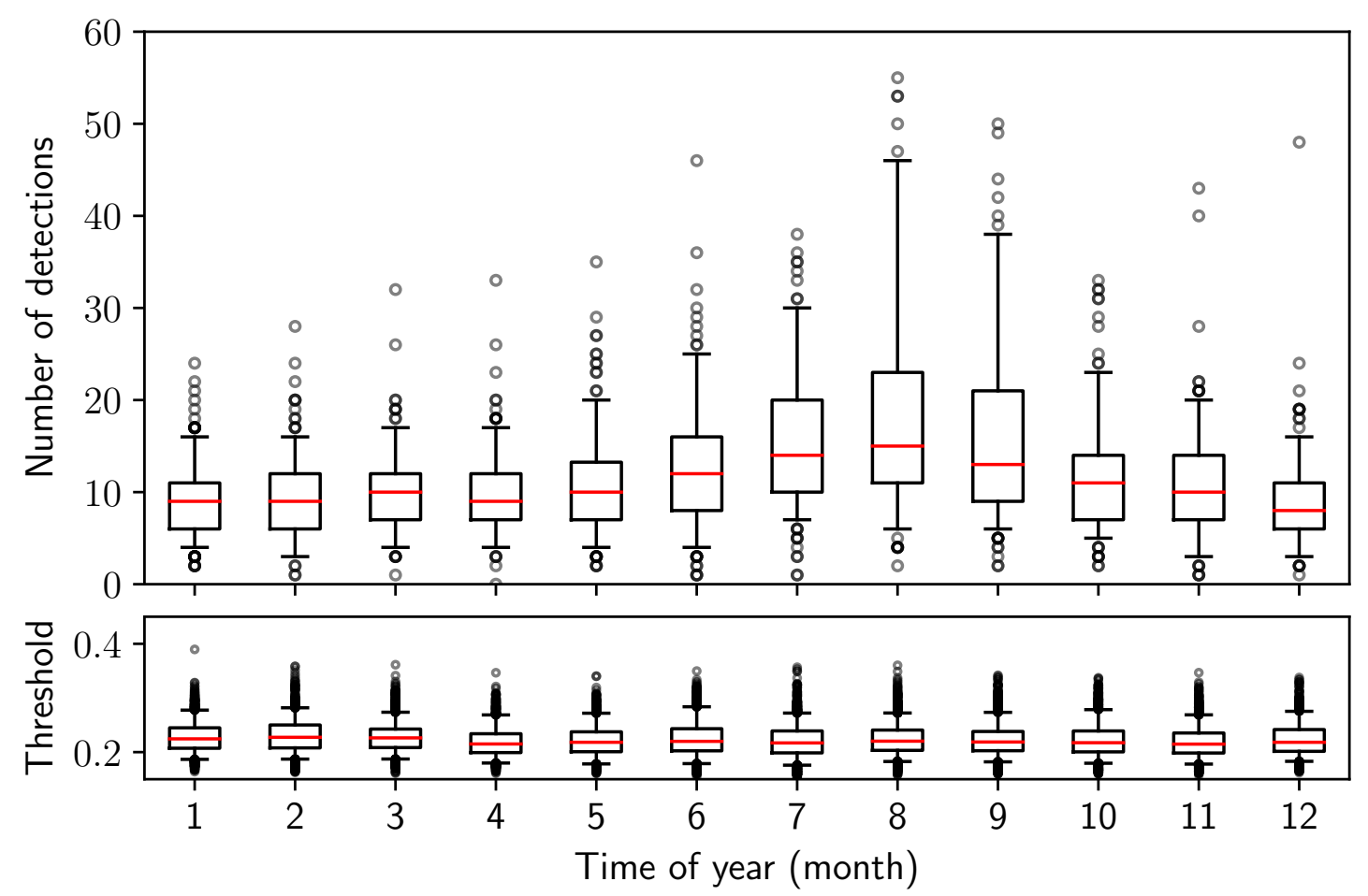

Figure 3.23: Number of detections per day grouped by month (top). Related threshold of detection per day, grouped by month (bottom).

noise sources change with the seasons, and because we incorporate some noise in our template events, the templates would have a greater correlation coefficient with the continuous stream when the noise in the latter is closer to the template's noise. There were more earthquakes in winter during the 14 months of the catalogue (see Figure 2.22). Therefore, this could introduce bias in our detection catalogue. However, a new catalogue, with only those detections resulting from templates that occurred during summer, still exhibits more detections in winter.

\subsubsection{Comparisons of microseismicity seismicity rates with hydrological observations}

As we are unable to fully explain the yearly cyclicity with noise and with a problem related to the data acquisition, we evaluate a range of physical and meteorological factors that could influence the seismicity rates. A comparison of median number of earthquakes and median snow depth at Rose Ridge SIN station per day of the year (Figure 3.24) exhibits that the seismicity rate increases during the period of snow accumulation, between June and September. However, the time series (Figure 3.25) reveals that some years $(2012,2013)$ had significant snow, but only a weak response in seismicity rate. A comparison of time series of microseismicity 


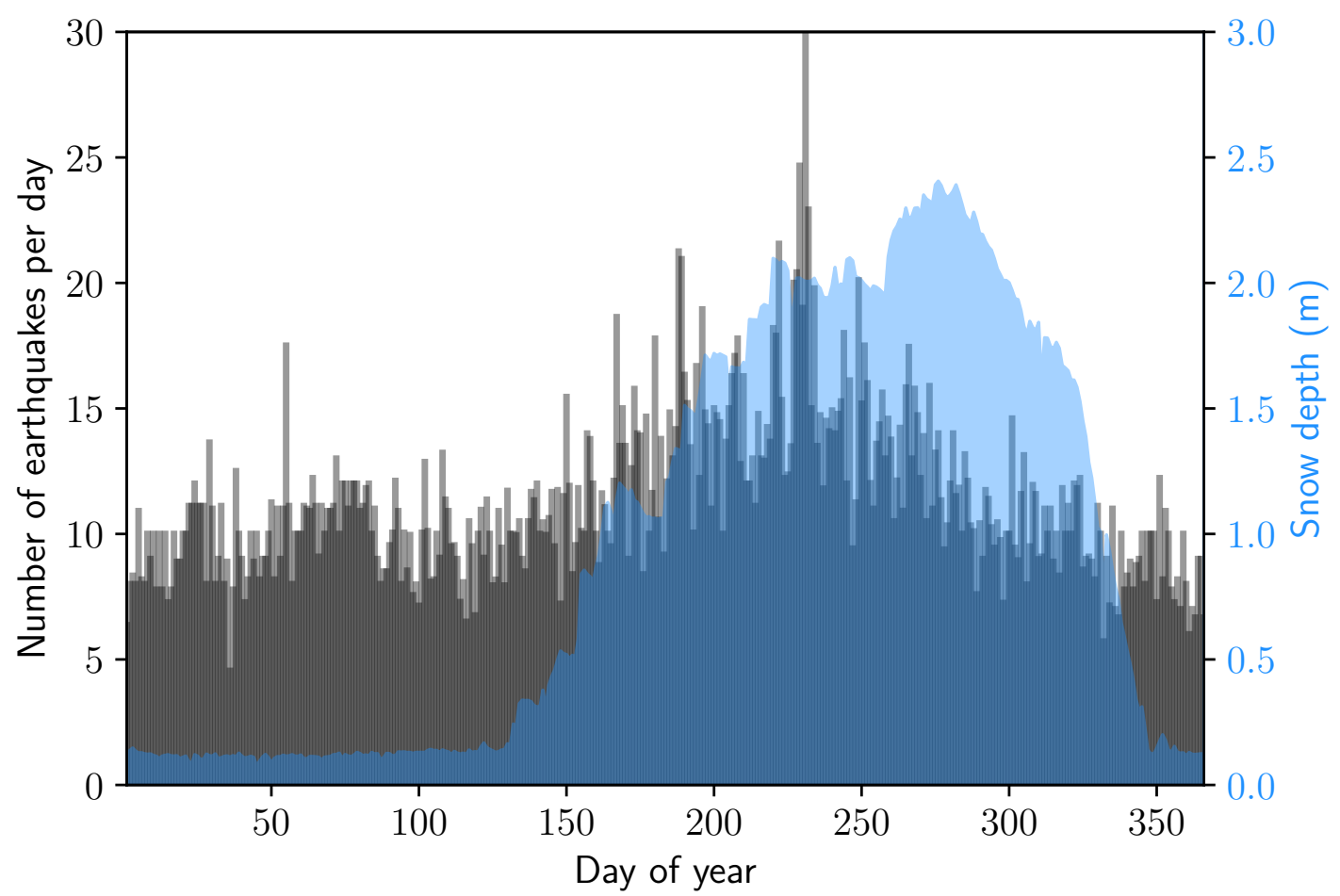

Figure 3.24: Ordinal year with median per day of earthquakes (grey) and snow in Rose Ridge (blue).

rates and water level at Lake Tekapo (Figure 3.26) indicates that the occurrence of swarms and microseismicity rates are higher during periods of decrease of the volume (and hence, load) of the lake. While the amplitude of lake level change is weakly negatively correlated (with a cross-correlation coefficient of -0.11 (0)) with the number of detected events in a day (see Figure 3.27), the time series reveals exceptions. For example, a large lake level decrease in 2013 did not result in a significant earthquake swarm.

One of the largest number of detections in a single swarm is observed in FebruaryMarch 2017. While we have no record of Lakes Pukaki and Tekapo water level for this period, we observe that this swarm occurred at a time of year with high lake levels (see Figure A.13) and reduced snow depth (see Figure 2.14) on average. 


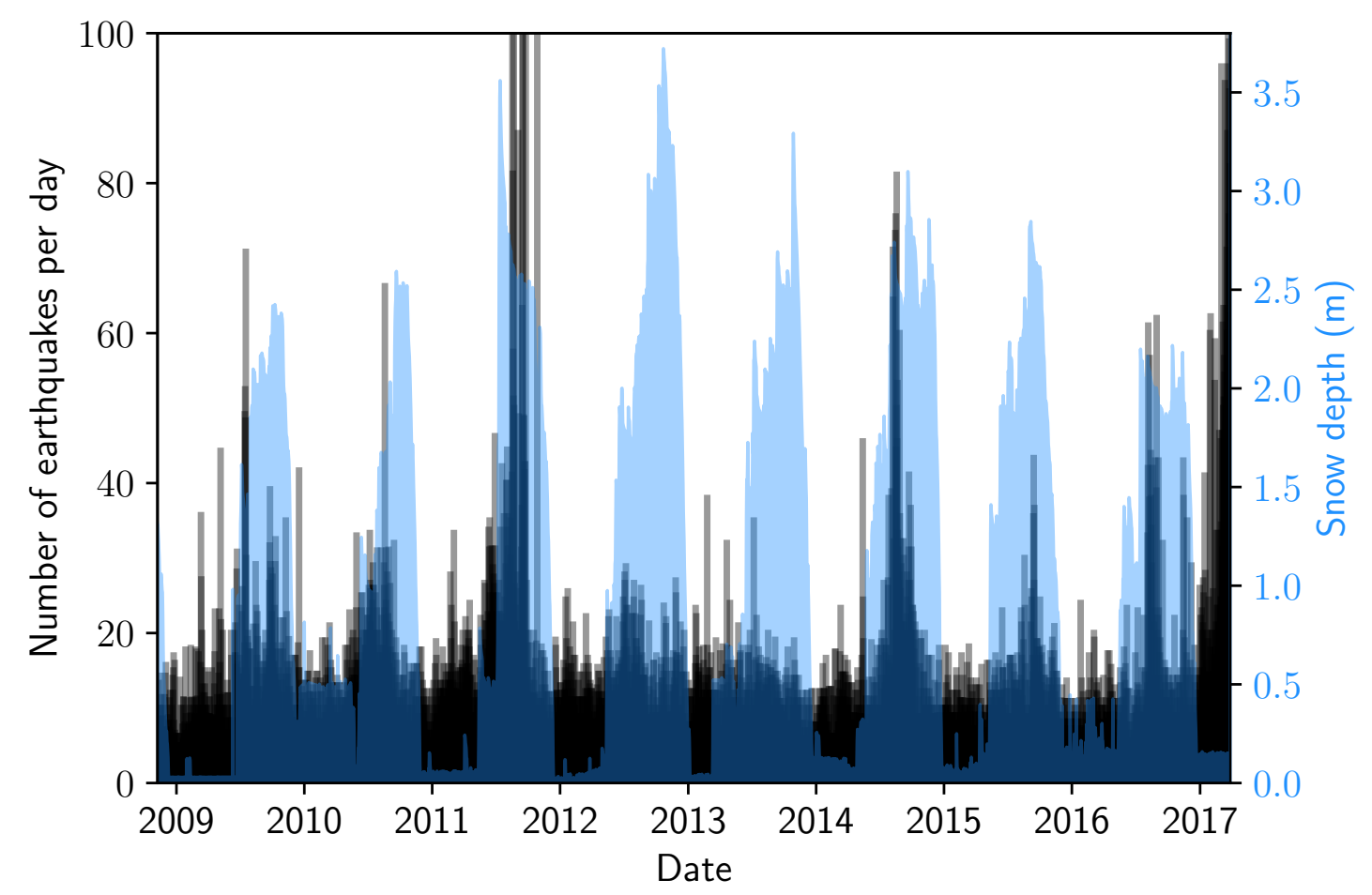

Figure 3.25: Time series of earthquakes (grey) and snow at Rose Ridge (blue).

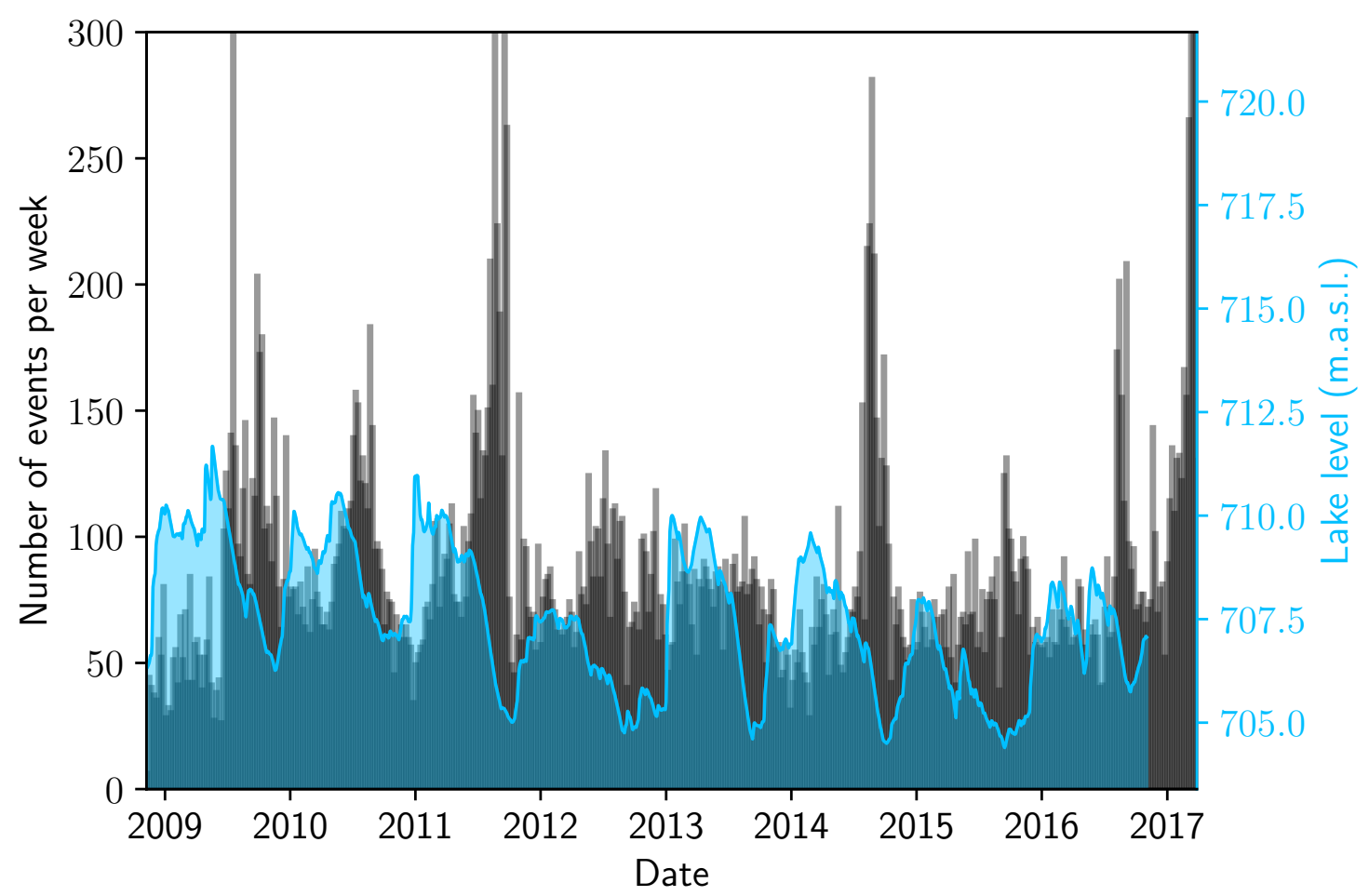

Figure 3.26: Time series of earthquakes (grey) versus the level of Lake Tekapo (blue). 


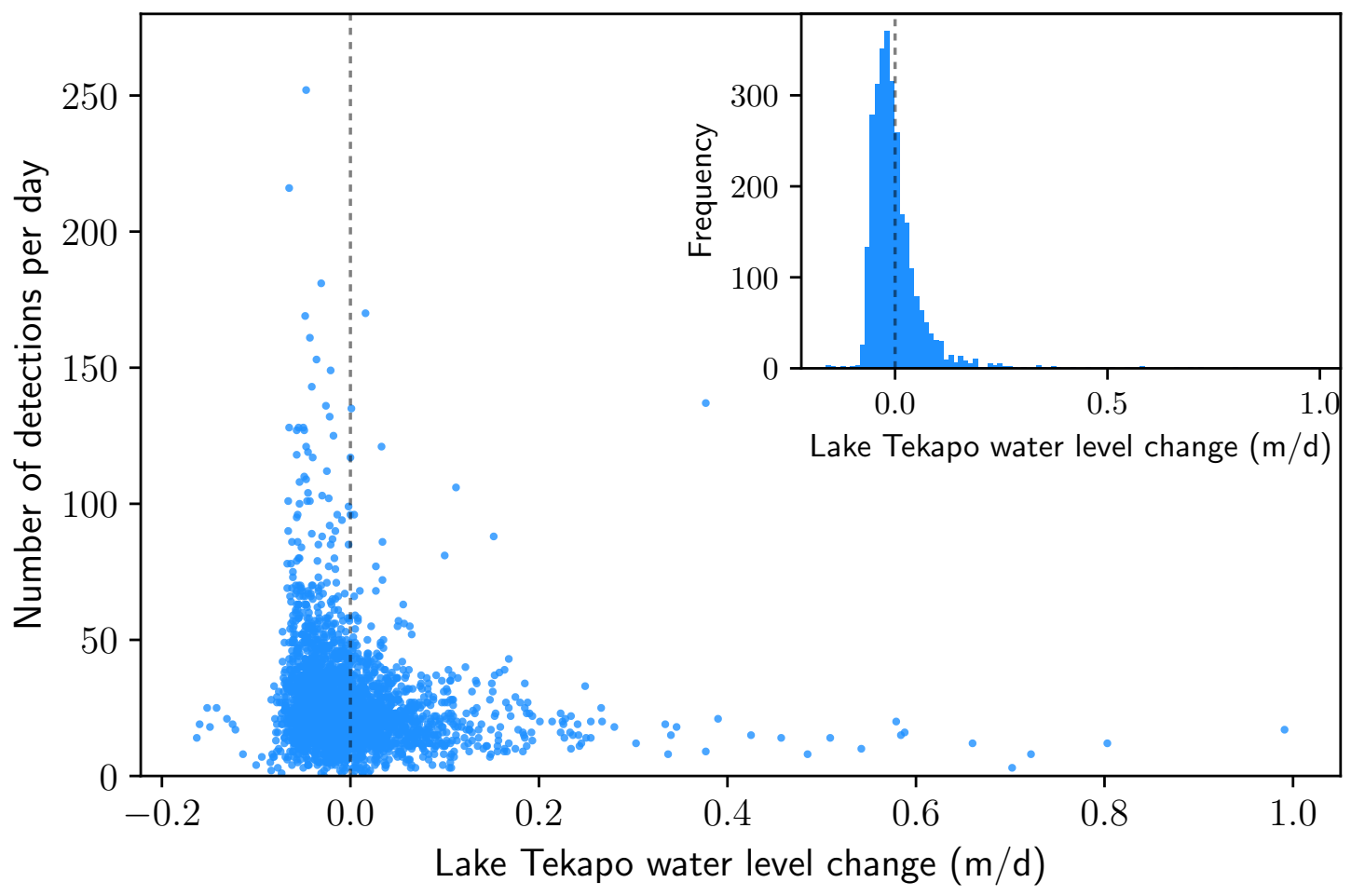

Figure 3.27: Cloud comparison plot of number of events in a day versus the change in Lake Tekapo water level on this day. The cross-correlation coefficient between the number of detection per day and the change of Lake level per day is $-0.11(0)$. Note that the distribution of Lake Tekapo water level change (inset) is positively skewed, influencing the results (the probability of observing days with large number of detections is higher where the number of observations is large). In this histogram, each bin is $1 \%$ of the water level change range.

\subsection{Summary of key observations}

In Section 3.1, we compared and cross-correlated cGPS time series with various environmental variables. We found that the closest fit is obtained with mathematical models of rainfall-infiltration and rainfall-snow-infiltration for high-elevated stations. Rainfall is shown to be well correlated with the transient ground deformation on short-timescales while snow depth is demonstrated to be well correlated with the seasonal ground deformation in sufficient altitude. Other parameters (near-surface air temperature, lake levels, atmospheric pressure and theoretical solid Earth tides) are less well correlated and are not considered as plausible factors to explain the variations observed in cGPS data, despite occasional similarities. In particular, some time series contain a seasonal component that is also found at a few cGPS stations. In the case of seasonal variability, observations are used in addition to cross-correlation coefficients to determine if the concerned 
environmental variables (near-surface air temperature, lake levels) could cause the cGPS fluctuations.

In Section 3.2, key results of our analysis of the seismicity rate in the central Southern Alps were shown. A catalogue of 38909 events, built by match-filtering of known earthquakes, provides a 8.5 year long time series of seismicity in the region, for 211 templates with known focal mechanisms (cf. Appendix C). This catalogue is used to assess whether the observed seasonality is explained by one type of earthquake focal mechanism more than another. No consistent differing behaviours are detected. Fourier analysis of the catalogues reveals that two frequencies dominate the spectrum, with periodicities of one day and one year. The diurnal cyclicity is shown to be simultaneous with the changes of number of gaps in the seismic data stream and with the variations in battery voltage. Other factors that could lead to a diurnal periodicity (e.g. tidal influences) are suspected (see Figure C.2) but cannot be demonstrated. The annual cyclicity, however, cannot be easily explained by a problem with data acquisition and is therefore compared with various environmental data. The increase in seismicity during winter is shown to be, most of the time, synchronous with the period of snow accumulation (increasing snow depth) and unloading of lakes Pukaki and Tekapo, in early to mid-winter. The swarm at the beginning of 2017 seems to be an exception to this rule, but we have no data for comparison with environmental factors for this recent time period. 


\section{Chapter 4}

\section{Discussion}

Here, we consider the ramifications of the temporal changes documented in Chapter 3 and consider:

- What environmental processes and observational factors may account for the observed seasonality of cGPS positions; and

- Whether the observed changes in microseismicity rate can be related to hydrogeological processes.

\subsection{Processes controlling the transient and sea- sonal cGPS position cycles}

Several environmental variables have the potential to induce the observed repetitive, reversible cGPS movement. These are tides, ice/snow wedging of bedrock fractures, thermoelasticity of the near-surface, seasonal surface loading and groundwaterlevel induced surface deformation. We also discuss the potential effects of instrumental noise.

\subsubsection{Instrumental noise}

In Section 2.3.3 we explored sources of instrumental noise that likely influence our cGPS positioning measurements, and may vary seasonally or cause apparent positioning offsets. These include monument noise, antenna thermal noise, snow and ice build-up on the antenna, multipath or atmospheric delays. Monument noise of the stations in the central Southern Alps was previously demonstrated 
to be small (Beavan, 2005) and cannot explain observed seasonal variations that exceed $1 \mathrm{~mm} / \mathrm{a}$.

However, the exact scale of effects from antenna thermal noise, or snow and ice buildup on the antenna, is unclear. In the comparison between cGPS position at Annette Plateau (NETT) and air temperature at Mueller Hut (located $\sim 3900 \mathrm{~m}$ apart and $\sim 400 \mathrm{~m}$ vertically, see Figure 3.5 ) the asymmetry in cGPS position cycle is not found in the temperature data, suggesting antenna thermal noise is not a major factor controlling GPS position seasonality. We do not have precise information regarding the timing or severity of snow and ice buildup at the Annette Plateau antenna. It appears that snow and ice build-up on the antenna may be significant at one of the stations. Vexation (VEXA) (Figure 1.3) shows an irregular $1 \mathrm{~m}$ vertical displacement in winter (see Appendix B), which we interpret to be caused by the station being buried under snow during winter. Unfortunately, we do not have a complete data set during winter, as the site is not recording continuously (see Table 2.4). The solar panel becomes covered with snow, interrupting the record until the solar panels are re-exposed to the sun, and the battery gains sufficient charge. Other sites at high altitude have fewer problems with snow coverage, due to the location of the sites and their exposure to strong wind, amongst other factors. At a height of $1054 \mathrm{~m}$, Haast (HAAS) experiences some snow cover during winter and some large temperature differences between summer and winter but does not demonstrate any significant seasonal shifts in position (see Figure 3.2). Overall, we conclude that the effects of antenna thermal noise, or snow and ice buildup are likely to be sub-millimetric in scale at most stations (Dong et al., 2002), but may exhibit a proportionality with snow accumulation which itself is roughly proportional with elevation. Future studies to investigate this effect could be undertaken by the careful recording and removal of antenna ice during site visits and the data examination for simultaneous and systematic positioning shifts. Other possibilities are time lapse photography of the antenna for comparison with position data and mounting a temperature logger on the antenna to assess if the antenna is covered with snow (by comparison with the air temperature).

To investigate if atmospheric deviations are correctly eliminated from the geodetic data, we compare the atmospheric pressure record at climate stations to their nearest cGPS site (e.g. Figure 3.4). The correlation between the two is generally low, in particular for the two horizontal components of cGPS, where the motion often has the largest amplitude. The comparison between Annette Plateau (NETT) and Hoophorn Spur (HORN) cGPS sites, separated by $\sim 4000 \mathrm{~m}$ and situated in the same region as Mueller Hut and Mt Cook Village, exhibits strong differences 
between the amplitude of seasonal movement. This indicates that the cause of the seasonal movement is a regional or perhaps even a local effect, not only related to atmospheric deviations.

Multipath noise is likely to be an important source of apparent motion at certain GPS stations, for example, Quarry (QUAR), which is surrounded by vegetation, and Hoophorn Spur (HORN), which has higher mountain peaks around the site (see Figure 1.3). Part of the observed seasonality at high-altitude stations could be due to variation in multipath noise that is caused by a change in signal reflection when a snow layer covers the ground. However, it seems unlikely that multipath is the primary source of the detected signal. Indeed, the direction of movement is different after a period of heavy rain and after snow accumulation. Moreover, there is significant $(>3 \mathrm{~mm})$ amplitude of detected displacements, much larger than expected for multipath noise (King and Williams, 2009). Another worker (Nievinski, 2017) suggests that snow loading is more likely than multipath as an explanation for the observed seasonal displacement.

Overall, we discard instrumental noise as being a significant factor influencing cGPS position variations at stations in this study.

\subsubsection{Tides}

Despite a strong influence on ground position and ground motion on a global scale, the gravitational forces induced by the sun and the moon seem to occur in a spatial direction and scale incompatible with the spatial direction and scale of cGPS position variations in this study (Figure 3.3). We conclude that they have been effectively removed by preprocessing of data because none of the solid Earth tides, oceanic tides or atmospheric tides are well-correlated to the cGPS data, and cGPS position variations were not linearly correlated to the distance from the site to the coast.

\subsubsection{Ice and snow wedging bedrock fractures}

cGPS stations Annette Plateau (NETT), Pilkington Glacier (PILK), Gunn Ridge (GUNR) and Mt Price (MTPR) are at altitudes sufficient for ice formation in bedrock fractures to occur in early winter and persist until spring. We expect that the process of water freezing inside the rock fractures would move blocks of rock away from each other during winter (see Figure 4.1). This would move sites 


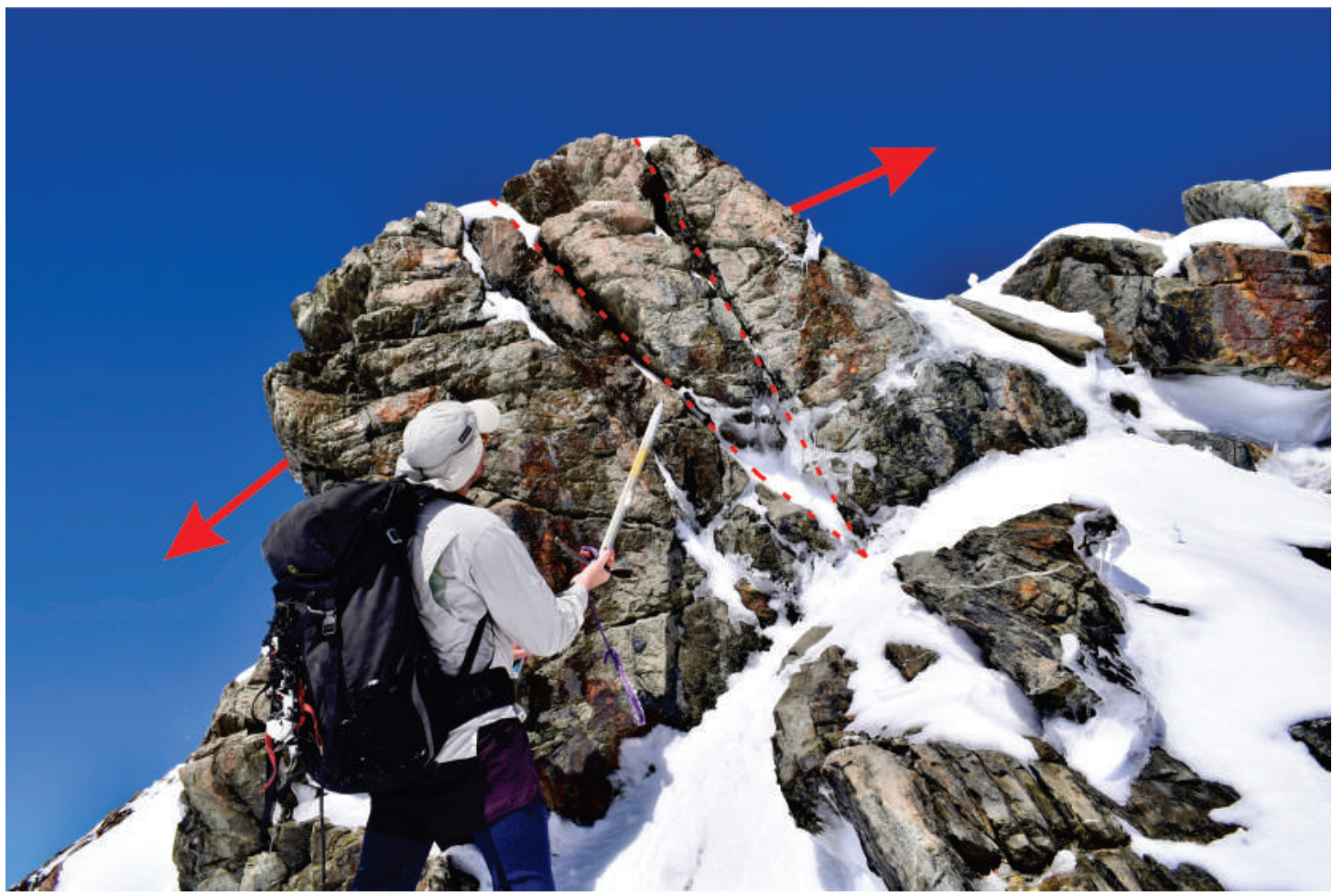

Figure 4.1: Set of fractures filled with ice, directly under Annette Plateau (NETT) cGPS station, with Simon Cox for scale (view to the S). The picture was taken on 30 October 2016. In this instance, freezing can be expected to dilate and lift the rock mass in the direction of the red arrows. Yet Annette Plateau (NETT) cGPS site falls during winter, in the direction of Annette Plateau Glacier (to the right of the photo), and rises during summer, in the opposite direction (to the left of the photo).

preferentially "away" from the topography in early winter, but with a dependency to local orientation of fractures or bedrock weaknesses such as bedding or foliation. However, the movement observed in the cGPS records for the concerned sites is commonly going towards the mountains and downwards in early winter (see Appendix B). This is at odds with the notion of local expansion and dilatancy of topography during the time of freezing.

\subsubsection{Thermoelasticity of the near-surface}

Thermoelasticity of the surface rocks results in changes of volume of the rocks and a tiny deformation of the surface $\left(\sim 10^{-5}{ }^{\circ} \mathrm{C}^{-1}\right)$ (Robertson, 1988). The cGPS and the daily mean temperature of the air have high cross-correlation coefficients at some sites (see Appendix B). The asymmetry in cGPS seasonality cannot, however, be seen in the temperature data set (Figure 3.5) and sites with little seasonality (B.7) sometimes had large differences in temperature through the year (e.g. Haast (HAAS)). These observations concur with previous work on this subject (Yan 
et al., 2009), allowing us to discard the hypothesis that thermoelasticity of the surface rocks might cause the observed fluctuations in GPS position.

\subsubsection{Seasonal surface loading}

Rain, snow and lake water measurement in the central Southern Alps have potential to generate surface loads that could bend the ground. A large input of water to the lakes, for example, produces a localised crustal load that can induce an elastic vertical subsidence and a horizontal movement in the direction of the lakes. The opposite motion results in opposite directions of displacement (Chanard et al., 2014).

Water levels at Lake Pukaki and Lake Tekapo are compared with ground displacement at the closest stations, respectively Mt Cox (MTCX) and Burnett Rock (BNET) for Lake Pukaki, Mt John (MTJO) for Lake Tekapo (e.g. Figure 3.12). While the volume of water added to Lake Pukaki in 2008 ( $10^{12} \mathrm{~L}$, see Section 3.1.7) significantly changes the crustal load of the lake, there was little equivalent positional response from the nearby GPS stations at Mt Cox (MTCX) and Burnett Rock (BNET). It appears the surface load changes from the lake level fluctuations of $10^{12} \mathrm{~L}$ did not bend the surface to cause measurable strain. Fluctuations in the water level of Lake Tekapo and volume of exchanged water are smaller at Lake Tekapo, and no significant concurrent displacement is observed at Mt John (MTJO) cGPS station.

Surface loading of the ground by rain could produce both horizontal and vertical ground movements (Chanard et al., 2014). Rainfall in the central Southern Alps is distributed throughout the year, and there is no extreme rain season or significant seasonal variations (see Section 1.3). This setting is quite different from other places where surface loading effects on GPS positioning has been studied, such as the Amazon or Ganges-Brahmaputra basins, where there is a rainy season or monsoon (Bevis, 2005, Steckler et al., 2010, Chanard et al., 2014). The total annual amount of rainfall in the central Southern Alps is, however, significant, with values exceeding $10 \mathrm{~m} / \mathrm{a}$ locally. There is also a sharp gradient of annual total rain amount between the western and eastern parts of the study area. The cGPS stations located close to the Main Divide and on the West Coast experience higher total annual rainfall (e.g. Figures 1.2 and 2.9) and exhibit a correlation with rainfall. The time lag for resulting motion is very short, sometimes less than a day. However, we observe that the ground movement after a rain storm is most often oriented away from the topography and upwards (Figures 3.8, 3.9 and B.8). 
We conclude that the surface loading due to rain either has too small an impact on the ground to be observed or another factor compensates and masks this effect at stations in the central Southern Alps.

The total annual precipitation can be locally considerable; snow dominates the precipitation during winter in the highest elevation regions (see chapter 1). A cGPS displacement, with movement of similar order of magnitude and seasonality to the one we observe at Annette Plateau (NETT) and Pilkington Glacier (PILK), was detected in a network of cGPS distributed along the western side of the mountain range in Japan (particularly in the northwestern Japanese Alps of Honshū Island) (Murakami and Miyazaki, 2001, Heki, 2001, 2003). There, the cGPS motion was attributed to the regional snow load. We examine if the same type of relationship could be verified in the central Southern Alps. Good correlation between the snow depth and the ground displacement at Annette Plateau (NETT), Pilkington Glacier (PILK), Gunn Ridge (GUNR) and Mt Price (MTPR) is observed (Figures 3.11 and 3.10). Snow accumulates progressively through winter and melts in a matter of weeks, in spring (see Section 3.1.6). The displacements in early winter at Annette Plateau (NETT), Pilkington Glacier (PILK), Gunn Ridge (GUNR) and Mt Price (MTPR) are oriented in the direction of snow accumulation zones, in the neighbourhood of the stations. These observations, together with the observed asymmetry in both the ground deformation and the snow accumulation highlights the likelihood of some causal relationship between snow and ground motion.

There are three main limitations of the surface load theory. Firstly the inter-annual variability in amplitude of ground displacement at Annette Plateau (NETT) is relatively low, conversely to the inter-annual variability in snow depth (Figure 3.11). If the snow load alone is inducing an elastic compression of the mountains in winter, a linear relationship could be reasonably expected between the amount of snow in winter and ground displacement. Secondly, the surface load of the main lakes in the study area does not seem to influence the surrounding GPS stations significantly. Fluctuations in water level were however demonstrated to induce significant $\left(10^{11} \mathrm{~L}\right.$ to $\left.10^{12} \mathrm{~L}\right)$ volume (and equivalent mass loading) changes. Finally, the surface load theory is unable to explain the direction of movement observed after rainstorms. A loading by the water from the rain would result in a downward movement, in the direction of the load (Chanard et al., 2014). However, we observe upward movements after rainstorms. 


\subsubsection{Groundwater level-induced surface deformation}

We estimate fluctuations in groundwater within the mountains using a simple rainfall-infiltration model, as in Figures 3.14, B.13 and 3.15. The models confirm that the shallow groundwater could plausibly be having some influence on cGPS measurements in the region. We interpret a mechanism whereby a change in the groundwater level will provoke a change in poroelastic pressure and the filling of fractures with water in the shallow bedrock. This, in turn, controls the opening and closure of the fractures and the expansion and contraction of the pores and therefore, a volumetric deformation of the rock mass.

As rainfall does not show any major seasonality on the West Coast or the central Southern Alps, stations in the area are greatly influenced by heavy rain storms. However, snow plays a role in mitigating the effect of these large, short duration rainfall events by storing water above the surface and forming a waterproof layer on the ground. For stations above an altitude of $\sim 1800 \mathrm{~m}$, where the snow tends to accumulate in winter, we observe that the modelled shallow groundwater reservoir depletion is coincident with clear changes in the cGPS record. Furthermore, the effect of recharge by heavy rain storms is only perceptible during summer months at these stations (Figure 3.11). Our explanation for this is a highly reduced infiltration rate during winter, either because precipitation comes as snow, or because the snow layer is thick enough to capture most of the rain before it reaches the ground surface. Conversely, the deformation during summer is similar to what we observe at lower altitude stations, with a response to heavy rainfall. During spring, snowmelt provides a large amount of water for infiltration (Sims et al., 2015), producing a large response in the cGPS position by saturating fracture voids and opening them under higher pore-fluid pressure (Section 2.3.3).

\subsubsection{Possible evolution in a warming climate}

In the case of unstable, steep bedrock, the repetitive reversible deformation of the rocks could lead to a phenomenon of rock-mass fatigue and a long-term evolution to irreversible deformation and rupture in rockslides (Weber et al., 2017). While the central Southern Alps experiences numerous rock avalanches (Allen et al., 2011), the effects of climate change in the region are expected to increase mean and extreme annual air temperature, and total annual precipitation (Caruso et al., 2017b). In particular, expected increased rainfall during winter, higher limit of permafrost and earlier melt (Caruso et al., 2017a) are of concern for the activity of 
rock avalanches in the central Southern Alps. Indeed, rapid elevation of the permafrost limit would expose a higher proportion of bedrock to zones of seasonal and sporadic frost. It would, therefore, enlarge the zone of reversible ground surface deformation, and the risk of rock avalanches caused by rock-mass fatigue processes (Preisig et al., 2016). In this case, the effect of groundwater fluctuations induced reversible rock-slope deformation increasing the rock-mass fatigue would amplify the well-known permafrost thawing induced rock-mass destabilisation effect (Cox and Allen, 2009, Huggel et al., 2012). 


\subsection{Hydrogeological controls on microseismicity rates: does surface water flux induce a seis- mic response?}

In Chapter 3 we evaluated the major caveats related to data acquisition. By analysing instrument detection limits, we were not able to completely explain observed changes in the rate of seismicity, so we further compared this geophysical data set with some physical, climatic and hydrologic parameters.

\subsubsection{Evidence for triggering by regional earthquakes}

Some of the swarms detected follow major distal earthquakes (see Figure 3.17). These include small earthquakes occurring shortly after, and therefore likely to be triggered by large distal earthquakes (Boese et al., 2014). However, some swarms seem to be unrelated to major earthquakes, and other major earthquakes did not trigger local sequences of small earthquakes in our study area. Analysis of the seismicity rates of our catalogues (Section 3.2) shows a relative increase in seismicity during winter compared to summer (see Figure 3.24). However, the seasonality shows no preference for one type of focal mechanism mover the others (Figure 3.19). The vast majority of the detected events (based on calculated depths for the templates (Boese et al., 2012)) are at a shallow depth $(<8 \mathrm{~km})$, where bedrock is highly fractured. Consequently, a likely candidate parameter for modulating seismicity rate is groundwater causing seasonal stress variations.

\subsubsection{Surface loading-unloading (elastic) seasonal stress vari- ations}

The unloading of large reservoirs like Lake Pukaki and Lake Tekapo can induce a change of elastic stress under the mountains (Figure 4.2). This assumption is based on the concept that loading/unloading of lakes can induce a deformation of the shallow crust (Section 4.1.5). This strain would result in a change of stress in the surroundings of the lakes. The loading of the snow on the mountains, which happens at the same time as the unloading of the lakes is also shown (and is partly balanced by the unloading of the shallow aquifer during its depletion). 


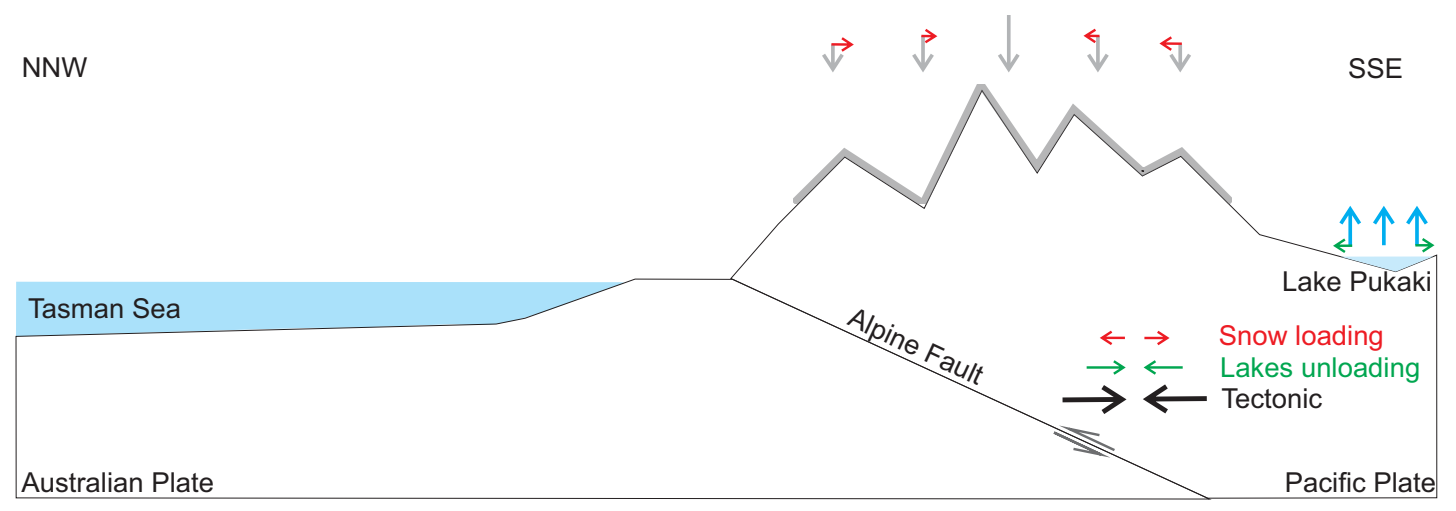

Figure 4.2: Schematic profile for the annual loading-unloading of the region during winter, inspired by the work of Bettinelli et al. (2008), Chanard et al. (2014), Kundu et al. (2017).

Seismicity rates in the study area can be related to the changes in the water level of the two largest lakes (Lake Pukaki and Lake Tekapo) and the changes in snow depth in the mountains. As the lake levels drop, there is usually a simultaneous increase in seismicity rate (see Figure 3.26). However, displacement at the cGPS stations close to these lakes is only weakly correlated with the volume of water added to or removed from the lake reservoirs each year (section 3.1.7). While the seismicity rate increases simultaneously with the period of snow accumulation (Figure 3.24), the analysis of time series reveals that some years with a large amount of snow had sometimes small increase in seismicity during winter (Figure 3.25). The period of snow accumulation is also a period of groundwater drawdown (Section 4.1.6), which means that the elastic loading of the snow layer is partly compensated by the unloading of groundwater in the shallow subsurface.

The seasonal timing of changes in microseismicity rates and surface loads make the theory of elastic seasonal stress variations as a cause for fluctuations in the microseismicity rates plausible. However, we mention several observations that are unexplained by this theory (e.g. relative low seismicity rates during winter with significant snow amount).

\subsubsection{Coupled drained and undrained (poroelastic) sea- sonal stress variations}

We constructed two models to simulate two theoretical surface pore-fluid pressure inputs at depth corresponding to the seismogenic zone, based on equation 2.15. They represent an asymmetric linear and asymmetric sinusoidal changes in groundwater level respectively. These mathematical models are not scaled, and large pres- 


\subsection{HYDROGEOLOGICAL CONTROLS ON MICROSEISMICITY RATES101}

sure changes with difference of an order of magnitude are applied to emphasise the lagged response of pore-fluid pressure at a depth of 3, 6 and $9 \mathrm{~km}$ respectively. We choose a high value of Skempton coefficient of 1 and a value of undrained Poisson's ratio of 0.45 . We have no measurements of these values in the field, and we set them willingly high to study the case of a rock mass saturated with a fluid (water) approaching being incompressible and isotropic. Based on the work from Talwani et al. (2007), we select values of hydraulic diffusivity varying from $0.1 \mathrm{~m}^{2} \mathrm{~s}^{-1}$ to $10 \mathrm{~m}^{2} \mathrm{~s}^{-1}$. These three parameters are chosen to represent bedrock dominated by the undrained effect on stress, as we observe in time series of seismicity rates that there is a time lag between the maximum groundwater level and generation of microseismicity at depth (Figure 3.26). The geometry and changing physical properties of cracks and fractures at various depth in the upper crust is not taken into account in this theoretical model.

The modelled pore-pressure response at depth to a surface input pressure in Figure 4.3 shows the immediate drained response, followed by a delayed undrained response, varying with depth. The effect fades with increasing depths. There is also a time lag between the maximum pore-pressure at various depth and the input pressure, in the case of a rock mass dominated by undrained effects. With such a high Skempton coefficient and undrained Poisson's ratio, the time lag is around $80 \mathrm{~d}$ to $90 \mathrm{~d}$ between the start of phase II and the maximum pore-pressure at the average depth of observed microseismicity.

Next, we build a model with an asymmetric sinusoidal change in input pressure (Figure 4.4). This model starts with a period of increasing input pressure at the ground surface to a maximum value, kept constant through phase II. Then, the input pressure decreases slowly to return to its initial value in phase III. The model aims to simulate the effects of poroelastic pressure changes due to groundwater level changes in spring and summer when snow and glacier ice melt, and in winter when there is a depletion of the groundwater reservoir, as seen with time series of Lake Pukaki and Lake Tekapo lake levels (e.g. Figure 2.17) and GPS measurements in the mountains.

Here again, there is a time lag between the start of the phase of maximum input pressure and the maximum pore-fluid pressure at depth, around $110 \mathrm{~d}$ to $120 \mathrm{~d}$. It occurs when the input pressure is already decreasing. In the central Southern Alps, this corresponds to the period of the year when the snow starts to accumulate, reducing the available water for infiltration in the ground or filling of the lakes (see Figure 3.24). We note, however, that the chosen values of hydraulic diffusivity, Skempton coefficient and undrained Poisson's ratio favour this behaviour. By 


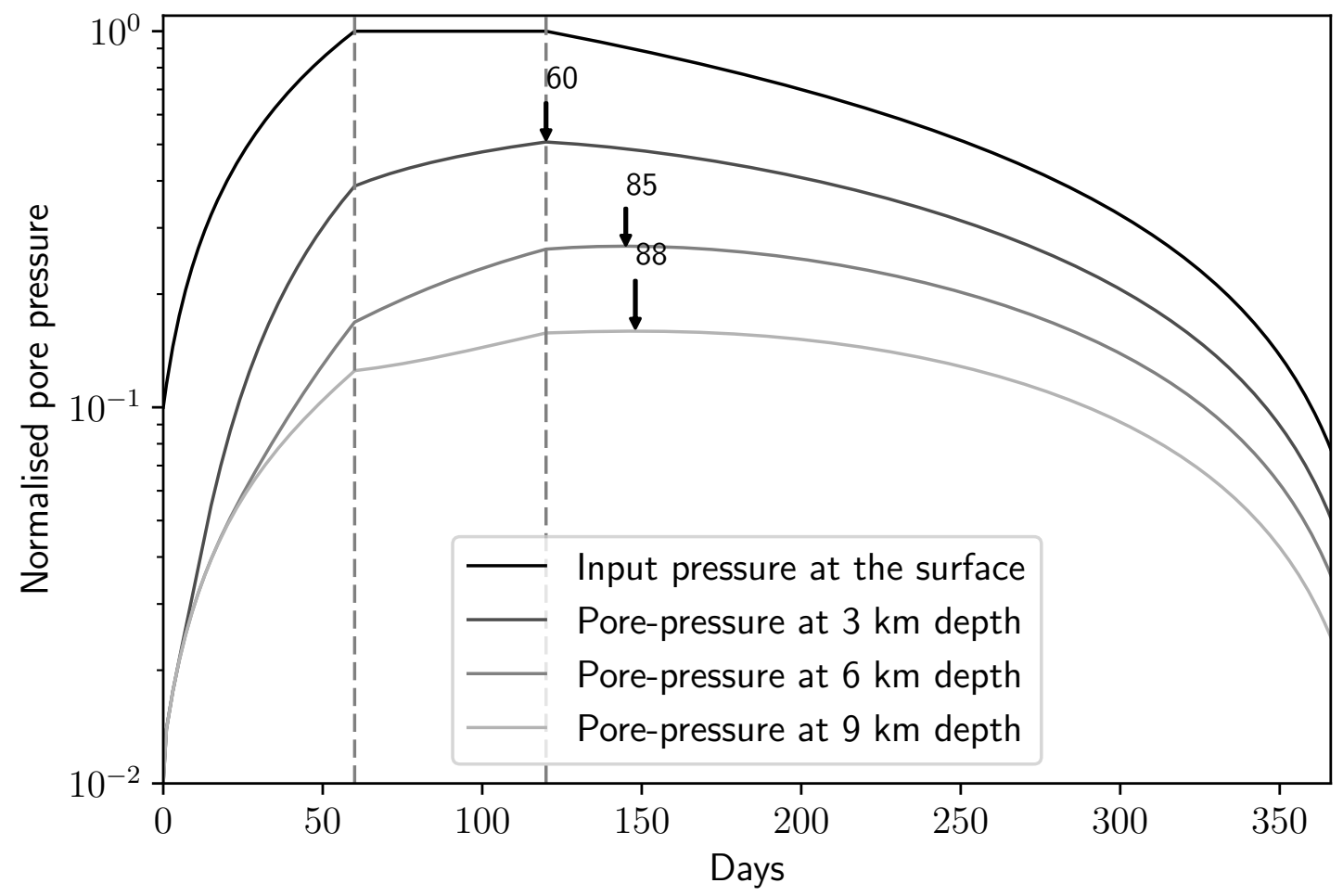

Figure 4.3: Theoretical pore-fluid pressure evolution at various depth, due to a modelled linear increase in pore-pressure at the surface (black line) during the phase I (60 days), followed by a steady state input pressure during phase II (60 days) and a linear decrease during phase III (246 days). Skempton coefficient $B$ is 1 , undrained Poisson's ratio $\nu$ is 0.45 , hydraulic diffusivity $\omega$ is $1 \mathrm{~m}^{2} \mathrm{~s}^{-1}$. The model simulates a seasonal quick input of water followed by a slow decrease, during the rest of the year. Arrows show the maximum of pore-pressure and the time lag after the maximum input pressure. Figure inspired by the work of Kundu et al. (2017).

taking a hydraulic diffusivity of $10 \mathrm{~m}^{2} \mathrm{~s}^{-1}$, the pore-pressure at $6 \mathrm{~km}$ depth peaks only $4 \mathrm{~d}$ after the start of the decreasing surface pressure, with $B=1$ and $\nu=0.45$.

The models are sensitive to parameters like hydraulic diffusivity, which is hard to evaluate and probably not constant with depth. Nevertheless, the model is unable to clearly discard the hypothesis that the increase in seismicity is related to poroelastic responses in the seismogenic zone. We infer that both the elastic and poroelastic responses to surface hydrologic processes could together modulate the rate of microseismicity in the region. 


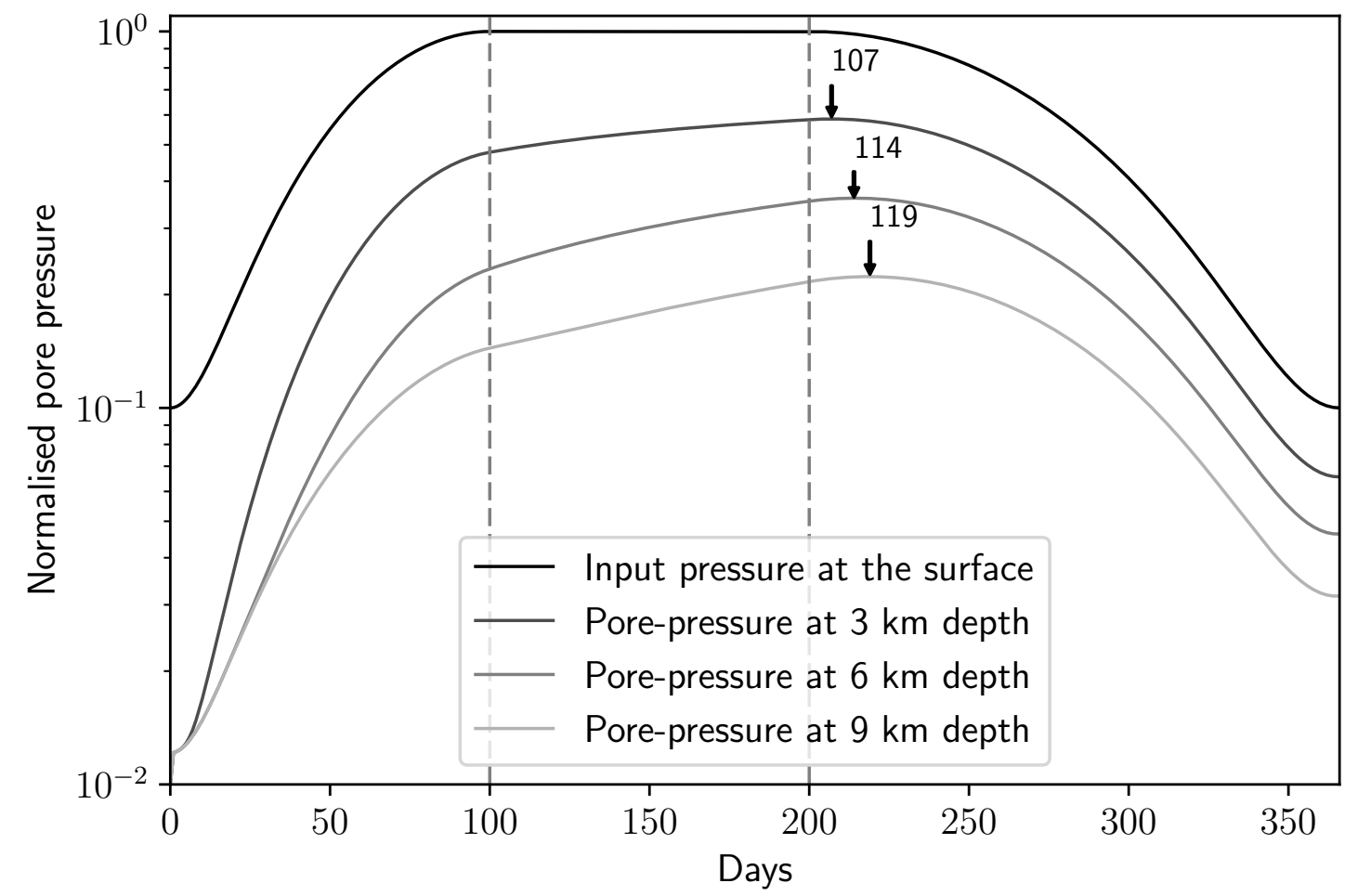

Figure 4.4: Theoretical poroelastic pressure evolution at various depth, due to a modelled sinusoidal increase in pore-fluid pressure at the surface (black line) during the phase I (100 days), followed by a steady-state input pressure during phase II (100 days) and a sinusoidal decrease during phase III (166 days). The same parameters are used as in Figure 4.3. Arrows show the maximum of pore-fluid pressure and the time lag after the maximum input pressure. 


\section{Chapter 5}

\section{Conclusions}

This thesis had two main objectives:

1. To examine and test the hypothesis that the previously unexplained seasonal cycles observed in cGPS time series in the central Southern Alps can be explained by a fluctuating groundwater table under the mountains (controlled by infiltration from rainfall and the extent of the snow cover).

2. To analyse the evolution of the rate of microseismicity in the area to investigate whether annual climatic variations in surface hydrology can produce a poroelastic response that may influence geologic processes in the shallow, seismogenic crust.

This study consisted of two interrelated parts. We evaluated different possibilities to explain the strong seasonal cycles observed in the record from geodetic stations throughout the region (Section 2.3.3) by the SAGENZ network since its construction in the early 2000's (Section 2.3.1) (Beavan et al., 2004, Denys et al., 2005). We evaluated some preferred explanations (Section 3.1). For this purpose, we analysed multiple meteorological, hydrological and geophysical data sets (Section 2.4). In parallel, we built the longest background seismicity record for the region to date (Section 2.5.1), using a matched-filtered detection method (Chamberlain et al., 2014), and a previous catalogue of earthquakes for 2008-2009 (Boese et al., 2012). We analysed the resulting expanded catalogue in both time- and frequency-domains (Section 3.2). We then proposed hypotheses to explain part of the observed variations in the rate of seismicity (Section 4.2). 


\subsection{Reversible ground surface deformation}

We performed a three-dimensional spatial analysis (Figure 2.6) and a frequencydomain analysis (Figure 2.8) of cGPS signals for stations located in remote and mountainous places (Figure 1.2) in the central Southern Alps (Section 2.3). We observed that some stations have a strong annual periodicity (Figure 2.8), and found a correlation between the amplitude of the seasonality and the altitude of the station (Figure 3.1). Our subsequent analyses suggested that this behaviour could not be entirely explained by preprocessing errors, and physical explanations (tidal influences, atmospheric pressure, thermoelasticity of the near-surface, surface mass loading, multipath effects, monument noise, and ice and snow wedging bedrock fractures).

We conjecture that the fluctuating groundwater table is a strong candidate to explain the seasonal variations of ground position (Section 3.1.8). On time-scales of days to weeks, the transient surface deformation observed at a majority of stations can be explained by the same mechanism. We built two mathematical models to simulate this process (Figures 3.14 and 3.15). One is a rainfall-runoff type model that is best suited for stations at low-altitude and on steep terrain, where the ground reacts to heavy rain storms by heaving and dry periods by contracting (Figure 3.8). The REROD-type model (Hansmann et al., 2012b) is more suitable for stations in high-altitude and on steep terrain, where the effect of snow is significant during winter (Figure 3.10). Precipitation as snow stores water above ground and strongly reduces infiltration to groundwater until melt begins (Lundberg et al., 2016). At altitude, snow stays in place long enough to see the depletion of the shallow groundwater reservoir, with a lowering of the groundwater table following a classic logarithmic depletion curve.

Our work shows it is possible to compute a modelled surface displacement with the existing climate stations for a daily solution of cGPS in the study area (Figure 3.14). With a more suitable model to accurately reproduce the reversible ground deformation, noise in the cGPS record could be significantly reduced for use in regional strain estimations, as the observed deformation results from a shallow and local origin (Section 4.1). 


\subsection{Seasonality in microseismicity rate}

We compiled two catalogues of earthquakes for the period November 2008 - March 2017, using two lists of template events (Section 2.5). Our smallest catalogue used is based on 211 templates, for each of which the focal mechanism is known, and results in 38909 detected earthquakes. The second catalogue contains 89474 events detected from 903 templates but has no information on the focal mechanism of the templates.

We find that the seismicity rate in the region fluctuates periodically on annual and diurnal timescales (Section 3.2). Power shortages at certain stations during the night and winter months would induce respectively diurnal and annual variations in rates of detected microseismicity. The observation of fewer detected events during the night than the day (Figure 3.21) is in agreement with this. However, we observe more detections in winter than in summer (Figure 3.23). Using comparisons between seismicity rates and seasonal changes in the effective stress at depths corresponding to the seismogenic crust, we propose two possibilities to explain the observed annual fluctuations:

- The change of elastic stress due to loading-unloading at the surface (Section 2.5.4); and

- The change of poroelastic stress (both drained and undrained) due to fluid migration from the surface to the seismogenic zone (Section 2.5.5).

We consider that both models are equally plausible. We note that both exhibit a change of seismicity rates due to small fluctuations in the stresses at depth, estimated at a few tens or hundreds of $\mathrm{kPa}$ elsewhere (Bettinelli et al., 2008, Kundu et al., 2017). On the San Andreas Faut in California, subtle modifications of pore-pressure in the same order of magnitude are demonstrated to be induced by tidal influences (Johnson et al., 2017), and we cannot discount the possibility that tides modify the rate of microseismicity in the region (Section 3.2.2). 


\subsection{Future work}

This study reveals that shallow groundwater fluctuations in the central Southern Alps induce reversible, repetitive surface deformation of the order of a few millimetres to centimetres (Section 4.1). Based on our findings, we suggest two directions of future work:

- The mapping of seasonal ground deformation, via InSAR or similar satellitebased methods, (e.g. Kääb et al. (2017)), in order to gain better insight into the spatial variability of the reversible ground surface deformation and spatial variations in groundwater table fluctuations in the central Southern Alps.

- The development of a more accurate mathematical groundwater model for corrections of the SAGENZ stations positions, in order to better constrain noise in the geodetic time series and perform more precise regional strain inversions.

This study also highlights the possible influence of surface water flux on the rates of shallow microseismicity under the central Southern Alps. Some more work that could be done is:

- A deeper analysis of the seismicity rate time series, with exploration of possible causes for the detected swarms, including the February-March 2017 "summer" swarm. 


\section{Bibliography}

Achtziger-Zupančič, P., Löw, S., and Hiller, A. (2017). Factors controlling the permeability distribution in fault vein zones surrounding granitic intrusions (Ore Mountains, Germany). Journal of Geophysical Research: Solid Earth, 122(3):1876-1899.

Agnew, D. (2007). 3.06 - Earth tides. In Schubert, G., editor, Treatise on Geophysics, pages 163 - 195. Elsevier, Amsterdam.

Allen, S. K., Cox, S. C., and Owens, I. F. (2011). Rock avalanches and other landslides in the central Southern Alps of New Zealand: a regional study considering possible climate change impacts. Landslides, 8(1):33-48.

Allen, S. K., Gruber, S., and Owens, I. F. (2009). Exploring steep bedrock permafrost and its relationship with recent slope failures in the Southern Alps of New Zealand. Permafrost and Periglacial Processes, 20(4):345-356.

Álvarez-Gómez, J. A. (2014). FMC: a one-liner Python program to manage, classify and plot focal mechanisms. In EGU General Assembly Conference Abstracts, volume 16 of EGU General Assembly Conference Abstracts, page 10887.

Amos, C. B., Audet, P., Hammond, W. C., Brgmann, R., Johanson, I. A., and Blewitt, G. (2014). Uplift and seismicity driven by groundwater depletion in central California. Nature, 509(7501):483-486.

Beavan, J. (2005). Noise properties of continuous GPS data from concrete pillar geodetic monuments in New Zealand and comparison with data from U.S. deep drilled braced monuments. Journal of Geophysical Research, 110(B8).

Beavan, J., Denys, P., Denham, M., Hager, B., Herring, T., and Molnar, P. (2010a). Distribution of present-day vertical deformation across the Southern Alps, New Zealand, from 10 years of GPS data: Southern Alps vertical deformation. Geophysical Research Letters, 37(16). 
Beavan, J., Ellis, S., Wallace, L., and Denys, P. (2007). Kinematic constraints from GPS on oblique convergence of the Pacific and Australian Plates, central South Island, New Zealand. In Okaya, D., Stern, T., and Davey, F., editors, Geophysical Monograph Series, volume 175, pages 75-94. American Geophysical Union, Washington, D. C.

Beavan, J., Matheson, D., Denys, P., Denham, M., Herring, T., Hager, B., and Molnar, P. (2004). A vertical deformation profile across the Southern Alps, New Zealand, from 3.5 years of continuous GPS data. In Proceedings of the Cahiers du Centre Europen de Godynamique et de Sismologie workshop: The State of GPS Vertical Positioning Precision: Separation of Earth Processes by Space Geodesy, Luxembourg, volume 23, pages 111-123.

Beavan, J., Samsonov, S., Denys, P., Sutherland, R., Palmer, N., and Denham, M. (2010b). Oblique slip on the Puysegur subduction interface in the 2009 July MW 7.8 Dusky Sound earthquake from GPS and InSAR observations: implications for the tectonics of southwestern New Zealand. Geophysical Journal International, 183(3):1265-1286.

Bengtsson, L. (2012). Water Balance of Lakes. In Bengtsson, L., Herschy, R. W., and Fairbridge, R. W., editors, Encyclopedia of Lakes and Reservoirs, pages 863-864. Springer Netherlands, Dordrecht. DOI: 10.1007/978-1-4020-4410$6 \_18$.

Berryman, K., Cochran, U., Clark, K., Biasi, G., Langridge, R., and Villamor, P. (2012). Major earthquakes occur regularly on an isolated plate boundary fault. Science, 336(6089):1687-1690.

Bettinelli, P., Avouac, J.-P., Flouzat, M., Bollinger, L., Ramillien, G., Rajaure, S., and Sapkota, S. (2008). Seasonal variations of seismicity and geodetic strain in the Himalaya induced by surface hydrology. Earth and Planetary Science Letters, 266(3-4):332-344.

Bevis, M. (2005). Seasonal fluctuations in the mass of the Amazon River system and Earth's elastic response. Geophysical Research Letters, 32(16).

Bevis, M., Kendrick, E., Cser, A., and Smalley, R. (2004). Geodetic measurement of the local elastic response to the changing mass of water in Lago Laja, Chile. Physics of the Earth and Planetary Interiors, 141(2):71-78.

Bilich, A. and Larson, K. M. (2007). Mapping the GPS multipath environment using the signal-to-noise ratio (SNR). Radio Science, 42(6). 
Blewitt, G., Lavalle, D. J., Clarke, P., and Nurutdinov, K. (2001). A new global mode of earth deformation: seasonal cycle detected. Science, 294:2342.

Boehm, J., Niell, A., Tregoning, P., and Schuh, H. (2006). Global Mapping Function (GMF): A new empirical mapping function based on numerical weather model data. Geophysical Research Letters, 33(7).

Boese, C. M., Jacobs, K. M., Smith, E. G. C., Stern, T. A., and Townend, J. (2014). Background and delayed-triggered swarms in the central Southern Alps, South Island, New Zealand. Geochemistry, Geophysics, Geosystems, 15(4):945-964.

Boese, C. M., Townend, J., Smith, E., and Stern, T. (2012). Microseismicity and stress in the vicinity of the Alpine Fault, central Southern Alps, New Zealand. Journal of Geophysical Research: Solid Earth, 117(B2).

Bollinger, L., Perrier, F., Avouac, J.-P., Sapkota, S., Gautam, U., and Tiwari, D. R. (2007). Seasonal modulation of seismicity in the Himalaya of Nepal. Geophysical Research Letters, 34(8).

Bourguignon, S., Bannister, S., Henderson, C. M., Townend, J., and Zhang, H. (2015). Structural heterogeneity of the midcrust adjacent to the central Alpine Fault, New Zealand: Inferences from seismic tomography and seismicity between Harihari and Ross. Geochemistry, Geophysics, Geosystems, 16(4):10171043.

Boutt, D. F. (2010). Poroelastic loading of an aquifer due to upstream dam releases. Ground Water, 48(4):580-592.

Caruso, B., Newton, S., King, R., and Zammit, C. (2017a). Modelling climate change impacts on hydropower lake inflows and braided rivers in a mountain basin. Hydrological Sciences Journal, 62(6):928-946.

Caruso, B. S., King, R., Newton, S., and Zammit, C. (2017b). Simulation of Climate Change Effects on Hydropower Operations in Mountain Headwater Lakes, New Zealand. River Research and Applications, 33(1):147-161.

Chamberlain, C. J. (2017). Personal communication.

Chamberlain, C. J., Shelly, D. R., Townend, J., and Stern, T. A. (2014). Lowfrequency earthquakes reveal punctuated slow slip on the deep extent of the Alpine Fault, New Zealand. Geochemistry, Geophysics, Geosystems, 15(7):2984-2999. 
Chanard, K., Avouac, J. P., Ramillien, G., and Genrich, J. (2014). Modeling deformation induced by seasonal variations of continental water in the Himalaya region: Sensitivity to Earth elastic structure. Journal of Geophysical Research: Solid Earth, 119(6):5097-5113.

Chen, B., Gong, H., Li, X., Lei, K., Zhu, L., Gao, M., and Zhou, C. (2017). Characterization and causes of land subsidence in Beijing, China. International Journal of Remote Sensing, 38(3):808-826.

Chew, C. C., Small, E. E., Larson, K. M., and Zavorotny, V. U. (2014). Effects of Near-Surface Soil Moisture on GPS SNR Data: Development of a Retrieval Algorithm for Soil Moisture. IEEE Transactions on Geoscience and Remote Sensing, 52(1):537-543.

Cochran, U., Clark, K., Howarth, J., Biasi, G., Langridge, R., Villamor, P., Berryman, K., and Vandergoes, M. (2017). A plate boundary earthquake record from a wetland adjacent to the Alpine fault in New Zealand refines hazard estimates. Earth and Planetary Science Letters, 464:175 - 188.

Costain, J. K. and Bollinger, G. A. (2010). Review: Research Results in Hydroseismicity from 1987 to 2009. Bulletin of the Seismological Society of America, 100(5A):1841-1858.

Costain, J. K., Bollinger, G. A., and Speer, J. A. (1987). HydroseismicityA hypothesis for the role of water in the generation of intraplate seismicity. Geology, 15(7):618.

Cox, S. and Allen, S. (2009). Vampire rock avalanches of January 2008 and 2003, Southern Alps, New Zealand. Landslides, 6(2):161-166.

Cox, S. and Barrell, D. (2007). Geology of the Aoraki area. Institute of Geological and Nuclear Sciences 1:250,000 Geological Map, 15:1-80.

Cox, S. C. and Findlay, R. H. (1995). The Main Divide Fault Zone and its role in formation of the Southern Alps, New Zealand. New Zealand Journal of Geology and Geophysics, 38(4):489-499.

Cox, S. C., Menzies, C. D., Sutherland, R., Denys, P. H., Chamberlain, C., and Teagle, D. A. H. (2015). Changes in hot spring temperature and hydrogeology of the Alpine Fault hanging wall, New Zealand, induced by distal South Island earthquakes. Geofluids, 15(1-2):216-239.

Cox, S. C. and Sutherland, R. (2007). Regional geological framework of South Island, New Zealand, and its significance for understanding the active plate 
boundary. In Okaya, D., Stern, T., and Davey, F., editors, Geophysical Monograph Series, volume 175, pages 19-46. American Geophysical Union, Washington, D. C.

Dach, R., Walser, P., Lutz, S., and Fridez, P. (2015). Bernese GNSS Software Version 5.2. Publikation Digital AG, Biel, Astronomical Institute, University of Bern.

Denys, P. (2001). Geodesy and GPS: Aspects of Advanced Surveying. Department of Surveying, Otago University.

Denys, P. (2016). Geodesy and GPS Survey Methods 2. School of Surveying, Otago University, Dunedin.

Denys, P. and D'Anastasio, E. (2016). Gunn Ridge cGPS. https://github.com/ GeoNet/help/issues/9. Accessed: 21.08.2017.

Denys, P. and Pearson, C. (2016). Positioning in active deformation zones - implications for NetworkRTK and GNSS processing engines. FIG Working Week 2016, Recovery from Disaster.

Denys, P., Pearson, C., Denham, M., and House, C. (2005). Strain accumulation across the central Southern Alps, New Zealand.

Denys, P., Pearson, C., Norris, R., and Denham, M. (2016). A geodetic study of Otago: results of the central Otago deformation network 20042014. New Zealand Journal of Geology and Geophysics, 59(1):147-156.

Detournay, E. and Cheng, A. H.-D. (1993). Fundamentals of Poroelasticity. In Fairhurst, C., editor, Analysis and Design Methods, pages 113 - 171. Pergamon, Oxford.

Dong, D., Fang, P., Bock, Y., Cheng, M. K., and Miyazaki, S. (2002). Anatomy of apparent seasonal variations from GPS-derived site position time series. Journal of Geophysical Research: Solid Earth, 107(B4):ETG 9-1-ETG 9-16.

Drake, N. F. (1912). Destructive earthquakes in China. Bulletin of the Seismological Society of America, 2(1):40-91.

Durá-Gómez, I. and Talwani, P. (2010). Reservoir-induced seismicity associated with the Itoiz Reservoir, Spain: a case study. Geophysical Journal International, 181(1):343-356. 
Eibl, E. P., Lokmer, I., Bean, C. J., Akerlie, E., and Vogfjörd, K. S. (2015). Helicopter vs. volcanic tremor: Characteristic features of seismic harmonic tremor on volcanoes. Journal of Volcanology and Geothermal Research, 304:108 - 117.

El-Hattab, A. I. (2013). Influence of GPS antenna phase center variation on precise positioning. NRIAG Journal of Astronomy and Geophysics, 2(2):272-277.

Elsegui, P., Davis, J. L., Mitrovica, J. X., Benett, R. A., and Wernicke, B. (2003). Crustal loading near Great Salt Lake, Utah. Geophysical Research Letters, $30(3)$.

Evans, S. G., Ge, S., and Liang, S. (2015). Analysis of groundwater flow in mountainous, headwater catchments with permafrost. Water Resources Research, 51(12):9564-9576.

Feenstra, J., Thurber, C., Townend, J., Roecker, S., Bannister, S., Boese, C., Lord, N., Bourguignon, S., and Eberhart-Phillips, D. (2016). Microseismicity and Pwave tomography of the central Alpine Fault, New Zealand. New Zealand Journal of Geology and Geophysics, 59(4):483-495.

Fjeldskaar, W. (1990). Elastic and isostatic subsidence of the Blsj artificial lake, Southern Norway. Terra Nova, 2(4):377-381.

Fu, Y., Freymueller, J. T., and Jensen, T. (2012). Seasonal hydrological loading in southern Alaska observed by GPS and GRACE. Geophysical Research Letters, 39(15).

Gama, J. and Milbert, D. (2015). Solid Earth Tide Computation. solidearthtide,R package version 1.0.0.

Godoi, V. A., Bryan, K. R., and Gorman, R. M. (2016). Regional influence of climate patterns on the wave climate of the southwestern Pacific: The New Zealand region. Journal of Geophysical Research: Oceans, 121(6):4056-4076.

Goring, D. G. and Walters, R. A. (2002). Ocean-tide loading and earth tides around New Zealand. New Zealand Journal of Marine and Freshwater Research, 36(2):299-309.

Grapenthin, R., Sigmundsson, F., Geirsson, H., rnadttir, T., and Pinel, V. (2006). Icelandic rhythmics: Annual modulation of land elevation and plate spreading by snow load. Geophysical Research Letters, 33(24).

Gruber, S. and Haeberli, W. (2009). Mountain Permafrost, pages 33-44. Springer Berlin Heidelberg, Berlin, Heidelberg. 
Hainzl, S., Aggarwal, S. K., Khan, P. K., and Rastogi, B. K. (2014). Monsooninduced earthquake activity in Talala, Gujarat, India. Geophysical Journal International, 200(1):627-637.

Hamling, I. J., Hreinsdóttir, S., Clark, K., Elliott, J., Liang, C., Fielding, E., Litchfield, N., Villamor, P., Wallace, L., Wright, T. J., D'Anastasio, E., Bannister, S., Burbidge, D., Denys, P., Gentle, P., Howarth, J., Mueller, C., Palmer, N., Pearson, C., Power, W., Barnes, P., Barrell, D. J. A., Van Dissen, R., Langridge, R., Little, T., Nicol, A., Pettinga, J., Rowland, J., and Stirling, M. (2017). Complex multifault rupture during the $2016 \mathrm{Mw} 7.8$ Kaikoura earthquake, New Zealand. Science, 356(6334).

Hansmann, J. (2017). Written communication.

Hansmann, J., Loew, S., and Evans, Keith, F. (2012a). Analysis of transient surface deformations above the Gotthard Base Tunnel (Switzerland). PhD thesis, ETH Zurich.

Hansmann, J., Löw, S., and Evans, K. F. (2012b). Reversible rock-slope deformations caused by cyclic water-table fluctuations in mountain slopes of the Central Alps, Switzerland. Hydrogeology Journal, 20(1):73-91.

Heki, K. (2001). Seasonal Modulation of Interseismic Strain Buildup in Northeastern Japan Driven by Snow Loads. Science, 293(5527):89.

Heki, K. (2003). Snow load and seasonal variation of earthquake occurrence in Japan. Earth and Planetary Science Letters, 207(1-4):159-164.

Hernndez-Pajares, M., Juan, J. M., Sanz, J., and Ors, R. (2007). Second-order ionospheric term in GPS: Implementation and impact on geodetic estimates. Journal of Geophysical Research: Solid Earth, 112(B8).

Heron, D. (2014). Geological map of New Zealand 1:250,000. GNS Science geological map 1.

Hillis, R. (2000). Pore pressure / stress coupling and its implications for seismicity. Exploration Geophysics, 31(1 and 2):448-454.

Hsu, L., Finnegan, N. J., and Brodsky, E. E. (2011). A seismic signature of river bedload transport during storm events. Geophysical Research Letters, 38(13).

Hu, J., Ding, X., Li, Z., Zhang, L., Zhu, J., Sun, Q., and Gao, G. (2016). Vertical and horizontal displacements of Los Angeles from InSAR and GPS time 
series analysis: Resolving tectonic and anthropogenic motions. Journal of Geodynamics, 99:27-38.

Huggel, C., Allen, S., Deline, P., Fischer, L., Noetzli, J., and Ravanel, L. (2012). Ice thawing, mountains fallingare alpine rock slope failures increasing? Geology Today, 28(3):98-104.

Ji, K. H. and Herring, T. A. (2012). Correlation between changes in groundwater levels and surface deformation from GPS measurements in the San Gabriel Valley, California. Geophysical Research Letters, 39(1). L01301.

Johnson, C. W., Fu, Y., and Bürgmann, R. (2017). Seasonal water storage, stress modulation, and california seismicity. Science, 356(6343):1161-1164.

Jones, E., Oliphant, T., Peterson, P., et al. (2001). SciPy: Open source scientific tools for Python. [Online; accessed 20 July 2017].

Kääb, A., Altena, B., and Mascaro, J. (2017). Coseismic displacements of the 14 November $2016 M_{\mathrm{w}} 7.8$ Kaikoura, New Zealand, earthquake using the Planet optical cubesat constellation. Natural Hazards and Earth System Sciences, 17(5):627-639.

Kaverina, A. N., Lander, A. V., and Prozorov, A. G. (1996). Global creepex distribution and its relation to earthquake-source geometry and tectonic origin. Geophysical Journal International, 125(1):249-265.

Kenyeres, A. and Bruyninx, C. (2009). Noise and Periodic Terms in the EPN Time Series, pages 143-148. Springer Berlin Heidelberg, Berlin, Heidelberg.

Kerr, T., Clark, M., Hendrikx, J., and Anderson, B. (2013). Snow distribution in a steep mid-latitude alpine catchment. Advances in Water Resources, 55:17-24.

King, M. A. and Williams, S. D. P. (2009). Apparent stability of GPS monumentation from short-baseline time series. Journal of Geophysical Research, 114(B10).

King, N. E., Argus, D., Langbein, J., Agnew, D. C., Bawden, G., Dollar, R. S., Liu, Z., Galloway, D., Reichard, E., Yong, A., Webb, F. H., Bock, Y., Stark, K., and Barseghian, D. (2007). Space geodetic observation of expansion of the San Gabriel Valley, California, aquifer system, during heavy rainfall in winter 20042005. Journal of Geophysical Research: Solid Earth, 112(B3).

Knauss, J. and Garfield, N. (2016). Introduction to Physical Oceanography: Third Edition. Waveland Press. 
Knight, J. (2009). Lake Level History. Technical Report 350712.00, Opus International Consultants Limited, Wellington 6144, New Zealand.

Kundu, B., Vissa, N. K., Panda, D., Jha, B., Asaithambi, R., Tyagi, B., and Mukherjee, S. (2017). Influence of a meteorological cycle in mid-crustal seismicity of the Nepal Himalaya. Journal of Asian Earth Sciences, 146:317 325.

Landis, C. and Coombs, D. (1967). Metamorphic belts and orogenesis in southern new zealand. Tectonophysics, 4(4):501 - 518 .

Leung, A. K. and Ng, C. W. W. (2016). Field investigation of deformation characteristics and stress mobilisation of a soil slope. Landslides, 13(2):229-240.

Little, T. A., Cox, S., Vry, J. K., and Batt, G. (2005). Variations in exhumation level and uplift rate along the oblique-slip Alpine Fault, central Southern Alps, New Zealand. GSA Bulletin, 117(5-6):707-723.

Lombardi, E. G. (2004). Ground-water induced settlements in rock masses and consequences for dams. In IALAD-Integrity Assessment of Large Concrete Dams Conference, Zurich, volume 24.

Lombardi, G. (1988). Les tassements exceptionnels au barrage de Zeuzier. Schweizerisches Gesellschaft fr Boden- und Felsmechanik, (118):11.

Lou, Y., Zhang, W., Wang, C., Yao, X., Shi, C., and Liu, J. (2014). The impact of orbital errors on the estimation of satellite clock errors and ppp. Advances in Space Research, 54(8):1571 - 1580.

Löw, S., Ebneter, F., Bremen, R., Herfort, M., Ltzenkirchen, V., and Matousek, F. (2007). Annual Opening and Closure of Alpine Valleys. Felsbau : rock and soil engineering, 25(5):60-65.

Lundberg, A., Ala-Aho, P., Eklo, O., Klve, B., Kvrner, J., and Stumpp, C. (2016). Snow and frost: implications for spatiotemporal infiltration patterns a review. Hydrological Processes, 30(8):1230-1250.

Lyard, F., Lefevre, F., Letellier, T., and Francis, O. (2006). Modelling the global ocean tides: modern insights from FES2004. Ocean Dynamics, 56(5):394-415.

Mackinnon, T. (1983). Origin of the torlesse terrane and coeval rocks, south island, new zealand. Geological Society of America Bulletin, 94(8):967-985. 
Masset, O. and Löw, S. (2010). Hydraulic conductivity distribution in crystalline rocks, derived from inflows to tunnels and galleries in the Central Alps, Switzerland. Hydrogeology Journal, 18(4):863-891.

Massey, C., Petley, D., and McSaveney, M. (2013). Patterns of movement in reactivated landslides. Engineering Geology, 159:1 - 19.

Mathews, P. M., Dehant, V., and Gipson, J. M. (1997). Tidal station displacements. Journal of Geophysical Research: Solid Earth, 102(B9):20469-20477.

Menzies, C. D., Teagle, D. A., Craw, D., Cox, S. C., Boyce, A. J., Barrie, C. D., and Roberts, S. (2014). Incursion of meteoric waters into the ductile regime in an active orogen. Earth and Planetary Science Letters, 399:1-13.

Menzies, C. D., Teagle, D. A., Niedermann, S., Cox, S. C., Craw, D., Zimmer, M., Cooper, M. J., and Erzinger, J. (2016). The fluid budget of a continental plate boundary fault: Quantification from the Alpine Fault, New Zealand. Earth and Planetary Science Letters, 445:125-135.

Ministry of Business, Innovation and Employment (2017). Energy in New Zealand 2017. Technical report, Energy and Building Trends.

Motagh, M., Djamour, Y., Walter, T. R., Wetzel, H.-U., Zschau, J., and Arabi, S. (2007). Land subsidence in Mashhad Valley, northeast Iran: Results from InSAR, levelling and GPS. Geophysical Journal International, 168(2):518526.

Mulargia, F. and Bizzarri, A. (2014). Anthropogenic triggering of large earthquakes. Scientific Reports, 4.

Murakami, M. and Miyazaki, S. (2001). Periodicity of strain accumulation detected by permanent GPS Array: Possible relationship to seasonality of major earthquakes' occurrence. Geophysical Research Letters, 28(15):2983-2986.

Nievinski, F. G. (2017). Written communication.

Nievinski, F. G. and Larson, K. M. (2014). Forward modeling of GPS multipath for near-surface reflectometry and positioning applications. GPS Solutions, $18(2): 309-322$.

Norris, R. J. and Cooper, A. F. (2001). Late Quaternary slip rates and slip partitioning on the Alpine Fault, New Zealand. Journal of Structural Geology, 23(2):507 - 520. 
Ouellette, K. J., de Linage, C., and Famiglietti, J. S. (2013). Estimating snow water equivalent from GPS vertical site-position observations in the western United States. Water Resources Research, 49(5):2508-2518.

Pan, Y., Shen, W.-B., Hwang, C., Liao, C., Zhang, T., and Zhang, G. (2016). Seasonal Mass Changes and Crustal Vertical Deformations Constrained by GPS and GRACE in Northeastern Tibet. Sensors, 16(8):1211.

Prawirodirdjo, L., Ben-Zion, Y., and Bock, Y. (2006). Observation and modeling of thermoelastic strain in Southern California Integrated GPS Network daily position time series. Journal of Geophysical Research: Solid Earth, 111(B2).

Preisig, G., Cornaton, F. J., and Perrochet, P. (2012). Simulation of flow in fractured rocks using effective stress-dependent parameters and aquifer consolidation. In Proceedings of the ModelCARE, pages 273-279.

Preisig, G., Eberhardt, E., Smithyman, M., Preh, A., and Bonzanigo, L. (2016). Hydromechanical Rock Mass Fatigue in Deep-Seated Landslides Accompanying Seasonal Variations in Pore Pressures. Rock Mechanics and Rock Engineering, 49(6):2333-2351.

Ray, J., Altamimi, Z., Collilieux, X., and van Dam, T. (2008). Anomalous harmonics in the spectra of GPS position estimates. GPS Solutions, 12(1):55-64.

Ray, R. D. and Ponte, R. M. (2003). Barometric tides from ECMWF operational analyses. Annales Geophysicae, 21(8):1897-1910.

Reyners, M. (1988). Reservoir-induced seismicity at lake Pukaki, New Zealand. Geophysical Journal International, 93(1):127-135.

Robertson, E. (1988). Thermal properties of rocks. Report 88-441.

Roux, P.-F., Walter, F., Riesen, P., Sugiyama, S., and Funk, M. (2010). Observation of surface seismic activity changes of an alpine glacier during a glacier-dammed lake outburst. Journal of Geophysical Research: Earth Surface, 115(F3).

Rouyet, L., Kristensen, L., Derron, M.-H., Michoud, C., Blikra, L. H., Jaboyedoff, M., and Lauknes, T. R. (2016). Evidence of rock slope breathing using groundbased InSAR. Geomorphology.

Salinger, M. and Mullan, A. (1999). New Zealand climate: temperature and precipitation variations and their links with atmospheric circulation 19301994. International Journal of Climatology, 19(10):1049-1071. 
Salinger, M. J. (1980). New Zealand Climate: I. Precipitation Patterns. Monthly Weather Review, 108(11):1892-1904.

Schmid, R., Steigenberger, P., Gendt, G., Ge, M., and Rothacher, M. (2007). Generation of a consistent absolute phase-center correction model for GPS receiver and satellite antennas. Journal of Geodesy, 81(12):781-798.

Schofield, J. C. (1964). Postglacial sea levels and isostatic uplift. New Zealand Journal of Geology and Geophysics, 7(2):359-360.

Seabold, S. and Perktold, J. (2010). Statsmodels: Econometric and statistical modeling with python. In 9th Python in Science Conference.

Simpson, D., Leith, W., and Scholz, C. (1988). Two types of reservoir-induced seismicity. Bulletin of the Seismological Society of America, 78(6):2025-2040.

Sims, A., Cox, S. C., Fitzsimons, S., and Holland, P. (2015). Seasonal infiltration and groundwater movement in schist bedrock, Southern Alps, New Zealand. Journal of Hydrology, 54(1):33.

Small, E. E., Larson, K. M., and Braun, J. J. (2010). Sensing vegetation growth with reflected GPS signals. Geophysical Research Letters, 37(12). L12401.

Snedecor, G. W. and Cochran, W. G. (1989). Statistical Methods. Iowa State University Press, eighth edition.

Steckler, M. S., Nooner, S. L., Akhter, S. H., Chowdhury, S. K., Bettadpur, S., Seeber, L., and Kogan, M. G. (2010). Modeling Earth deformation from monsoonal flooding in Bangladesh using hydrographic, GPS, and Gravity Recovery and Climate Experiment (GRACE) data. Journal of Geophysical Research: Solid Earth, 115(B8).

Strozzi, T., Delaloye, R., Poffet, D., Hansmann, J., and Löw, S. (2011). Surface subsidence and uplift above a headrace tunnel in metamorphic basement rocks of the Swiss Alps as detected by satellite SAR interferometry. Remote Sensing of Environment, 115(6):1353-1360.

Sturman, A. and Wanner, H. (2001). A comparative review of the weather and climate of the Southern Alps of New Zealand and the European Alps. Mountain Research and Development, 21(4):359-369.

Suriñach, E., Vilajosana, I., Khazaradze, G., Biescas, B., Furdada, G., and Vilaplana, J. (2005). Seismic detection and characterization of landslides and other mass movements. Natural Hazards and Earth System Science, 5(6):791-798. 
Sutherland, R., Davey, F., and Beavan, J. (2000). Plate boundary deformation in South Island, New Zealand, is related to inherited lithospheric structure. Earth and Planetary Science Letters, 177(3):141 - 151.

Sutherland, R., Eberhart-Phillips, D., Harris, R. A., Stern, T., Beavan, J., Ellis, S., Henrys, S., Cox, S., Norris, R. J., Berryman, K. R., Townend, J., Bannister, S., Pettinga, J., Leitner, B., Wallace, L., Little, T. A., Cooper, A. F., Yetton, M., and Stirling, M. (2007). Do great earthquakes occur on the Alpine Fault in central South Island, New Zealand? In Okaya, D., Stern, T., and Davey, F., editors, Geophysical Monograph Series, volume 175, pages 235-251. American Geophysical Union, Washington, D. C.

Sutherland, R., Townend, J., Toy, V., Upton, P., Coussens, J., Allen, M., Baratin, L.-M., Barth, N., Becroft, L., Boese, C., Boles, A., Boulton, C., Broderick, N., Janku-Capova, L., Carpenter, B., Clrier, B., Chamberlain, C., Cooper, A., Coutts, A., Cox, S., Craw, L., Doan, M.-L., Eccles, J., Faulkner, D., Grieve, J., Grochowski, J., Gulley, A., Hartog, A., Howarth, J., Jacobs, K., Jeppson, T., Kato, N., Keys, S., Kirilova, M., Kometani, Y., Langridge, R., Lin, W., Little, T., Lukacs, A., Mallyon, D., Mariani, E., Massiot, C., Mathewson, L., Melosh, B., Menzies, C., Moore, J., Morales, L., Morgan, C., Mori, H., Niemeijer, A., Nishikawa, O., Prior, D., Sauer, K., Savage, M., Schleicher, A., Schmitt, D., Shigematsu, N., Taylor-Offord, S., Teagle, D., Tobin, H., Valdez, R., Weaver, K., Wiersberg, T., Williams, J., Woodman, N., and Zimmer, M. (2017). Extreme hydrothermal conditions at an active plate-bounding fault. Nature, 546(7656):137-140.

Sutherland, R., Toy, V., Townend, J., Eccles, J., Prior, D., Norris, R., Mariani, E., Faulkner, D., de Pascale, G., Carpenter, B., Boulton, C., Menzies, C., Cox, S., Little, T., Hasting, M., Cole-Baker, J., Langridge, R., Scott, H., Lindroos, Z., Fleming, B., and Wing, R. (2013). Operations and well completion report for boreholes DFDP-1A and DFDP-1B, Deep Fault Drilling Project, Alpine Fault, Gaunt Creek, New Zealand. GNS Science report.

Sutherland, R., Toy, V. G., Townend, J., Cox, S. C., Eccles, J. D., Faulkner, D. R., Prior, D. J., Norris, R. J., Mariani, E., Boulton, C., Carpenter, B. M., Menzies, C. D., Little, T. A., Hasting, M., De Pascale, G. P., Langridge, R. M., Scott, H. R., Lindroos, Z. R., Fleming, B., and Kopf, A. J. (2012). Drilling reveals fluid control on architecture and rupture of the Alpine fault, New Zealand. Geology, 40(12):1143-1146. 
Tait, A., Henderson, R., Turner, R., and Zheng, X. (2006). Thin plate smoothing spline interpolation of daily rainfall for New Zealand using a climatological rainfall surface. International Journal of Climatology, 26(14):2097-2115.

Tait, A., Sturman, J., and Clark, M. (2012). An assessment of the accuracy of interpolated daily rainfall for New Zealand. Journal of Hydrology, 51(1):2544.

Tait, A. and Turner, R. (2005). Generating Multiyear Gridded Daily Rainfall over New Zealand. Journal of Applied Meteorology, 44(9):1315-1323.

Tait, A. B. and Fitzharris, B. B. (1998). Relationships between New Zealand rainfall and south-west Pacific pressure patterns. International Journal of Climatology, 18(4):407-424.

Talwani, P., Chen, L., and Gahalaut, K. (2007). Seismogenic permeability, ks. Journal of Geophysical Research: Solid Earth, 112(B7). B07309.

Upton, P. and Sutherland, R. (2014). High permeability and low temperature correlates with proximity to brittle failure within mountains at an active tectonic boundary, Manapouri tunnel, Fiordland, New Zealand. Earth and Planetary Science Letters, 389:176 - 187.

van Herwijnen, A. and Schweizer, J. (2011). Monitoring avalanche activity using a seismic sensor. Cold Regions Science and Technology, 69(2):165 - 176. International Snow Science Workshop 2010 Lake Tahoe.

Warren-Smith, E., Chamberlain, C. J., Lamb, S., and Townend, J. (2017). Highprecision analysis of an aftershock sequence using matched-filter detection: The 4 may $2015 \mathrm{ml} 6$ wanaka earthquake, southern alps, new zealand. Seismological Research Letters, 88(4):1065-1077.

Watson, K. M., Bock, Y., and Sandwell, D. T. (2002). Satellite interferometric observations of displacements associated with seasonal groundwater in the Los Angeles basin. Journal of Geophysical Research: Solid Earth, 107(B4):1-15.

Wdowinski, S., Bock, Y., Zhang, J., Fang, P., and Genrich, J. (1997). Southern California permanent GPS geodetic array: Spatial filtering of daily positions for estimating coseismic and postseismic displacements induced by the 1992 Landers earthquake. Journal of Geophysical Research: Solid Earth, 102(B8):18057-18070. 
Weber, S., Beutel, J., Faillettaz, J., Hasler, A., Krautblatter, M., and Vieli, A. (2017). Quantifying irreversible movement in steep, fractured bedrock permafrost on Matterhorn (CH). The Cryosphere, 11(1):567-583.

Webster, C. S., Kingston, D. G., and Kerr, T. (2015). Inter-annual variation in the topographic controls on catchment-scale snow distribution in a maritime alpine catchment, New Zealand. Hydrological Processes, 29(6):1096-1109.

Welch, L. A. and Allen, D. M. (2012). Consistency of groundwater flow patterns in mountainous topography: Implications for valley bottom water replenishment and for defining groundwater flow boundaries. Water Resources Research, 48(5). W05526.

Woods, R., Hendrikx, J., Henderson, R., Tait, A., and others (2006). Estimating mean flow of New Zealand rivers. Journal of Hydrology (New Zealand), 45(2):95.

Wratt, D. S., Ridley, R. N., Sinclair, M. R., Larsen, H., Thompson, S. M., Henderson, R., Austin, G. L., Bradley, S. G., Auer, A., Sturman, A. P., Owens, I., Fitzharris, B., Ryan, B. F., and Gayet, J.-F. (1996). The New Zealand Southern Alps Experiment. Bulletin of the American Meteorological Society, 77(4):683-692.

Yan, H., Chen, W., Zhu, Y., Zhang, W., and Zhong, M. (2009). Contributions of thermal expansion of monuments and nearby bedrock to observed GPS height changes. Geophysical Research Letters, 36(13).

Zemansky, G. M., Westerhoff, R., and GNS Science (N.Z.) (2013). Evaluation of selected satellite remote sensing methods for application to characterization of New Zealand aquifers. OCLC: 867720028.

Zoback, M. D. (2007). Reservoir Geomechanics. Cambridge University Press. 


\section{Appendix A}

\section{Supplementary meteorological data}

In this appendix, we show some of the datasets we use in the thesis, but that are not in the main text for clarity and conciseness.

\section{A.1 Seasonality in rainfall}

In this Section, we present rainfall at each climate stations used for the meteorological overview of the region. The only site with significant seasonality is Mueller Hut rain gauge. This high altitude $(1800 \mathrm{~m})$ rain gauge catches less rain during winter than during summer. This is not consistent with surrounding rain gauges, for example Mt Cook EWS, which is situated $~ 3200 \mathrm{~m}$ southeast and $1050 \mathrm{~m}$ lower than Mueller Hut, in the Hooker valley. Mueller Hut records less rain annually than Mt Cook EWS (Figure 2.9). The rain gauge is situated close to the Hut, in an area exposed to severe winds. Due to the altitude, precipitation falls as snow during the winter months and sporadically during the rest of the year. The effect of wind combined with snow induces an undercatch of the rain gauge, for total precipitation. NIWA, the owner of the rain gauge, installed a windshield and a heater to try reducing the loss in 2013. The influence of this installation is visible in the record of rain in Mueller Hut (Figure A.10). However, the mechanism, visible in Figure 2.13 cannot annihilate completely the effect of snow and wind combined. 


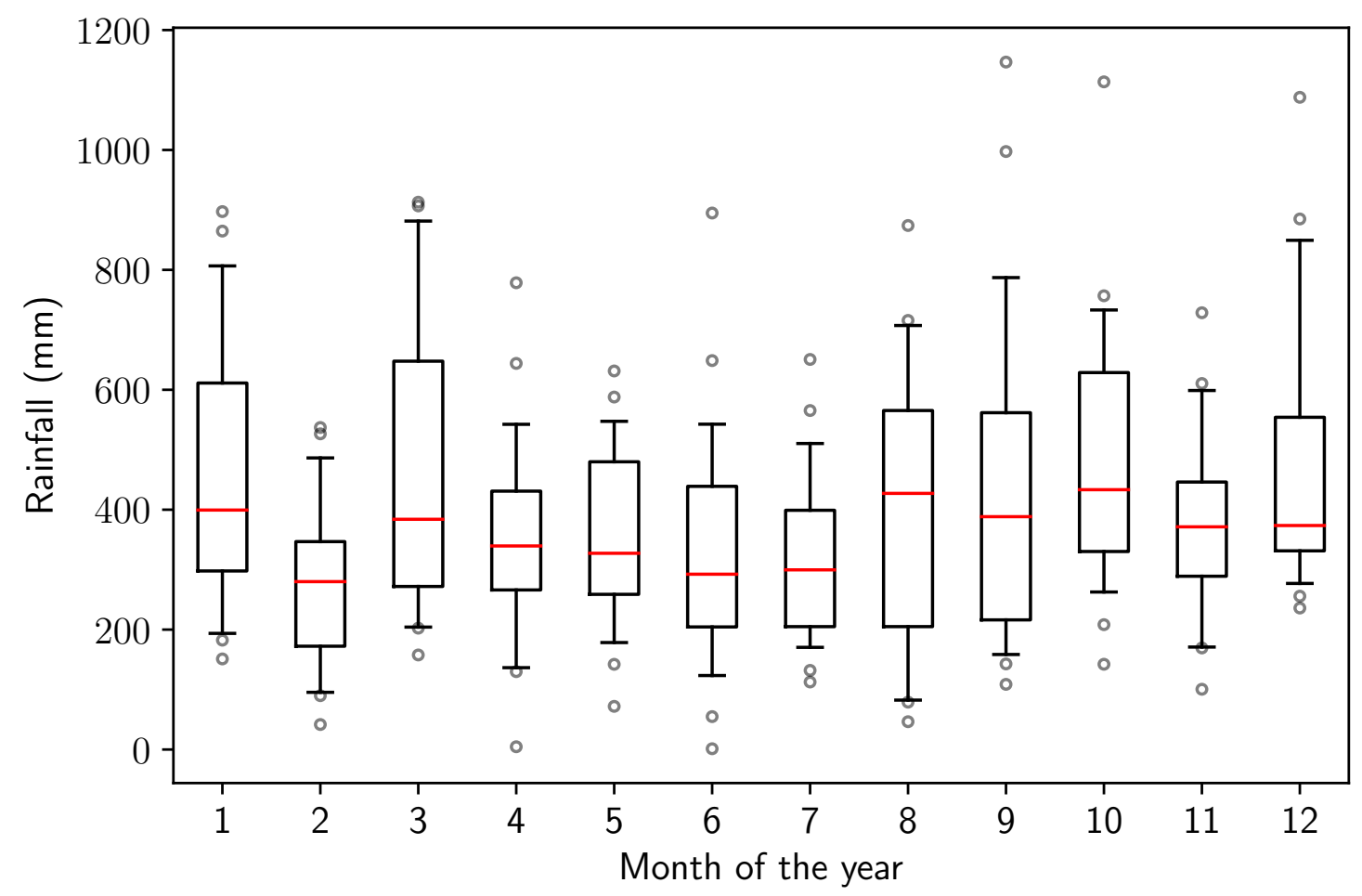

Figure A.1: Monthly rainfall at Fox Glacier between 1967 and 1994. Median rainfall per month is evenly distributed through the year, and there is no clear seasonality.

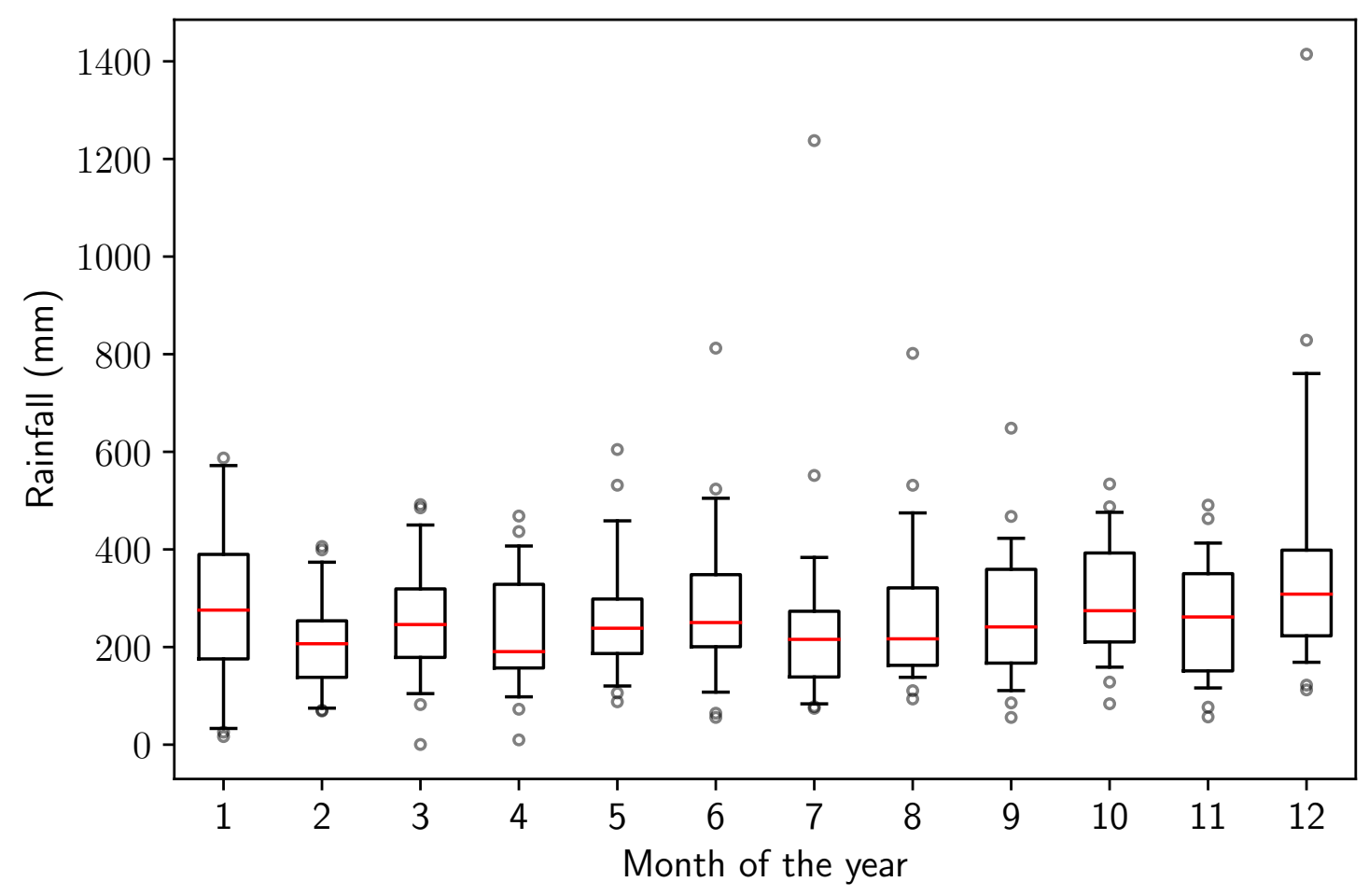

Figure A.2: Monthly rainfall at Haast between 1982 and 2017. 


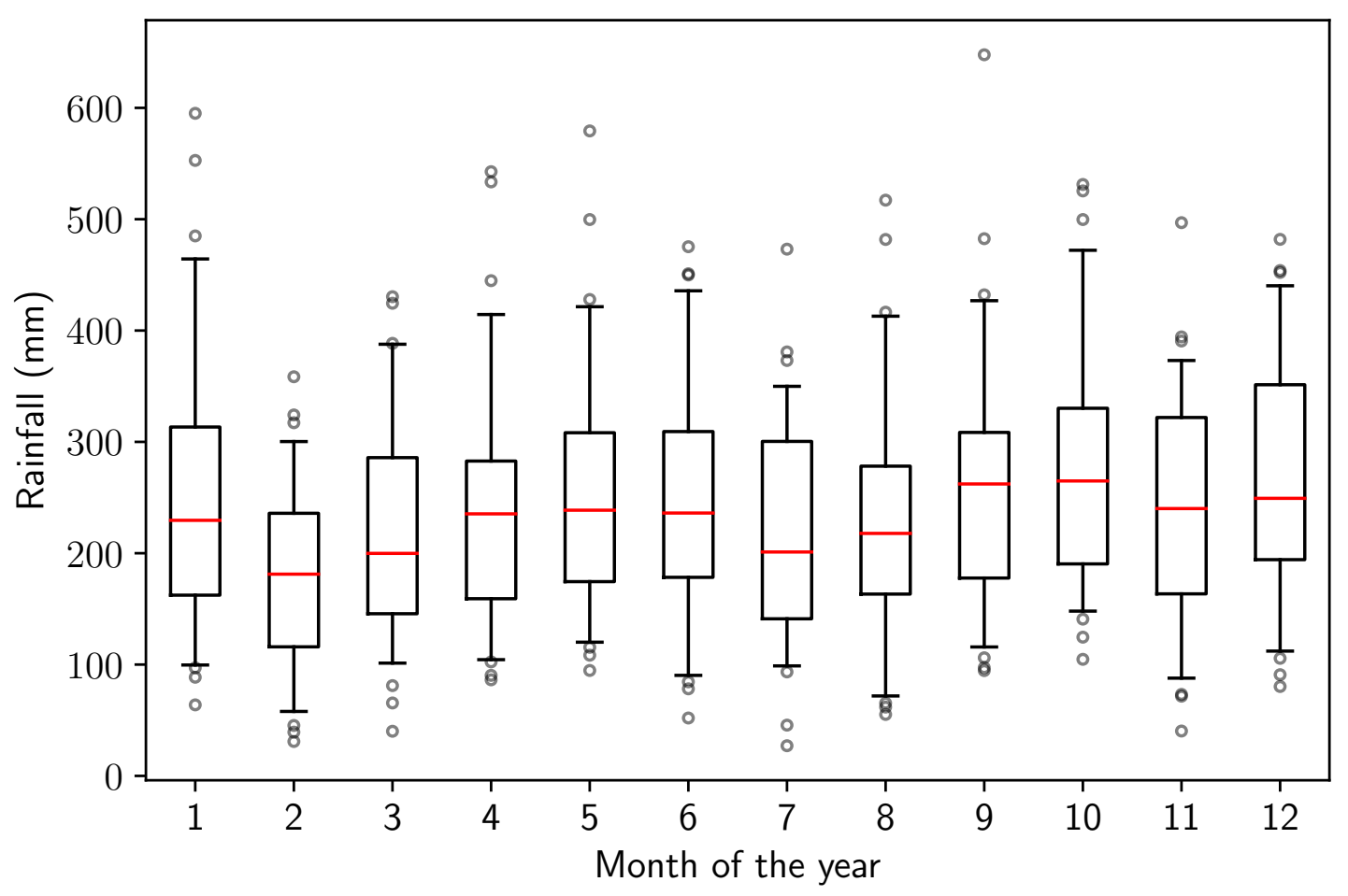

Figure A.3: Monthly rainfall at Hokitika between 1963 and 2017.

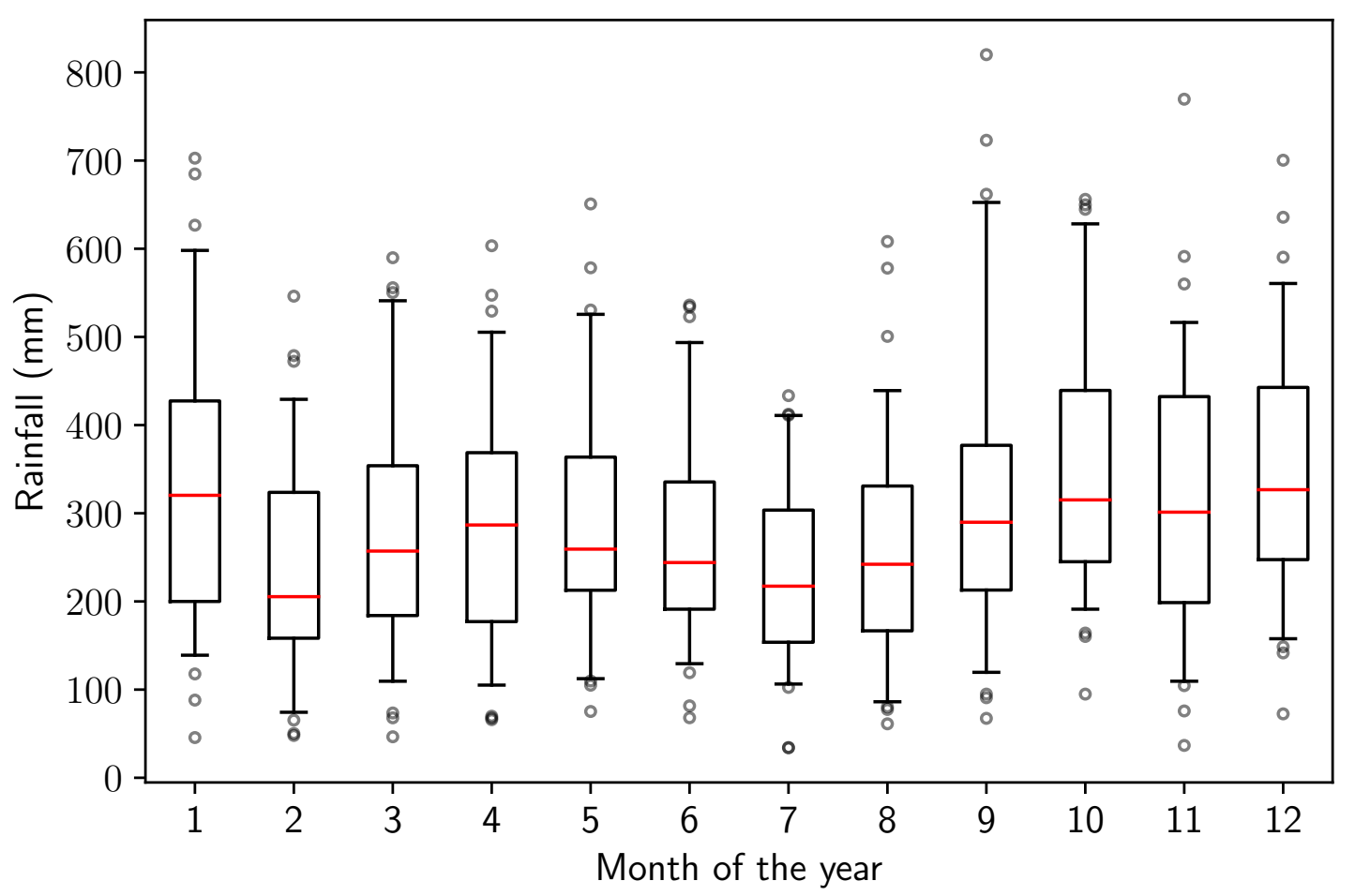

Figure A.4: Monthly rainfall at Kowhitirangi between 1965 and 2017. 


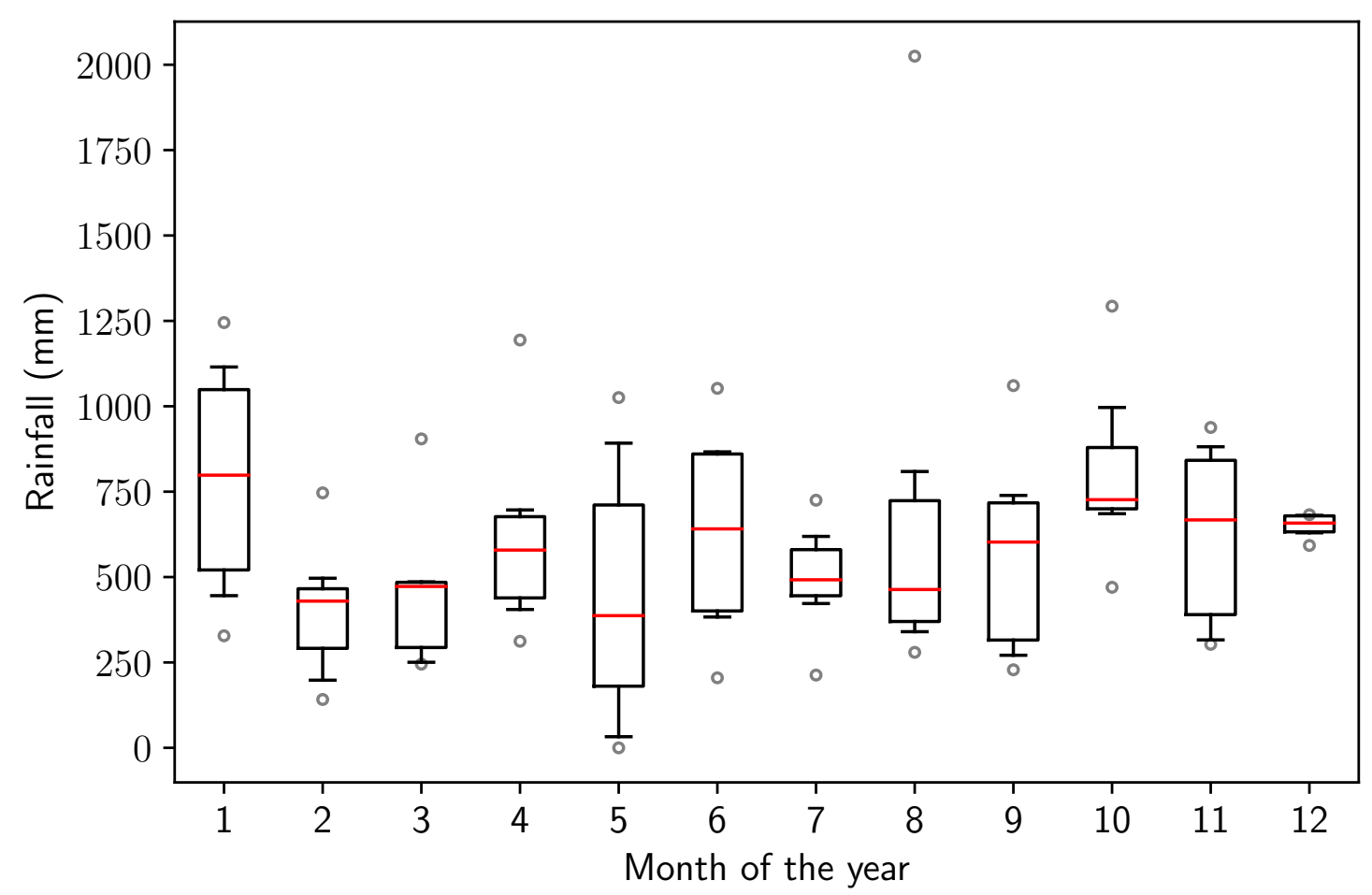

Figure A.5: Monthly rainfall at Ivory Glacier between 2009 and 2017. Due to the reduced period of recording, the variability is higher at this site.

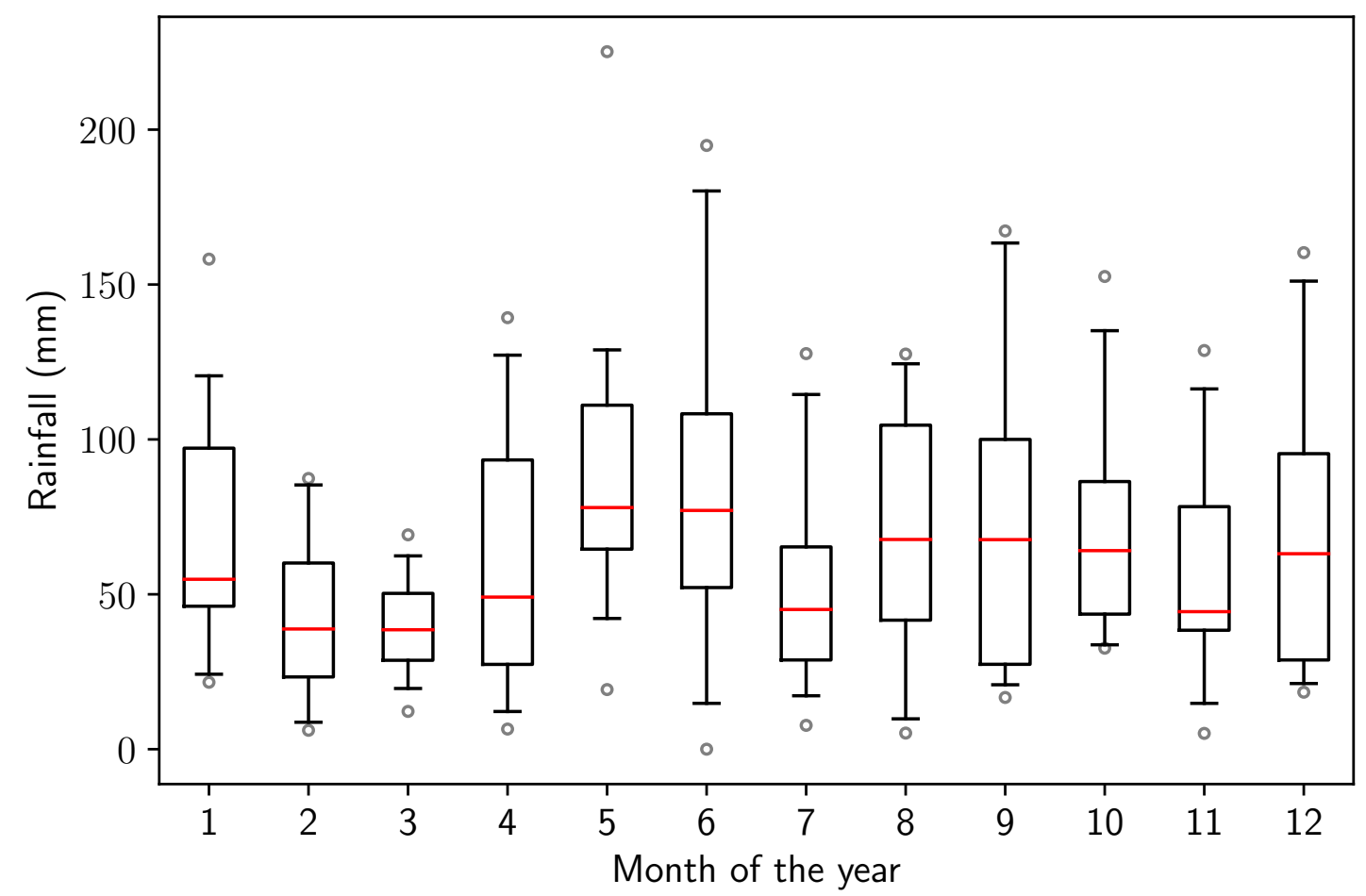

Figure A.6: Monthly rainfall at Lake Pukaki Guide Hill between 2000 and 2017. Due to the reduced period of recording, the variability is higher at this site. 


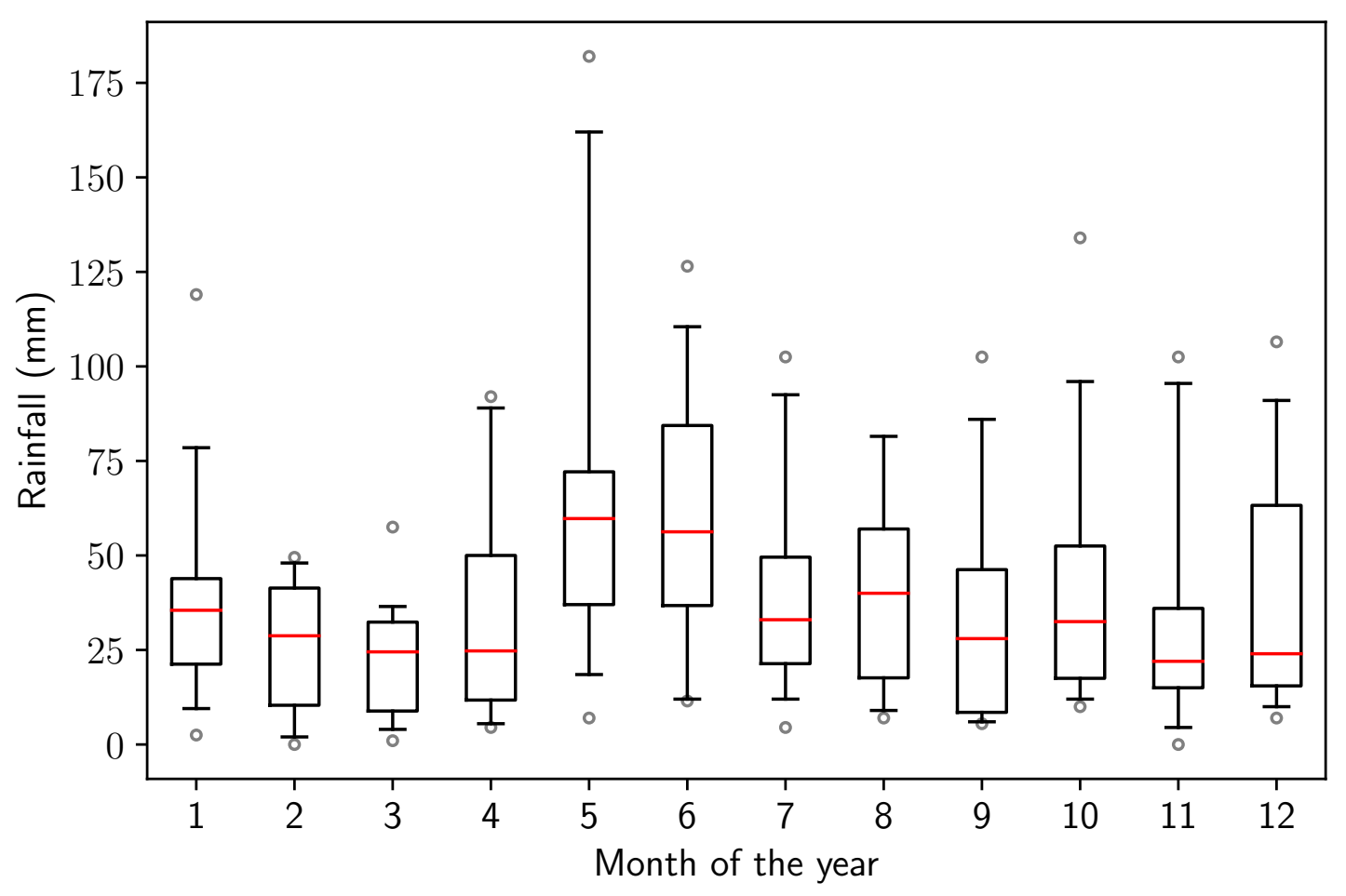

Figure A.7: Monthly amount of rainfall at Tekapo between 2000 and 2016.

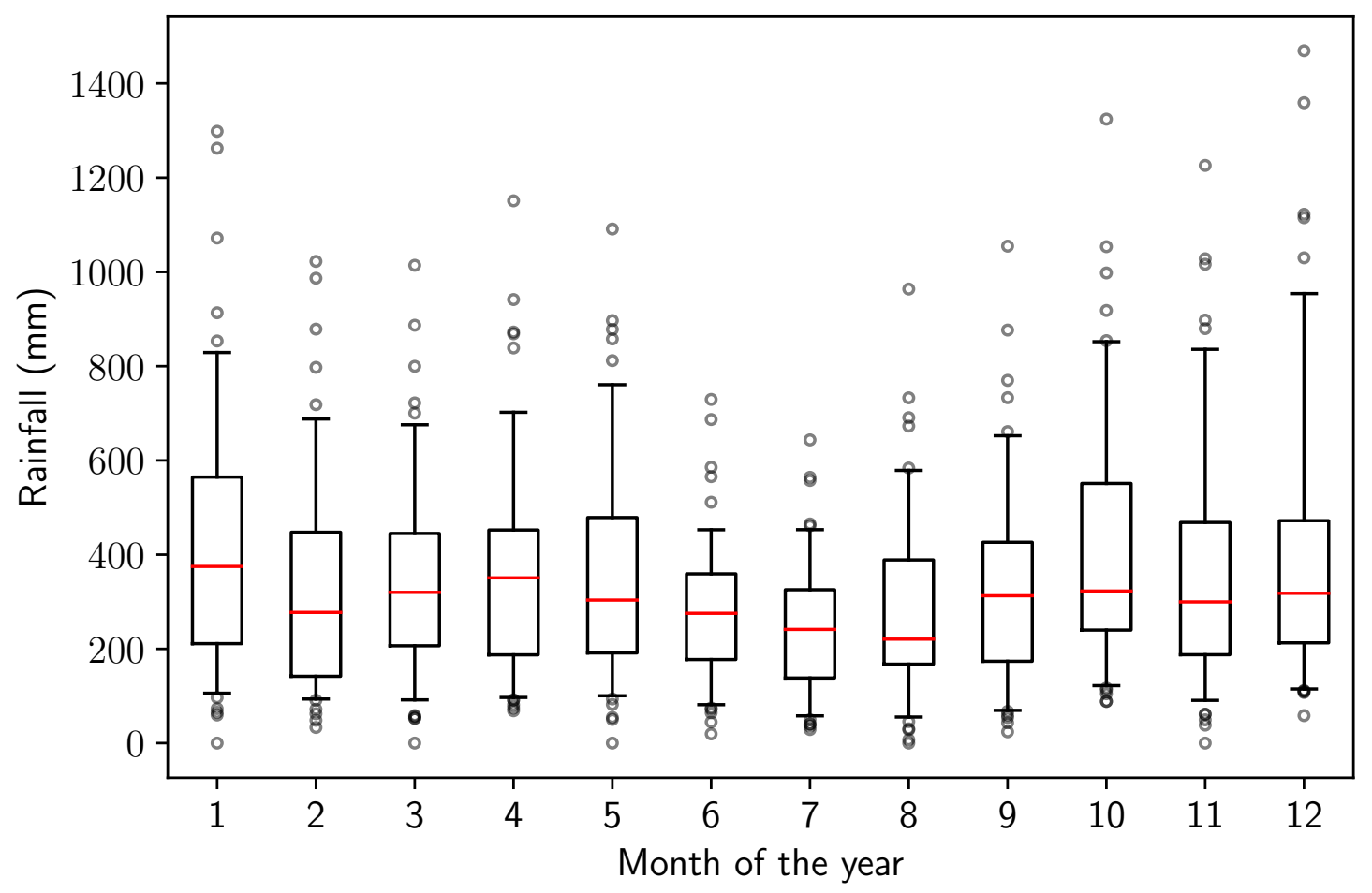

Figure A.8: Monthly rainfall at Mount Cook village between 1928 and 2017. 


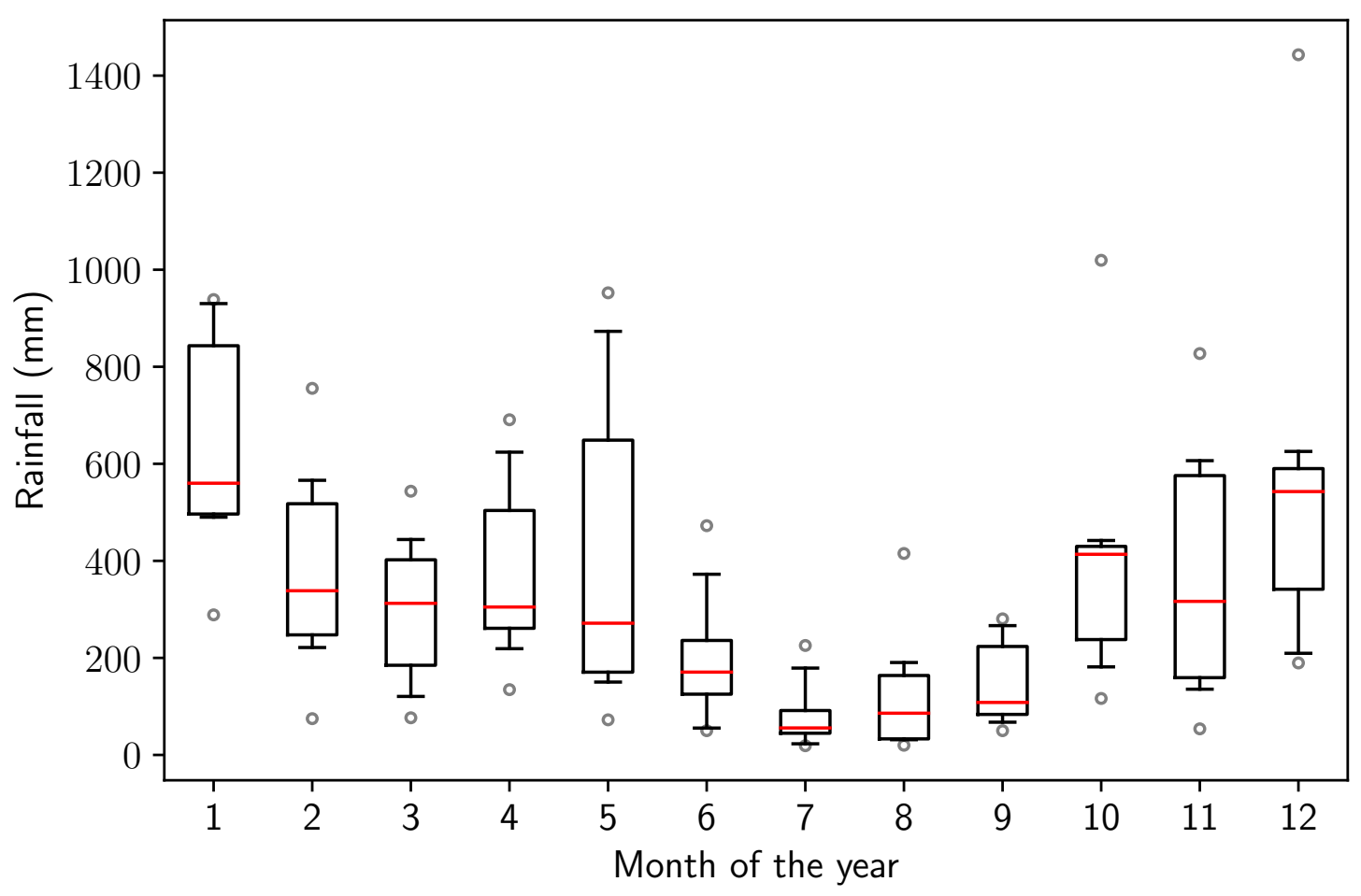

Figure A.9: Monthly rainfall at Mueller Hut between 2010 and 2017.

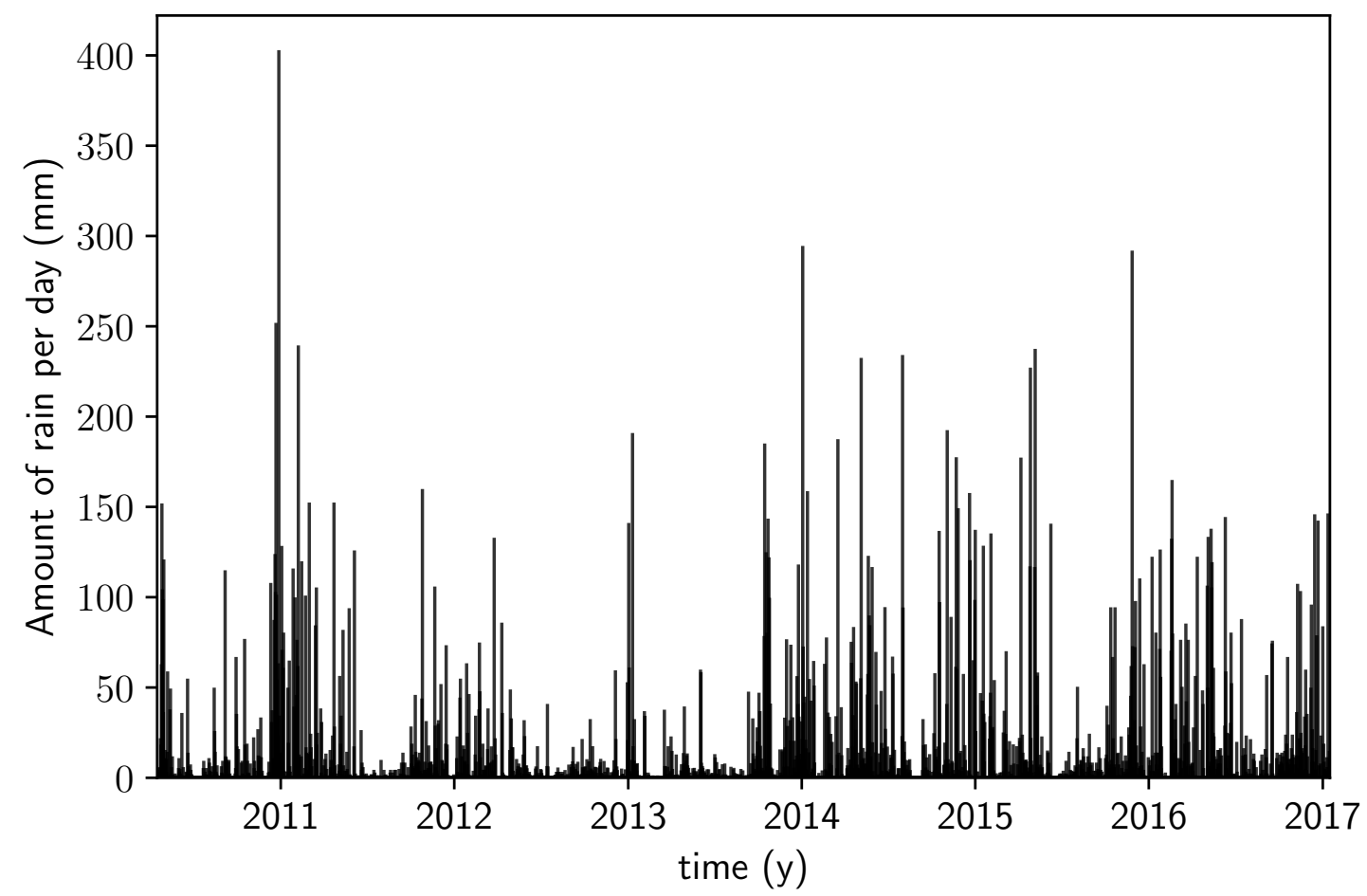

Figure A.10: Time series of rain at Mueller Hut for the period $2010-2017$. 


\section{A.2 Snowfall}

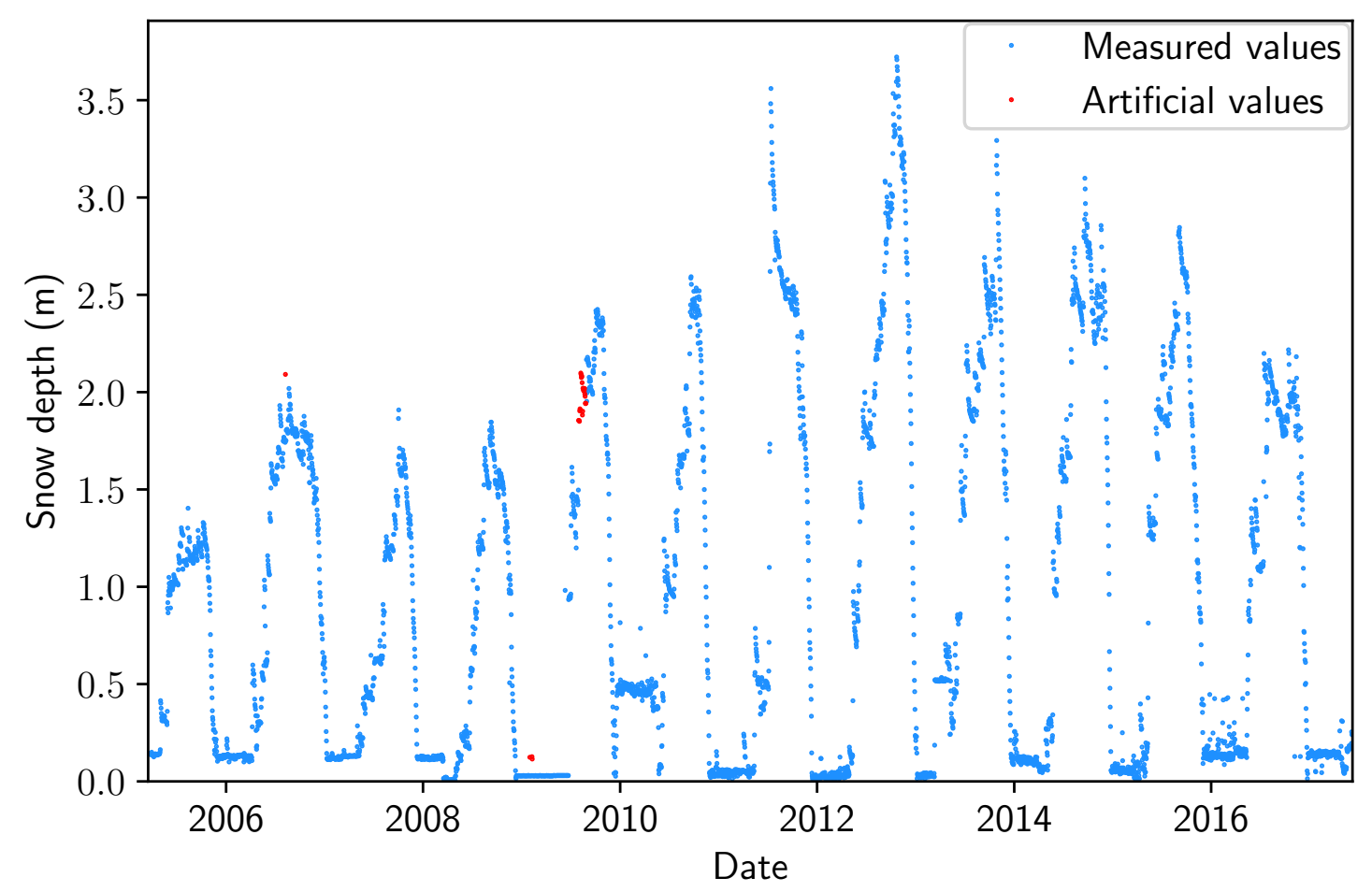

Figure A.11: Completed dataset for snow accumulation at Rose Ridge (altitude: $2000 \mathrm{~m}$ ). Artificial values are in red. The percentage of missing values is $1 \%$.

Time series of snow depth in Mueller Hut was shown in the Chapter 2 (Figure 2.15). Data for Mount cook Ews and Rose Ridge SIN are shown here. There was a large amount of missing data at Mount Cook village station and this station was of limited utility for the study. Rose Ridge however has a better ratio of missing data and period of recording, but is situated farther from most of the cGPS stations than Mueller Hut. 


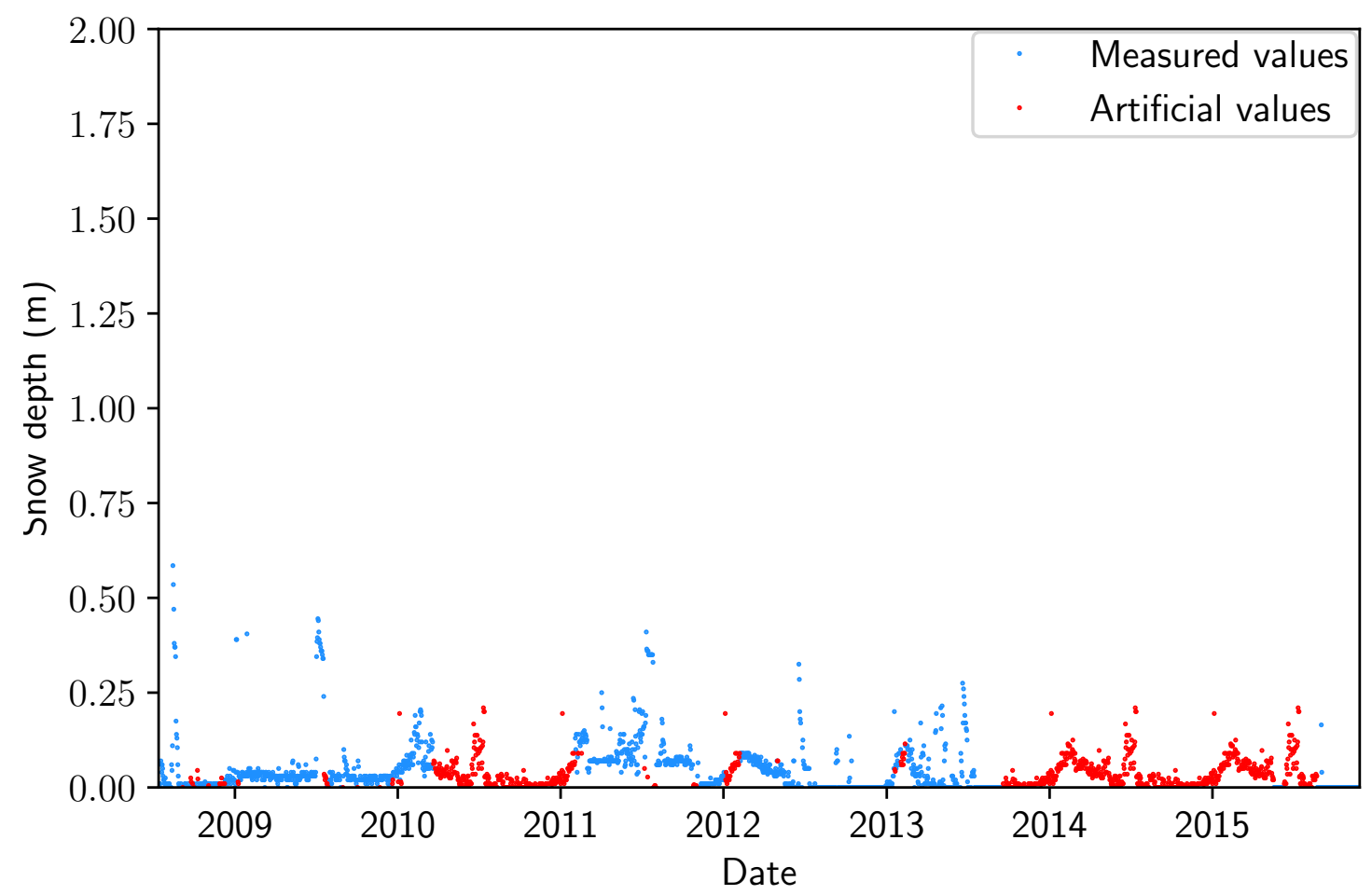

Figure A.12: Completed dataset for snow accumulation at Mount Cook Ews (altitude: $2000 \mathrm{~m}$ ). Artificial values are in red. The percentage of missing values is $41 \%$.

\section{A.3 Seasonality in lake levels}

The records of Lake Pukaki and Lake Tekapo water level show substantial annual fluctuations (Figure 2.17). On an ordinal year, the inter-annual variability is nonnegligible as well (Figure A.13). On average, the levels of both lakes are higher during summer than during winter. We also note that the amplitude of fluctuations are higher for Lake Pukaki than for Lake Tekapo. 


\section{A.4. ATMOSPHERIC PRESSURE AND NEAR-SURFACE AIR TEMPERATURE133}
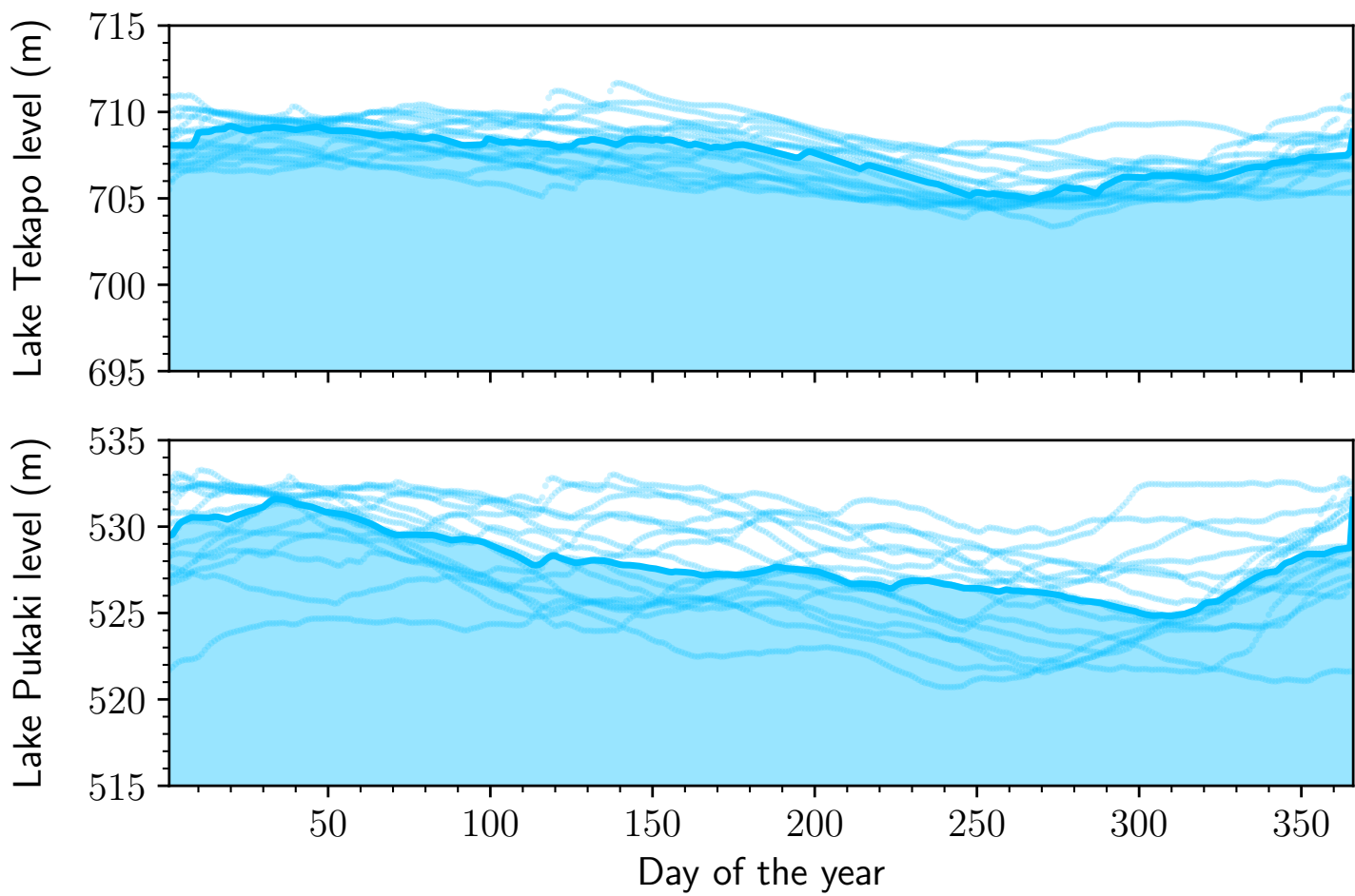

Figure A.13: Lake level, per day of the year. The blue line is the median level per day of the year, the dashed lines are all recorded years, stacked on one year. The water level is given in meters above sea level. The recording periods are 2000-2015 for Lake Pukaki and 2000-2016 for Lake Tekapo.

\section{A.4 Atmospheric pressure and near-surface air temperature}

All time series used for atmospheric pressure and near-surface air temperature are presented in Figures A.14 and A.15. 

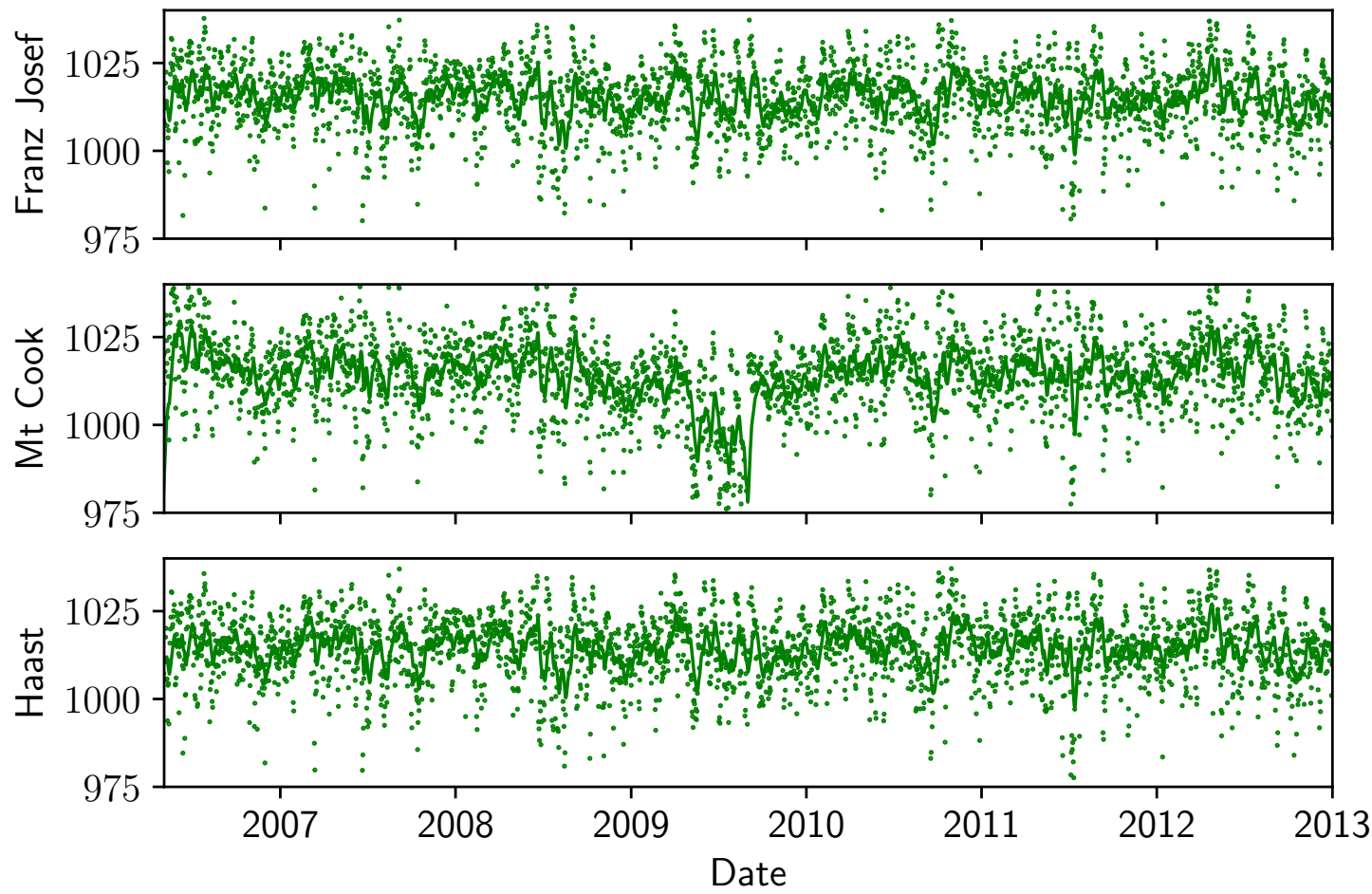

Figure A.14: Pressure time series at Franz Josef EWS, Mount Cook village EWS, Haast AWS for the period 01 May 2006 to 01 January 2013.
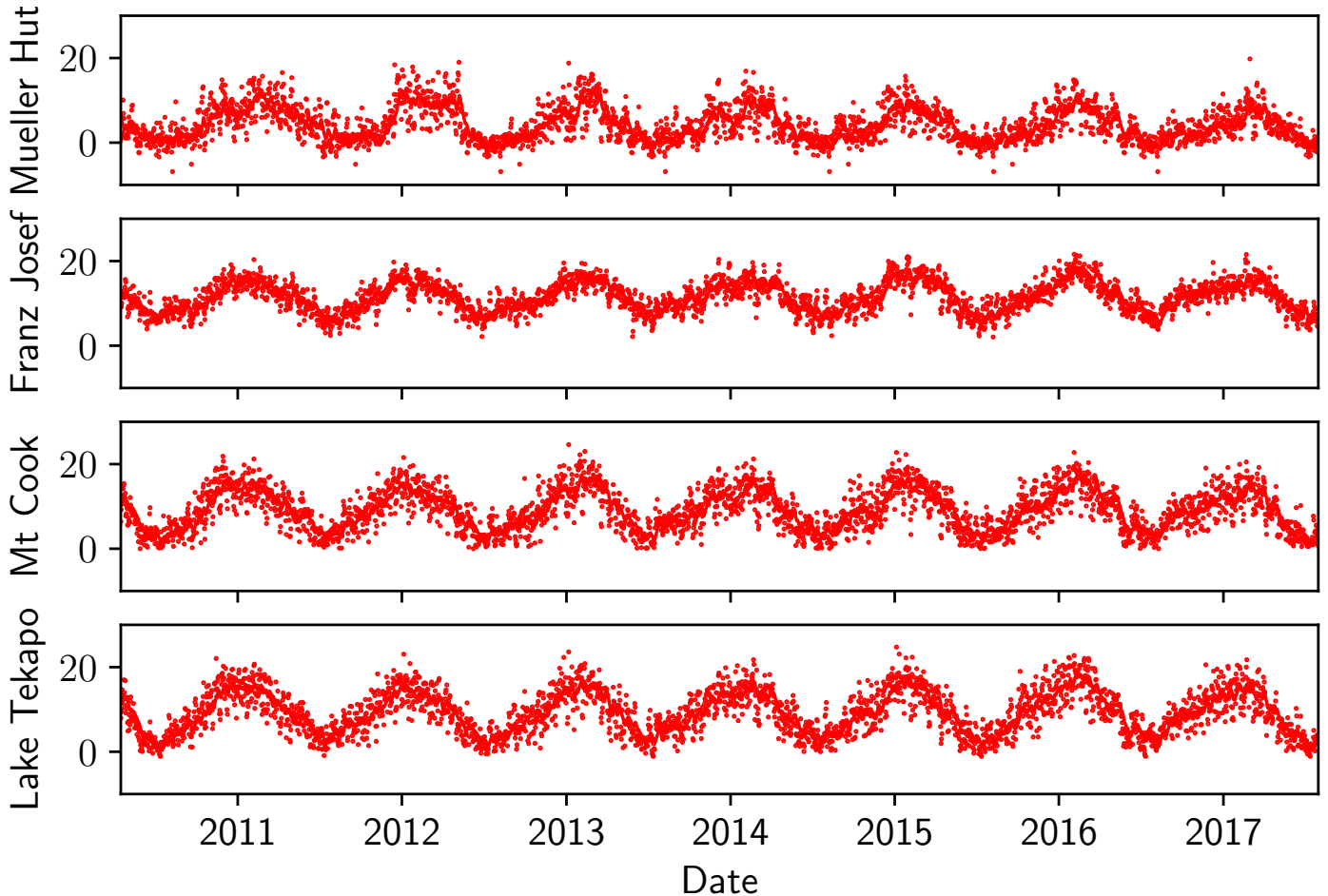

Figure A.15: Temperature time series at Mueller Hut, Franz Josef EWS, Mount Cook village EWS, Lake Tekapo for the period 16 April 2010 to 31 July 2017. 


\section{Appendix B}

\section{Supplementary geodetic data and detailed geologic maps}

We present here some detailed geologic maps at each station (except Makaroa (MAKA), MCKE, Vexation (VEXA) and Red Deer Col (REDD)), with the principal direction of displacement if possible. The four stations listed above have too much missing data $(30 \%)$ and are not considered for statistical reasons in the analysis of motion.

The blue arrow represents the general direction of displacement during the winter groundwater reservoir depletion. The black arrow represents the average direction of displacement after a heavy rain storm. For stations showing depletion during winter (diminished infiltration due to the presence of a snow layer), we compute only the summer storms. The geologic mapping was done by GNS Science. The legend of all geologic maps in this thesis are available in Cox and Barrell (2007) and Heron (2014). Red triangles are the GPS stations. Arrows are not scaled, they only indicate the average horizontal direction of movement.

The tables with cross-correlation coefficients were all made using cross-correlation coefficients, as explained in Section 2.2, and choosing the nearest climate stations with the longest record of data simultaneous to the cGPS record. Cross-correlation coefficients are given for the best lag in a period of 30 days. The number of lagged days to obtain this coefficient is given in brackets (e.g. $0.10 \mathrm{~d}$ is a cross-correlation of 0.1 with a lag of 0 days.) For stations with more than $30 \%$ of missing data, filling the dataset with the method of the ordinal median was not possible and in this case, values for Pearson's correlation coefficients are given instead of crosscorrelation coefficients with a lag of $0 \mathrm{~d}$. 


\section{B.1 Burnett Rock (BNET)}
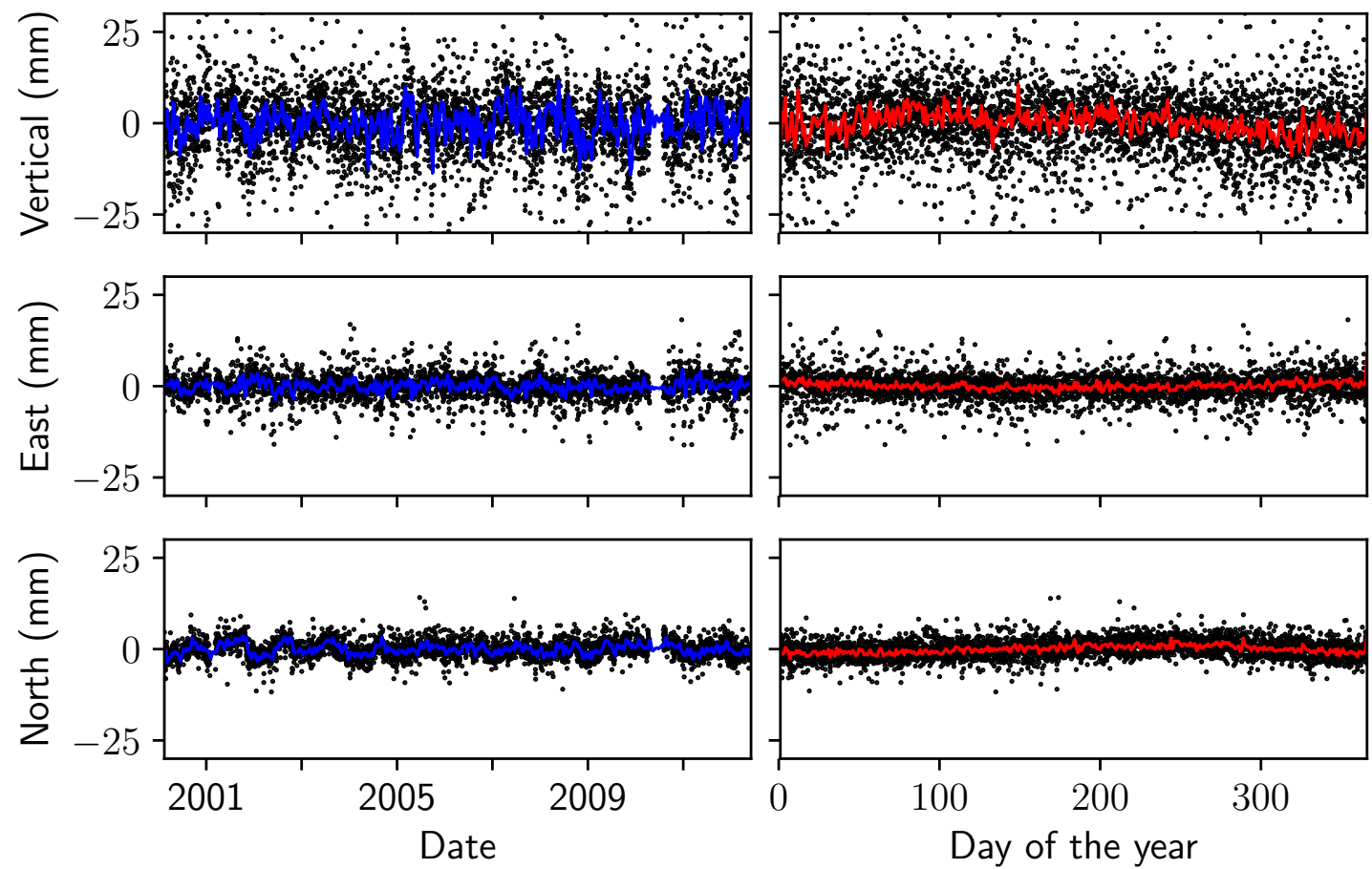

Figure B.1: Time series of ground position at Burnett Rock (BNET), in the three spatial directions with a low-pass filtering of the data in blue (left), relative to ITRF2014 reference frame. Same data represented on an ordinal year, with the daily median in red (right).

Table B.1: Cross-correlation coefficients at Burnett Rock (BNET)

\begin{tabular}{llll}
\hline & North & East & Up \\
\hline Rainfall (Lake Pukaki Guide Hill) & $0.13(2)$ & $-0.09(2)$ & $-0.22(2)$ \\
Snowfall (Mount Cook Ews) & $-0.08(28)$ & $0.05(18)$ & $0.06(22)$ \\
Temperature (Mount Cook) & $-0.24(4)$ & $0.17(3)$ & $0.19(2)$ \\
Pressure (Mount Cook) & $-0.08(2)$ & $0.10(2)$ & $0.32(0)$ \\
Lake Level (Lake Pukaki) & $-0.32(0)$ & $0.06(29)$ & $-0.11(29)$ \\
\hline
\end{tabular}




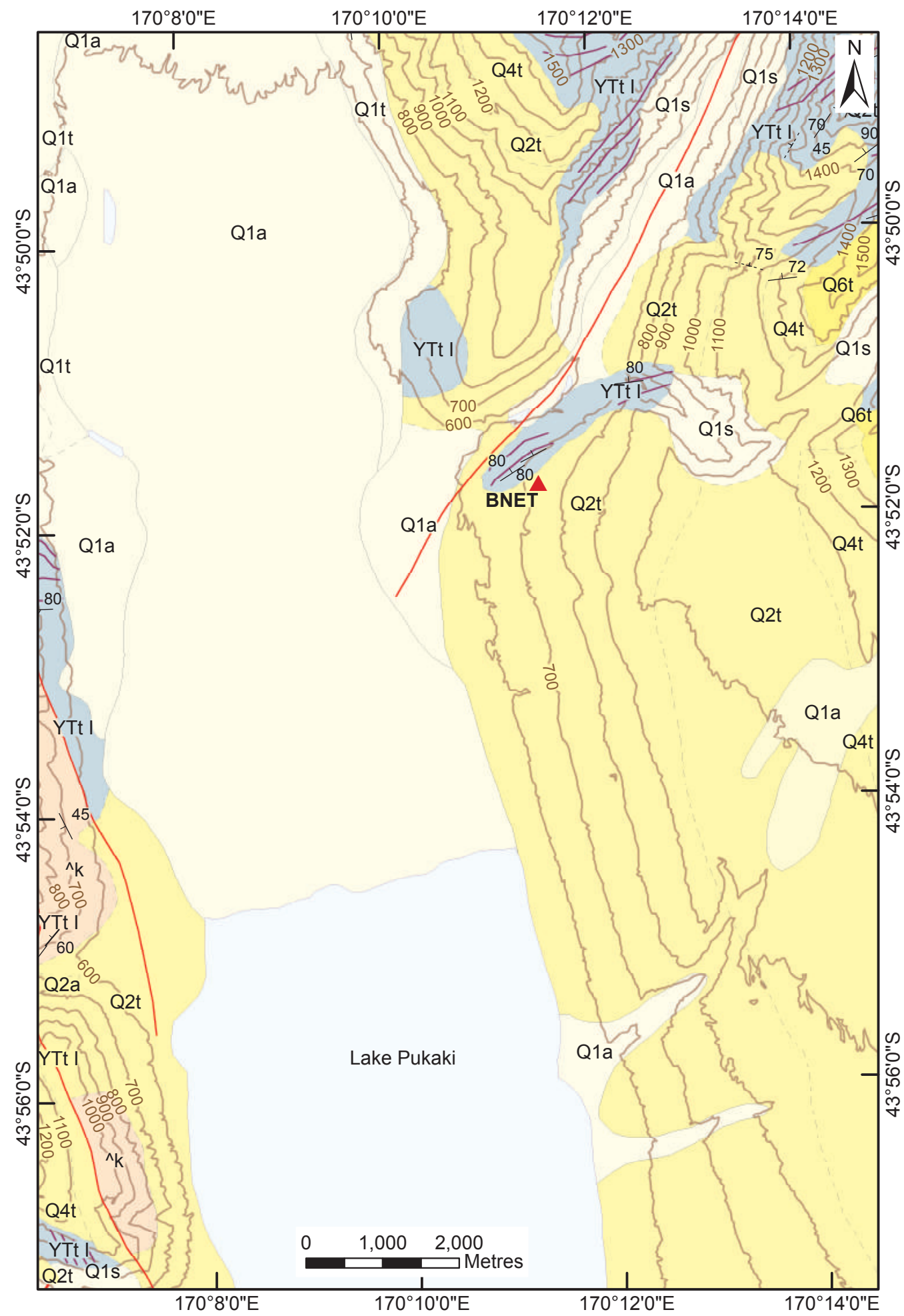

Figure B.2: Detailed geologic map around Burnett Rock (BNET) 


\section{B.2 Conical Hill (CNCL)}
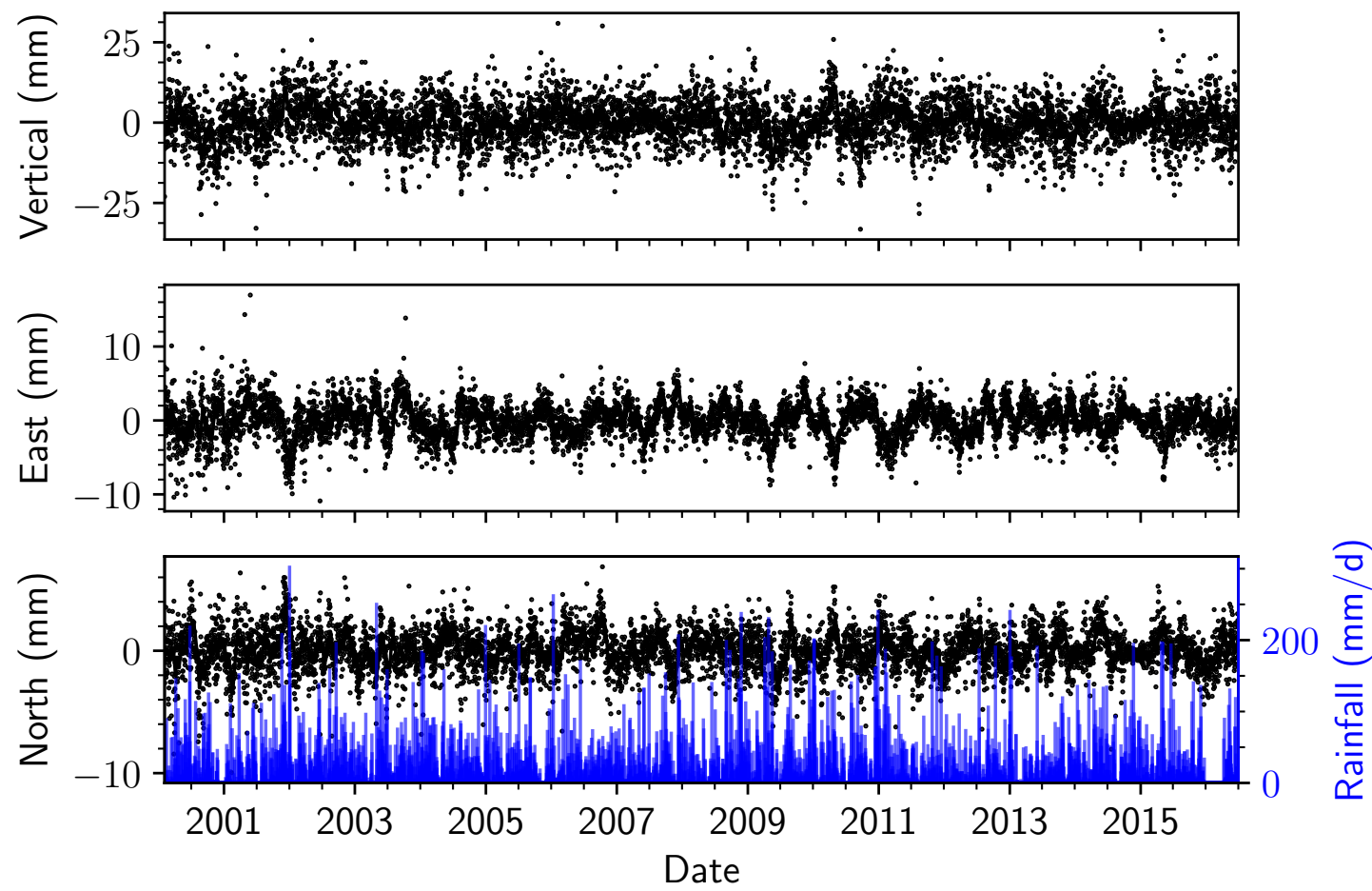

Figure B.3: Comparison between cGPS at Conical Hill (CNCL) and rainfall at Franz Josef EWS.

Table B.2: Cross-correlation coefficients at Conical Hill (CNCL)

\begin{tabular}{llll}
\hline & North & East & Up \\
\hline Rainfall (Mueller Hut) & $0.12(0)$ & $-0.14(0)$ & $0.13(3)$ \\
Snowfall (Mueller Hut) & $-0.11(1)$ & $0.33(0)$ & $-0.20(2)$ \\
Temperature (Mount Cook) & $-0.10(29)$ & $0.06(29)$ & $0.27(2)$ \\
Pressure (Haast) & $-0.07(25)$ & $0.05(0)$ & $0.29(0)$ \\
Lake Level (Lake Pukaki) & $-0.08(0)$ & $-0.29(13)$ & $-0.03(0)$ \\
\hline
\end{tabular}




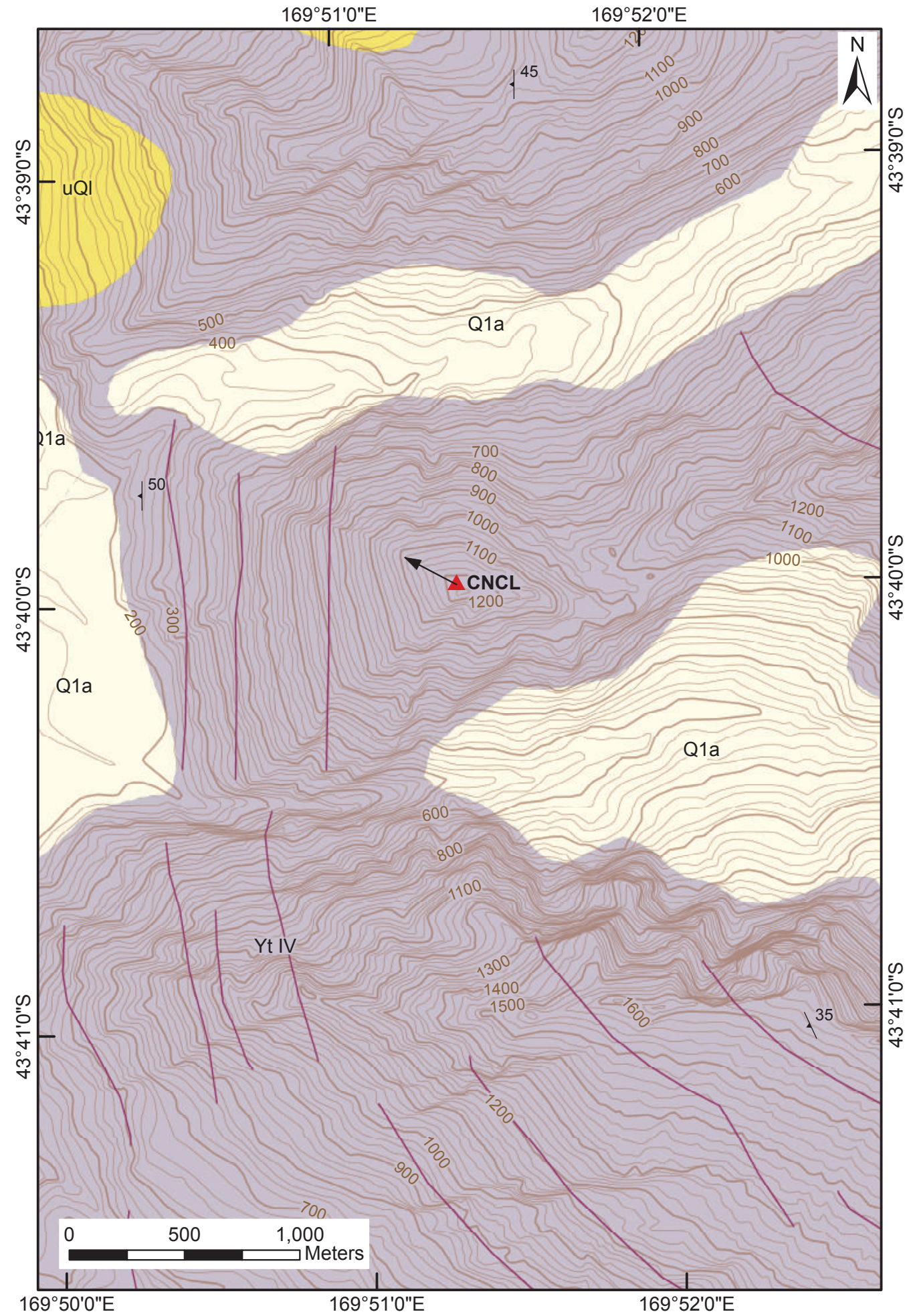

Figure B.4: Detailed geologic map around Conical Hill (CNCL) 


\section{B.3 Gunn Ridge (GUNR)}
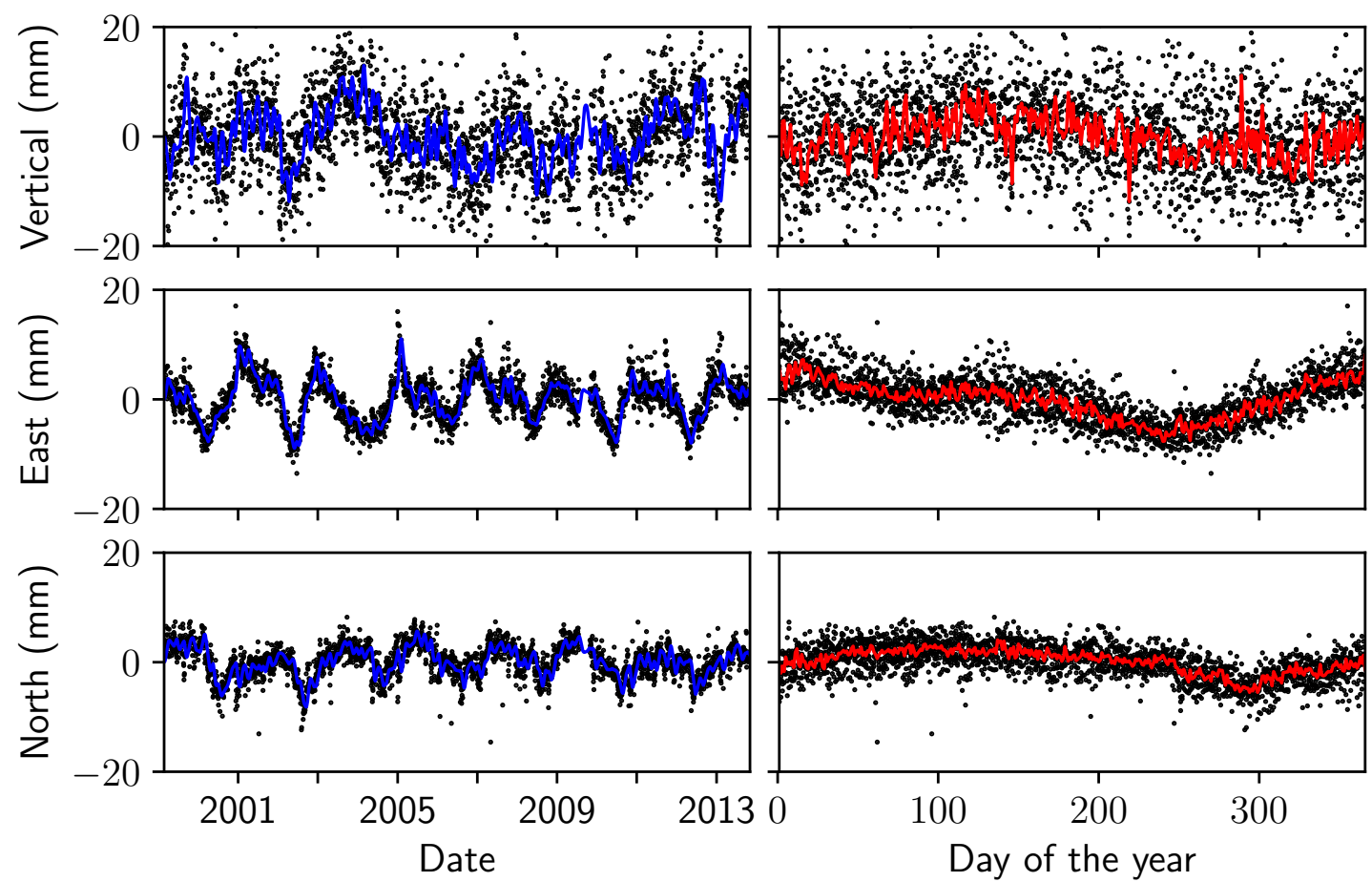

Figure B.5: Time series of ground position at Gunn Ridge (GUNR), in the three spatial directions with a low-pass filtering of the data in blue (left), relative to ITRF2014 reference frame. Same data represented on an ordinal year, with the daily median in red (right).

Table B.3: Cross-correlation coefficients at Gunn Ridge (GUNR)

\begin{tabular}{lllll}
\hline & North & East & Up & PC 1 \\
\hline Rainfall (Franz Josef) & $-0.14(0)$ & $0.15(0)$ & $0.06(2)$ & $0.06(2)$ \\
Snowfall (Rose Ridge) & $-0.40(0)$ & $-0.65(20)$ & $-0.16(2)$ & $-0.16(2)$ \\
Temperature (Franz Josef) & $-0.17(29)$ & $0.49(0)$ & $-0.17(26)$ & $-0.18(26)$ \\
Pressure (Haast) & $0.12(0)$ & $0.06(9)$ & $0.31(0)$ & $0.31(0)$ \\
Lake Level (Lake Pukaki) & $0.11(0)$ & $0.54(14)$ & $0.02(26)$ & $-0.02(0)$ \\
\hline
\end{tabular}




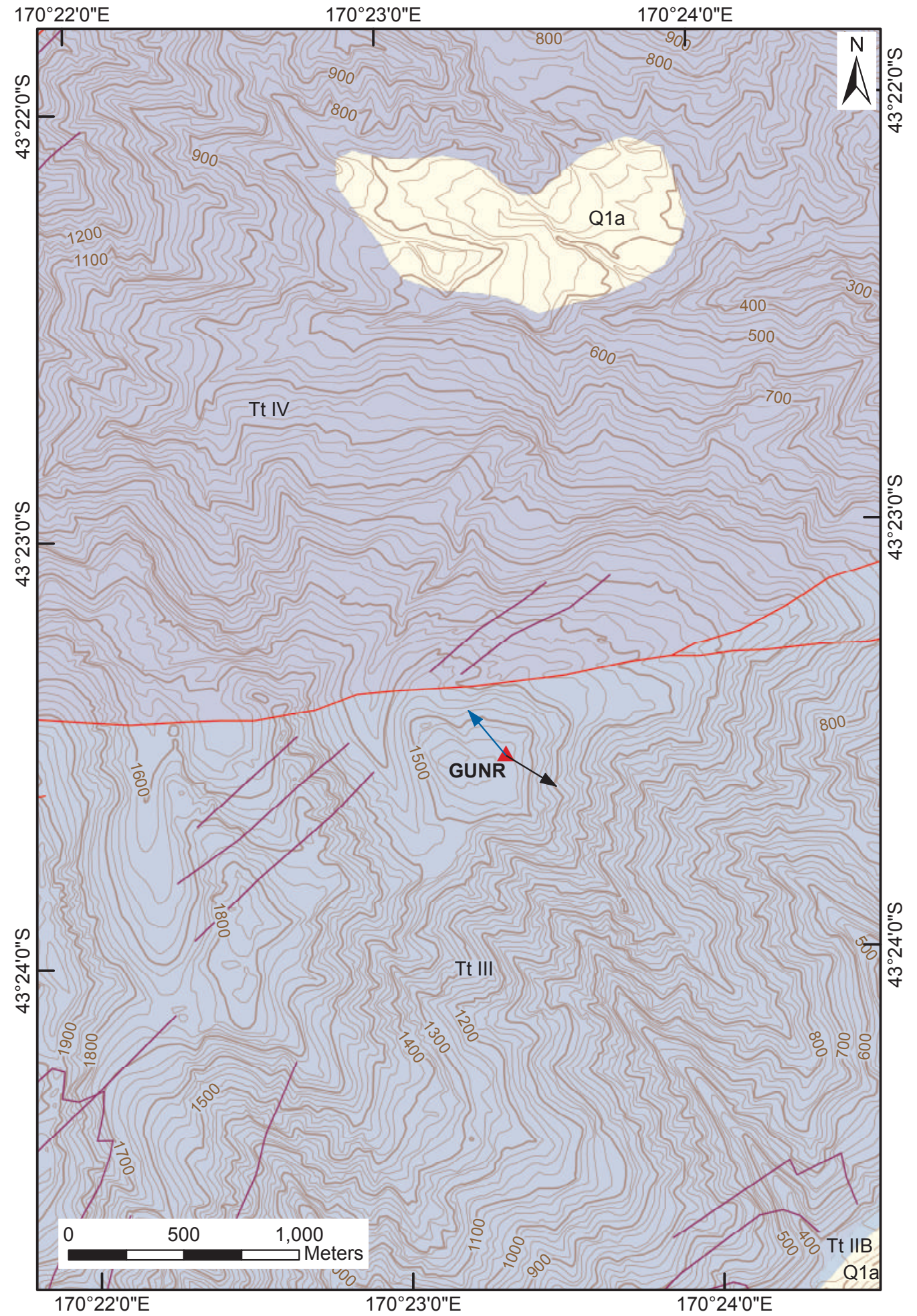

Figure B.6: Detailed geologic map around Gunn Ridge (GUNR) 


\section{B.4 Haast (HAAS)}
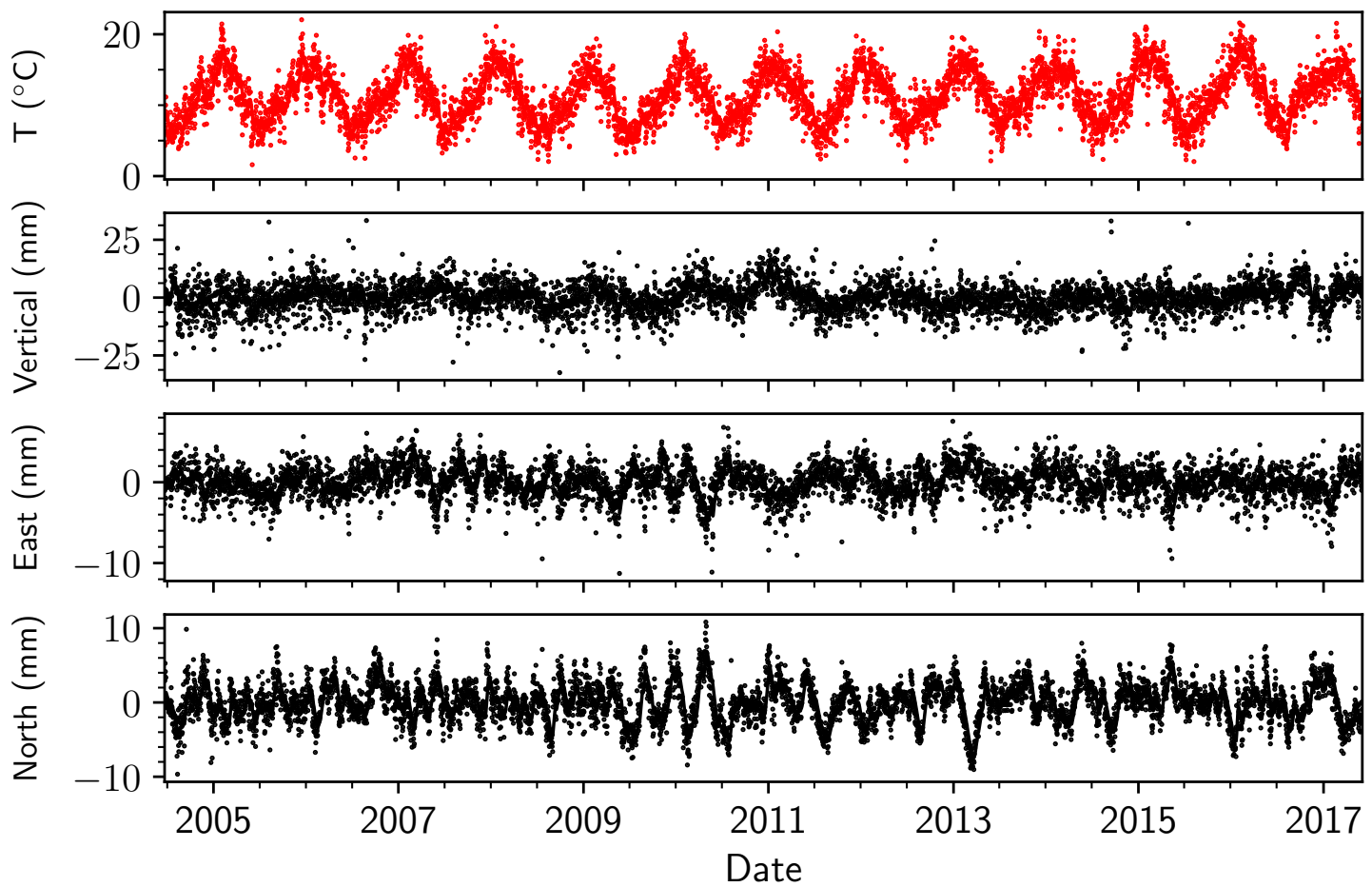

Figure B.7: cGPS at Haast (HAAS) (black) versus Mean Air Temperature at Haast (red). Note that the Vertical component of the GPS has a different scale than the horizontal components.

Table B.4: Cross-correlation coefficients at Haast (HAAS)

\begin{tabular}{llll}
\hline & North & East & Up \\
\hline Rainfall (Haast) & $0.19(0)$ & $-0.13(0)$ & $-0.11(0)$ \\
Snowfall (Mueller Hut) & $0.04(1)$ & $0.05(0)$ & $-0.21(2)$ \\
Temperature (Franz Josef) & $0.02(13)$ & $0.14(4)$ & $0.24(3)$ \\
Pressure (Haast) & $-0.08(26)$ & $0.09(1)$ & $0.34(1)$ \\
Lake Level (Lake Pukaki) & $0.19(29)$ & $-0.12(19)$ & $0.08(0)$ \\
\hline
\end{tabular}




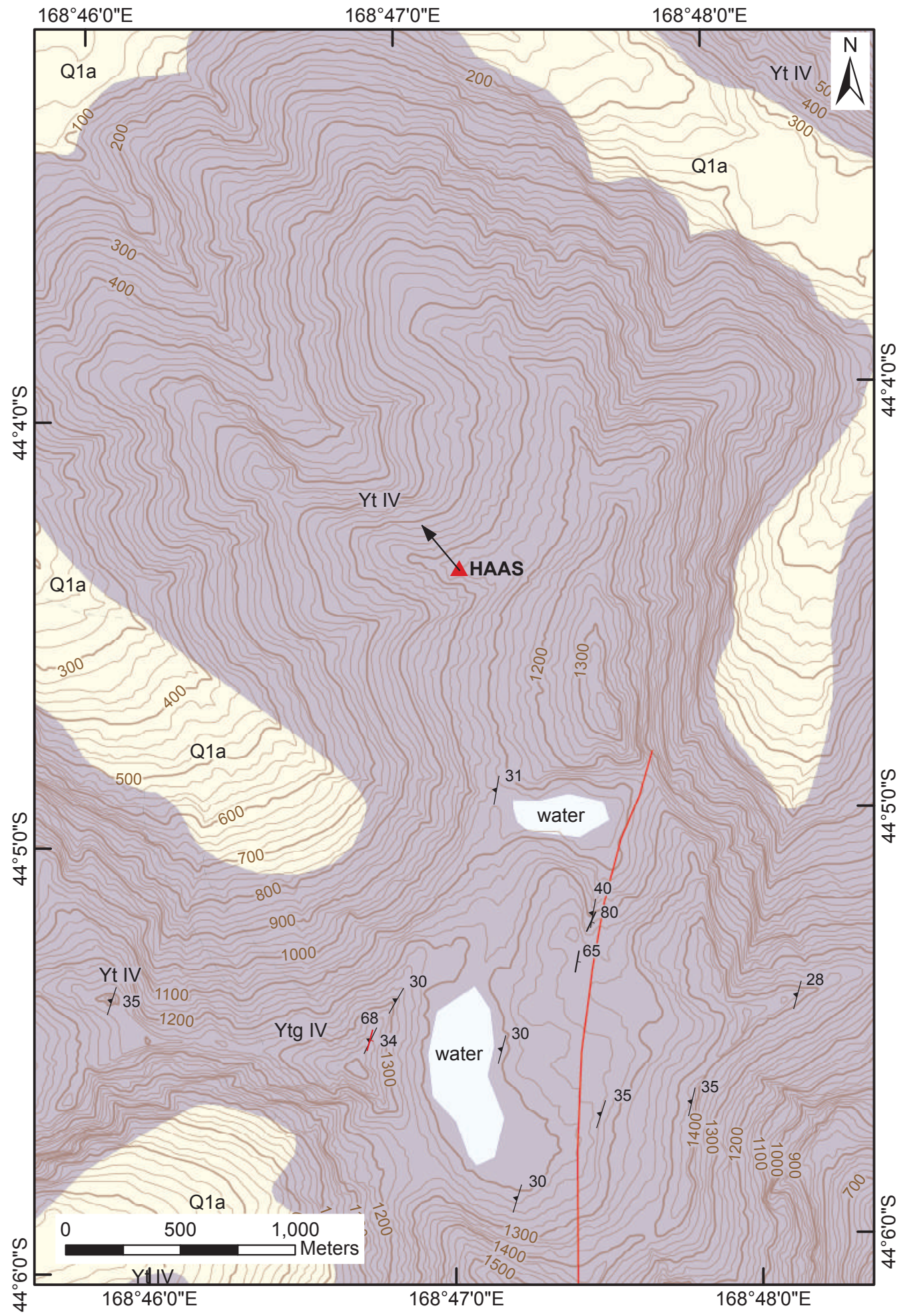

Figure B.8: Detailed geologic map around Haast (HAAS) 


\section{B.5 Hokitika (HOKI)}
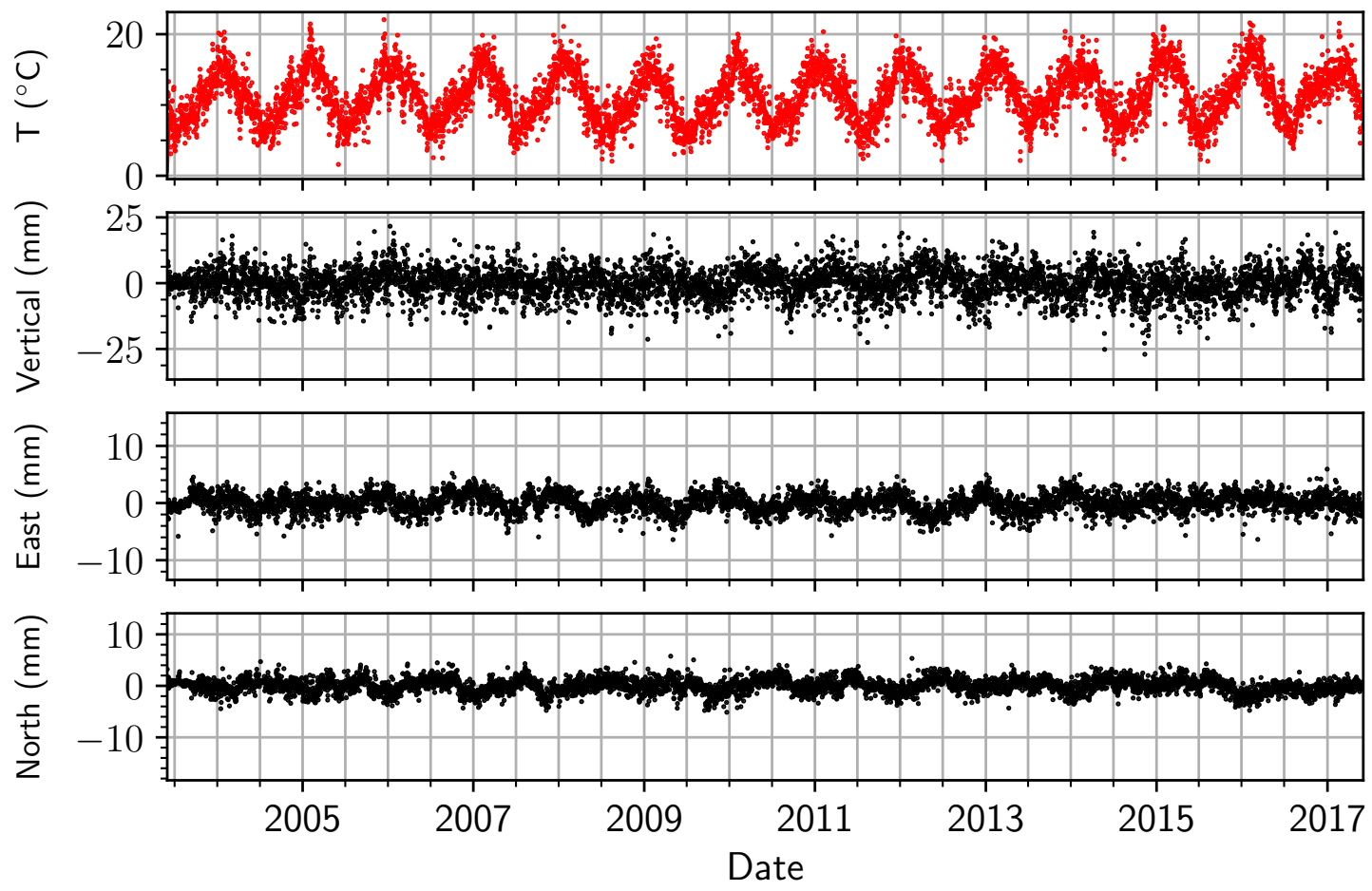

Figure B.9: cGPS at Hokitika (HOKI) (black) versus Mean Air Temperature in Franz Josef (red). Note that the Vertical component of the GPS has a different scale than the horizontal components.

Table B.5: Cross-correlation coefficients at Hokitika (HOKI)

\begin{tabular}{llll}
\hline & North & East & Up \\
\hline Rainfall (Hokitika) & $0.04(2)$ & $-0.07(2)$ & $-0.17(0)$ \\
Snowfall (Mueller Hut) & $0.17(29)$ & $0.10(0)$ & $-0.24(2)$ \\
Temperature (Franz Josef) & $-0.35(28)$ & $0.29(22)$ & $0.26(2)$ \\
Pressure (Haast) & $-0.08(27)$ & $0.06(1)$ & $0.36(0)$ \\
Lake Level (Lake Pukaki) & $-0.16(29)$ & $-0.02(2)$ & $-0.05(29)$ \\
\hline
\end{tabular}




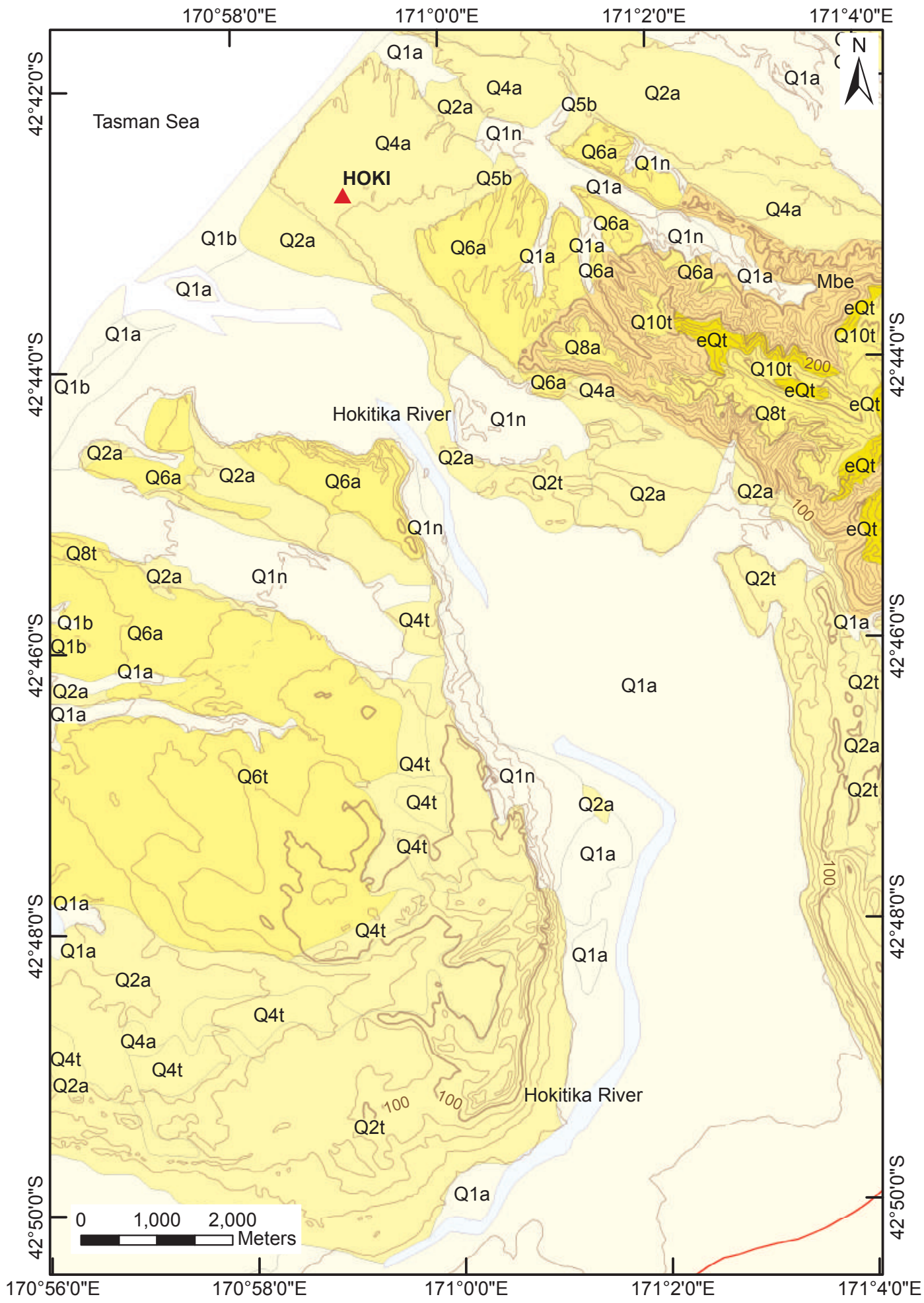

Figure B.10: Detailed geologic map around Hokitika (HOKI) 


\section{B.6 Hoophorn Spur (HORN)}
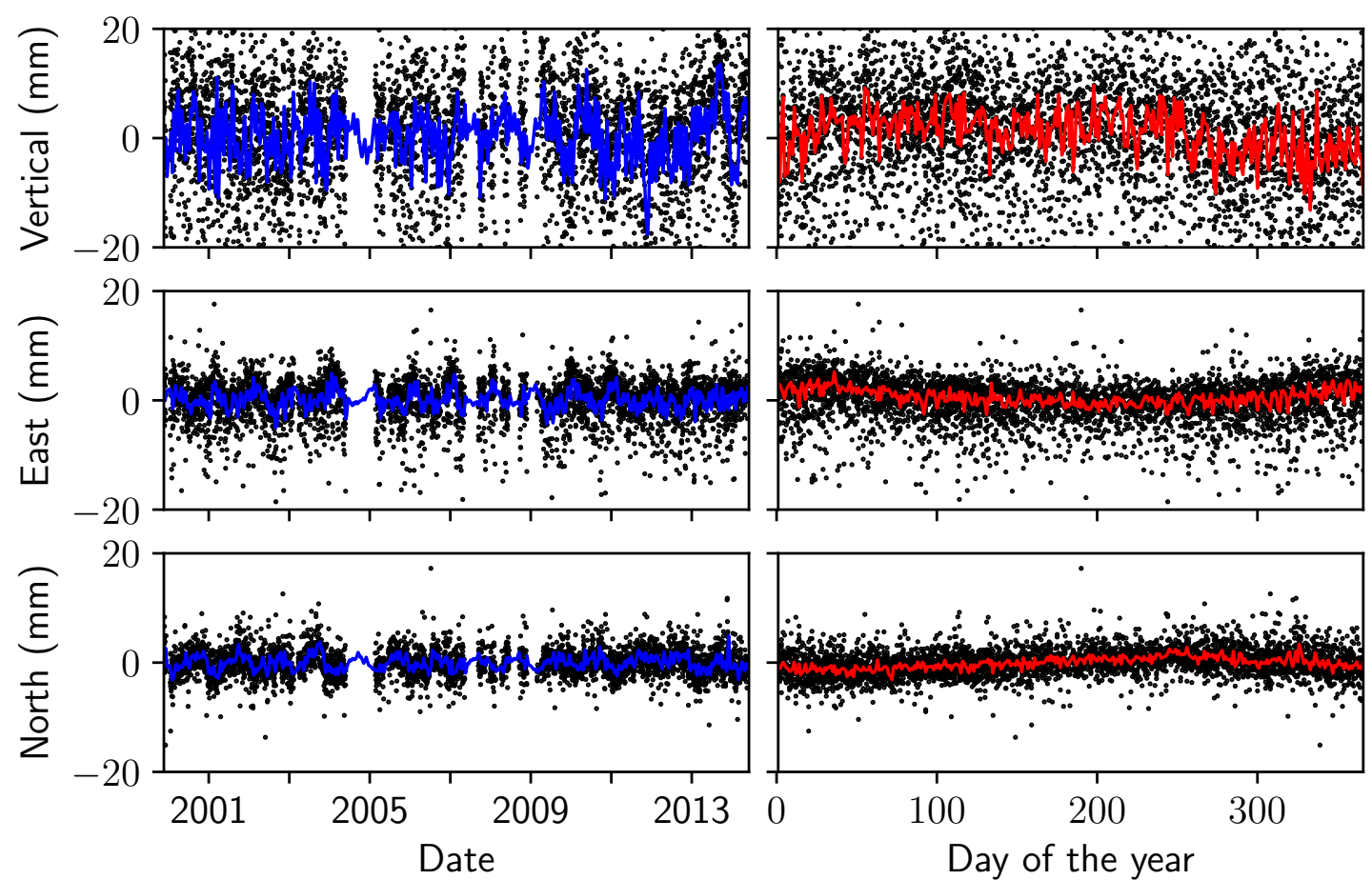

Figure B.11: Time series of ground position at Hoophorn Spur (HORN), in the three spatial directions with a low-pass filtering of the data in blue (left), relative to ITRF2014 reference frame. Same data represented on an ordinal year, with the daily median in red (right).

Table B.6: Cross-correlation coefficients at Hoophorn Spur (HORN)

\begin{tabular}{llll}
\hline & North & East & Up \\
\hline Rainfall (Mount Cook) & $0.05(3)$ & $-0.15(2)$ & $-0.26(2)$ \\
Snowfall (Mount Cook Ews) & $-0.15(28)$ & $0.11(8)$ & $0.09(19)$ \\
Temperature (Mount Cook) & $-0.19(0)$ & $0.23(4)$ & $-0.11(26)$ \\
Pressure (Mount Cook) & $-0.07(29)$ & $0.12(2)$ & $0.31(1)$ \\
Lake Level (Lake Pukaki) & $-0.23(2)$ & $0.14(0)$ & $-0.05(29)$ \\
\hline
\end{tabular}




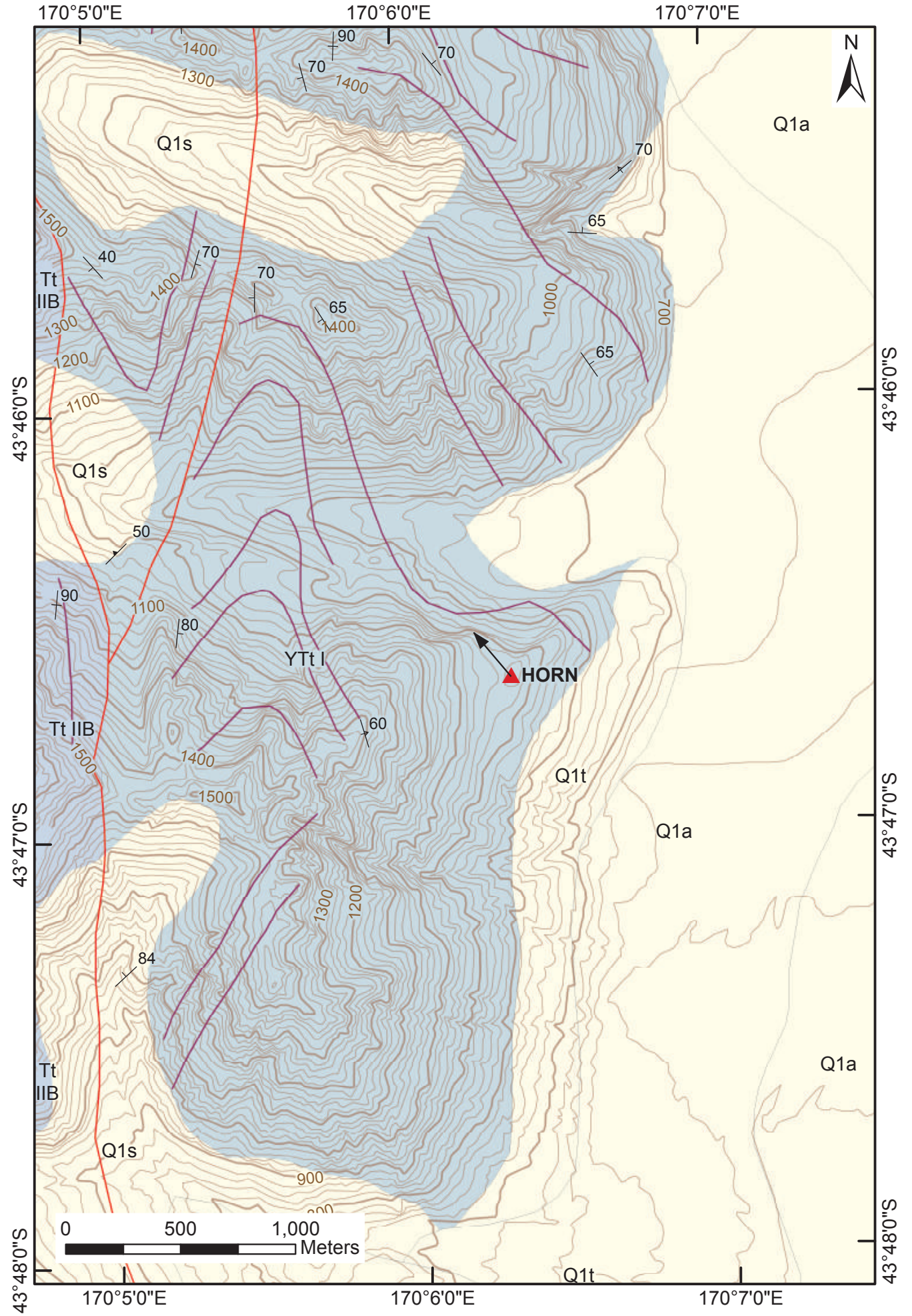

Figure B.12: Detailed geologic map around Hoophorn Spur (HORN) 


\section{B.7 Karangarua (KARA)}
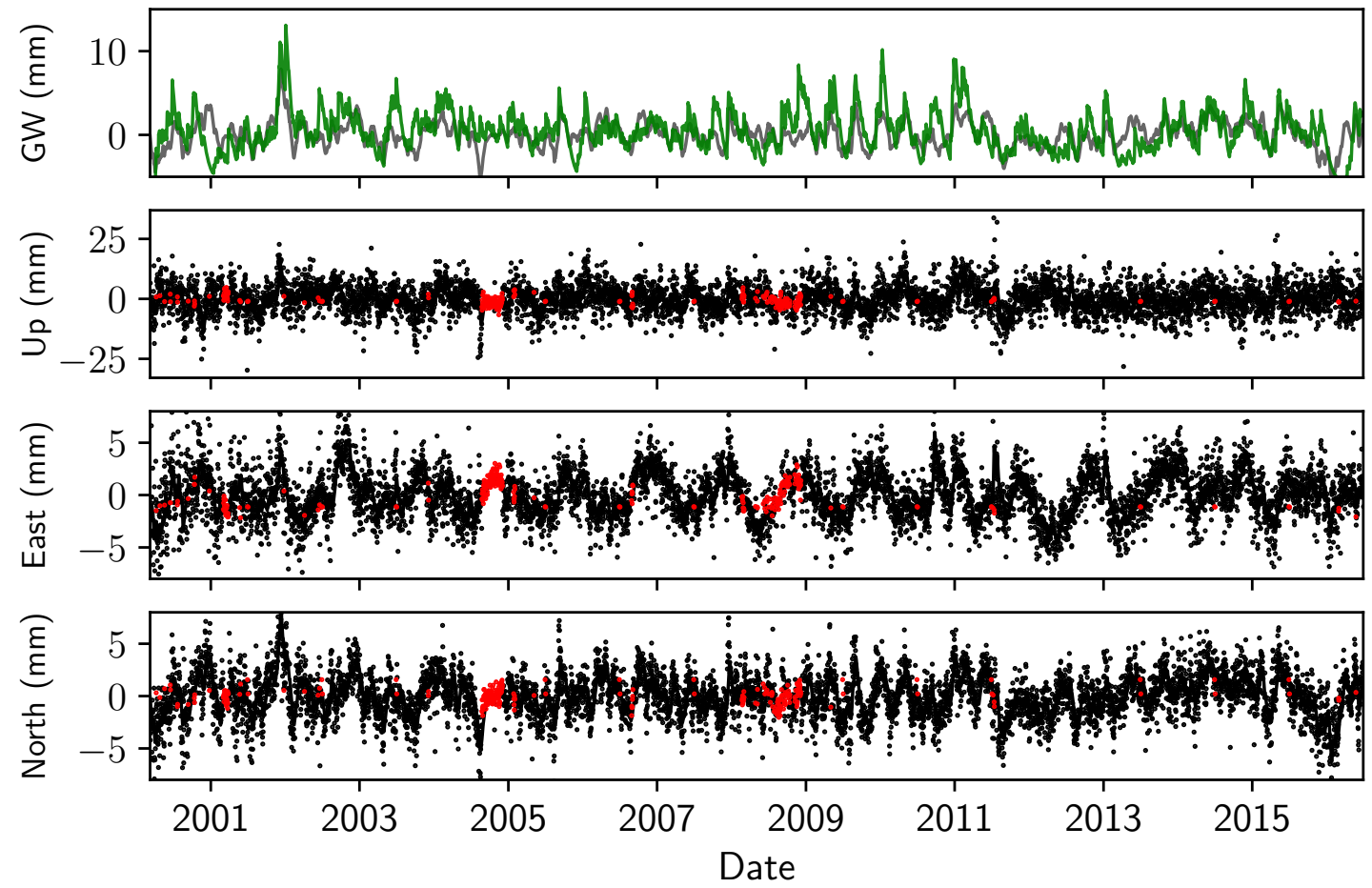

Figure B.13: Modelled unidimensional displacement due to groundwater level only (green), with North component of GPS for comparison. GPS displacement at Karangarua (KARA) (Measured in black, artificial in red). Note that the scale is different for the vertical component.

Table B.7: Cross-correlation coefficients at Karangarua (KARA)

\begin{tabular}{llll}
\hline & North & East & Up \\
\hline Rainfall (Franz Josef) & $0.17(0)$ & $0.19(0)$ & $0.10(3)$ \\
Snowfall (Mueller Hut) & $-0.10(7)$ & $0.32(0)$ & $-0.20(2)$ \\
Temperature (Franz Josef) & $0.05(0)$ & $0.23(29)$ & $0.24(2)$ \\
Pressure (Haast) & $-0.09(0)$ & $-0.17(0)$ & $0.24(0)$ \\
Lake Level (Lake Pukaki) & $0.18(29)$ & $0.11(29)$ & $0.14(23)$ \\
\hline
\end{tabular}




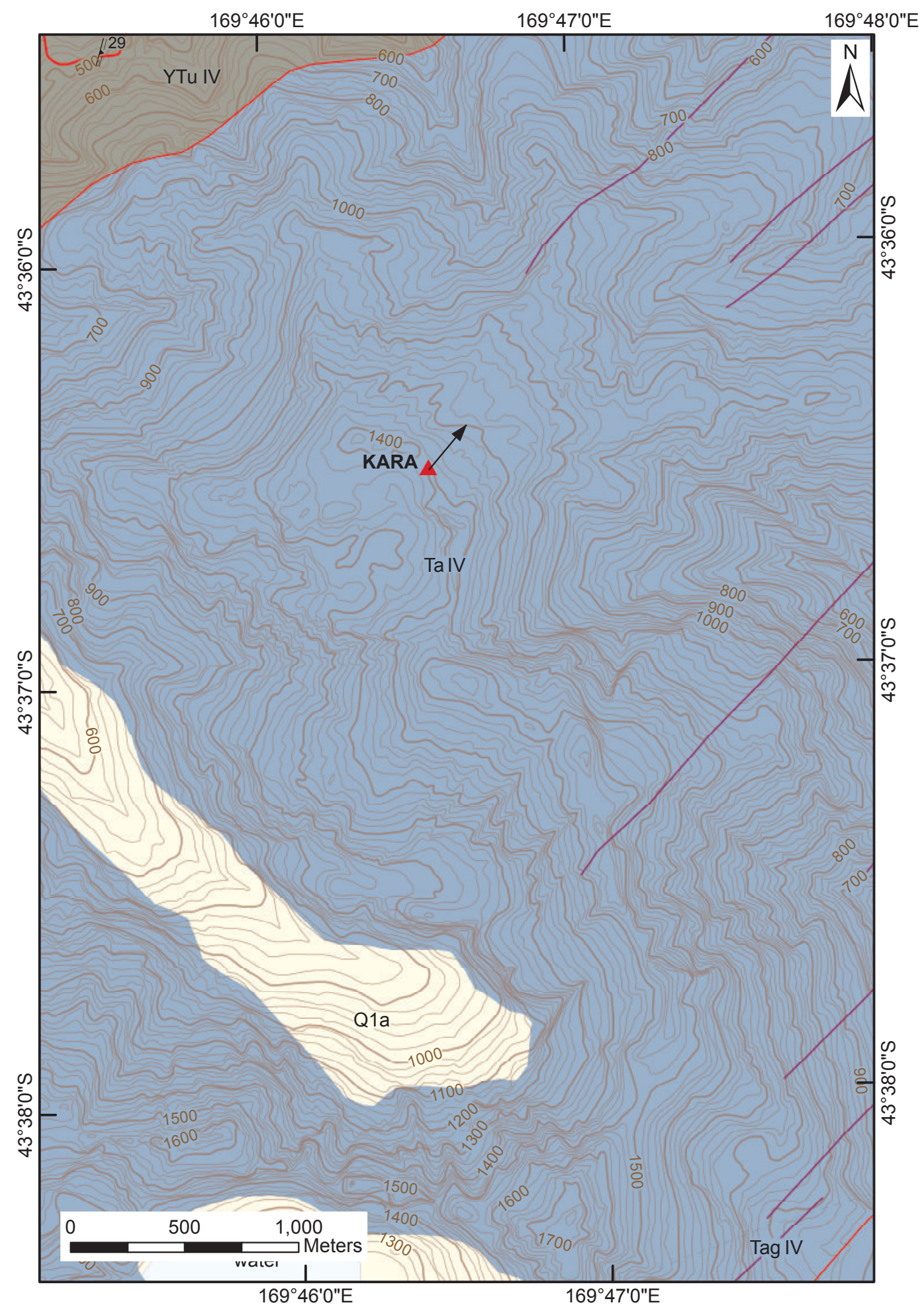

Figure B.14: Detailed geologic map around Karangarua (KARA) 


\section{B.8 Leo Creek (LEOC)}
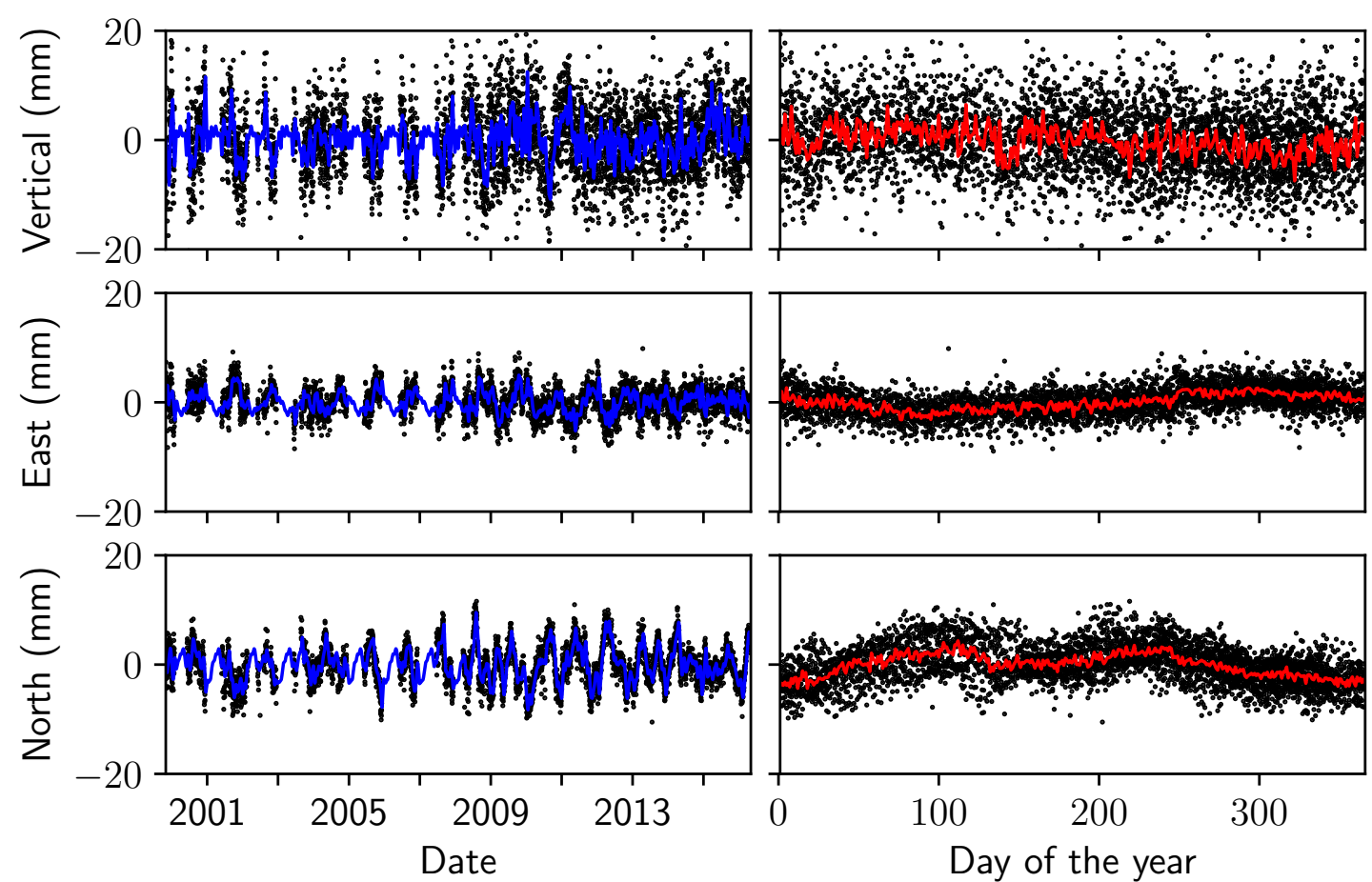

Figure B.15: Time series of ground position at Leo Creek (LEOC), in the three spatial directions with a low-pass filtering of the data in blue (left), relative to ITRF2014 reference frame. Same data represented on an ordinal year, with the daily median in red (right).

Table B.8: Cross-correlation coefficients at Leo Creek (LEOC)

\begin{tabular}{llll}
\hline & North & East & Up \\
\hline Rainfall (Franz Josef) & $-0.10(0)$ & $0.08(0)$ & $0.14(2)$ \\
Snowfall (Mueller Hut) & $0.12(29)$ & $0.39(0)$ & $-0.19(1)$ \\
Temperature (Franz Josef) & $-0.35(29)$ & $0.18(29)$ & $0.19(2)$ \\
Pressure (Mount Cook) & $0.13(0)$ & $-0.13(9)$ & $0.20(0)$ \\
Lake Level (Lake Pukaki) & $-0.37(29)$ & $-0.11(0)$ & $0.10(13)$ \\
\hline
\end{tabular}




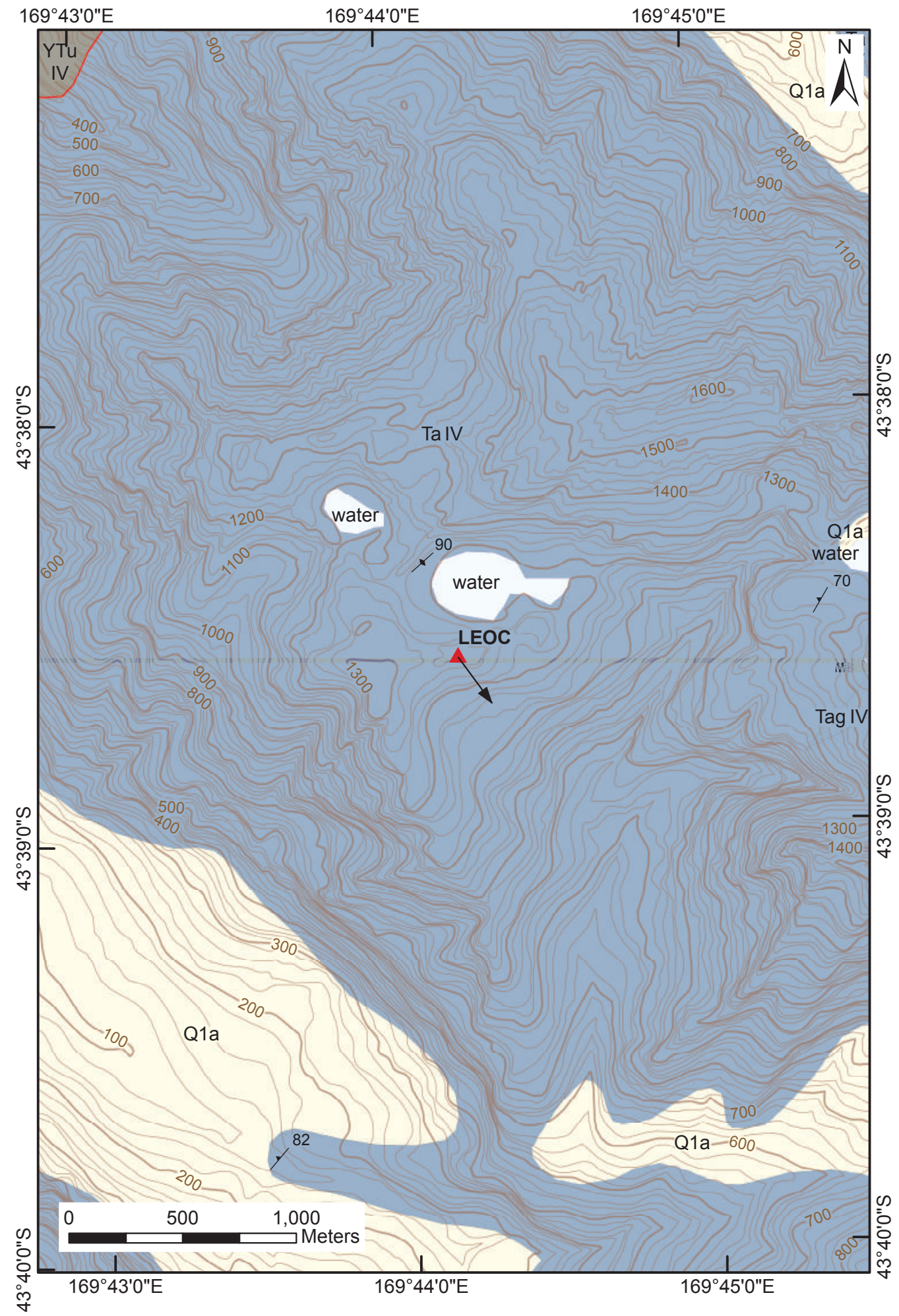

Figure B.16: Detailed geologic map around Leo Creek (LEOC) 


\section{B.9 Mount Cox (MTCX)}
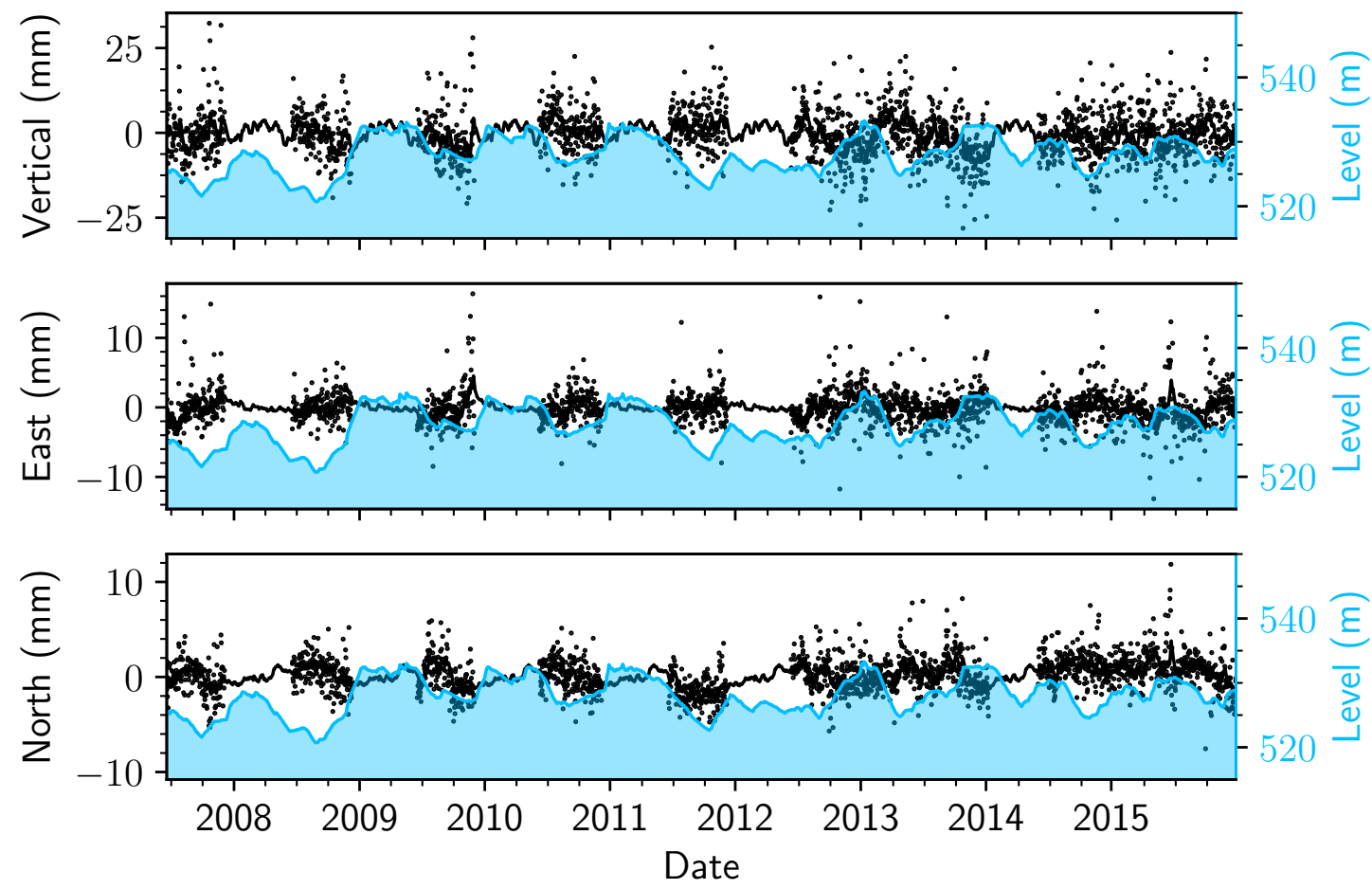

Figure B.17: Comparison between Burnett Rock (BNET) position measured (black) and Lake Pukaki lake level (blue). Note that the scale is different for each cGPS component.

Table B.9: Cross-correlation coefficients at Mt Cox (MTCX)

\begin{tabular}{llll}
\hline & North & East & Up \\
\hline Rainfall (Mueller Hut) & $0.08(1)$ & $0.07(4)$ & $-0.08(0)$ \\
Snowfall (Mueller Hut) & $0.11(29)$ & $-0.05(29)$ & $-0.11(2)$ \\
Temperature (Mueller Hut) & $-0.16(22)$ & $0.12(23)$ & $0.16(2)$ \\
Pressure (Mount Cook) & $-0.04(2)$ & $-0.07(0)$ & $0.18(0)$ \\
Lake Level (Lake Pukaki) & $-0.03(29)$ & $0.04(29)$ & $-0.10(29)$ \\
\hline
\end{tabular}




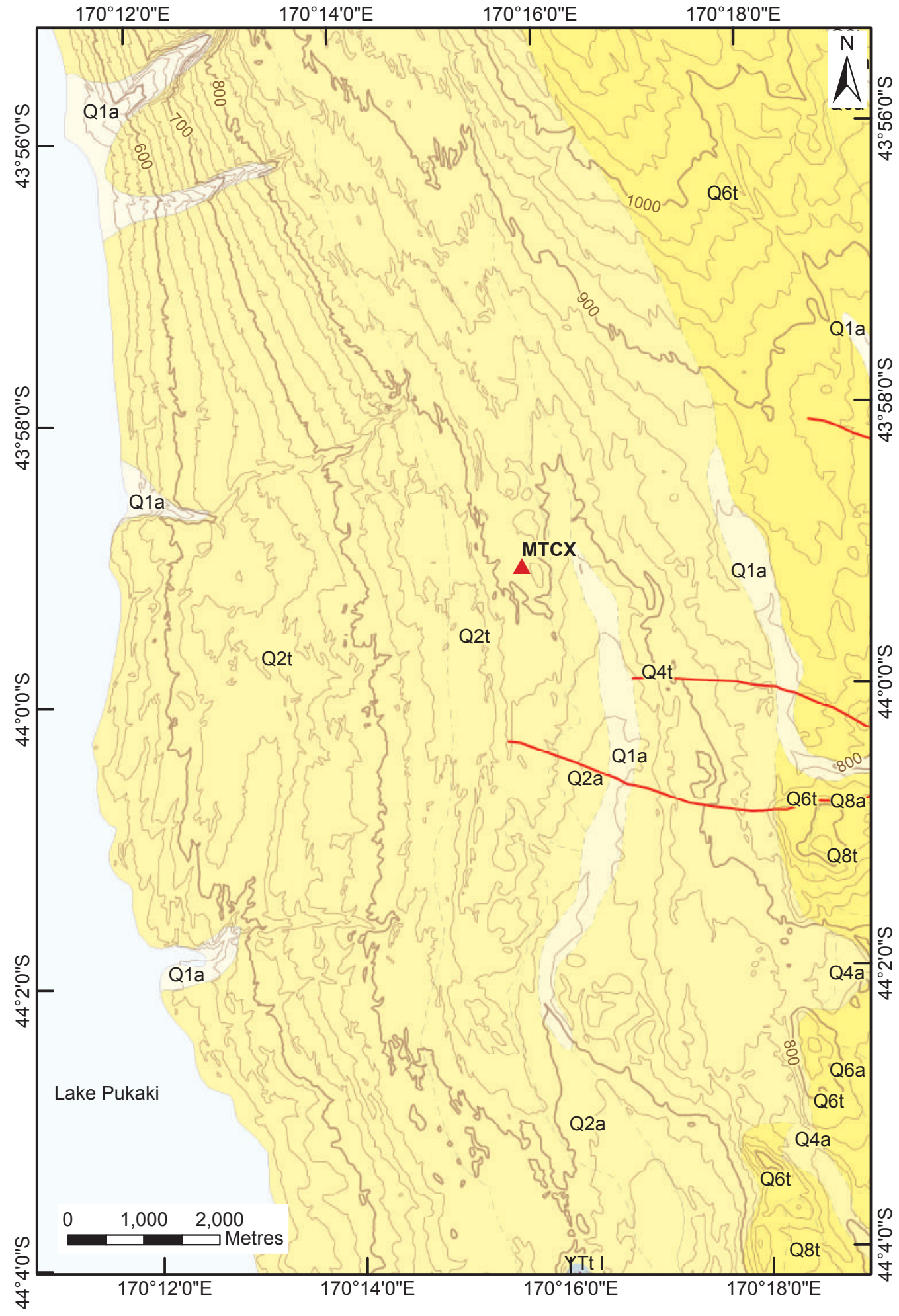

Figure B.18: Detailed geologic map around Mt Cox (MTCX) 


\section{B.10 Mount John (MTJO)}
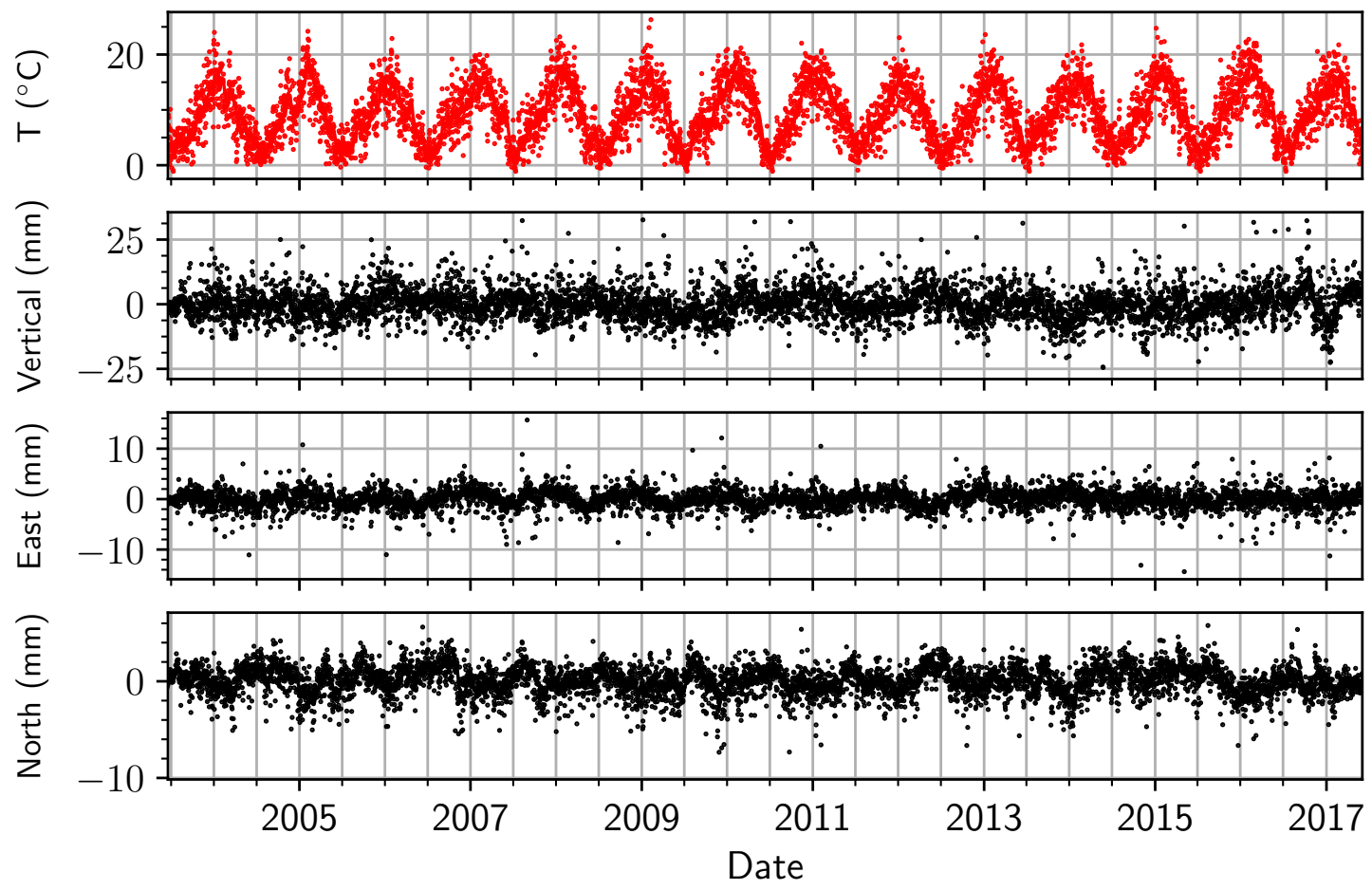

Figure B.19: cGPS at Mount John (black) versus Mean Air Temperature at Lake Tekapo (red). Note that the Vertical component of the GPS has a different scale than the horizontal components.

Table B.10: Cross-correlation coefficients at Mt John (MTJO)

\begin{tabular}{llll}
\hline & North & East & Up \\
\hline Rainfall (Lake Tekapo) & $0.04(23)$ & $-0.02(1)$ & $0.10(2)$ \\
Snowfall (Mueller Hut) & $0.10(29)$ & $0.06(0)$ & $-0.11(1)$ \\
Temperature (Lake Tekapo) & $-0.28(1)$ & $0.20(25)$ & $0.22(2)$ \\
Pressure (Mount Cook) & $0.20(1)$ & $-0.07(25)$ & $0.29(0)$ \\
Lake Level (Lake Tekapo) & $-0.21(29)$ & $-0.08(0)$ & $-0.05(1)$ \\
\hline
\end{tabular}



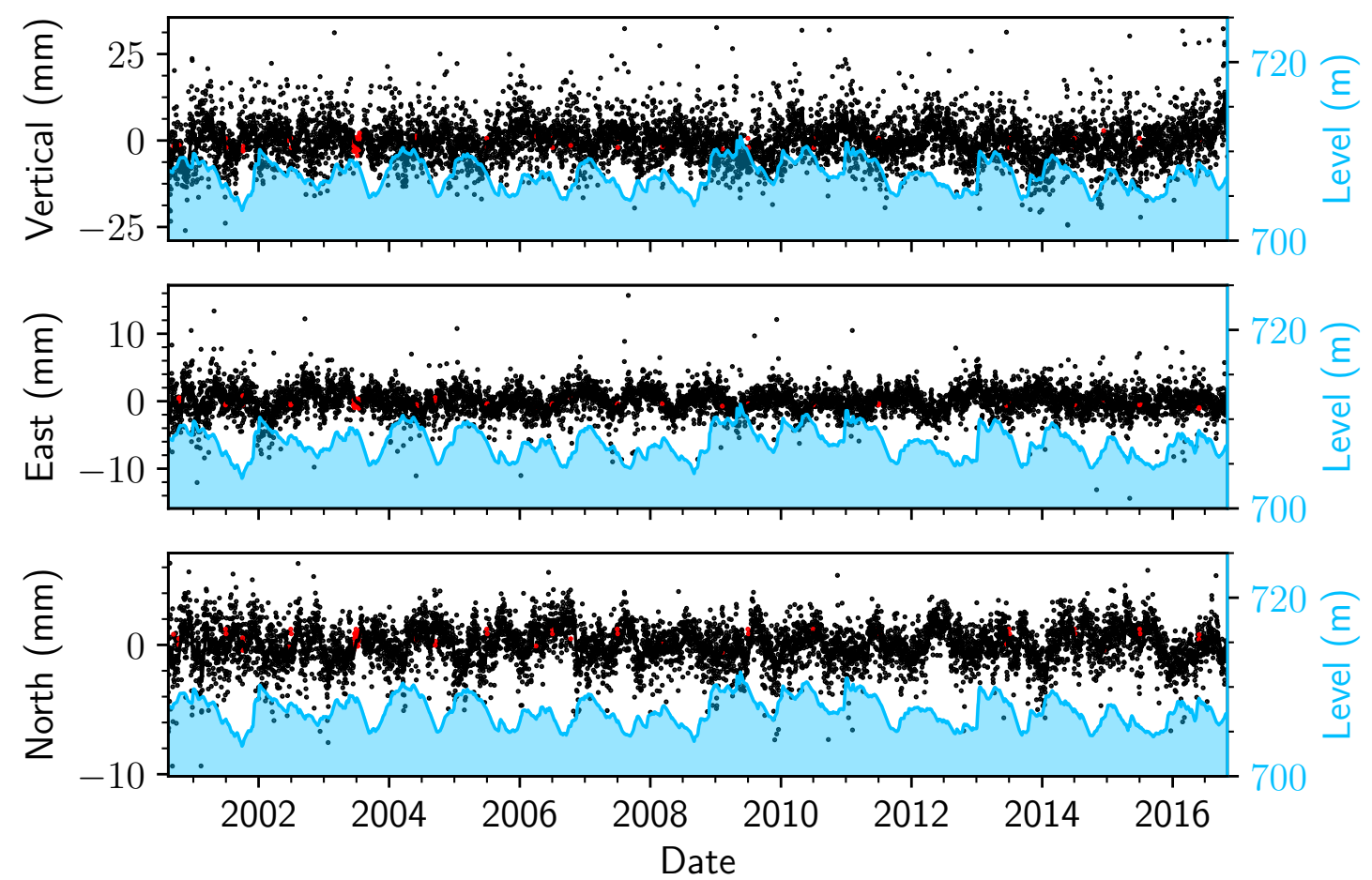

Figure B.20: Comparison between Mt John (MTJO) position measured (black), artificially filled (red) and Lake Tekapo lake level (blue). Note that the scale is different for each GPS component. The Pearson's correlation coefficients are -0.05 (U), -0.08 (E), $-0.14(\mathrm{~N})$. 


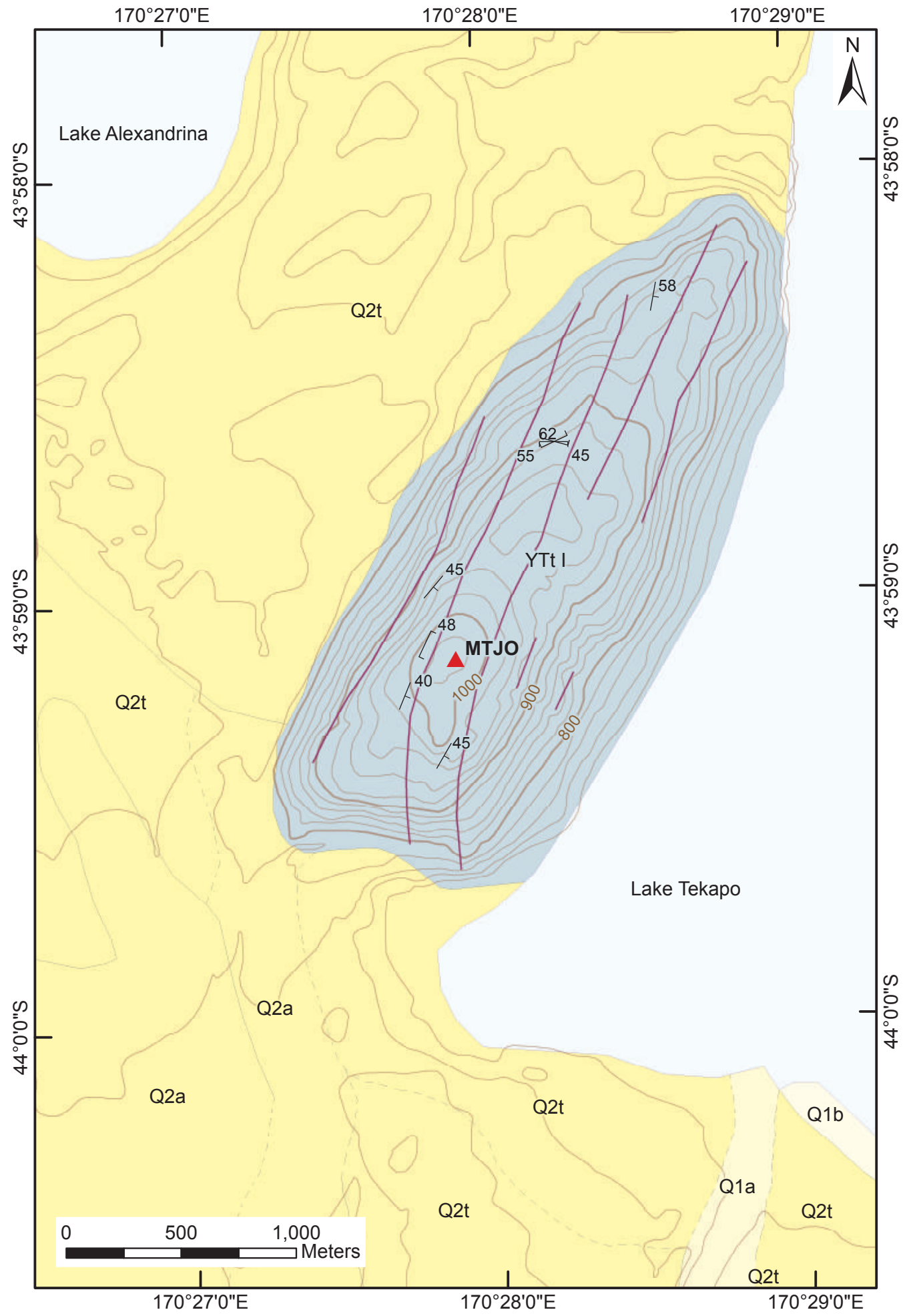

Figure B.21: Detailed geologic map around Mt John (MTJO) 
This page intentionally left blank. 


\section{B.11 Mount Price (MTPR)}
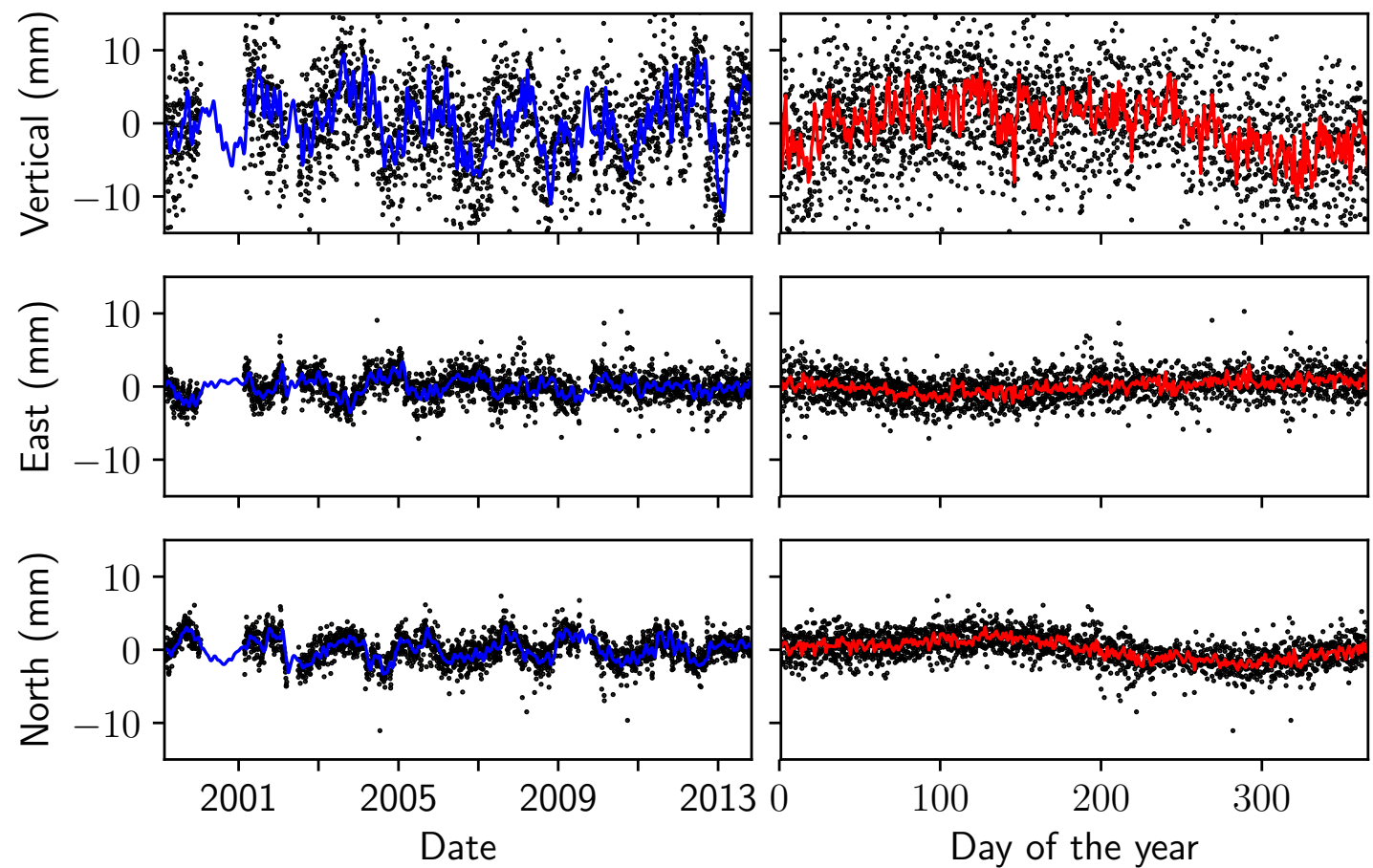

Figure B.22: Time series of ground position at Mt Price (MTPR), in the three spatial directions with a low-pass filtering of the data in blue (left), relative to ITRF2014 reference frame. Same data represented on an ordinal year, with the daily median in red (right).

Table B.11: Cross-correlation coefficients at Mt Price (MTPR)

\begin{tabular}{lllll}
\hline & North & East & Up & PC 1 \\
\hline Rainfall (Franz Josef) & $0.08(0)$ & $0.07(4)$ & $-0.11(0)$ & $-0.11(0)$ \\
Snowfall (Rose Ridge) & $-0.49(0)$ & $0.21(0)$ & $0.11(29)$ & $0.10(29)$ \\
Temperature (Franz Josef) & $0.15(0)$ & $0.09(29)$ & $-0.23(29)$ & $-0.23(29)$ \\
Pressure (Haast) & $0.08(5)$ & $-0.12(7)$ & $0.31(1)$ & $0.31(1)$ \\
Lake Level (Lake Pukaki) & $0.21(2)$ & $0.13(29)$ & $-0.13(29)$ & $-0.13(29)$ \\
\hline
\end{tabular}




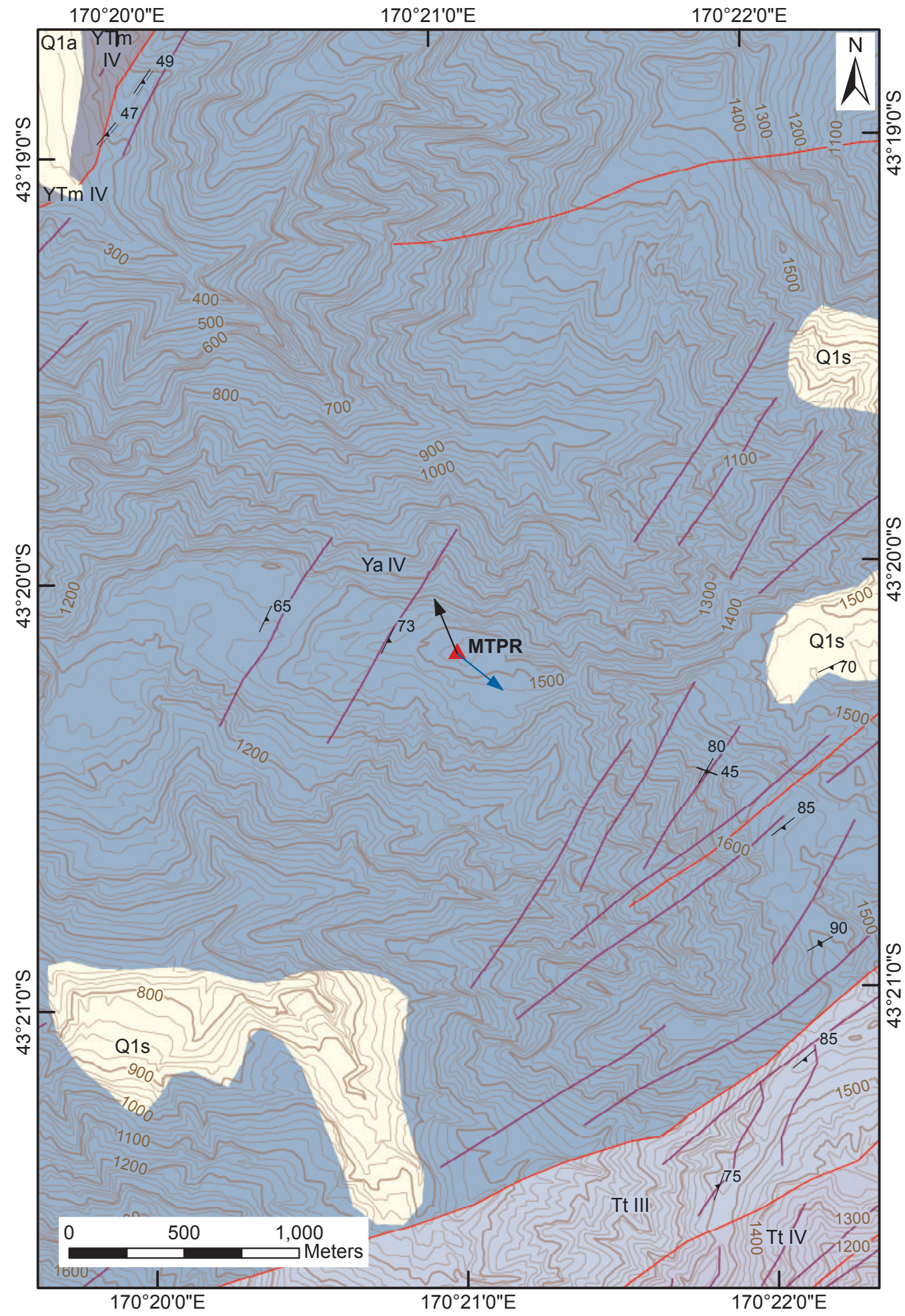

Figure B.23: Detailed geologic map around Mt Price (MTPR) 


\section{B.12 Annette Plateau (NETT)}

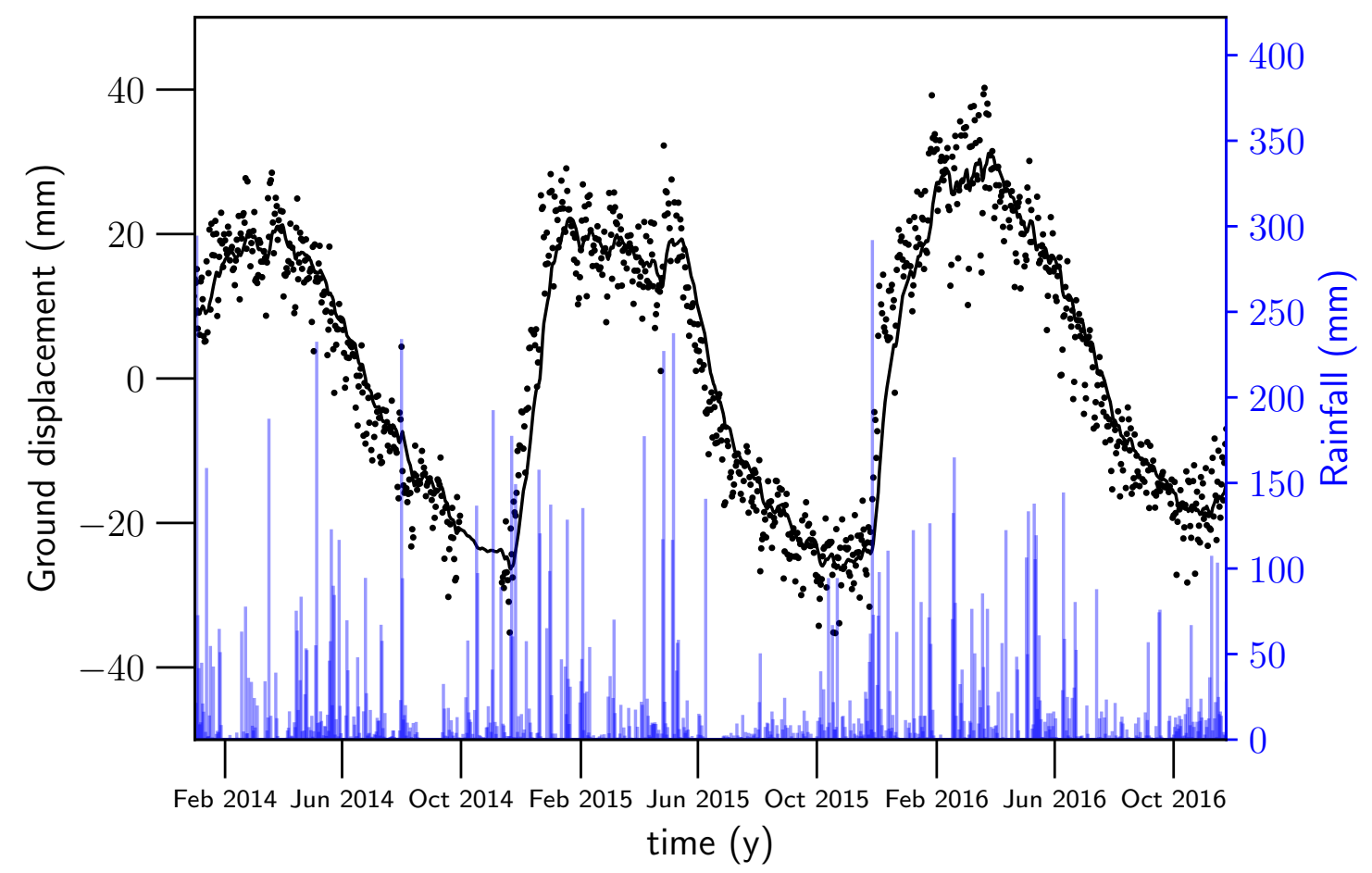

Figure B.24: time series of ground position at Annette Plateau (NETT) compared with rainfall at Mueller Hut. The rain event in 2015 is a good example of ground displacement due to rainstorm. The relatively dry period before the storm allows for a start of groundwater depletion. the rainstorm, in late summer 2015 is followed by a ground motion of $>1 \mathrm{~cm}$.

Table B.12: Cross-correlation coefficients at Annette Plateau (NETT)

\begin{tabular}{lllll}
\hline & North & East & Up & PC 1 \\
\hline Rainfall (Mueller Hut) & $-0.14(0)$ & $0.16(0)$ & $-0.07(2)$ & $0.12(0)$ \\
Snowfall (Mueller Hut) & $0.59(29)$ & $-0.84(10)$ & $-0.72(3)$ & $-0.86(8)$ \\
Temperature (Mueller Hut) & $-0.52(2)$ & $0.55(0)$ & $0.44(2)$ & $0.55(3)$ \\
Pressure (Mount Cook) & $-0.09(27)$ & $0.12(27)$ & $0.26(1)$ & $0.13(2)$ \\
Lake Level (Lake Pukaki) & $-0.42(10)$ & $0.51(4)$ & $0.31(0)$ & $0.48(0)$ \\
\hline
\end{tabular}




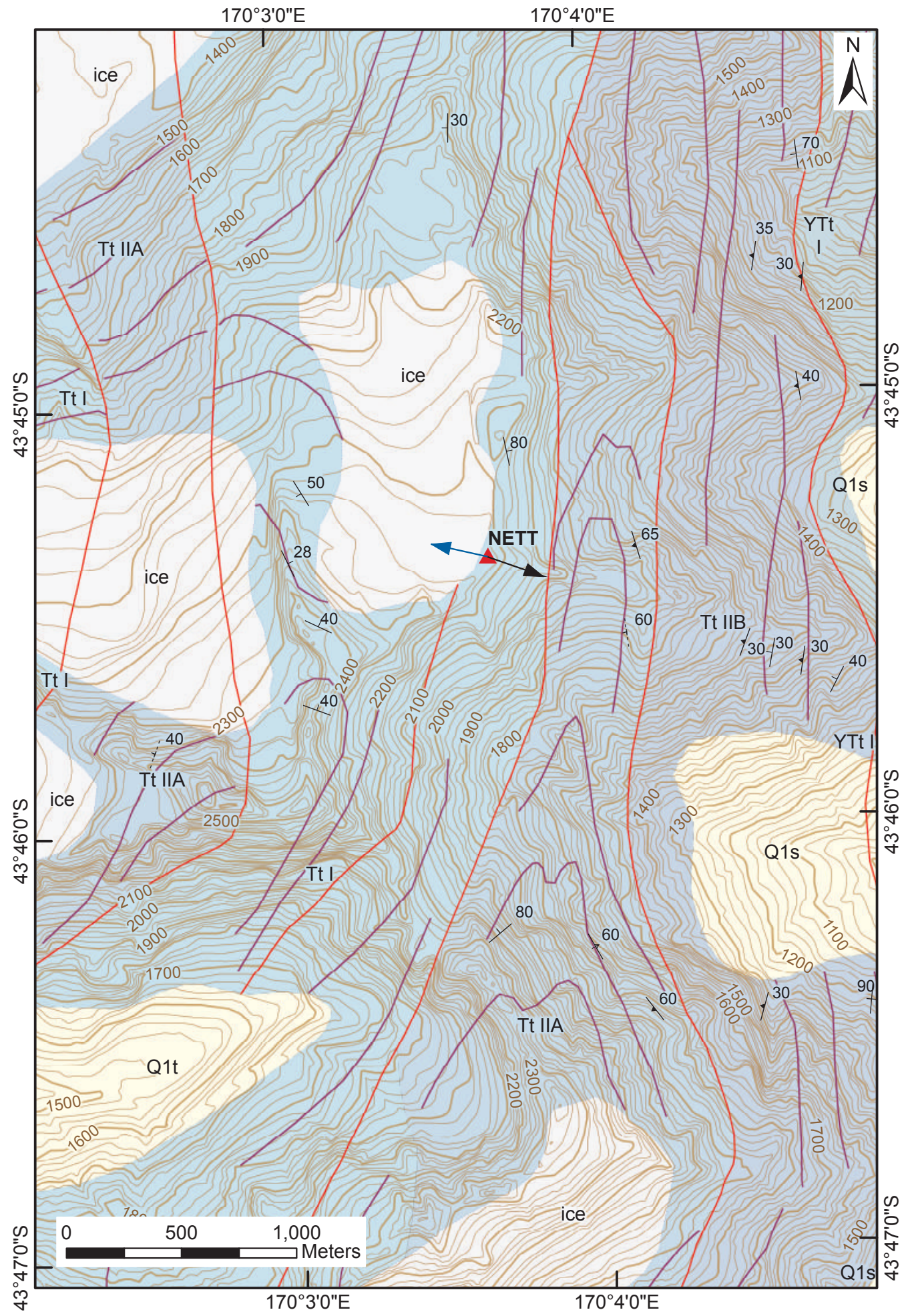

Figure B.25: Detailed geologic map around Annette Plateau (NETT) 


\section{B.13 Pilkington Glacier (PILK)}

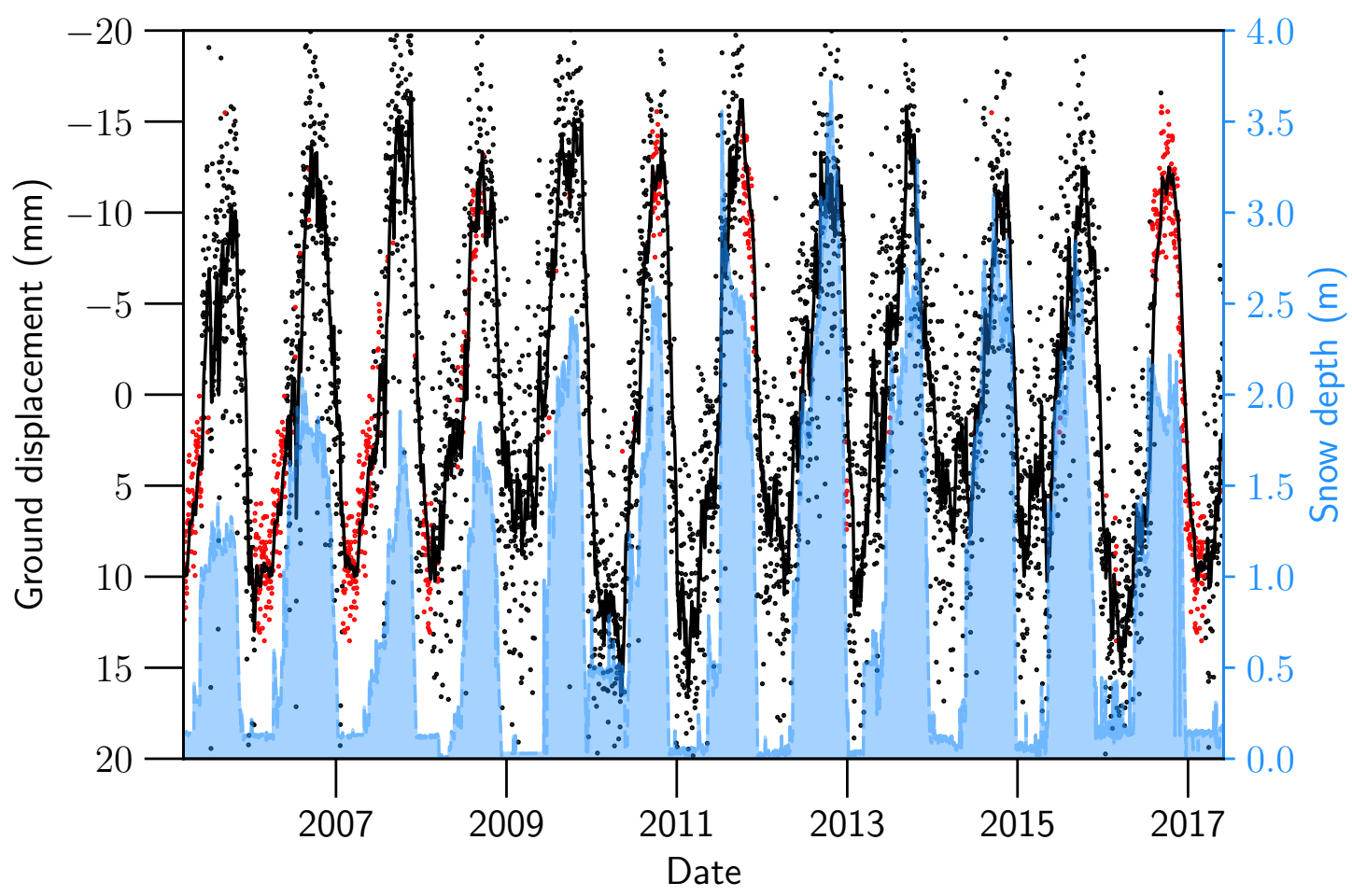

Figure B.26: Snow depth at Rose Ridge (blue) versus ground motion at Pilkington Glacier (PILK) (measurements are in black, artificial values in red), along the single direction defined in Section 2.3.2. For better readability, the displacement axis is inverted.

Table B.13: Cross-correlation coefficients at Pilkington Glacier (PILK)

\begin{tabular}{lllll}
\hline & North & East & Up & PC 1 \\
\hline Rainfall (Mueller Hut) & $-0.20(1)$ & $-0.15(2)$ & $0.09(3)$ & $0.11(3)$ \\
Snowfall (Rose Ridge) & $0.63(29)$ & $0.76(0)$ & $-0.64(2)$ & $-0.72(2)$ \\
Temperature (Mueller Hut) & $-0.54(29)$ & $-0.43(0)$ & $0.47(2)$ & $0.50(2)$ \\
Pressure (Mount Cook) & $0.06(0)$ & $-0.20(25)$ & $0.25(0)$ & $0.21(0)$ \\
Lake Level (Lake Pukaki) & $-0.48(29)$ & $-0.51(5)$ & $0.38(5)$ & $0.44(6)$ \\
\hline
\end{tabular}




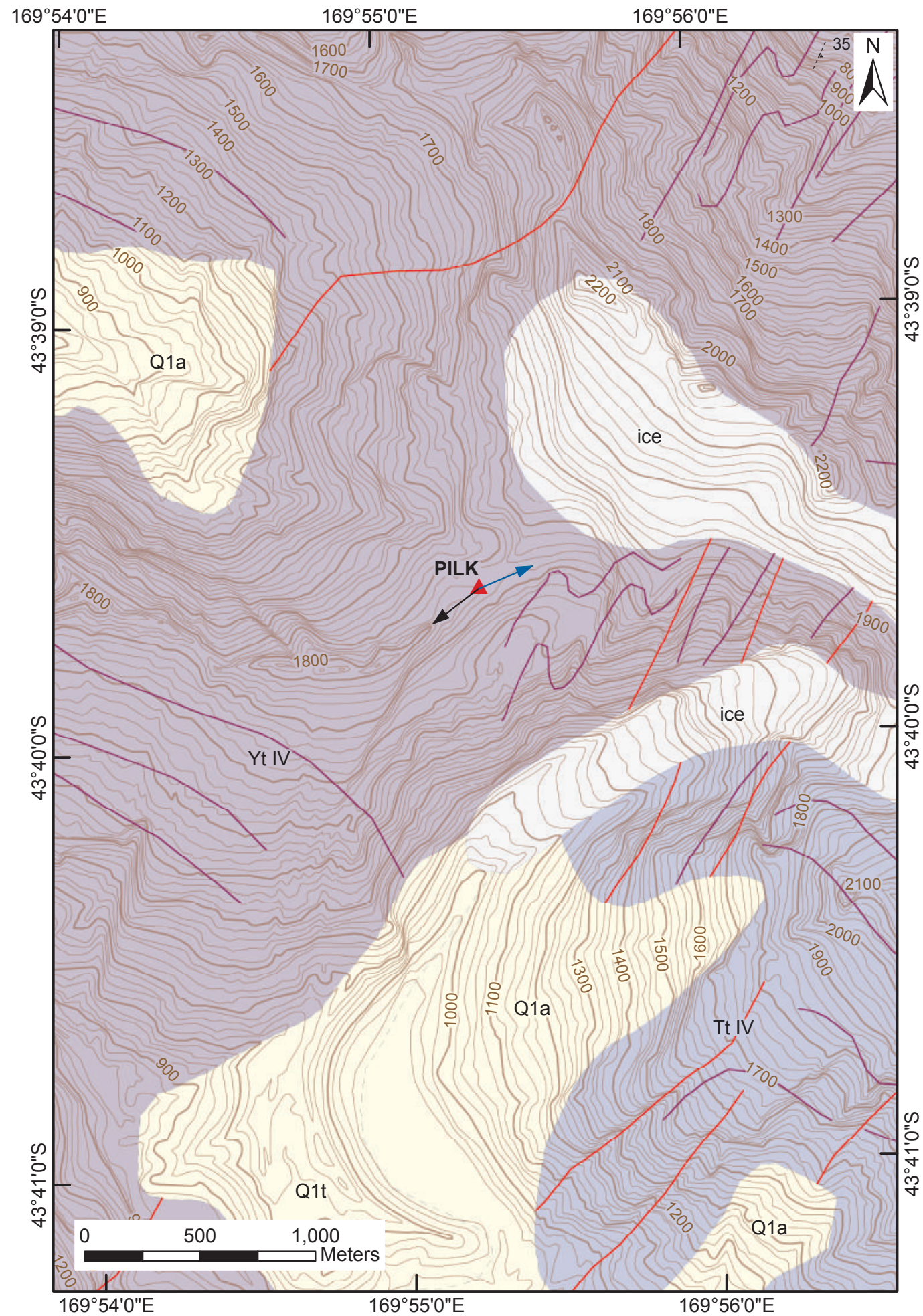

Figure B.27: Detailed geologic map around Pilkington Glacier (PILK) 


\section{B.14 Quarry (QUAR)}
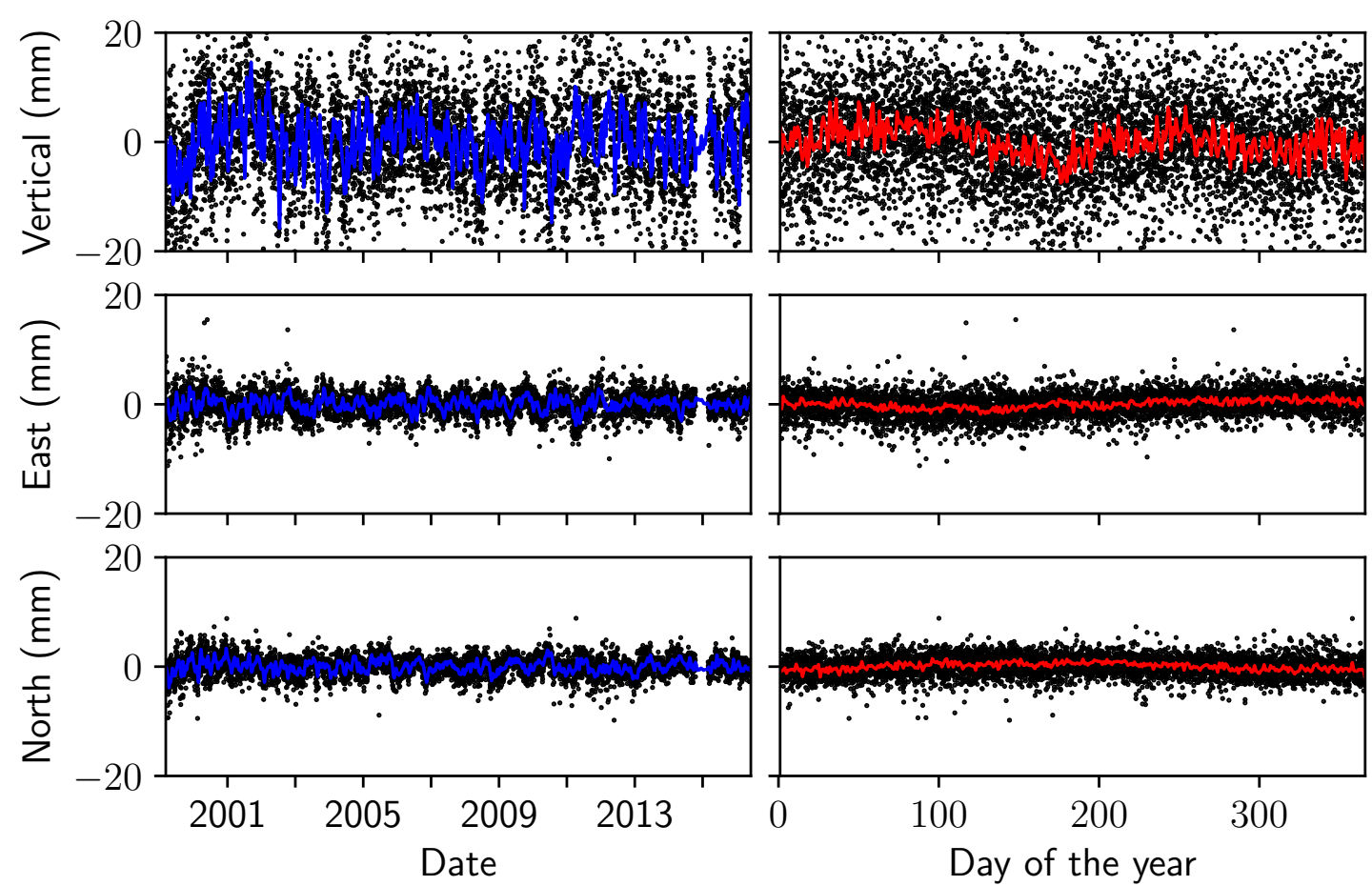

Figure B.28: Time series of ground position at Quarry (QUAR), in the three spatial directions with a low-pass filtering of the data in blue (left), relative to ITRF2014 reference frame. Same data represented on an ordinal year, with the daily median in red (right).

Table B.14: Cross-correlation coefficients at Quarry (QUAR)

\begin{tabular}{llll}
\hline & North & East & Up \\
\hline Rainfall (Franz Josef) & $-0.05(2)$ & $-0.10(1)$ & $0.12(2)$ \\
Snowfall (Mueller Hut) & $-0.21(0)$ & $0.24(0)$ & $-0.11(2)$ \\
Temperature (Franz Josef) & $-0.24(29)$ & $0.15(29)$ & $0.28(2)$ \\
Pressure (Haast) & $-0.04(28)$ & $0.09(1)$ & $0.25(0)$ \\
Lake Level (Lake Pukaki) & $-0.10(29)$ & $-0.11(4)$ & $-0.05(1)$ \\
\hline
\end{tabular}




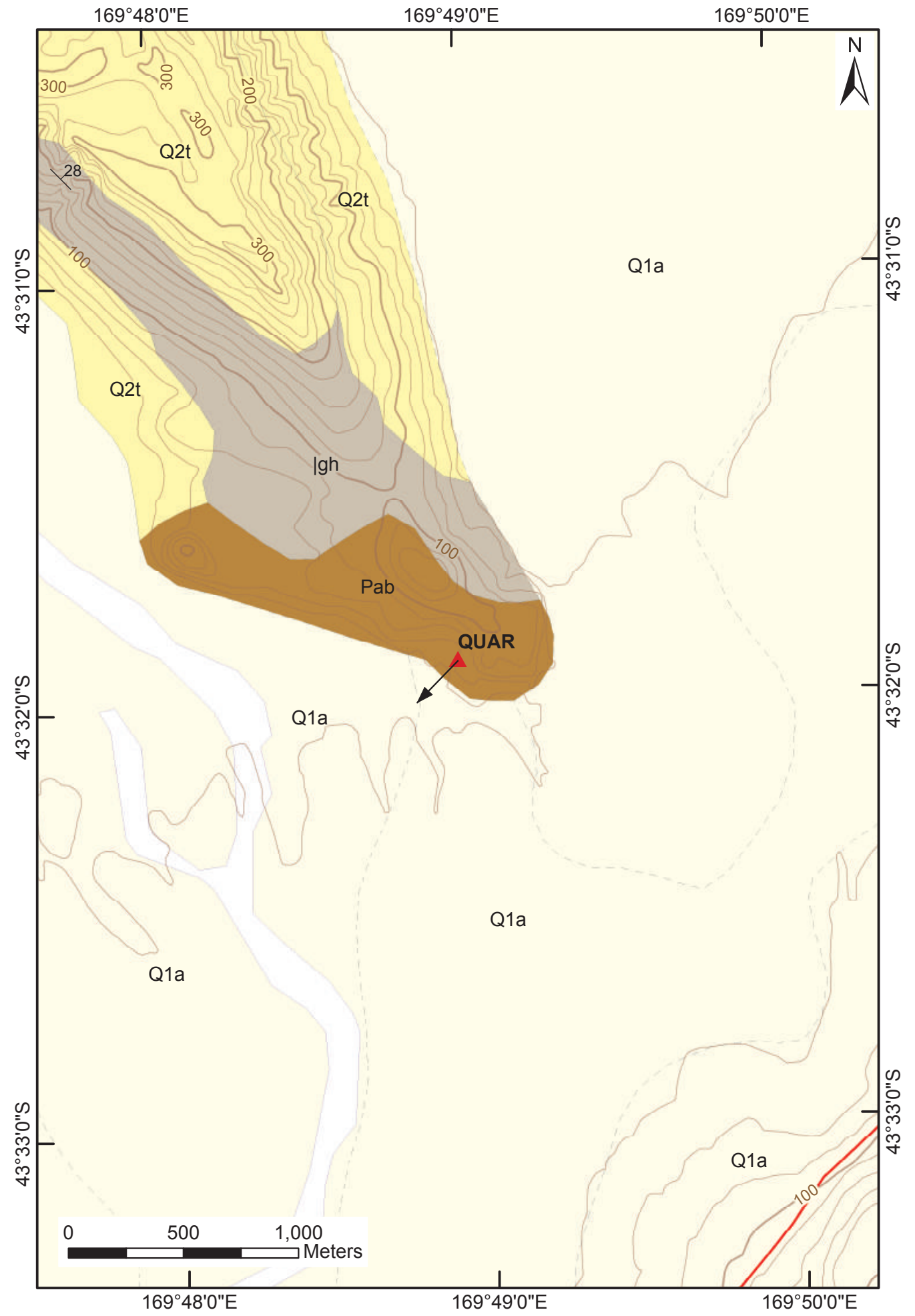

Figure B.29: Detailed geologic map around Quarry (QUAR) 


\section{B.15 Waka Mara (WAKA)}
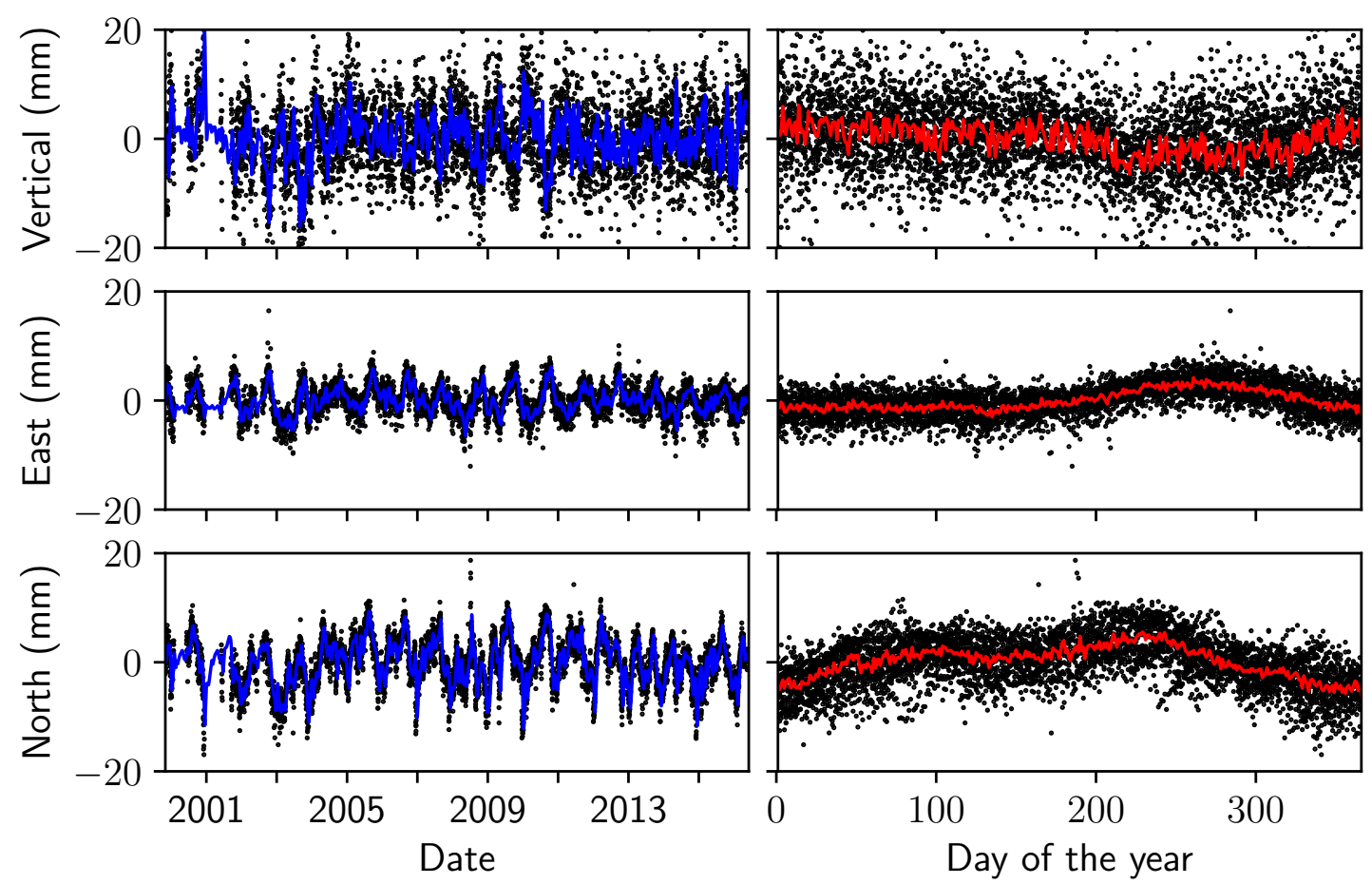

Figure B.30: Time series of ground position at Waka Mara (WAKA), in the three spatial directions with a low-pass filtering of the data in blue (left), relative to ITRF2014 reference frame. Same data represented on an ordinal year, with the daily median in red (right).

Table B.15: Cross-correlation coefficients at Waka Mara (WAKA)

\begin{tabular}{llll}
\hline & North & East & Up \\
\hline Rainfall (Franz Josef) & $-0.18(0)$ & $-0.08(2)$ & $0.12(2)$ \\
Snowfall (Mueller Hut) & $0.26(29)$ & $0.61(11)$ & $-0.27(2)$ \\
Temperature (Franz Josef) & $-0.38(29)$ & $-0.22(0)$ & $0.28(2)$ \\
Pressure (Haast) & $0.15(1)$ & $0.06(2)$ & $0.19(0)$ \\
Lake Level (Lake Pukaki) & $-0.51(29)$ & $-0.43(12)$ & $0.15(26)$ \\
\hline
\end{tabular}




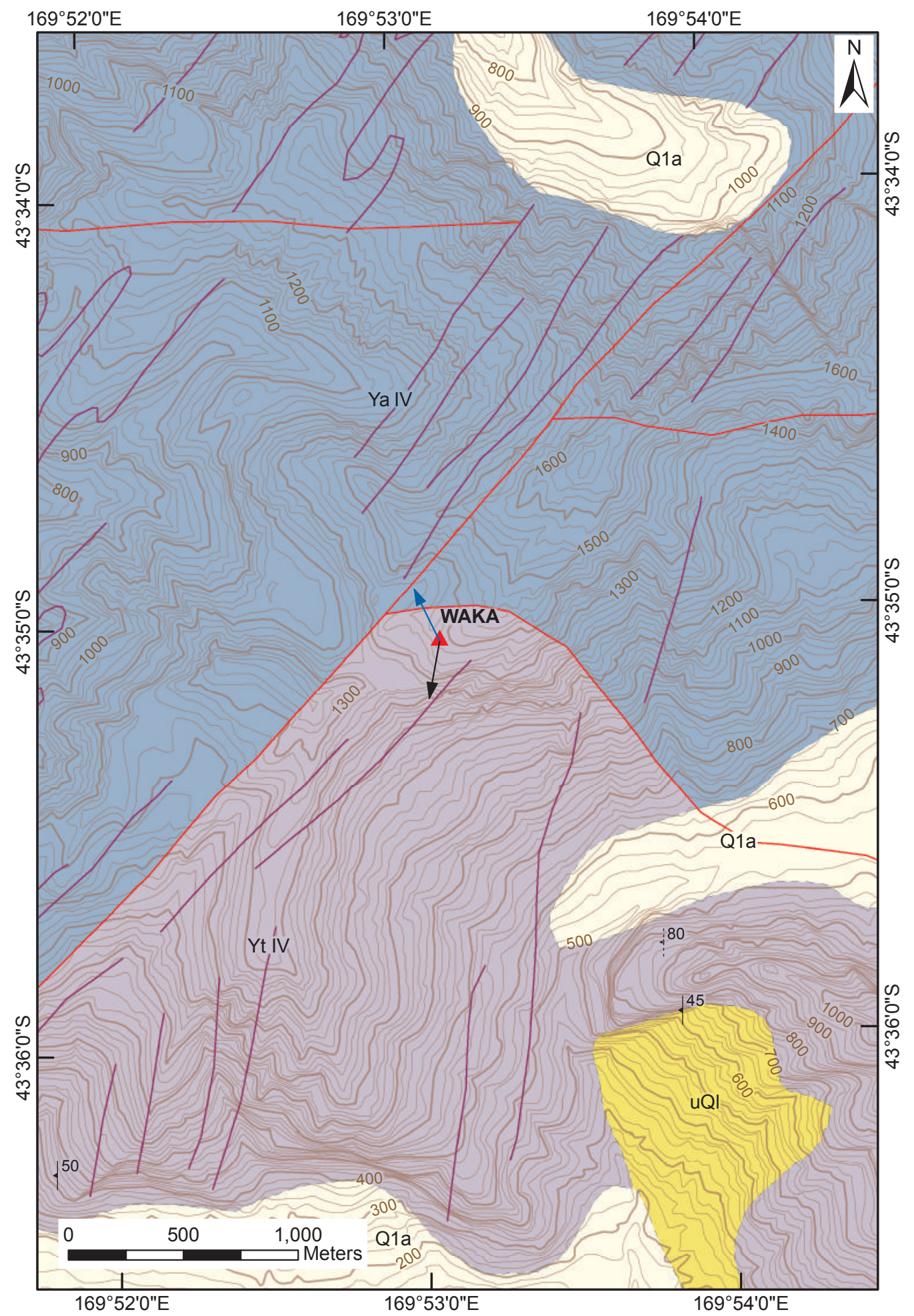

Figure B.31: Detailed geologic map around Waka Mara (WAKA) 


\section{Appendix C}

\section{Supplementary microseismicity analysis}

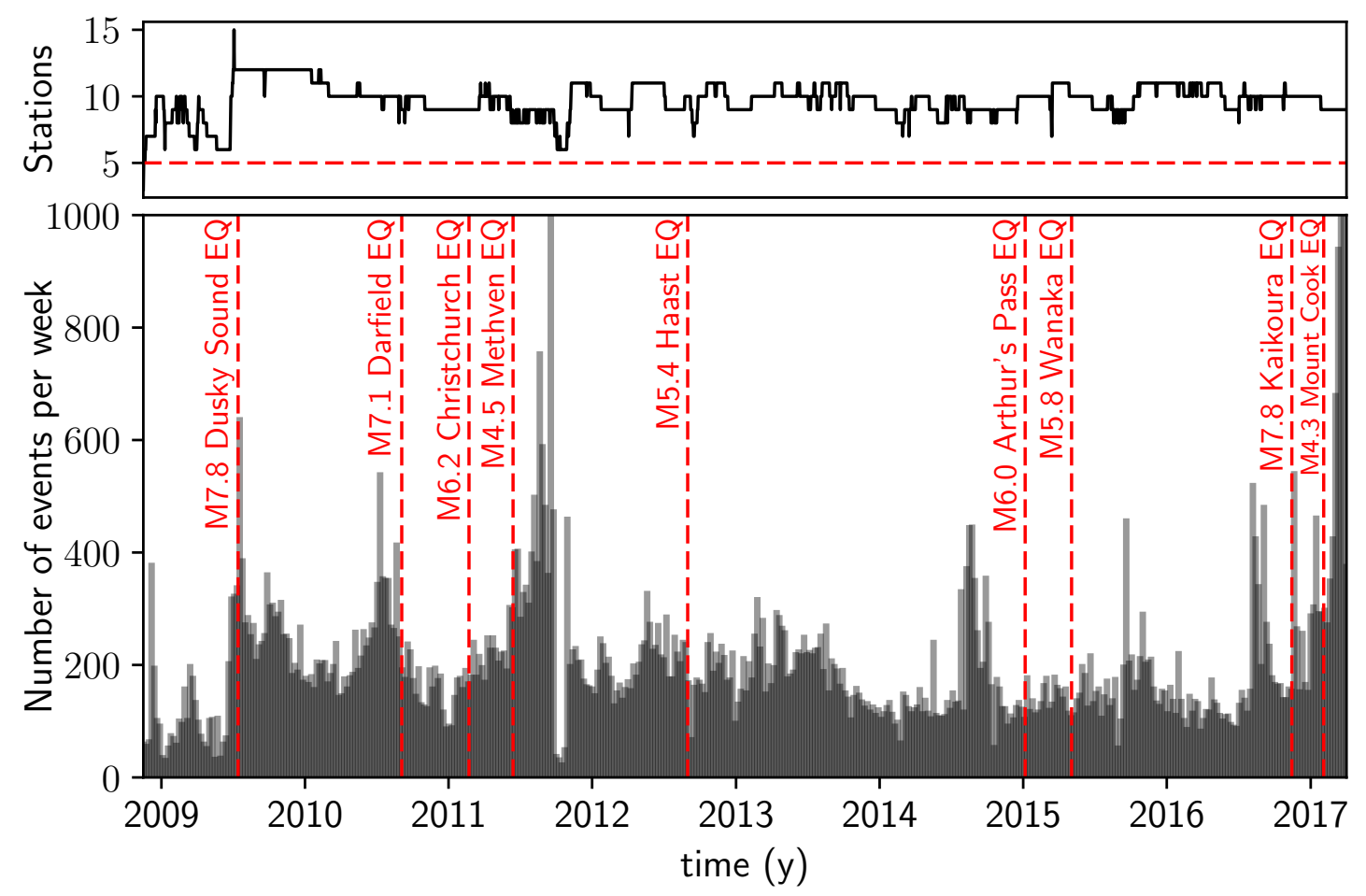

Figure C.1: Top: Number of available stations for EQcorrscan. Five stations (red line) is the threshold under which a detection is eliminated. Bottom: raw number of detections per week (grey bars) for the catalogue without focal mechanisms, and major earthquakes on the South Island.

In this Appendix, we present the results of matched-filter detection using 902 templates (Figure 2.22), not all of which have corresponding focal mechanisms. This yields a catalogue of 89474 events. 


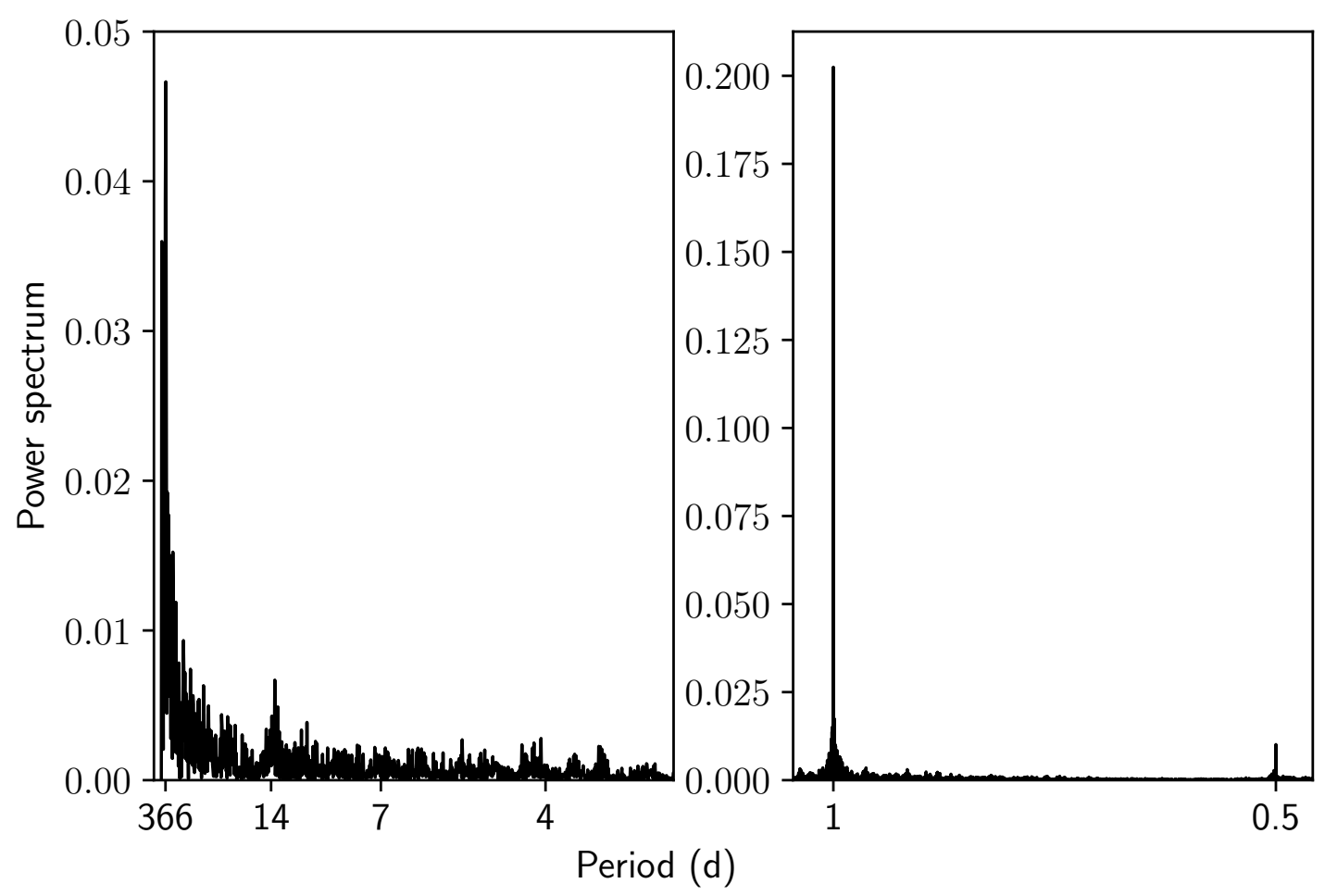

Figure C.2: Periodogram of number of events per hour for the catalogue without focal mechanism solutions. Note that the scale is not the same for the low and high frequencies. The two major periodicities are centred around one year and one day. Other peaks are $0.5 \mathrm{~d}$ and $14 \mathrm{~d}$. We observe that these periodicities correspond to major tidal cyclicities (Agnew, 2007). 


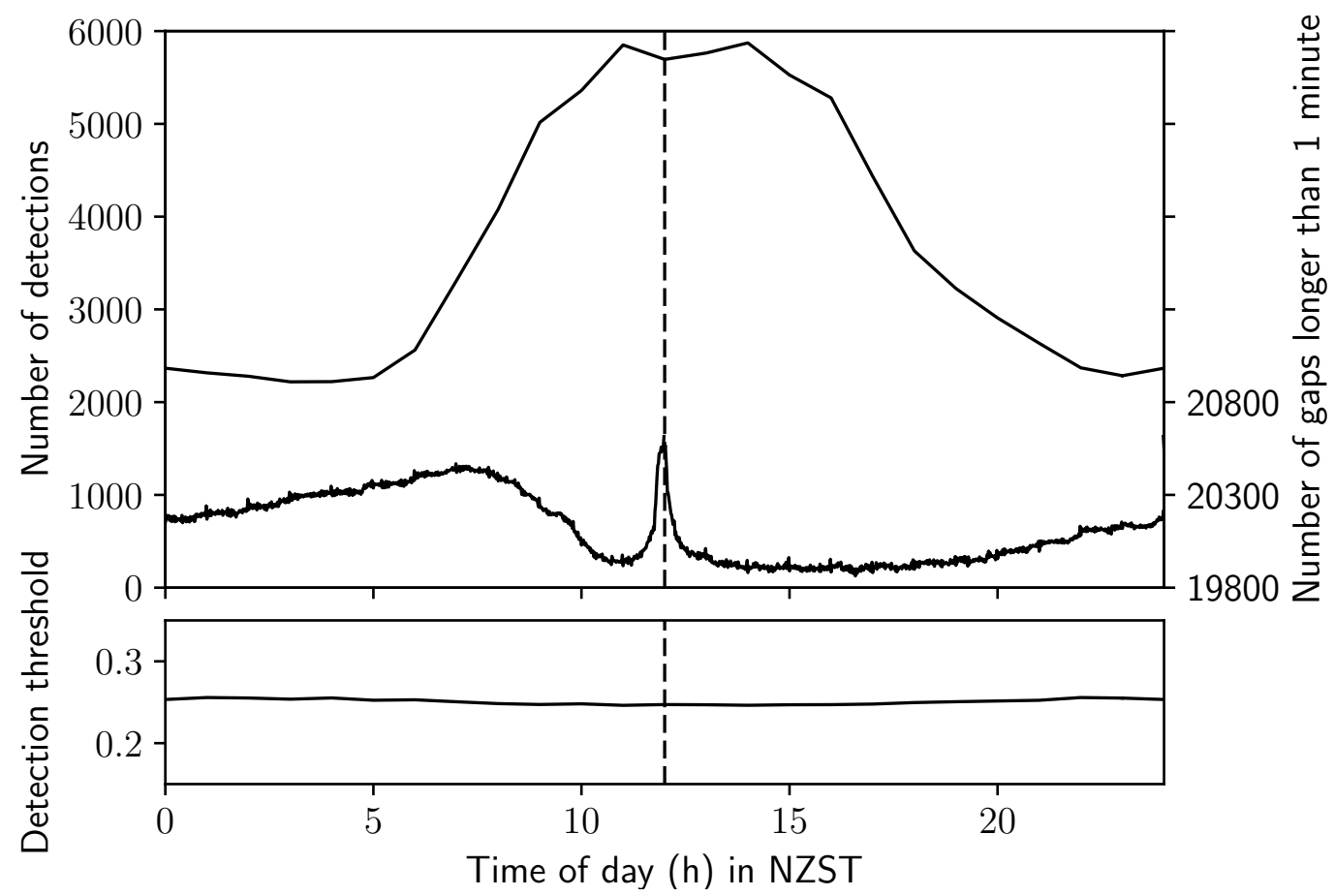

Figure C.3: Top: Median of the number of detections per minute of the day and total number of gaps longer than a minute grouped per minute of the day for the catalogue without focal mechanism solutions. Bottom: Related median of threshold of detection per minute. Vertical dashed line is at $12 \mathrm{pm}$, the usual beginning (end) of the continuous seismic streams.
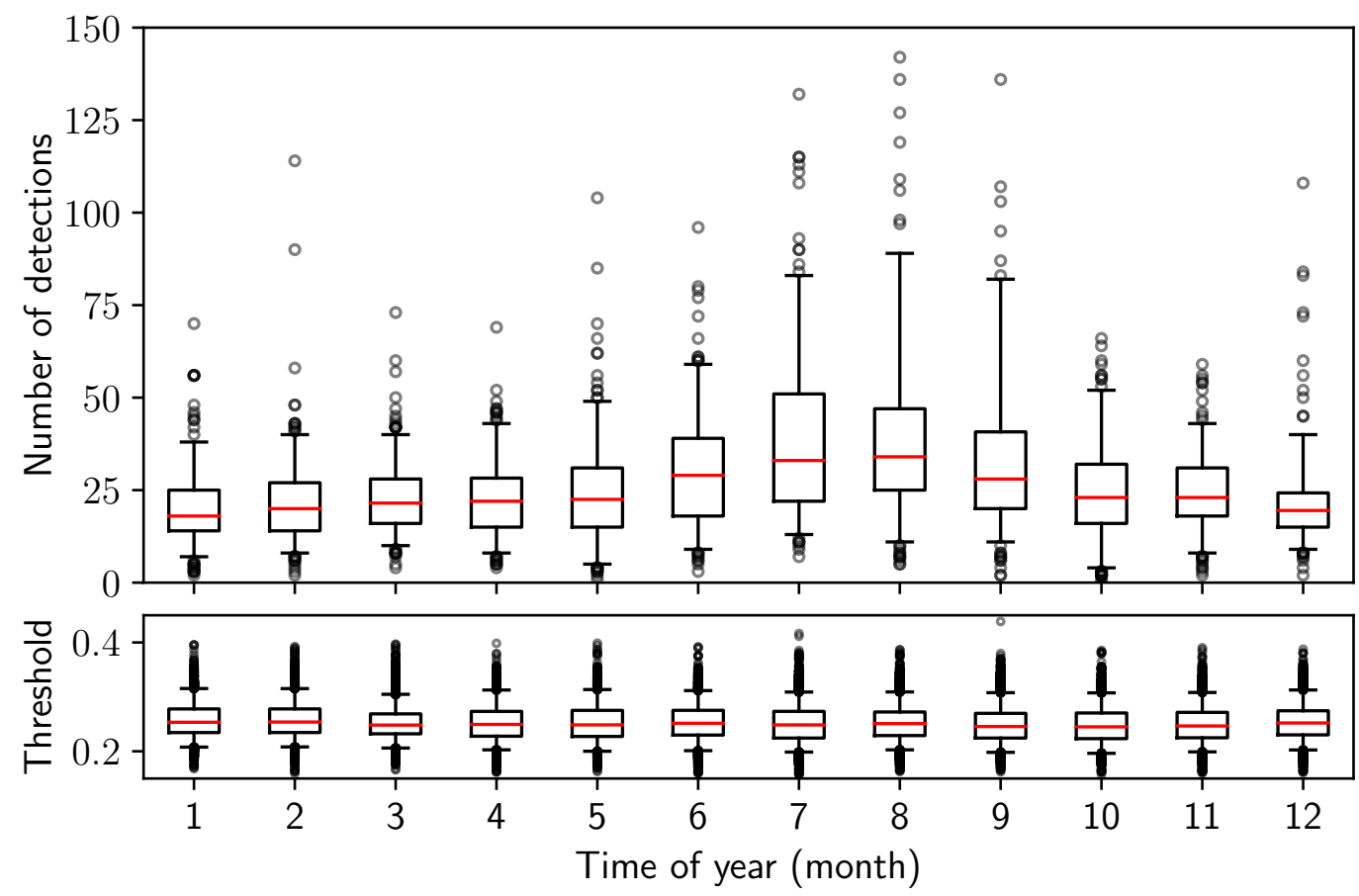

Figure C.4: Number of detections per day grouped by month (top) for the catalogue of earthquakes without focal mechanism solutions. Related threshold of detection per day, grouped by month (bottom). 


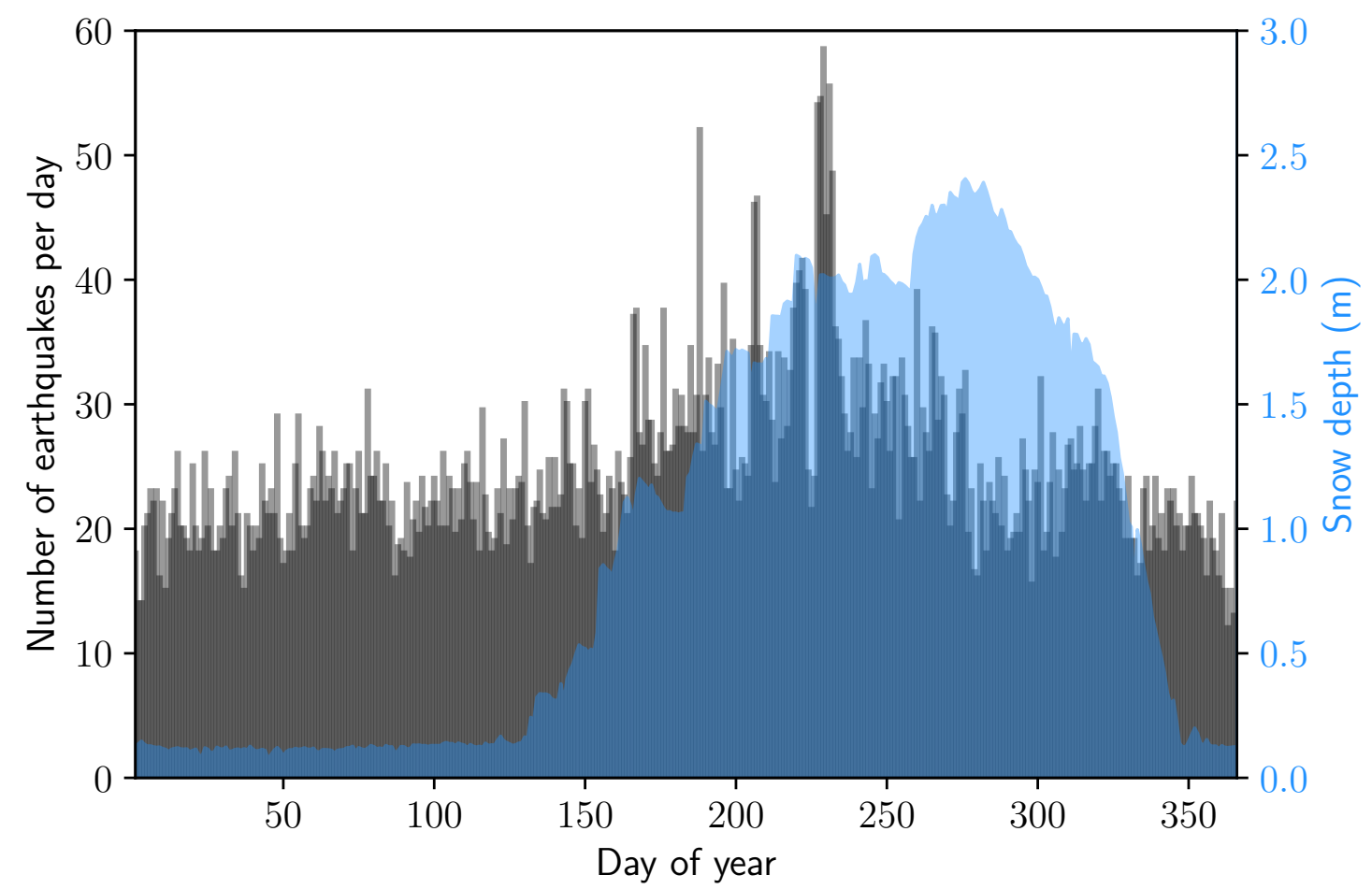

Figure C.5: Ordinal year with median per day of earthquakes for the catalogue without focal mechanism solutions (grey) and snow in Rose Ridge (blue).

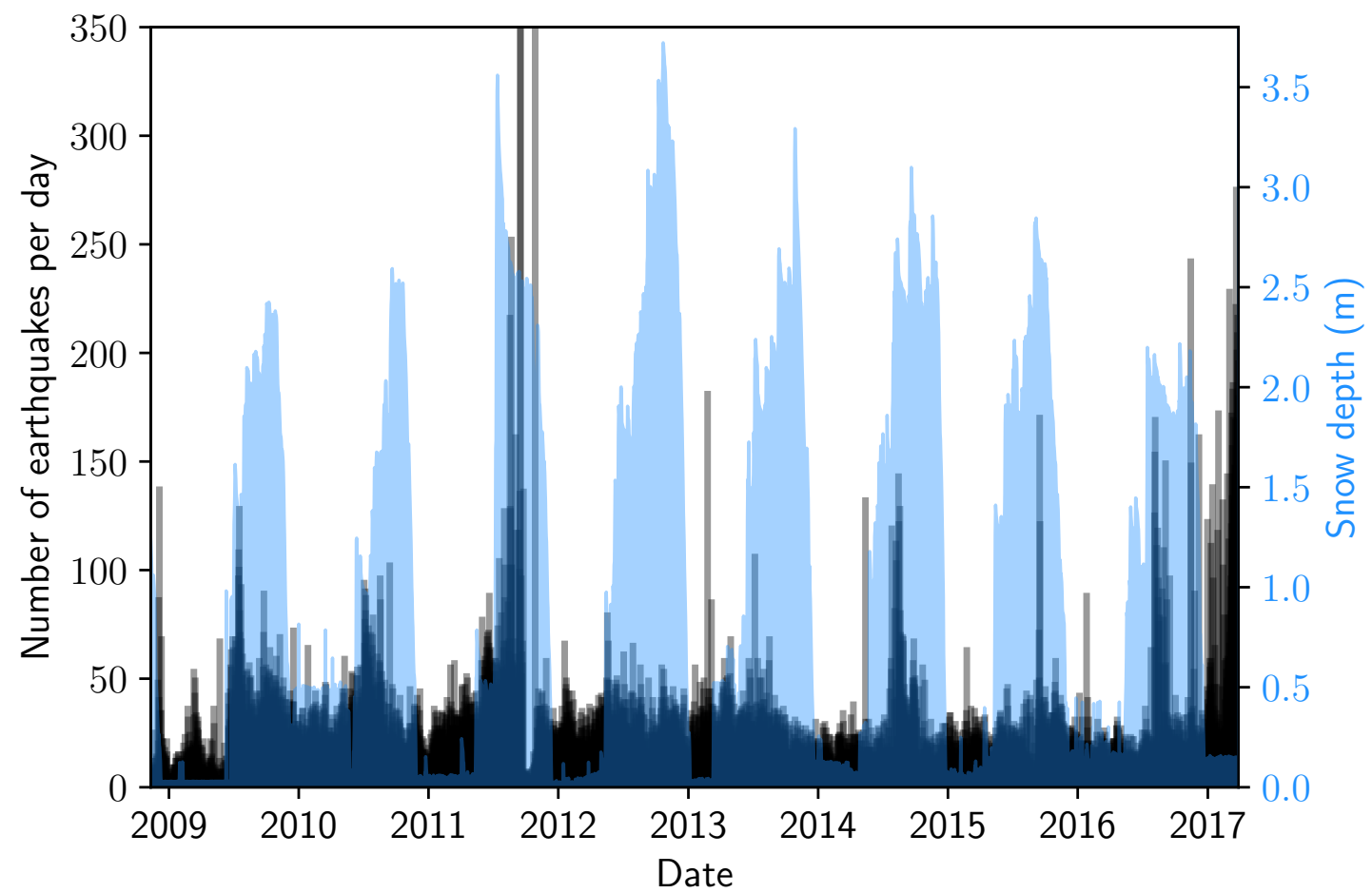

Figure C.6: Time series of earthquakes for the catalogue without focal mechanism solutions (grey) and snow in Rose Ridge (blue). 


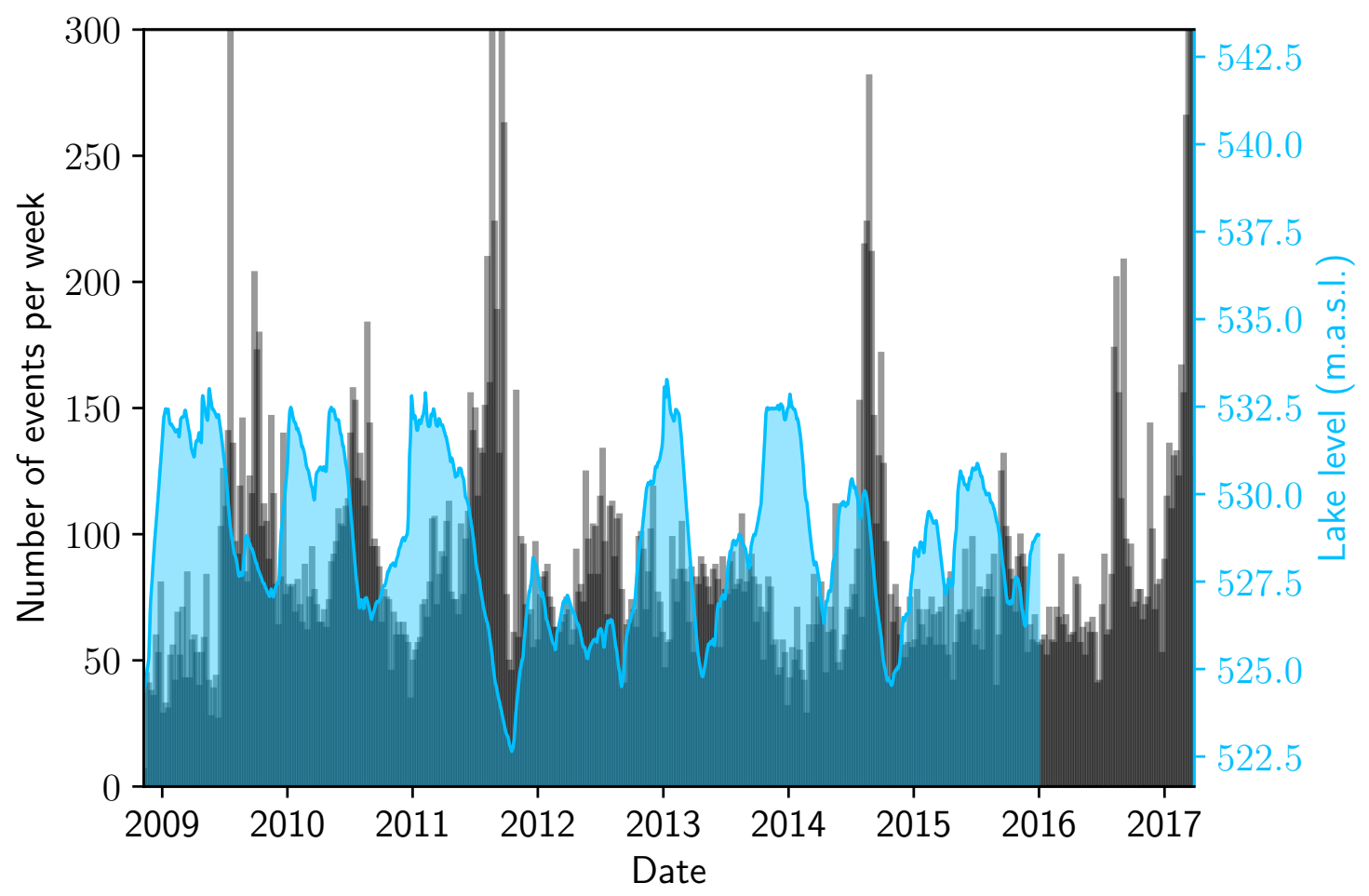

Figure C.7: Time series of earthquakes (grey) versus the level of Lake Pukaki (blue).

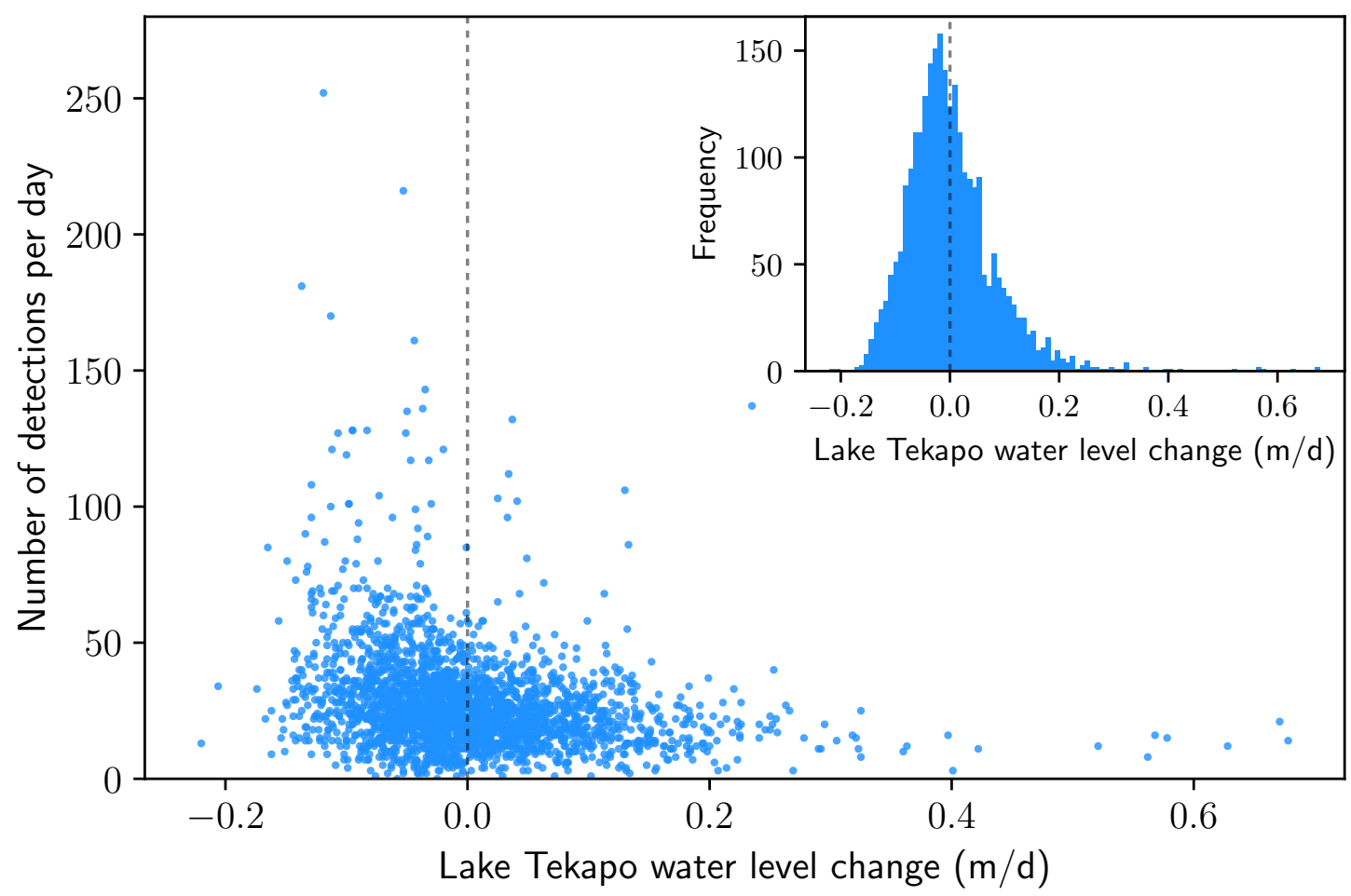

Figure C.8: Cloud comparison plot of number of events in a day versus the change in Lake Pukaki water level per day. The cross-correlation coefficient between the number of detection per day and the change of Lake level per day is -0.19 (0). In the histogram of water level change at Lake Pukaki (inset), each bin is $1 \%$ of the water level change range. 